(Coords.)
Arturo
Selene
Flor C
González
Céspedes
Montes
López
del Fierro
Rodríguez

Prólogo:

Gregorio Martínez Garza

\title{
Personal Branding: Una tendencia del marketing holístico como proceso formativo
}

Cuadernos Artesanos de Comunicación / 135
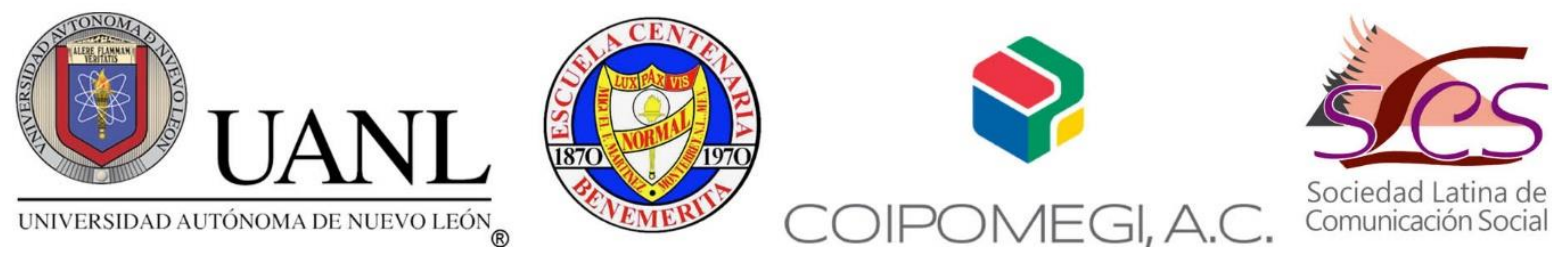


\title{
Cuadernos Artesanos de Comunicación
}

Coordinador editorial: José Manuel de Pablos - jpablos@ull.edu.es

\author{
Comité Científico \\ Presidencia: José Luis Piñuel Raigada (UCM) \\ Secretaría: Alberto Ardèvol (ULL)
}

- Miquel Rodrigo Alsina (Universidad Pompeu Fabra, UPF)

- Xosé Soengas (Universidad de Santiago de Compostela)

- José Miguel Túñez (Universidad de Santiago de Compostela, USC)

- Victoria Tur (Universidad de Alicante, UA)

- Miguel Vicente (Universidad de Valladolid, UVA)

- Ramón Zallo (Universidad del País Vasco, UPV-EHU)

- Núria Almiron (Universidad Pompeu Fabra, Barcelona, UPF)

- Francisco Campos Freire (Universidad de Santiago de Compostela)

- José Cisneros (Benemérita Universidad Autónoma de Puebla, BUAP)

- Bernardo Díaz Nosty (Universidad de Málaga, UMA)

- Carlos Elías (Universidad Nacional de Educación a Distancia, UNED)

- Paulina B. Emanuelli (Universidad Nacional de Córdoba, UNC)

- Marisa Humanes (Universidad Rey Juan Carlos, URJC)

- Juan José Igartua (Universidad de Salamanca, USAL)

- Xosé López (Universidad de Santiago de Compostela)

- Maricela López-Ornelas (Universidad Autónoma de Baja California, AUBC)

- Javier Marzal (Universidad Jaume I, UJI)

- José Antonio Meyer (Benemérita Universidad Autónoma de Puebla, BUAP)

- Ramón Reig (Universidad de Sevilla, US)

* Queda expresamente autorizada la reproducción total o parcial de los textos publicados en este libro, en cualquier formato o soporte imaginables, salvo por explícita voluntad en contra del autor o autora o en caso de ediciones con ánimo de lucro. Las publicaciones donde se incluyan textos de esta publicación serán ediciones no comerciales y han de estar igualmente acogidas a Creative Commons. Harán constar esta licencia y el carácter no venal de la publicación.

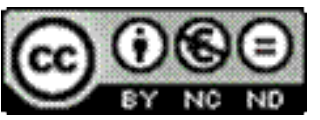

Este libro y cada uno de los capítulos que contiene (en su caso), así como las imágenes incluidas, si no se indica lo contrario, se encuentran bajo una Licencia Creative Commons Atribución-No Comercial-Sin Derivadas 3.0 Unported. Puede ver una copia de esta licencia en http://creativecommons.org/licenses/by-nc-nd/3.0/ Esto significa que Ud. es libre de reproducir y distribuir esta obra, siempre que cite la autoría, que no se use con fines comerciales o lucrativos y que no haga ninguna obra derivada. Si quiere hacer alguna de las cosas que aparecen como no permitidas, contacte con los coordinadores del libro o con el autor del capítulo correspondiente.

* La responsabilidad de cada texto es de su autor o autora. 


\section{Arturo González López, Selene Céspedes del Fierro y Flor del Carmen Montes Rodríguez (Coords.)}

Prólogo: Gregorio Martínez Garza

\section{Personal Branding: Una tendencia del marketing holístico como proceso formativo}

Carlos GonzÁlez Campos/María Cristina Useche Aguirre/ Flor Del CARMEN MONTES RODRÍGUEZ/CYOMARA INURRIGARRO GUILLÉN/MARÍA Guadalupe Martínez Ortiz/ Oscar Yael Navarro Montes/SELEnE CÉSPEDES DEL FIERRO/TEMÍSTOCLES MuÑoZ LÓPEZ/ARTURO GONZÁLEZ López/PABlo AdÁn Micó/InOCEnTE MELitón García/MONSERRAT

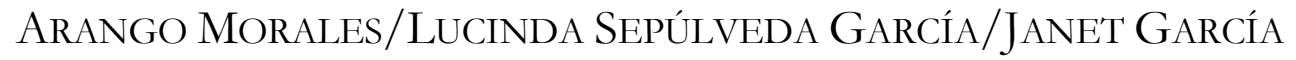
González/María Mirna Granat Ramos/Alicia de la PeÑa de

LEÓN/JUAN BERNARDo AmEZCUA NúÑEZ/JuANA MARÍA SAUCEDO

Soto/Alicia Hernández Bonilla / Dulce Karen Herrera Mata /Arturo Pérez Patiño/Guadalupe Minerva / Brenda AZuCEna Muñoz YANes / Miguel SÁNCHEZ Maldonado / GABRiela de la PeÑA Astorga /

Cuadernos Artesanos de Comunicación / 135
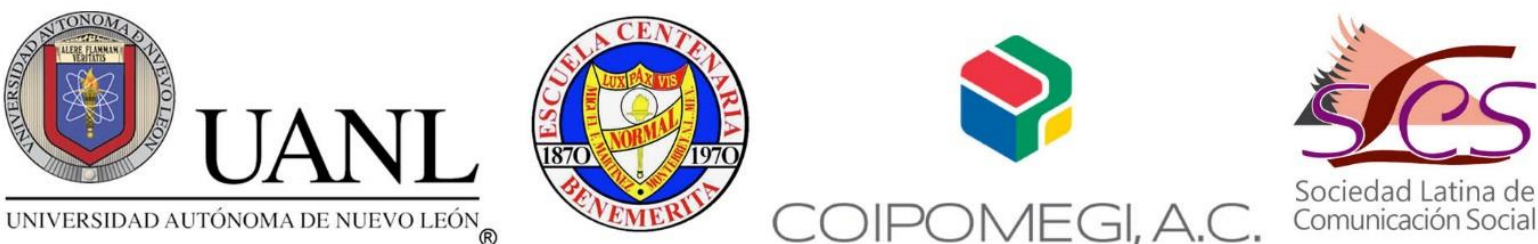
CAC $135^{\circ}$ - Personal Branding: Una tendencia del marketing holístico como proceso formativo

Arturo González López, Selene Céspedes del Fierro y Flor del Carmen Montes Rodríguez | Precio social: 8,75€ | Precio en librería. 11,40€

Editores: Javier Herrero y Milena Trenta

Diseño: F. Drago

Ilustración de portada: Fragmento del cuadro Mijer con bernegal, de Pedro de Guezala (1958).

Imprime y distribuye: F. Drago. Andocopias S. L.

c/ La Hornera, 41. La Laguna. Tenerife.

Teléfono: 922250554 | fotocopiasdrago@telefonica.net

Edita: Sociedad Latina de Comunicación Social - edición no venal - La Laguna (Tenerife), 2017 - Creative Commons http://www.revistalatinacs.org/12SLCS/portada2014.html Descargar en pdf: http://www.cuadernosartesanos.org/\#135

Protocolo de envío de manuscritos: http://www.cuadernosartesanos.org/protocolo.html

ISBN - 978-84-16458-88-2

DL: TF-1.140-2017

DOI: $10.4185 / \operatorname{cac} 135$ 


\section{Personal Branding: Una tendencia del marketing holístico como proceso formativo}

\section{RESUMEN}

La recopilación de las investigaciones que suceden a estas líneas se plantean un nuevo mundo donde el eje central sean las personas, y en esa línea una serie de investigadores en diferentes campos como la Educación, el Personal Branding y la Innovación Social han abierto una vía de reflexión colectiva hacia la mejora de los espacios personales de relación social.

En este entorno se ha trabajado de forma colaborativa, como no podía ser de otra manera. Ha sido intenso y enriquecedor, y ha fluido de forma natural el intercambio de conocimiento y opiniones entre destacados profesionales de las diferentes áreas de trabajo y diferentes sociedades.

El valor de esta antología de investigaciones es múltiple. No sólo ha conseguido aportar un valor considerable a la actualidad social y educativa, sino que sienta, en cierto modo, las bases de la formación para futuros profesionistas e involucrarlos en áreas tan poco explotadas como la investigación.

Este escenario, donde las personas toman el protagonismo y la preferencia social, impregnará todos los entornos de la vida pública, desde la política a la relación laboral. Es cuestión de tiempo, pero vamos en el camino correcto.

PALABRAS CLAVES: Comunicación, Educación, Personal Branding, Axiología, Percepción.

\section{Forma de citar este libro}

Arturo González López, Selene Céspedes del Fierro y Flor del Carmen Montes Rodríguez (2017). Personal Branding: Una tendencia del marketing holístico como proceso formativo. Cuadernos Artesanos de Comunicación, cac135. La Laguna (Tenerife): Latina.

DOI: $10.4185 / \operatorname{cac} 135$ 


\section{Índice}

Prólogo:

Presentación:

1. Marca personal de docentes en Gerencia

2. Percepción social e identidad: el docente de educación Básica

3. Importancia de la validación de instrumentos de investigación: Un caso de medición para la obtención del perfil del branding axiológico

4. Emprender en la innovación social con estrategias de personal branding

5. Planificación por competencias, herramienta para mejorar la docencia e imagen profesional de los formadores de docentes

6. Alfabetización digital para el desarrollo de la Marca Personal de niñas indígenas migrantes de Monterrey, Nuevo León

7. Estudiantes de nivel superior y el impacto de las redes sociales en su personal branding

8. Construcción de marcas personales a través de las Selfies..145

9. Una experiencia exitosa: Los entornos telemáticos en la práctica profesional de los futuros maestros

10. Matrimonios igualitarios, adopción homoparental y marcha por la familia. 


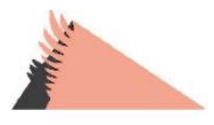 \\ Prólogo}

$\mathrm{E}$

L concepto "Personal Branding", surgió en Estados Unidos y se expandió rápidamente a nivel mundial a finales de la década de los noventa. El artículo de Tom Peters titulado "The Brand Called You" y publicado en la revista Fast Company propone: "Las grandes compañías entienden la importancia de las marcas. Hoy, en la Era de las Personas, tú debes ser tu propia marca."

Desde entonces han pasado 20 años y aquél artículo de Tom Peters está más vigente que nunca. Hoy vivimos en un mundo globalizado, interconectado, donde las redes sociales son un potente catalizador para el manejo y el posicionamiento de la marca personal.

Alguna vez nos hemos preguntado, ¿por qué a cierta persona le dieron una extraordinaria oportunidad? La respuesta no necesariamente es "porque tenía las mejores calificaciones en la escuela". Generalmente, las mejores oportunidades se otorgan a las personas que reúnen conocimiento, habilidades, valores y competencias, aquellos que "se saben mover bien", que se "saben vender bien". Esto es precisamente de lo que estamos hablando: "Personal Branding".

Desde luego, tal como se comenta en una de las investigaciones de este libro, un individuo con acceso a una educación de calidad y con nivel socioeconómico superior, tiene viento a su favor para desarrollar la forma en que quiere presentarse o ser percibido por los demás, ya sea ante su grupo de amigos o en el mercado laboral. Pero esto no significa que el resto de las personas no puedan alcanzar este objetivo.

Creo que el libro "Personal Branding: Una Tendencia del Marketing Holístico como Proceso Formativo", integra de manera efectiva 
interesantes hallazgos respecto a la importancia de preparar a nuestros maestros a esta nueva realidad del siglo XXI, con miras a contribuir adecuadamente en la formación profesional de las siguientes generaciones que más pronto que tarde estarán conformadas por "nativos digitales".

Para la actual generación de profesionistas en general, los estudios aquí presentados demuestran que los procesos de comunicación para buscar oportunidades están cambiando. Y que es el momento de actuar y de revisar nuestra marca personal. Hay que trabajar en esto de inmediato, ya que ninguna marca se posiciona de un día para otro.

Agradezco al Comité Editorial por esta distinción y los invito a disfrutar la lectura de este libro.

Gregorio Martínez Garza 


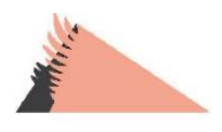

\section{Presentación}

— L libro de Personal Branding: Una tendencia del marketing holístico como proceso formativo, es una ventana abierta para entender el impacto e importancia que guarda la imagen personal como principio básico en las interrelaciones en ámbitos académicos y profesionales. La Percepción social e identidad: el docente de educación básica, Marca personal de docentes en Gerencia, Importancia de la validación de instrumentos de investigación: Un caso de medición para la obtención del perfil del branding axiológico, Emprender en la innovación social con estrategias de personal branding, Planificación por competencias, herramienta para mejorar la docencia e imagen profesional de los formadores de docentes, Alfabetización digital para el desarrollo de la Marca Personal de niñas indígenas migrantes de Monterrey, Nuevo León, Estudiantes de nivel superior y el impacto de las redes sociales en su personal branding, Construcción de marcas personales a través de las Selfies, y Una experiencia exitosa: Los entornos telemáticos en la práctica profesional de los futuros maestros, son los temas que se podrán leer en este trabajo realizado por distintos docentes e investigadores. 



\title{
Marca personal de docentes en Gerencia
}

\author{
Carlos González Campos \\ Universidad Rafael Urdaneta, Venezuela \\ María Cristina Useche Aguirre \\ Universidad del Zulia, Venezuela
}

\section{Resumen:}

La marca personal visibiliza las acciones desarrolladas por las personas en su entorno personal, social y profesional, para destacarse en su ámbito laboral. En el ámbito universitario directa o indirectamente los docentes van forjando y consolidando su marca personal mediante la investigación, docencia y extensión; sin embargo, no se ha medido en la Universidad del Zulia las acciones racionales empleadas para tal fin, de allí que, el objetivo del presente trabajo fue analizar la marca personal de los docentes de los programas de maestría en gerencia de la Universidad del Zulia. El trabajo se sustentó en las posturas de Pérez (2008) y de Adán (2012), mediante un tipo de investigación analíticadescriptiva, diseño de investigación fue no experimental-transeccional; la recolección de datos se hizo mediante la entrevista, empleando la técnica del cuestionario estructurado con escala Likert, aplicado a una población conformada por ciento cuarenta y cinco (145) docentes activos de los programas de maestría en gerencia de esa casa de estudio. Se concluye que los docentes se encuentran gestionando su marca personal, a través de acciones personales, profesionales, de posicionamiento y comunicación, buscando la diferenciación en su entorno profesional de su mercado meta, apoyados en atributos 
que les permite destacarse y ser recordados, por quienes han requerido de sus servicios.

Palabras Clave: Acciones personales, acciones profesionales, acciones de posicionamiento, estrategias de comunicación, docentes universitarios.

\section{Introducción}

— $\mathrm{N}$ Venezuela, al igual que en otros países existen diversas 1 profesiones que juegan un papel importante dentro de la sociedad. Llegar a ser un docente universitario se enmarca en un alto estatus profesional y personal; pero en los últimos tiempos los niveles de exigencia en el ámbito universitario han motivado a los docentes a focalizar sus esfuerzos para destacarse y ocupar una posición predominante entre sus homólogos y en la percepción de su público meta.

En este sentido, los docentes universitarios buscan ser reconocidos por su propia marca personal, mediante acciones personales, profesionales, de posicionamiento y de comunicación que antes no eran de interés para ellos y ha conducido a hacer cambios paulatinos o radicales en su modo de actuar, para diferenciarse y que se reconozca el valor añadido que aportan a la comunidad universitaria y a la sociedad en general.

Tener una marca personal ayuda a posicionarse en un lugar privilegiado en la mente del público objetivo; así mismo permite a un profesional ser percibido como una persona singular, única y que aporta unos beneficios claros al mercado y al entorno. Para descubrir una marca personal, los docentes tienen que ser conscientes de quienes son, lo que saben hacer y lo que tienen que mejorar para desarrollarse plenamente en el largo plazo.

Para ello es necesario identificarse con acciones que generen confianza al participante que diseña su marca personal, destacando personalidad, creencias, adaptación a los cambios, espacio y tiempo, desarrollo de competencias, visibilidad, confianza y relaciones públicas que promuevan un mejor desempeño de sus relaciones con el entorno y que éstas tengan trascendencia en el tiempo.

En el ámbito educativo aspectos como el interés por acreditarse con 
nuevos planes de estudio y la participación en el campo virtual han cambiado sustancialmente la forma de relacionarse del docente universitario con los alumnos, colegas, y otros escenarios. En la actualidad, es importante que el docente universitario aborde con propiedad nuevos escenarios, inclinándose a una educación por competencias; para ello debe tenerse en cuenta el desarrollo integral del eje alumno-docente y su relación con el entorno, donde ambas figuras utilicen nuevas herramientas, impulse acciones que les permitan convertirse en miembros activos de la sociedad.

En el sector educativo universitario es de relevancia el crecimiento profesional y la diferenciación en su entorno para diseñar su marca personal, sin embargo, es normal encontrar docentes que tienen una marca personal creada pero no gestionada y no lo saben, y por desconocimiento no han desarrollado la misma, a pesar de tener un cúmulo de productos en investigación, docencia y extensión, con los cuales fácilmente hubiesen o pueden impulsarla gestión de su marca personal; por otra parte, existen docentes nóveles - que por limitaciones presupuestarias son pocos- que tienen pleno conocimiento de lo que implica tener una marca personal y desde su ingreso a la casa de estudio se centran en la creación de la misma, pero consolidarla implica tiempo.

Otros docentes consumidos en realizar sus actividades rutinarias son absorbidos por la monotonía y cercan su campo de acción sin mayores aspiraciones, lo cual limita aprovechar la oportunidad de ser reconocido como un profesional de referencia, abordar relaciones con otros profesionales, conocer nuevas formas de interactuar con las empresas que faciliten compartir experiencias e información, entre otros. En este sentido, se consideró interesante analizar la marca personal de los docentes de los programas de maestría en gerencia en la Universidad del Zulia; abordando cuatro dimensiones, los cuales serán expuestos posteriormente.

\section{Metodología}

Desde el tipo de investigación analítica se descompuso la variable en cuatro dimensiones: acciones personales, acciones profesionales, acciones de posicionamiento y acciones de comunicación y se empleó 
el diseño de investigación contemporáneo-transeccional, pues se observó la variable en un tiempo único, comprendido desde enero 2015 hasta enero 2016, por considerarse tiempo suficiente para el desarrollo de todas las fases del proceso de investigación.

Para esta investigación la población estuvo conformada por 145 docentes activos regulares y que forman parte de la base de datos de docente de planta de los programas de maestría en el área gerencial de la Universidad del Zulia, clasificados por el Directorio Nacional de Postgrado y autorizadas por el Consejo Nacional de Universidades (2015). La técnica empleada fue el censo poblacional por tener acceso a toda la población (ver cuadro 1), siendo las unidades de observación programas de maestría en el área gerencial y los agentes informantes los docentes activos regulares de cada programa.

La técnica empleada para la recolección de datos fue la encuesta, mediante el instrumento tipo cuestionario estructurado, con escala Likert, el cual se sometió a validación por parte de expertos en la variable y asesores de marcas, generando su opinión y observaciones sobre dos elementos básicos: coherencia y contenido; así como la pertinencia de los ítems con respecto a la variable y sus dimensiones e indicadores.

Cuadro 1 Población de la Investigación

\begin{tabular}{|c|c|c|}
\hline $\begin{array}{c}\text { División de } \\
\text { Estudios para } \\
\text { Graduados }\end{array}$ & $\begin{array}{l}\text { Programas } \\
\text { de Maestría } \\
\text { en Gerencia }\end{array}$ & $\begin{array}{c}\text { Población docentes } \\
\text { de los programas } \\
\text { de maestrías }\end{array}$ \\
\hline $\begin{array}{l}\text { Facultad de } \\
\text { Ingeniería }\end{array}$ & $\begin{array}{l}\text { O Maestría en Gerencia de } \\
\text { Mantenimiento. }\end{array}$ & 13 \\
\hline $\begin{array}{l}\text { Facultad de Ciencias } \\
\text { Económicas y } \\
\text { sociales }\end{array}$ & $\begin{array}{l}\text { O Maestría en Gerencia } \\
\text { Pública. } \\
\text { Maestría en Gerencia de } \\
\text { Empresas Mención: } \\
\text { Gerencia de Mercadeo } \\
\text { O Maestría en Gerencia de } \\
\text { Empresas Mención: } \\
\text { Gerencia de Proyecto } \\
\text { Maestría en Gerencia de } \\
\text { Empresas Mención: } \\
\text { Gerencia Financiera }\end{array}$ & \\
\hline
\end{tabular}




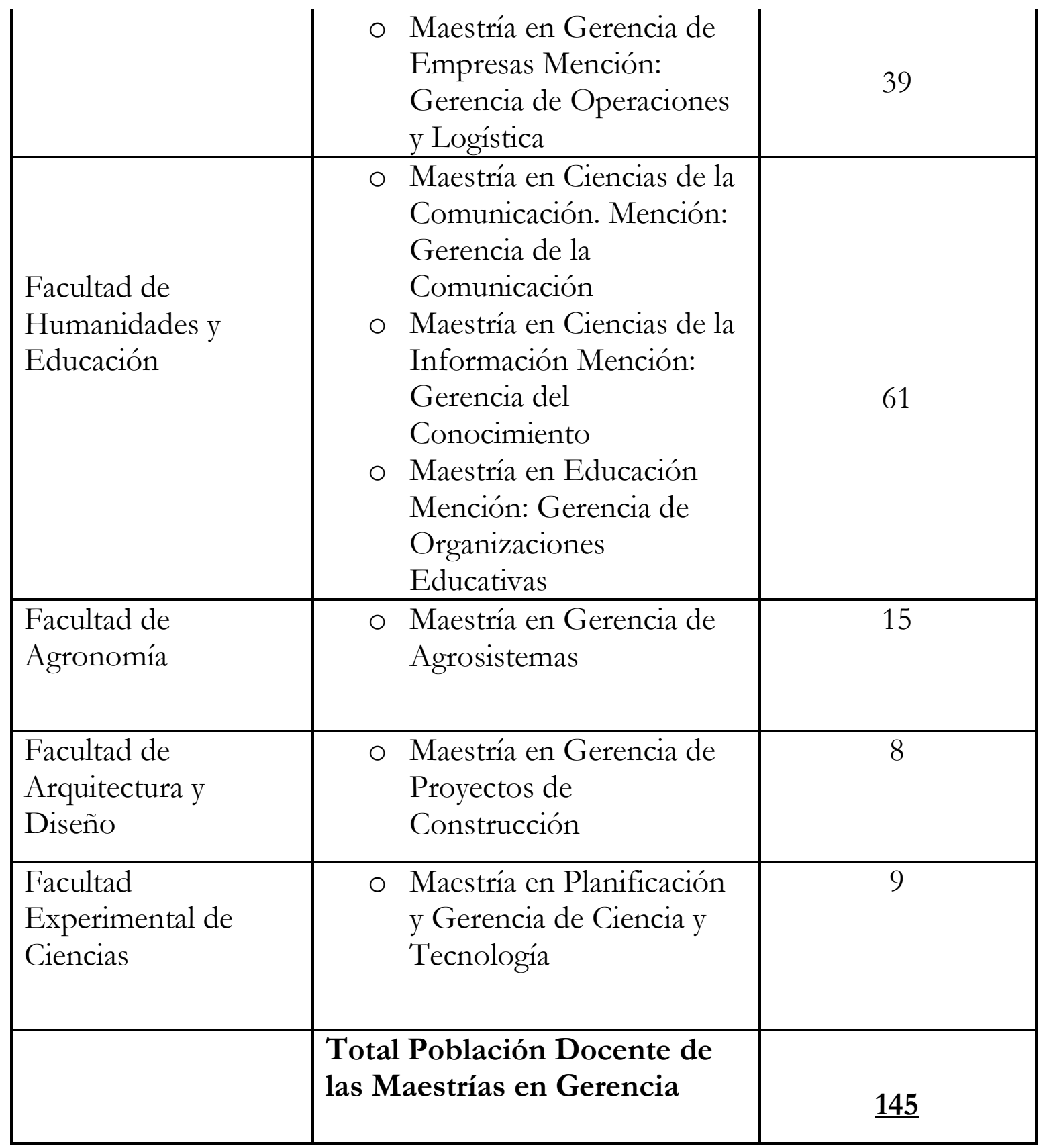

Fuente: Ministerio del Poder Popular para la Educación Universitaria (2015).

Para determinar la confiabilidad del instrumento de medición de esta investigación, con el propósito de determinar sí los ítems miden realmente las variables, dimensiones e indicadores estudiados, se aplicó el cuestionario al 20\% de docentes de los programas de maestría en gerencia. A los resultados obtenidos se les aplicó el índice estadístico del coeficiente de Alfa de Cronbach, obteniendo una confiabilidad de 0,98 . 
El cuestionario se diseñó con apoyó del uso de las tecnologías de información y comunicación (TIC) bajo la plataforma de Google Drive, mediante la tecnología de formularios de Google (Google Forms), y usando las bondades del internet, se envió el cuestionario a una base de datos creadas con los correos de los docentes, facilitados por las coordinaciones de los programas de maestría de esa casa de estudios. El empleo de la tecnología de formularios de Google facilitó la recolección de datos, así como monitorear la frecuencia de y rapidez por parte de los docentes en completar el cuestionario

Una vez obtenido los datos, se agruparon los mismos por tendencias, de acuerdo al grado de aceptación, negación o indiferencia expresada en las alternativas de respuestas. La tendencia positiva se conformó con los resultados correspondientes a las alternativas totalmente de acuerdo y de acuerdo; la tendencia negativa la conformaron los resultados correspondientes a las alternativas totalmente en desacuerdo y desacuerdo y la tendencia neutral la conformó los resultados, acorde a la alternativa ni de acuerdo y ni en desacuerdo.

\section{Marco Teórico}

\section{La marca personal}

Pérez (2008) concibe la marca personal como una forma de aclarar y comunicar aquello que hace a un individuo diferente o especial, y utilizar esas cualidades para guiar sus decisiones profesionales y empresariales. Implica conocer los atributos que hacen único al individuo; es decir, fortalezas, habilidades, valores, pasiones, entre otras; y utilizarlos para diferenciarse de la competencia. De igual manera, explica que una marca personal es la percepción que tiene el entorno sobre aquellos atributos que hacen a una persona, sobresalir, diferenciarse y ser tomada en cuenta por aquellos que necesitan de sus servicios.

Bajo ese mismo enfoque, Adán (2012) plantea que ese conjunto de atributos, aptitudes y actitudes de la marca personal provienen de la identidad personal, y se construye con base a la realidad, proyectada en metas y deseos. Complementa su posición explicando que la finalidad de la marca personal es evidenciar a una persona coherente, edificada 
sobre valores, competitiva y diferente, pero sobre todo con una clara promesa de valor.

En concordancia con las posiciones anteriores, Schawbel (2011), manifiesta que la marca personal describe el proceso por el cual los individuos se diferencian y destacan entre una multitud, identificando y expresando su propuesta de valor único, ya sea profesional o personal; después la promocionan en distintas plataformas, con un mensaje y una imagen consistentes que les permiten alcanzar una meta específica. De este modo, los individuos pueden conseguir que se les reconozca cada vez más, como expertos en su terreno, labrarse una reputación y credibilidad, fomentar su carrera, así como mejorar la confianza en sí mismos.

En tal sentido, Pérez (2011) indica que la marca personal debe ser abordada desde 4 perspectivas: acciones personales, acciones profesionales, acciones de posicionamiento y acciones de comunicación y en base a ellas se elaboró el siguiente apartado del trabajo, donde se abordan cada una de ellas y se contrastan los datos recolectados con la postura de autores expertos en la temática.

\section{Resultados}

\section{Marca personal de docentes universitarios en gerencia}

\subsection{Acciones personales}

Las acciones personales para Pérez (2008) son el conjunto de habilidades y conocimientos mediante los cuales una persona se diferencia de otras y genera una contribución a la sociedad, las cuales se basan en el emprendimiento desarrollado, la capacidad innovadora, de adaptación a los cambios, creencias, motivación y personalizar las acciones y/o productos generados. En este trabajo, las acciones personales de los docentes universitarios están basadas en conocimientos y habilidades que ha adquirido a través de su vida y que los han motivado para estimular el emprendimiento en todos sus quehaceres, desarrollar la investigación para generar nuevos aportes en sus espacios y/o adaptarse a los cambios de su entorno, distinguir las acciones y estrategias que desarrolla, permitiendo diferenciarse de otras personas, bajo un conjunto creencias inculcados en su vida y ha 
permitido fortalecer sus relaciones sociales.

Basada en esa visión de acciones personales, se consultó a los agentes informantes y se detectó una tendencia positiva con 92\% de aceptación sobre el emprendimiento en su modo de ser.

Mientras que la tendencia negativa fue muy baja (4\%), así como la neutral que oscila en 4\% (ver gráfico 1).

Este resultado refleja que el emprendimiento es un eslabón importante en la personalidad de los docentes para desarrollar las acciones personales, que según Pérez (2008), indica que el desarrollo del ser humano guarda estrecha relación con el descubrimiento y la utilización de sus fortalezas, así como con la consecución de sus objetivos.

\section{Gráfico 1}

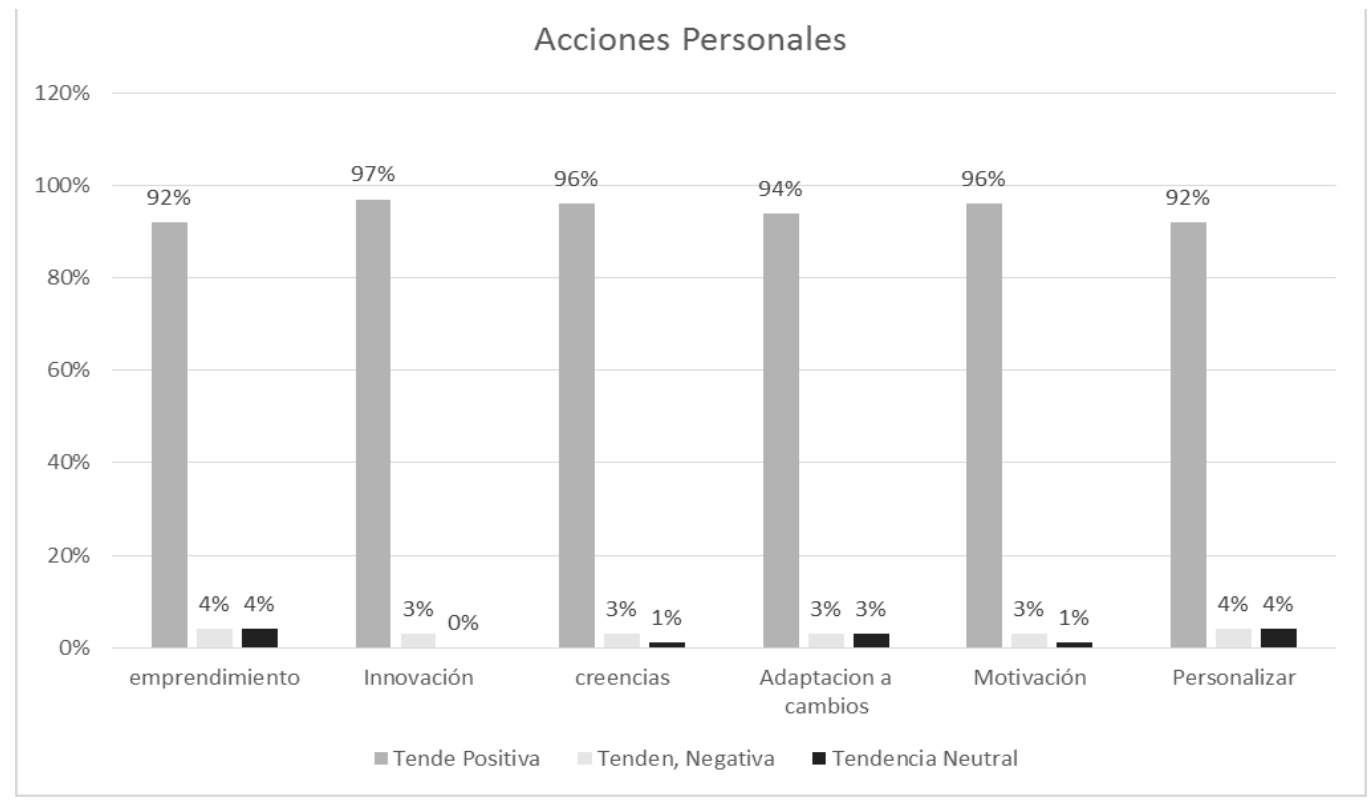

Fuente: Elaboración propia.

La importancia del emprendimiento en la marca personal es aumentar el valor de las personas, sacando lo mejor de la persona y utilizarlo para mejorar su entorno. Para Pérez (2008:133), el emprendimiento es una faceta permanente de las personas, la cual "implica hacer un análisis profundo de quién es la persona, qué es capaz de hacer y con qué recursos cuenta. (...), de esta forma se está en una mejor posición para asumir riesgos, ser más creativos y tomar iniciativas"

Una vez abordado el emprendimiento, se indagó sobre la innovación. En tal sentido, se detectó una tendencia positiva de 97\% de los 
docentes manifiestan su esfuerzo por innovar, vigorizando las acciones innovativas presentes en su modo de ser; la tendencia negativa con $3 \%$, mientras que la tendencia neutral marcó $0 \%$.

Tomando en cuenta que la innovación se considera una excelente alternativa para mantenerse vigentes y lograr destacarse, la tendencia positiva confirma el planteamiento de Adán (2012) quien explica que innovar no es un milagro de la naturaleza, solo es necesario un mínimo de conocimientos de la profesión, ser consciente de las habilidades personales y formarse para desarrollarlas y aportes ideas, productos y/o servicios diferentes.

Por lo tanto, la innovación en una marca personal se requiere disciplina para aprender y experimentar, e implica perseverancia para intentar, una y otra vez, nuevas fórmulas hasta lograr aquello que se busca. Por lo que, se puede aseverar que la innovación es un aspecto de las acciones personales que requiere la marca personal para sorprender al segmento de mercado en el cual se desenvuelve.

Otro indicador considerado fueron las creencias, cabe destacar que en los resultados se obtuvo que $96 \%$ con tendencia positiva de los docentes que consideran que sus valores marcan su comportamiento; mientras que 3\% de la tendencia negativa junto con los otros docentes que se mantienen en una tendencia neutral con $1 \%$, consideraron con indiferencia que los valores no determinan su comportamiento. Los resultados descritos permiten deducir que las convicciones que posee cada individuo acerca de sus valores influyen sobre sus acciones personales a la hora de manifestar su comportamiento.

Esta marcada tendencia positiva corresponde con la visión de Pérez (2008), relacionada con el desarrollo ideología-filosofía de las personas, considerada necesaria e imprescindible para salir de la neutralidad. La marca personal parte de la creencia del ser humano, en el individuo y en la capacidad de gestionar su vida y adaptarse a los cambios, de allí el próximo indicador.

En relación a la adaptación a los cambios, se obtuvo que 94\% marcó una tendencia positiva basada en el uso de tecnologías de información y comunicación (TIC), por lo que es una herramienta básica para adaptarse a los cambios actuales. A diferencia de la tendencia negativa con $3 \%$ y la tendencia neutral con 3\%, respectivamente. Sobre esto, 
Adán (2012), destaca lo imperante de la flexibilidad del ser humano para comprender situaciones distintas y adaptarse a ellas, lo cual permite o no la capacidad competitiva. De modo similar, Acosta (2006), destaca que el individuo con creatividad tiene una variedad de valores y motivaciones que se solapan, en algún modo, con otros indicadores. Para subsanar ello, busca autonomía y la competencia, aplicando sus habilidades para crear algo totalmente propio, una prolongación de sí mismo, caracterizado por el cambio.

Otro indicador de relevancia en los docentes es la motivación que posean, al respecto, 96\% de los agentes informantes marcaron una tendencia positiva al realizar su trabajo con motivación. Sin embargo; $3 \%$ considera el hecho de trabajar sin motivación y otro $1 \%$ se ubica en una posición neutral. La marcada tendencia se relaciona a la flexibilidad de horarios laborales, autonomía en sus espacios de trabajos, programas y alternativas de formación locales, regionales, nacionales e internacionales que ofrece la institución, así como la conciliación de la vida personal y laboral; a pesar de circunstancias políticas y económicas que aquejan al sector universitario en el país y afectan a la comunidad universitaria en general.

La motivación tiene mucha relación con personalizar las acciones individuales, y tanto este indicador, como motivación, tuvieron similares tendencias, al constatar que $92 \%$ de los docentes manifestaron con una tendencia positiva que personalizan sus actividades; solo 4\% consideró con una tendencia negativa y 4\% se mantuvo en tendencia neutral, es decir, que no era de su interés eso. Esos datos fortalecen la postura de Acosta (2006), quien considera que estar en contacto con otras personas en formación y capacitación motiva al individuo, estimula la creatividad y entusiasmo en los seres humanos.

$\mathrm{Al}$ personalizar las actividades se ponen en práctica conocimientos sobre páginas web, foros, blogs, networking, entre otros medios de las TIC para gestionar la información y contrarrestar aquella información sobre lo que no se tiene control.

Sobre esto, Adán (2012), plantea que el individuo debe intentar trazar de manera única su rumbo a alguna parte. Por lo que, dejar una huella distintiva genera un compromiso con una parte del entorno, aportar 
algo a beneficio de los demás, mediante una cadena de acontecimientos que generen efectos duraderos.

Como ha podido observarse, la tendencia predominante en las acciones personales ha sido positiva y con una distancia significativa de las tendencias negativa y neutral, ello expresa que los docentes reconocen la importancia como seres de conocimientos que tienen los aspectos abordados de manera intrínseca y sobre todo el carácter único como seres pensantes. En términos personales, los docentes basan sus acciones en creencias, emprenden estrategias personalizadas e innovadoras para adaptarse a los cambios, y los motiva la evolución educativa de los seres humanos.

\subsection{Acciones profesionales}

Para Pérez (2011), las acciones profesionales son las habilidades precisas que se ofrecen al mercado, destacando los servicios, beneficios, satisfacción o contribuciones por los que se valora un profesional cuantitativo y cualitativamente. En este tipo de acciones se deben destacar los aportes que realiza el profesional de manera individual, con quienes se relaciona y a la sociedad, procurando dejar huellas, como: trabajos físicos, servicios basados en la innovación, asesorías, coordinar la solución de problemas, generación de contenidos, información o conocimientos, pues el tiempo ha demostrado que la generación de documentos como libros, guías, páginas de internet, videos, manuales, entre otros, construye la reputación del profesional.

Para indagar sobre esta dimensión se trabajó con cinco indicadores: competencias, conocimientos destacados, herramientas tecnológicas, técnicas de diferenciación y progreso organizacional. Al abordar la competencia se detectó un $90 \%$ con tendencia positiva en relación al desarrollo de competencias con sus estudiantes; mientras que sólo 3\% muestra una tendencia negativa y otro $7 \%$ se ubica en la tendencia neutral, respecto a su voluntad de no estimular el desarrollo profesional por competencias.

En este sentido, los resultados corresponden con la visión de Adán (2012), ya que los docentes en la carrera profesional están completamente formados y dispuestos a enseñar en la maestría, 
destacando tanto la competencia directiva como la competencia técnica. En la primera se demuestra la capacidad de identificar, analizar y resolver problemas, sin sentirse agobiado en las condiciones de incertidumbre o de información incompleta, y en la segunda, se manejan situaciones que conlleven al enfrentamiento de personas, con quienes no siempre comprende o sabe tratar.

En el ámbito de la docencia universitaria, la competencia se encuentra muy relacionado con el indicador de los conocimientos más destacados; donde se obtuvo que $96 \%$ de los docentes conoce la importancia que tienen sus conocimientos más destacados. Sólo una tendencia negativa del 3\% y una leve tendencia neutral que oscila en un $1 \%$ se inclina a agrupar los docentes que no identifican sus conocimientos destacados.

\section{Gráfico 2}

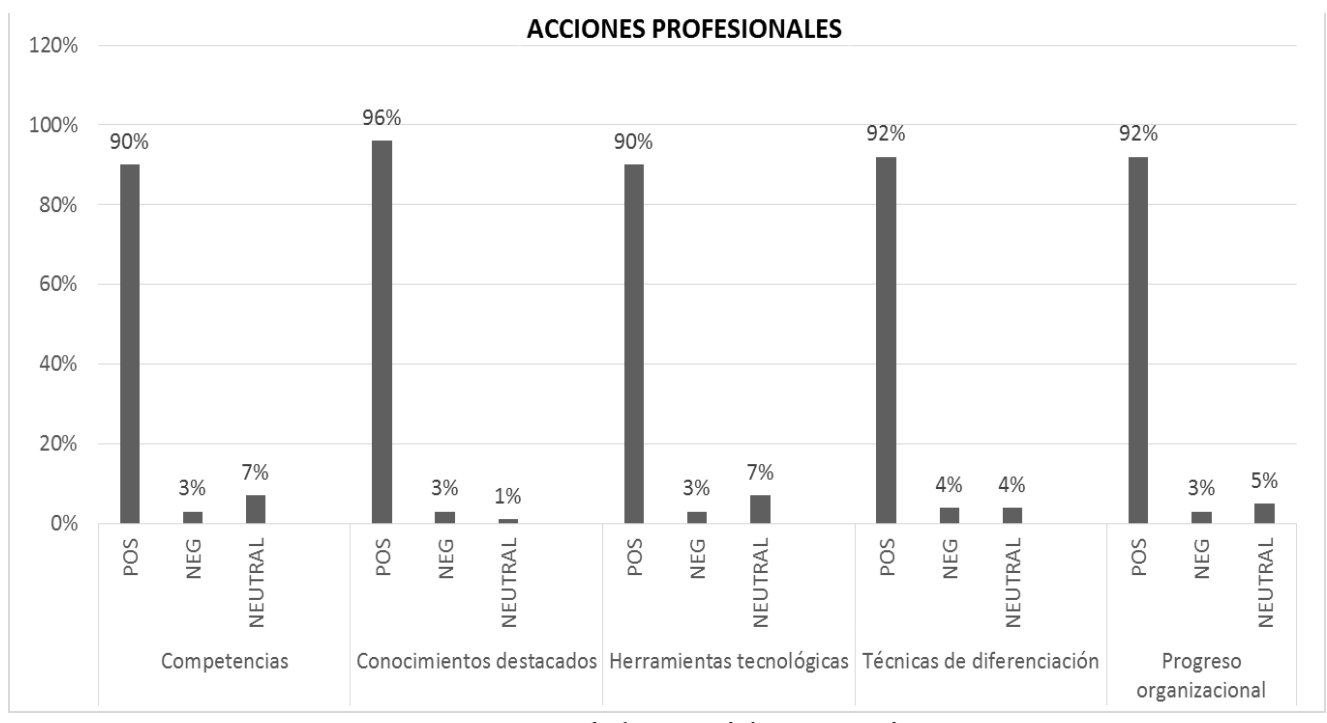

Fuente: Elaboración propia.

Al observar los valores de la tendencia positiva se confirma la postura de Pérez (2008), quien argumenta que en una visión clara de la marca personal de un profesional se destacan los valores, habilidades, acciones que los demás asocian con esa persona y cuyo objetivo es influir en la forma en que los demás lo perciben y transformar esa percepción en oportunidad.

Esto lo consigue el docente haciendo uso de sus conocimientos en asesorías a empresas, instituciones y estudiantes de los programas de 
asesorías, así como generando productos de investigación que son compartidos con la comunidad científica, mediante la divulgación de los mismo en artículos científicos, así como la disertación de perspectivas en congresos, foros y demás actividades científicas. De esta forma se puede transmitir al entorno quién es el docente, qué hace y qué lo diferencia o cómo aporta valor a su mercado objetivo. De esta forma el docente usa la marca personal para identificar el valor que tiene su experiencia y conocimientos, y ser ampliamente conocido, con el fin de alimentar y aumentar ese valor a lo largo de la vida y, de acuerdo a Pérez (2008), generar resultados extraordinarios.

Como apoyo al conocimiento, en el siglo XXI las herramientas tecnológicas juegan un rol preponderante, y así se evidencia en los resultados, al constatar que $90 \%$ de los docentes respondieron bajo una tendencia positiva que emplean la tecnología para modelar sus técnicas e inferir con este tipo de acciones al mejoramiento profesional y mantenerse a la vanguardia de los cambios tecnológicos. Sólo 3\% se encuentra en una tendencia negativa y $7 \%$ con tendencia neutral, que consideran hacer poco uso las herramientas tecnológicas, determinando un pequeño grupo de docentes que se mantienen conservador con respecto al uso de la tecnología. Los hallazgos positivos demuestran la postura de Pérez (2008), quien explica que en la marca personal el empleo de tecnología de vanguardia facilita la diferenciación, mediante la especialización, convertirse en especialista o sobresalir del resto con algún atributo distintivo, mediante la notoriedad como especialistas.

Otro indicador abordado son las técnicas de diferenciación del ejercicio profesional del docente, con respecto a sus competidores más cercanos, observándose en el gráfico 2 que $92 \%$ de los docentes manifiestan una tendencia positiva sobre el empleo de técnicas de diferenciación para ser más competitivos en su entorno profesional; es de acotar que otro nivel identificado con el $4 \%$ de tendencia negativa y el $4 \%$ con tendencia neutral no emplea técnicas para diferenciarse del resto. La diferenciación logra crear un posicionamiento de cada persona en la mente de su público objetivo. Para alcanzarlo y transformar la identidad en una marca personal, se busca, de acuerdo a Pérez (2008), destacar los atributos profesionales.

Una vez abordado el indicador de técnicas de diferenciación, conviene 
destacar el progreso organizacional. Como se puede observar en el gráfico 2 , que $92 \%$ de los docentes manifestó una tendencia positiva al considerar que su trabajo contribuye con el progreso organizacional, $3 \%$ de tendencia negativa y otro pronunciamiento con $5 \%$ de tendencia neutral manifestó que su trabajo no contribuye con el progreso institucional, ello demarca, de acuerdo a Adán (2012), el compromiso de la gestión profesional que desarrolla.

Basado en los resultados presentados en las acciones profesionales, se puede destacar la marcada tendencia positiva presentada en cada uno de los indicadores que se abordan, indican el esfuerzo e interés de los docentes por ser conocidos como expertos reconocidos y valorados ante las otras personas de su interés y afianzar los lazos profesionales desarrollados en el quehacer universitario.

\subsection{Acciones de posicionamiento}

En esta etapa se indagan los atributos que la persona desee la identifiquen y descubrirá o corroborará aquellos atributos por los que es conocida, generando vínculos emocionales, mediante la gestión de aspectos subjetivos y emocionales con quienes forman el mercado o público objetivo.

El posicionamiento se construye mediante las acciones personales y profesionales emprendidas, reflejando los valores y cualidades distintivas, reconocibles y valiosas; se basan en lo que realmente es la persona; por lo que es la suma de los logros, actitudes y trato con otras personas durante el tiempo.

Para Pérez (2011), se logra el posicionamiento de la marca personal cuando los atributos asociados de una persona son identificados por el mercado meta, y mediante ellos se reconoce a una persona; por lo que no pueden ser genéricos, sino poco comunes, valiosos para el individuo y para los demás, pero, sobre todo, que generen beneficios a otros. A medida que el tiempo pasa, el posicionamiento cambia y evoluciona conjuntamente con la madurez de los atributos, pero se debe tener cuidado pues ser conocido es sencillo, ser reconocido es difícil, pero ser valorado es más complicado.

En relación al posicionamiento, se abordaron entre los indicadores la 
confianza, acciones de fidelización, entorno profesional, crecimiento profesional y reconocimiento, respectivamente. Al respecto, la confianza y el crecimiento profesional son indicadores que están estrechamente relacionados, y eso se corrobora al obtener para ambos indicadores las mismas tendencias en los resultados, pues considera el $94 \%$ con tendencia positiva que mediante el crecimiento profesional obtienen la seguridad necesaria para compartir sus conocimientos en el ámbito de maestrías en gerencia; a diferencia de otros docentes con tendencia negativa de 3\% y la tendencia neutral de 3\% opinaron que esta condición no es influyente para su seguridad como persona (ver gráfico 3). Para Pérez (2011), convertirse en un especialista reconocido y divulgarlo, mediante la promoción y el uso de técnicas publicitarias conforma la herramienta ideal para visibilizarse, mediante su productividad científica, vinculación con entes científicos, empresariales, gubernamentales, entre otros y ello transmite seguridad, y por tanto confianza.

\section{Gráfico 3}

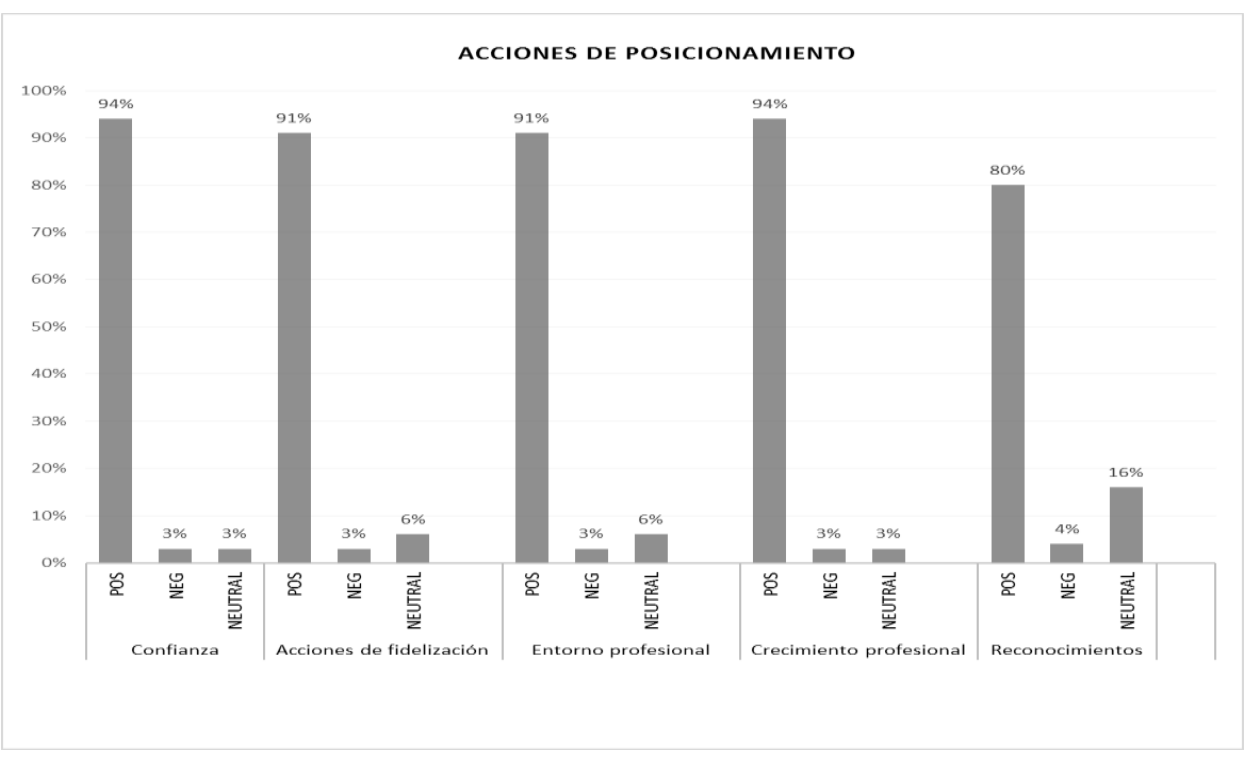

Fuente: Elaboración propia.

En relación a las acciones de fidelización, en el gráfico 3, se observa que $91 \%$ de los docentes considera importante mantener el sentido de pertenencia, constancia en las relaciones y mantener activas actividades simultáneas. Sin embargo, una leve tendencia negativa del 3\% y otra con tendencia neutral del $6 \%$ manifestó no interesarles la fidelidad.

Las acciones de fidelización corresponden con los resultados referentes 
al entorno profesional; donde $91 \%$ de los docentes se agruparon en una tendencia positiva, confirmando su relación con estudiantes y colegas en el entorno profesional; el resto de los agentes informantes manifestaron una tendencia negativa de $3 \%$ y otra neutral de $6 \%$ de indiferencia sobre la forma continua de relacionarse con su entorno.

Estos resultados se inclinan con el punto de vista de Adán (2012), quien plantea que las acciones conjuntas suponen relación con otras marcas y productos como la responsabilidad social personal, con características de empresario, directivo, autónomo o profesional independiente. El docente atrae más público si mejora su popularidad y para ello el desarrollo de las tres funciones universitarias de la Universidad del Zulia, como: extensión, investigación y docencia, aunado a servicio comunitario, empleada para comprender, integrarse $\mathrm{y}$ atender los problemas sociales que inciden en el entorno.

Traspasando a los reconocimientos profesionales de los docentes, se determinó que $80 \%$ bajo la tendencia positiva se esfuerza por obtener reconocimientos en el ámbito laboral. Sin embargo, se identificó igualmente en esta fase que una tendencia negativa de $4 \%$ y una tendencia neutral muy marcada de $16 \%$, no se esfuerzan por recibir reconocimientos de esta índole.

El predominio de la tendencia positiva quiere decir que los docentes han roto círculos de rutina de estancamiento disciplinarios, destacando la autenticidad de los aportes realizados a la comunidad científica y profesional, así como manteniendo los perfiles académicos actualizados e innovando multidisciplinariamente con sus homólogos nacionales e internacionales, siendo valorados por estudiantes y colegas durante los años transcurridos en su quehacer universitario. Por eso es conveniente, según Pérez (2011), centrase en las redes que reúnen los profesionales y directivos con los que se puede colaborar o intercambiar información y recursos.

\subsection{Acciones de comunicación}

Las acciones de comunicación significan en la marca personal visibilizar de manera consciente, eficaz e intencionada las interacciones con el mercado meta. Estas acciones se basan en el uso de herramientas para transmitir el trabajo, los logros alcanzados y la generación de 
contenidos, por lo que a través de la comunicación se demuestran las virtudes y habilidades, pero sobre todo compartir los resultados generados a través de su gestión personal y profesional, ya que según Pérez (2011:163), “lo que se ve es más fiable que lo que no se conoce. Pues de nada sirve decirle a todo el mundo que existes si no eres capaz de asociar tu nombre a algo relevante".

Para abordar la comunicación se consideraron 5 indicadores a saber: medios de comunicación, relaciones personales, acciones de diferenciación, herramientas y redes sociales, así como el uso del nombre y apellido del docente como marca personal. En relación a los medios de comunicación, se detectó que son empleados para mantenerse comunicados, así lo indican un $87 \%$ de los agentes informantes que manifestaron una tendencia positiva, mientras que sólo una leve tendencia negativa del 3\% y una tendencia neutral de 10\% manifestó no usar medios de comunicación (ver gráfico 4).

\section{Gráfico 4}

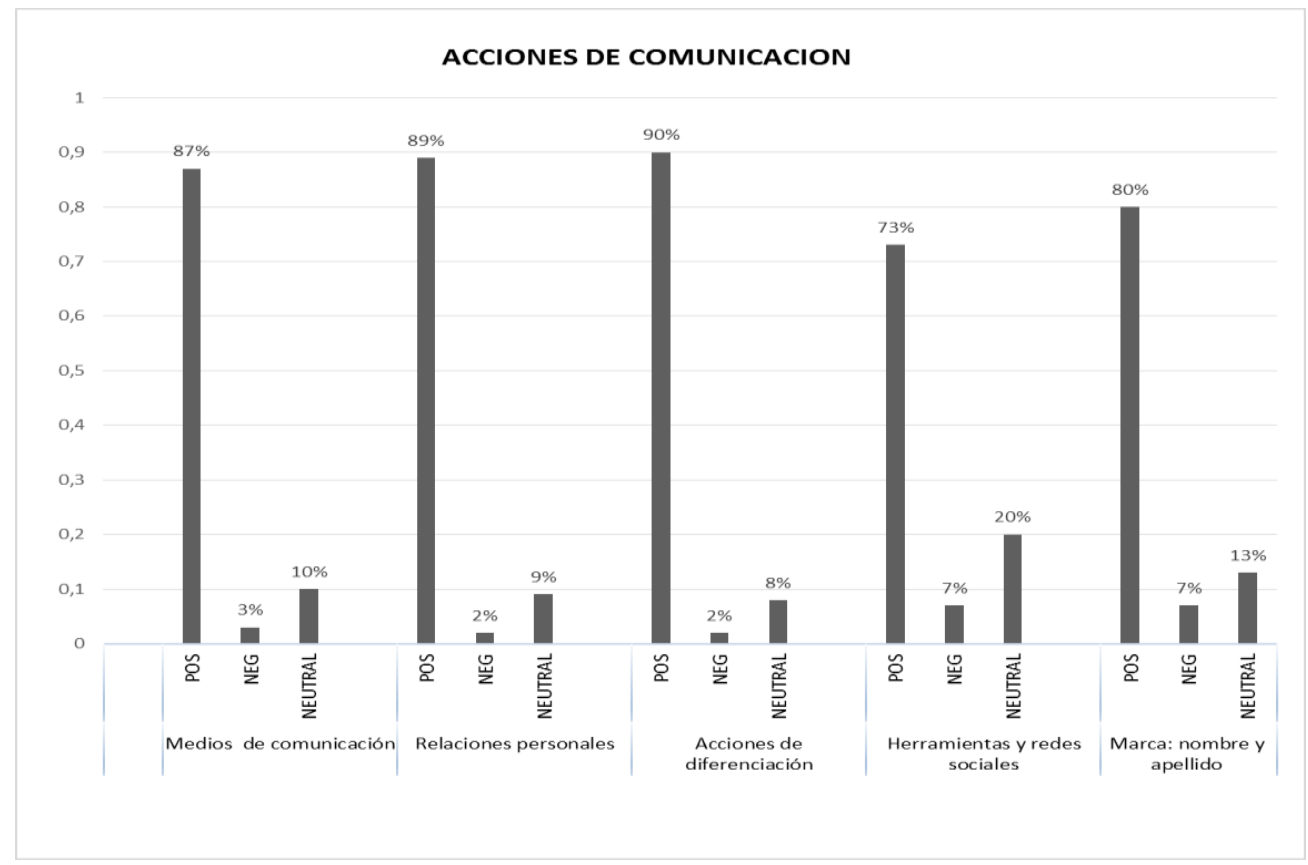

Fuente: Elaboración propia.

Para Adán (2012), estos resultados de tendencia positiva son congruentes, pues en el siglo XXI la comunicación es parte de la vida de la persona, donde se interconectan con otras personas, mediante programas de radio, entrevistas por televisión, publicidad digital, entre otros. En este sentido, la notoriedad en la comunicación se manifiesta 
en la forma en que el docente se hace ver, y recordar, entendiendo a todos aquellos con quienes se relaciona y desarrolla capacidades comunicativas para estar alineado a una marca personal que busca estar comunicada con su entorno.

Ahora bien, los medios de comunicación facilitan la construcción de nuevas relaciones personales, así se evidencia en el gráfico 4, cuando $89 \%$ de los docentes concordaron en una tendencia positiva estar conformes con su capacidad para conocer nuevas personas; a diferencia de una leve tendencia negativa de $2 \%$ y una creciente tendencia de $9 \%$ determinó que no se interesan a conocer personas con facilidad.

Sobre esto, Pérez (2008), considera que las personas son seres sociales, y por tanto requieren de las relaciones sociales como instrumento para conseguir notoriedad y visibilidad de marca personal y están en una permanente búsqueda de formas de relacionarse con otros y de la posición que se ocupa dentro de ese conjunto de relaciones con amigos, personas que se contactan a través del trabajo o de las aficiones, son las que perciben las acciones del individuo e influyen sobre su manera de ser.

Las acciones de diferenciación emprendidas por los docentes indican que $90 \%$ concordaron en una tendencia positiva, es decir, que si trabajan en diferenciarse de sus homólogos; mientras que una leve tendencia negativa del 2\% y una leve tendencia neutral del $8 \%$ no están de acuerdo con este tema. Estos resultados corresponden con la postura de Pérez (2008), quien indica que la diferenciación es una estrategia de comunicación para dejar clara la relevancia, especialización y diferenciación personal. Asimismo, permite posicionarla en la mente de su entorno y su mercado de la mejor manera posible.

Para facilitar la comunicación son de gran utilidad las redes sociales y consideradas como herramienta estratégica para compartir los progresos de los docentes con su entorno. Las tendencias son que 73\% afirmó de forma positiva; $7 \%$ demarcó una tendencia negativa, y 20\% de forma considerable se comportó indiferente ante eso.

Los resultados con tendencia positiva, por predominar la mayoría de los agentes informantes, comprueban el punto de vista de Pérez (2011), 
cuando explica que al comunicarse se transmite información que interesa, para hacer partícipe a otros de aquello que se tiene; se trata de hacerse público y notorio a través del networking como una forma sistematizada de establecer y mantener el contacto con los profesionales que influyen en el proyecto persona; así como también las redes sociales online, red de contactos, creando comunidades con intereses comunes.

Las redes sociales virtuales son un soporte excelente para gestionar las relaciones de los docentes, ya que ahorran tiempo, permiten ampliar la red de investigadores tanto en el ámbito nacional como internacional, recuperar contactos perdidos, fortalecer las relaciones interinstitucionales, permiten compartir contenidos de eventos como foros, congresos, jornadas, entre otros; asimismo, hacen visible a la persona y definen claramente su círculo social.

Finalmente, se consultó a los docentes si empleaban su nombre y apellido, como su marca personal. Al respecto 80\% afirmó utilizar su nombre y apellido como una marca personal agrupándose en la tendencia positiva; 7\% negó esta acción agrupándose en la tendencia negativa y 13\% manifestó neutral, es decir, indiferente.

Los resultados positivos se generalizan con el planteamiento de Pérez (2008), quién destaca que muchos profesionales están dándose cuenta del poder que tienen para comunicarlos resultados, productos y logros que hace a un docente diferente o especial, utilizando sus cualidades para guiar sus decisiones profesionales y empresariales. Ello implica conocer los atributos que hacen único al docente en el ámbito científico; es decir, fortalezas, habilidades, valores, pasiones, entre otras; y utilizarlos para diferenciarse de otros, a quienes puede considerar su competencia.

El uso del nombre como marca personal según Adán (2012), permite transmitir atributos, aptitudes y actitudes que conforman la identidad personal del docente, y se construye en base a la propia realidad proyectada hacia las metas y deseos personales e institucionales con una clara promesa de valor para influir en las percepciones, sentimientos y creencias que se genera en los demás, y esto significa que tener marca personal es un baluarte. 
Al comparar los resultados obtenidos y observar en esta dimensión el predominio de la tendencia positiva con las bases teóricas, se corrobora el planteamiento y postura de Pérez (2008), Pérez (2011) y Adán (2012), quienes concuerdan en que una marca personal se construye y se edifica sobre valores y relaciones entre personas, visibilizar actitudes mediante las diferentes herramientas comunicacionales.

\section{Conclusiones}

Considerando los resultados antes abordados y dadas las condiciones generales en la población estudiada, se puede presumir que los motivos que influyen en el proceso de decisión para iniciar el diseño de una marca personal, están asociados a muchos elementos intrínsecos y otros de carácter externos. En cualquiera de los casos el marketing personal está asociado para que exista un posicionamiento que representa una cuota de valor para los docentes universitarios y encontrar una valiosa fuente de indicadores que ayudaran a mantener alineados la marca personal con el público objetivo.

En tal sentido, el nivel de aplicación de estrategias se corresponde con el nivel de prácticas y acciones personales, profesionales, de posicionamiento y de comunicación; lo cual indica la confiabilidad de los aportes para el diseño y el alcance de una marca personal perdurable en el tiempo del docente universitario de los programas de gerencia en la Universidad del Zulia.

Considerando el rol del docente al desarrollar su marca personal, la institución requiere de escenarios complejos donde participen todos los docentes de los programas de maestría en gerencia como personas con marcas propias y en un nuevo diseño de relaciones. Estas relaciones no salen de laboratorios ni de grandes consultorías o probablemente de grandes expertos mundiales ni de asesores de empresas, nacen del rol como docente participativo dentro de la comunidad universitaria.

En tal sentido, resulta imperante que la Universidad del Zulia siga siendo dinamizador, no sólo de derechos estudiantiles o desarrollo académico, sino también del valor de las personas que la integran; principalmente de sus docentes que van tomando conciencia de su credibilidad y promesa de valor por encima de sus intereses personales. 
El desarrollo de las marcas personales plantea y reta a asumir un nuevo rol en el que cada uno juega su papel por el bien común y por el propio desarrollo. Una cosa no excluye a la otra. Sin embargo, una marca personal hay que colocarla en movimiento, superando el autoconocimiento para alcanzar los objetivos, para ello se desarrolla una estrategia y se definen los medios y las herramientas para poner en acción y en valor la marca personal.

\section{Referencias bibliográficas}

Acosta Vera, José María. (2006). Marketing Personal. Segunda edición. Madrid España. Editorial ESIC.

Adán Pablo. (2012). Marketing Humano (Liderazgo, Marca personaly Comunicación II). Primera Edición. España. Editorial Diazotec, S.A.

Ministerio del Poder Popular para la Educación Universitaria (2015).

Directorio Nacional de Postgrado autorizados por el Consejo

Nacional de Universidades. Enlace online. Acceso 15/05/2015.

Disponible en:

http://www.ccnpg.gob.ve/directorio_nacional/busqueda_inst.asp Pérez Ortega, Andrés. (2008). Marca personal, cómo convertirse en la opción preferente. Madrid. Editorial ESIC.

Pérez Ortega, Andrés. (2011). Expertología. La ciencia de convertirse en un profesional de referencia. Editorial Alienta. España. 



\title{
Percepción social e identidad: el docente de educación básica
}

\author{
Flor del Carmen Montes Rodríguez \\ Cyomara Inurrigarro Guillén \\ María Guadalupe Martínez Ortiz \\ Oscar Yael Navarro Montes
}

Escuela Normal Miguel F. Martínez Centenaria y Benemérita, México

\section{Resumen}

El presente ensayo expresa los resultados de un estudio exploratoriodescriptivo orientado a conocer: la imagen social que, de los docentes de educación básica de escuelas públicas, se tenía desde la perspectiva de los estudiantes de licenciatura, del sector público y del privado, de los universitarios y los normalistas. A su vez, se buscó identificar la percepción que sobre la identidad docente poseían los estudiantes normalistas sobre su profesión. Los indicadores que se contemplaron para el estudio fueron: los atributos asociados a la innovación, las experiencias significativas de su vida escolar, así como la valoración de la profesión. Para caracterizar a imagen social se consideraron atributos profesionales, personales y propios de la docencia.

Palabras clave: percepción social, identidad profesional e imagen social.

\section{Introducción}

— Lsegundo decenio del siglo XXI ha sido controversial para la imagen docente en México, desde el preludio de la Reforma Educativa (finales del 2012) a la fecha del estudio (2016), era casi tema 
cotidiano escuchar en las noticias de radio o televisión, referentes sobre la docencia asociados a conflicto magisterial, disidencia, sindicalismo, oposición, bloqueos, suspensión de clases, protestas y daños, aviadores, resistencia al cambio; una postura de choque-negociación entre la Secretaría de Educación y la organización sindical magisterial. Incluso con una sencilla búsqueda en la red de internet se pueden encontrar referentes noticiosos con connotación negativa en dicho periodo.

Los acontecimientos citados, las imágenes televisivas, los videos virales, los encabezados de los periódicos, así como la diversidad de opiniones que circularon por las redes sociales, impactaron en la figura de la docencia, ¿cómo afectó esto su imagen social? ¿cuál fue la visión de los estudiantes normalistas? La presente investigación buscó conocer la percepción de los estudiantes de licenciatura, de diferentes estratos socioeconómicos (universidad pública vs privada). Adicionalmente, se trató de entender la concepción del normalista sobre su identidad como futuro docente.

La representación social es resultante de los sistemas cognitivos, en los cuales la información recibida se procesa, así el sujeto puede percibir, aprender o comunicar; ello, para reconocer la presencia de estereotipos o mini-modelos que influyan en las actitudes personales, esta puede ser negativa o positiva. Para el presente estudio, se entiende por imagen social al estereotipo o mini-modelo descrito por Moscovici, sobre la teoría de las representaciones sociales citado en Araya (2002). Para poder crearse una imagen de algún objeto, figura, teoría o creencia, se parte de las percepciones que se tienen hacia cada una de éstas, pero, ¿qué hace que se perciba como positiva o negativa? En este sentido se define la percepción como una imagen mental que se forma con ayuda de las experiencias y necesidades de cada individuo.

Los sujetos perciben de manera distinta su entorno, por lo que, para dar respuesta al cuestionamiento antes planteado, se definen dos componentes de la percepción que ayudarán a comprender la razón del porqué determinada situación se valora como positiva o negativa. Uno de ellos, las sensaciones o el estímulo físico que proviene del medio externo; se hace referencia, en este caso, de acciones por parte del docente. Por otro lado, influyen las características del sujeto (necesidades, experiencias y motivaciones). Esto es lo que propicia que 
cada uno configure una idea distinta del docente, independientemente de los estímulos que se encuentren a su alrededor.

La representación surge en forma inicial de la percepción de cada sujeto, ésta varía según sus componentes, es decir, la percepción se convierte en imagen social. En el caso de la docencia, estos profesionistas se ven afectados por las críticas que escuchan y saturan el contexto bajo el cual se cuestiona su trabajo y no con base en sus cualidades y retos, entre ellos, trabajar en espacios reducidos, en muchas ocasiones con una gran cantidad de niños; Esteve, Franco y Vera (1995) citados por Páez y Hernández (s/f), señalan que cuando esta percepción se generaliza provoca la retirada del apoyo social en torno a la significatividad de su trabajo. Señalan a su vez que diversos agentes, tales como los medios de comunicación, funcionarios educativos y padres de familia, responsabilizan a los docentes de la vulnerabilidad e incapacidad de los sistemas educativos para cumplir con las expectativas sociales.

\section{Metodología}

Partiendo de la situación descrita en el apartado anterior, el estudio realizado buscó identificar cuál era la imagen social sobre la docencia de educación básica, de escuelas públicas, que tenían los estudiantes de licenciatura, en el estado de Nuevo León. La investigación se realizó el último trimestre del 2016; se buscaba establecer un comparativo sobre cómo percibían a los maestros los estudiantes de tres instituciones de educación superior del estado, de distintas escuelas de procedencia: universidad púbica (estatal), universidad privada y una escuela normal del estado. En torno a la identidad profesional de los alumnos normalistas se consideró su edad, intereses y motivaciones.

El instrumento empleado para la recolección de los datos fue una encuesta en línea, misma que se aplicó a alumnos de la comunidad normalista, estudiantes de la universidad estatal de sostenimiento público y con la colaboración de jóvenes de una institución educativa del mismo nivel de reconocido renombre y alto estatus económico de Nuevo León. En este trabajo se presentan los resultados iniciales derivados del estudio cuantitativo de tipo exploratorio-descriptivo (Latorre, Rincón y Arnal, 2005), que busca tener un conocimiento de 
la opinión pública de estudiantes de licenciatura, con y sin acentuación en formación docente.

Los propósitos de la investigación fueron:

- Caracterizar la identidad profesional de los estudiantes normalistas sobre los docentes.

- Comparar la imagen social de los docentes de educación básica de escuelas públicas de acuerdo con los estudiantes de licenciatura de diferentes contextos socioeconómicos: universidad pública y privada.

- Comparar la imagen social de los docentes de educación básica de escuelas públicas de acuerdo con los estudiantes de licenciatura, con y sin acentuación en formación docente.

Los datos se recopilaron directamente en el lugar de estudio donde se desempeñan los individuos, por lo cual se constituye en un estudio de campo; la encuesta se respondió en forma anónima y voluntaria. De acuerdo con Sáenz (2012), es una investigación denominada básica, dado que los objetivos que se persiguieron tenían la intención de conocer la percepción de los participantes para definir la imagen social sobre los docentes; esta se comparó con la de los estudiantes normalistas con la finalidad de encontrar similitudes y diferencias entre estos.

La encuesta tenía 44 ítems organizados en tres bloques; el primero, dirigido a conocer la percepción de los participantes en torno a atributos profesionales: de carácter laboral, de personalidad, de compromiso social e innovación y de imagen social. El segundo corte enfocado en la valoración social y la propia percepción de la docencia. El tercero, se centró en los estudiantes normalistas, para comparar la imagen que ellos tenían sobre los docentes y sobre cómo caracterizaban su identidad profesional. El instrumento se validó a través de juicio de expertos, es decir, se presentó el cuestionario a tres especialistas en educación -doctores- quienes lo aprobaron; además se hizo una prueba piloto con 85 estudiantes normalistas, con base en las observaciones se hicieron los ajustes necesarios.

La muestra fue intencional, contó con 186 estudiantes de licenciatura: 79 de escuela normal, 61 de universidad particular y 46 de la 
universidad estatal. De acuerdo con su género, la mayoría, un 73\% de los que respondieron fueron mujeres; el resto, el 27\%, hombre. En cuanto al área de estudio de la licenciatura que cursaban, de mayor a menor presencia fue: el 52\% de Artes, Educación y Humanidades; el $22 \%$, estudiantes de Ciencias Sociales y Administrativas; el 15\% de Ingeniería y Tecnología; con una representación del 4\% Arquitectura, Diseño y Urbanismo, así como alumnos de Ciencias Naturales y Exactas; el 2\% de Ciencias Agropecuarias y sólo un 2\% del campo de Ciencias de la Salud. La mayoría indicó que tenía un familiar docente, en el caso de los estudiantes de universidad particular en un $69 \%$, el $67 \%$ de los normalistas y el $59 \%$ de quienes estudiaban en la universidad pública estatal.

Los hallazgos recuperados del estudio concordaban con los objetivos de la UNESCO del 2016; organización que señalaba la necesidad de tener más docentes, preparados con las competencias necesarias para educar en el siglo XXI, señalaban se debía reivindicar la imagen docente para captar a los mejores candidatos hacia la profesión y que esta se revalorara. Esta afirmación lleva implícita la existencia de que dicha imagen era negativa o no idónea y por tanto debía restituirse.

En el caso de Nuevo León, durante los ciclos 2015-2016 y 2016-2017, hubo una reducción significativa en el número de candidatos interesados en ingresar a las escuelas oficiales formadoras de docentes del Estado; por ejemplo, en la Normal participante los últimos ciclos asistieron alrededor de 800 candidatos, años anteriores inmediatos, giraban alrededor de los 1500. En el contexto social y el momento histórico, el tener claridad de la imagen social que se tiene del maestro, así como reconocer la identidad profesional de los estudiantes normalistas no sólo importante, sino necesario para las instituciones formadoras de docentes.

\section{El docente y la imagen social}

El tópico referente a la imagen social del docente ha sido investigado y estudiado por autores como Esteve (2001), Urusa y Malik (2013), e Imbernón, Jarauta y Bozu (s/f), entre otros, encontrando con sus estudios que dicha imagen del docente como ente social se ha ido transformando con el paso del tiempo. Esteve (2001), citando a Eric 
Hoyle, refiere a los estereotipos que dominan la imagen pública como aquellos que se modifican a largo plazo y con lentitud, asimismo, de acuerdo con el Diccionario de la Real Academia de la Lengua española (2016), éstos son el conjunto de rasgos que caracterizan ante la sociedad a una persona o entidad. Esteve (2001) menciona que esta percepción actúa en tres direcciones.

La primera dirección según Esteve (2001) son las expectativas de las personas ajenas a la profesión, los no docentes; éstas se enfocan en la manera en que se forman las relaciones con personas como los padres de familia y los alumnos, entre otros. El segundo punto de influencia es en la calidad y cantidad del juicio de quienes tienen la opción de elegir para finalmente impactar en el autoconcepto de su profesión, un ejercicio que puede reafirmar o desvalorizar su profesión, esto tendrá que ver con el tipo de estereotipo, ya sea positivo o negativo.

La identidad profesional está fuertemente relacionada con la imagen social; eso se demuestra en la cantidad de personas que desean ingresar a la docencia y ayuda a entender una parte del disgusto social que vive dicha profesión. Esto es un tema importante de estudio tomando en cuenta la publicación que hace la UNESCO (2016), en el marco de la celebración del día del maestro, donde menciona que se requiere reivindicar su imagen, aunado a que se necesita de un elevado número de docentes para un futuro muy cercano en 2030.

Todo docente por ser una figura que tiene comunicación con una gran cantidad de personas de la comunidad, frecuentemente es objeto de señalamientos por parte de esas, quienes lo comunican a los medios que, de acuerdo con Esteve (2001), sigue poniendo al maestro como una figura idílica, la cual es una concepción más antigua centrada en las relaciones interpersonales con el alumno; se puede encontrar en las películas tradicionales donde se resalta la imagen del educador cuya cualidad más fuerte es el vínculo con el estudiante que hace que se vuelva exitosa la labor educativa.

La segunda de estas visiones es la conflictiva, donde sobresalen los enfrentamientos personales e ideológicos como si se tratara de la realidad que se vive día a día; en el caso particular de México, mencionado en la introducción, basta con notar la cantidad de noticias referentes al conflicto magisterial, paros laborales, marchas en gran 
parte del país, los bajos resultados educativos siendo éstos culpa del docente, entre otros temas.

Esteve (2001) señala que el problema de la imagen conflictiva del docente puede estar auto alimentándose a través de la conjugación del sentimiento que se multiplica y el sensacionalismo periodístico. Además, la realidad no se ajusta perfectamente a estas dos visiones, ya que están en polos opuestos del espectro, entonces lo que sucede es que en la cotidianeidad tiende a juzgarse contra estos dos paradigmas opuestos, por ende, es muy difícil llegar al ideal utópico e idílico, por lo tanto, el opuesto extremo (conflictivo) es el más cercano para ajustar a lo real.

En cuanto a la influencia de estas visiones en la formación docente, ésta no responde a la realidad por lo cual el choque es inminente. Cuando un novel se enfrenta a las aulas va desde la aceptación del conflicto, la contradicción entre los ideales y la realidad en la que se inserta, la negación y la depresión resultante del predominio de la ansiedad generada por no ser capaz de alcanzar la imagen idílica.

Este impacto de lo social, lo público, lo privado y lo particular se conjugan en la definición de la identidad factores extrínsecos e intrínsecos (Veirave, Ojeda, Núñez y Delgado, 2006; Sayago 2008). Toda elección, incluyendo la profesión docente, implica responder las preguntas ¿qué quiero ser? y ¿para qué? según Sayago (2008); dicho lo anterior, esta elección es intersubjetiva - relacional y se elabora con base a un proceso social.

En relación con lo mencionado anteriormente, Veirave, Ojeda, Núñez y Delgado (2006), descubrieron en sus estudios algunos aspectos importantes que influyen en la definición de la identidad profesional: personas significativas, las razones por las que escogieron la carrera, las elecciones laborales, la experiencia de la formación inicial, así como las del trabajo docente, los contextos socio-históricos y los cambios en el sistema educativo a partir de la reforma. Asimismo, autores como Sayago, Z.; Chacón, M. Y Rojas, M. (2008) y Vairave, Ojeda, Núñez y Delgado (2006), señalan la importancia de las vivencias familiares.

En cuanto a la historia, Núñez (2004) selecciona cuatro identidades, las cuales no son excluyentes pero la continuidad y el cambio coexisten en la definición de las mismas: la primera de éstas como apóstol, donde se 
veía al docente como quien luchaba contra la ignorancia, era portador de la luz y el saber; la segunda, como funcionario pública, la cual tomó un rol laicista; el rol técnico que es la siguiente, vino con la manifestación del sistema, los sindicatos creados y se da la formación de maestros bajo la "normalización" de calidad vs cantidad; para finalizar, el docente como profesión se crea en la sociedad del conocimiento involucrando innovación, autonomía profesional y sentido de responsabilidad.

Con todo esto, existe la necesidad de reivindicar la imagen docente para poder atender la demanda inminente de profesores en una sociedad en la cual se ha llegado a desconfiar en el sistema educativo propio del país, pues el maestro es el "chivo expiatorio" de esta situación (Esteve, 2001; Núñez, 2004; y UNESCO, 2016).

Cabe mencionar que cada persona tiene la capacidad de dejar una huella o una marca personal que represente su esencia, aún y aunque el personal branding o marca personal se relacione más al mundo de los negocios y empresas. Esta marca no es algo con lo que se nace, sino que se va formando al paso de un periodo de tiempo y que envuelve diversas características esenciales por las cuales es reconocido. Tales características pueden ser negativas o positivas, o representar un aspecto de la vida, como el ámbito profesional, personal, académico, deportivo, social, cultural, artístico, entre otros muchos.

Sin duda, un docente incide como primera instancia en las personas cercanas a él, principalmente en sus alumnos, padres y compañeros. Desde la perspectiva creada de los autores de este documento, la marca del docente se forma desde diversos atributos, tales como:

- Atributos de carácter laboral: son los periodos de trabajo y descanso, salario suficiente, prestaciones, organización laboral.

- Atributos de compromiso social: se incluye el trabajo extraescolar, responsabilidad en el trabajo y vocación docente y de servicio.

- Atributos profesionales: hacen referencia a las características que posee un docente relacionadas con su práctica profesional, tales como preparación académica o profesional, planeación y en su trabajo, conocimientos generales. 
- Atributos de innovación: son aquéllos como el uso de diversos recursos materiales y tecnológicos.

- Atributos de personalidad: se refieren a las formas de actuar en el aula, temperamento personal, actitud frente al trabajo.

De la misma manera, se tomaron en cuenta semblantes de reconocimiento social haciendo referencia a las experiencias personales que se han vivido con algún maestro.

\section{E1 malestar docente}

Uno de los aspectos que interviene determinadamente en la forma como la sociedad percibe al docente tiene que ver con la autopercepción del propio maestro. La docencia en los últimos años se ha transformado en muchos casos de un trabajo motivado a uno estresante, lo que afecta la eficiencia y el rendimiento de cada uno de ellos; además de las relaciones que se forman entre éstos con sus estudiantes, con otros maestros, con directivos, pero principalmente con los padres o tutores.

Otro de los aspectos a mencionar es el estrés laboral crónico, el cual se manifiesta por actitudes negativas y una constante queja al trabajo o a la labor profesional, que al principio quizá se disfrutaba, al agotamiento emocional, entre otros, son lo que Gil-Monte y Peiró (1997), llaman "el síndrome de Burnout", el cual se relaciona con el malestar que los docentes manifiestan al realizar su trabajo. Para Esteve (1994), el malestar se refiere a una situación alarmante entre maestros por causa de la desmotivación, que conlleva a un bajo desempeño pedagógico.

La actitud de malestar entre los docentes impacta en la manera en que la sociedad genera un juicio de ellos en general, a tal grado que la Organización Internacional del Trabajo ha catalogado a la profesión docente como un foco de alerta y de alto riesgo, tanto mentalmente como físicamente (Buzzi \& Dubiella, 2013), debido al alto índice de molestia entre los que la ejercen.

Relacionado a esto, la imagen del docente se ve afectada por la propensión a generalizar y etiquetar a toda la profesión a partir de diversas acciones, defectos o características negativas, que presentan de forma pública uno o varios profesores, haciendo a un lado todo un 
trayecto de arduo trabajo y dedicación de un gran número de ellos. Del mismo modo, existe una creencia errónea de que los maestros son personas sabiondas que cuentan con casi "todos" los conocimientos y contenidos al hablar de ciencias o diferentes temas, y por lo tanto, el cometer algún error hace que la profesión sea mal vista por la sociedad. Además, el docente al ser el encargado de enseñar, tanto a aquellos que no saben cómo a los que no quieren (Pérez, 2012), le implica enfrentar diversos retos y resolver constantemente situaciones para las que no fue formado.

Todos estos factores desencadenan inevitablemente un desprestigio y descenso de la imagen social que tiene la labor pedagógica, que afectan desfavorablemente al docente, formando una gran cantidad de indicadores como son la apatía, depresión, ansiedad, agotamiento, falta de expectativas, entre otras (Pérez, 2012).

En la actualidad, el docente es México es evaluado principalmente por las autoridades educativas, pero también de manera indirecta por los miembros de la comunidad en la que se desempeña, quienes, de forma contradictoria, encomiendan la formación de los niños a las escuelas y a la vez son un obstáculo en las acciones que se toman para educarlos. Junto a esto, la imagen del docente sigue siendo afectada aún más por la delegación de responsabilidades del Estado a los profesores debido a la ineficiencia de los modelos y programas de estudio, y por la escasez de equipamiento, medios y recursos que son necesarias en las instituciones educativas.

La imagen que los padres o tutores de los alumnos elaboran respecto a los docentes depende de las funciones que estos últimos desempeñan, tales como ser instructor, educador, médico, solucionador de problemas, psicólogo, niñero, reparador o sustituto en relaciones familiares disfuncionales, mediador en distintas situaciones conflictivas, entre muchas otras, las cuales impactan de manera negativa o positiva en la imagen del docente dependiendo de que tan bien las ejecuten, desde la perspectiva evaluadora de los padres (Prieto, 2008).

Por el contrario, cuando los docentes cuentan con un ambiente favorable de trabajo, inmerso en un ambiente comprensivo, comunicativo y colaborador a la actividad pedagógica, la salud y el 
bienestar, tanto físico como mental se ven beneficiados, los cuales son causas de prácticas exitosas. El bienestar del maestro es el motor que genera calidad en la educación (Buzzi \& Dubiella, 2013).

\section{Resultados}

Imagen social:

El análisis de los resultados en este apartado se realiza desde tres ámbitos de reconocimiento de los atributos de un maestro:

\footnotetext{
$\checkmark$ Atributos profesionales y laborales.

$\checkmark$ Atributos asociados a la personalidad.

$\checkmark$ Cualidades del docente que manifiestan su compromiso social.
}

En cuanto a los atributos de un docente, los ítems estaban organizados de tal manera que los encuestados pudiesen seleccionar entre cuatro criterios de aceptación: en total desacuerdo (1), en desacuerdo (2), en acuerdo (3) y en total acuerdo (4).

En lo que se refiere a los atributos profesionales se pudo observar que la mayoría de los estudiantes de licenciatura están en desacuerdo en cuanto a la afirmación de que los maestros están mal preparados (gráfico 1); estableciéndose el 67\% para los estudiantes de la normal pública, el 59\% para los de la universidad estatal. Y sólo el 49\% de los estudiantes de universidad particular. Observándose que estos últimos compartieron su opinión con aquellos que piensan que los maestros tienen mala preparación (51\%).

\section{Gráfico 1. Los maestros están mal preparados}

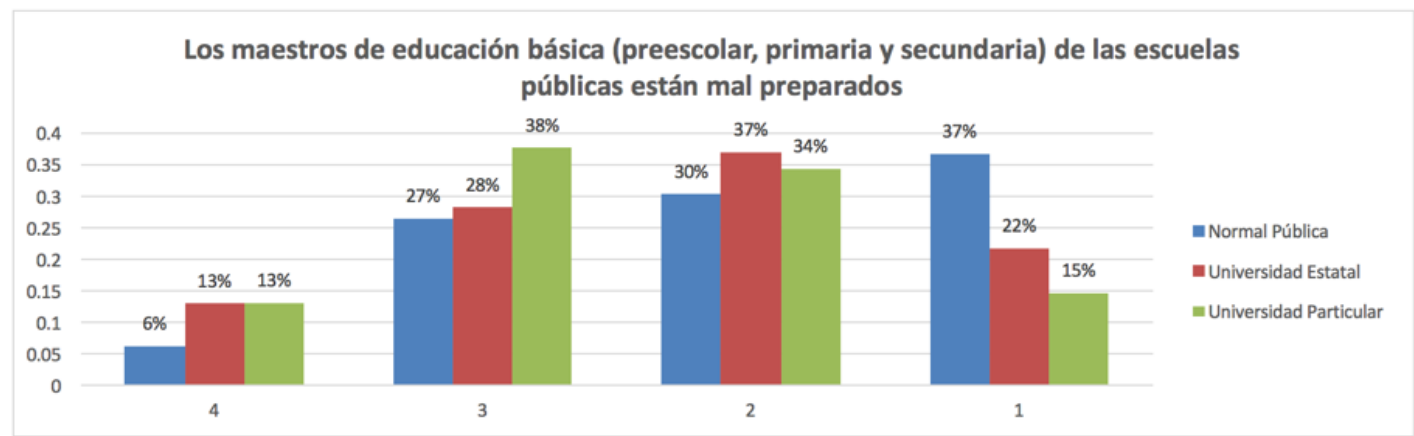


En el ítem que corresponde a "los maestros saben mucho", se encontró que los estudiantes de licenciatura están de acuerdo con este enunciado, ya que el 80 y $8 \%$ de los normalistas, el 61\% de los universitarios estatales y el $45 \%$ de los universitarios de escuelas privadas lo refiere. Sin embargo, se hace patente que el 55\% de estos últimos no están de acuerdo con ello (Gráfico 2).

\section{Gráfico 2. Los maestros saben mucho}

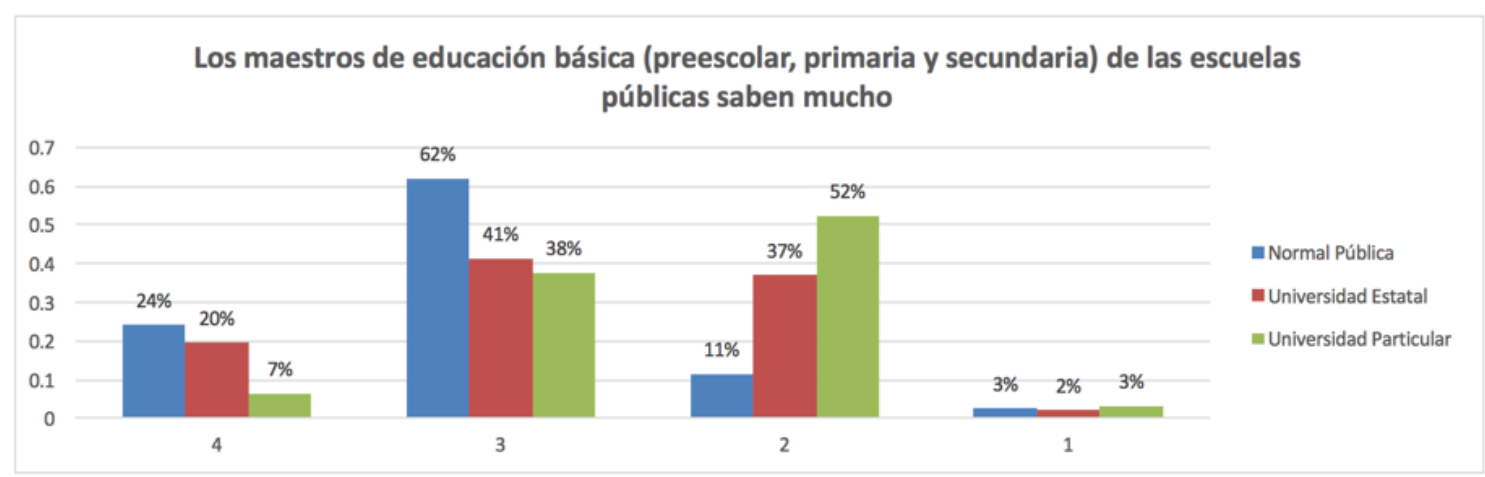

En cuanto a atributos laborales (Gráfico 3), es decir que están asociados a las cuestiones del trabajo, los tres grupos de encuestados concuerdan en afirmar que los docentes tienen muchas vacaciones; mostrando en este caso, los estudiantes de escuelas particulares una mayor empatía.

\section{Gráfico 3. Los maestros tienen muchas vacaciones}

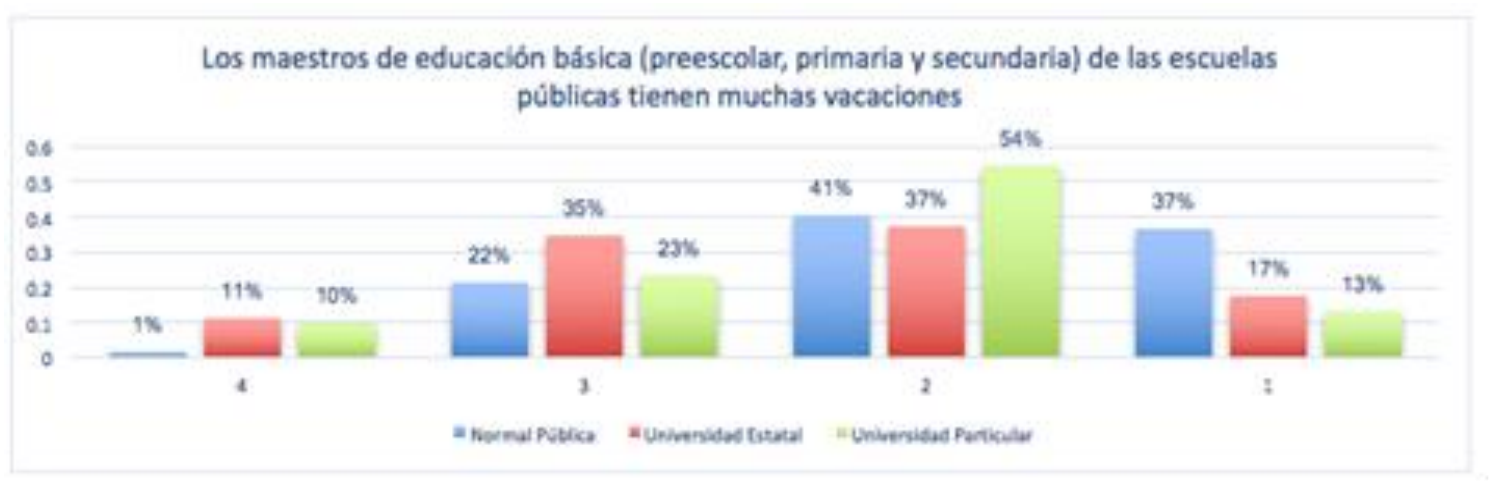

Sobre la filmación "los docentes estaban muy bien pagados", se puede observar un desacuerdo mayoritario en los tres grupos de encuestados: el $77 \%$ de los de escuelas normales, el $72 \%$ de los universitarios de la universidad estatal y el 79\% de los de particulares. 
Gráfico 4. Los docentes están muy bien pagados

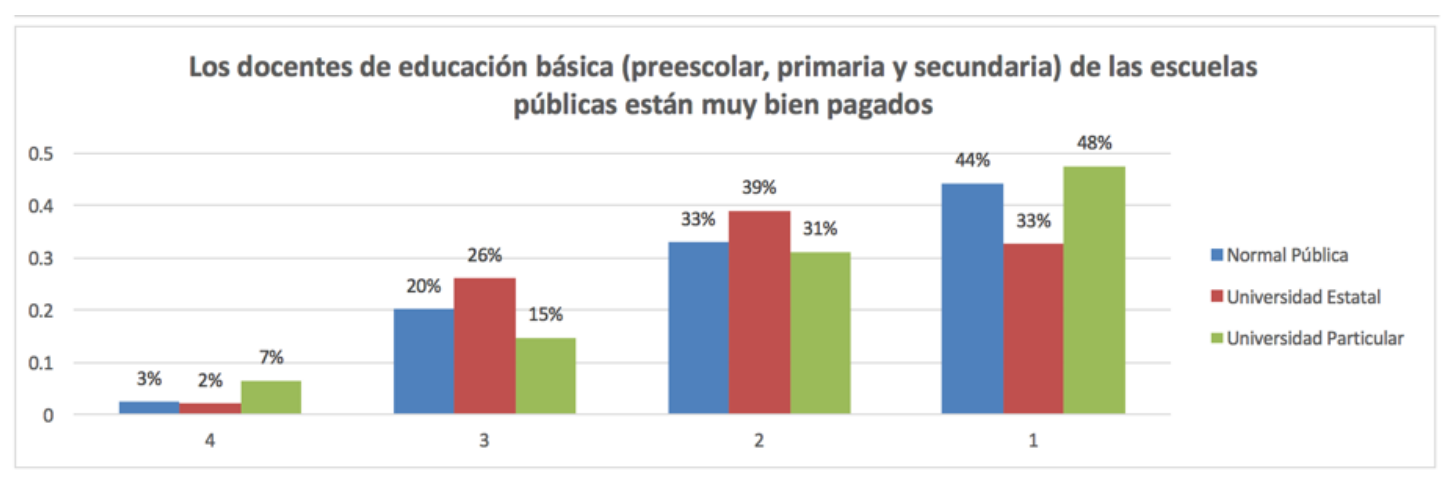

Asimismo, se pudo observar que los tres grupos de encuestados coincidieron en opinar que "los maestros de educación básica de escuelas públicas eran huelguistas" (Gráfico 5), manifestado por el 61\% de los estudiantes de instituciones particulares, el $77 \%$ de los normalistas y el $60 \%$ de los universitarios escuelas públicas.

\section{Gráfico 5. Los maestros son huelguistas}

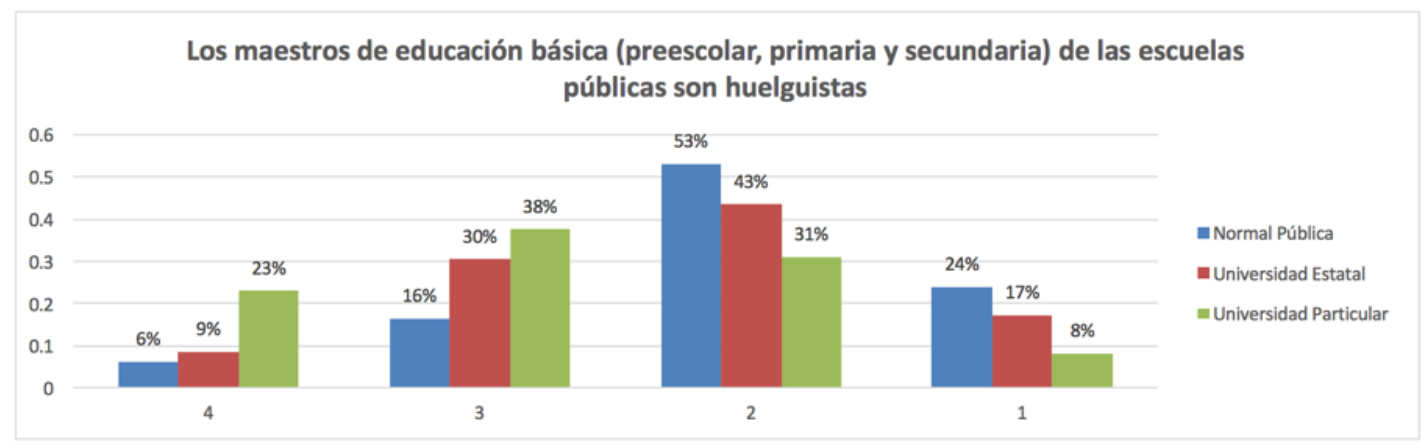

En el apartado relacionado con los atributos asociados a la personalidad del docente de educación básica, el 82\% de los alumnos de escuelas normales mostraron desacuerdo en que "los maestros de las escuelas públicas son muy gritones" (Gráfico 6); mas el 63\% de los estudiantes de la universidad estatal y el 65\% de la universidad particular si están de acuerdo con ella; pudiéndose apreciar una diferencia muy pequeña entre éstos. 
Gráfico 6. Los maestros son muy gritones

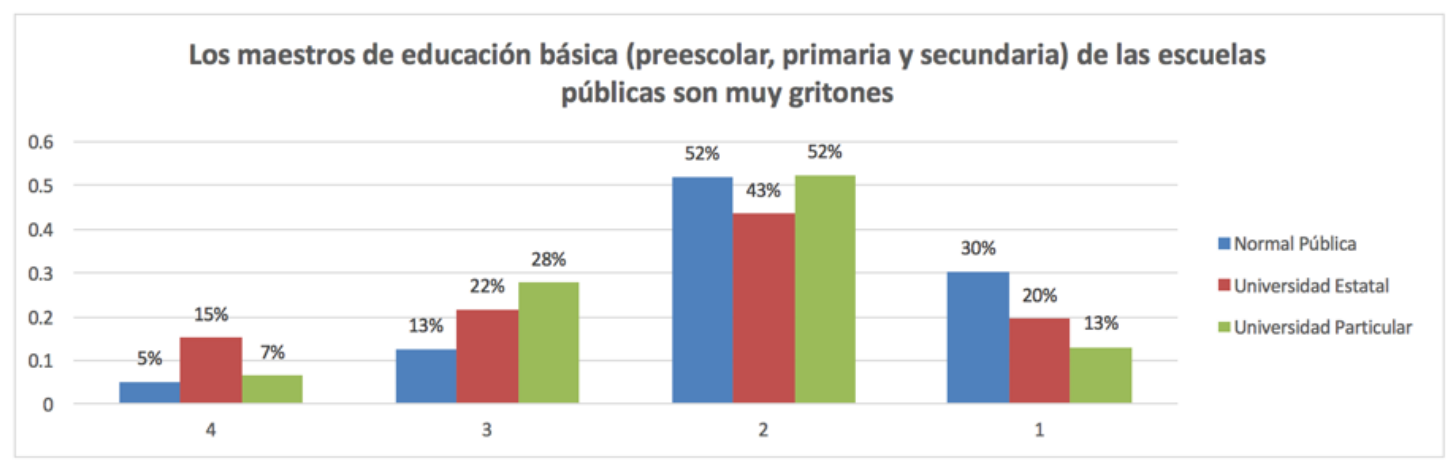

En cuanto a la afirmación de que "los docentes tienen muy mal carácter” (Gráfico 7), se destacó el señalamiento hecho por los alumnos de escuelas normales (82\%), en comparación con de los universitarios del estado y los particulares $(63 \%$ y el $67 \%$ respectivamente).

\section{Gráfico 7. Los docentes tienen muy mal carácter}

Otra de las cualidades evaluadas fue "los docentes son muy flojos" en la que se pudo observar que el $84 \%$ de los normalistas, el $61 \%$ de los

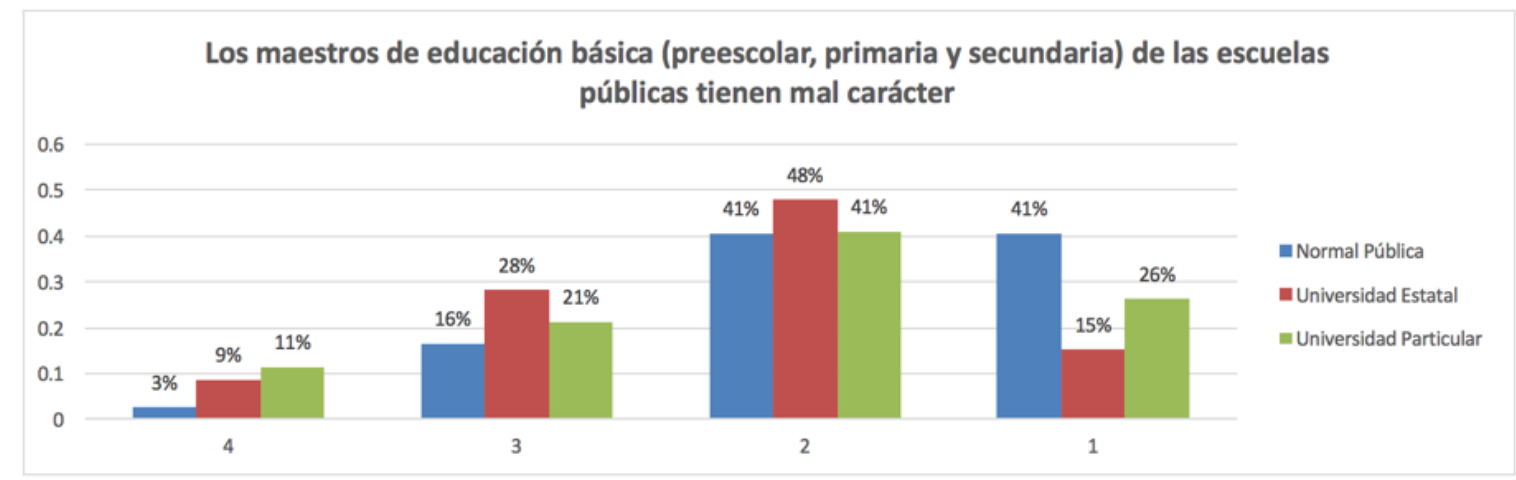

universitarios y el $64 \%$ de los particulares mostraron desacuerdo en esta afirmación (Gráfico 8). 


\section{Gráfico 8. Los docentes son muy flojos}

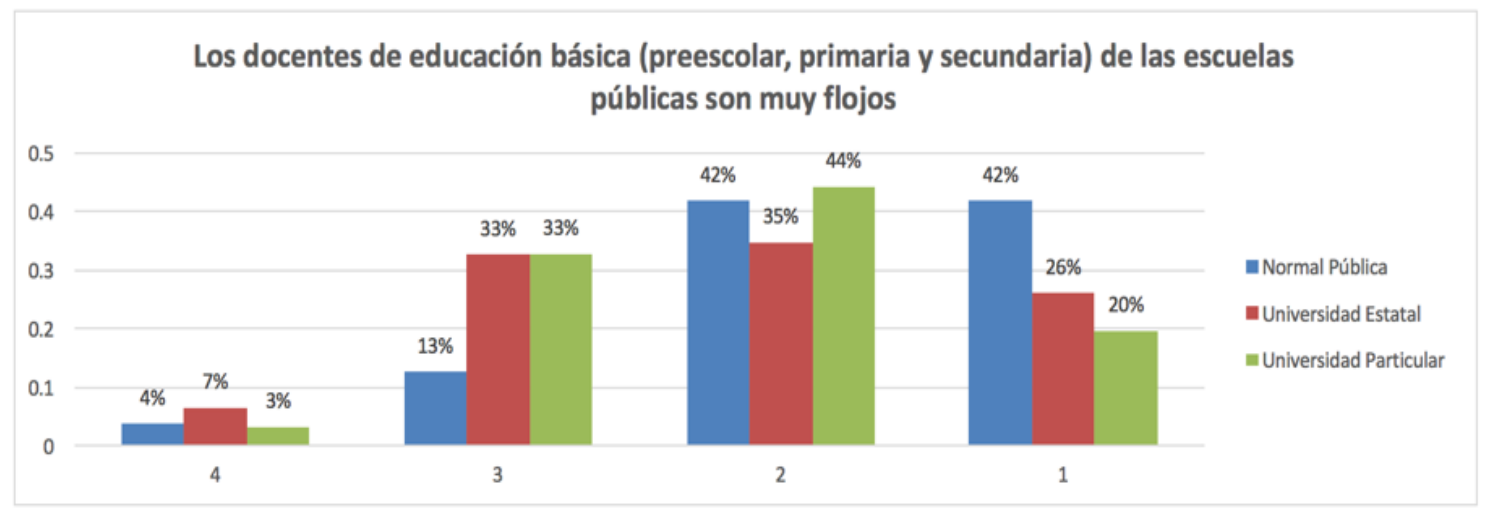

Una de las afirmaciones que fue valuada en la que los tres grupos de encuestados mostraron su desacuerdo fue "a los docentes de educación básica de las escuelas públicas les gustaba castigar”, manifestándose por el 90\% de los normalistas, El 70 y 8\% de los universitarios escuelas públicas y el $76 \%$ de los universitarios de escuelas particulares (Gráfico 9).

\section{Gráfico 9. A los docentes les gusta castigar}

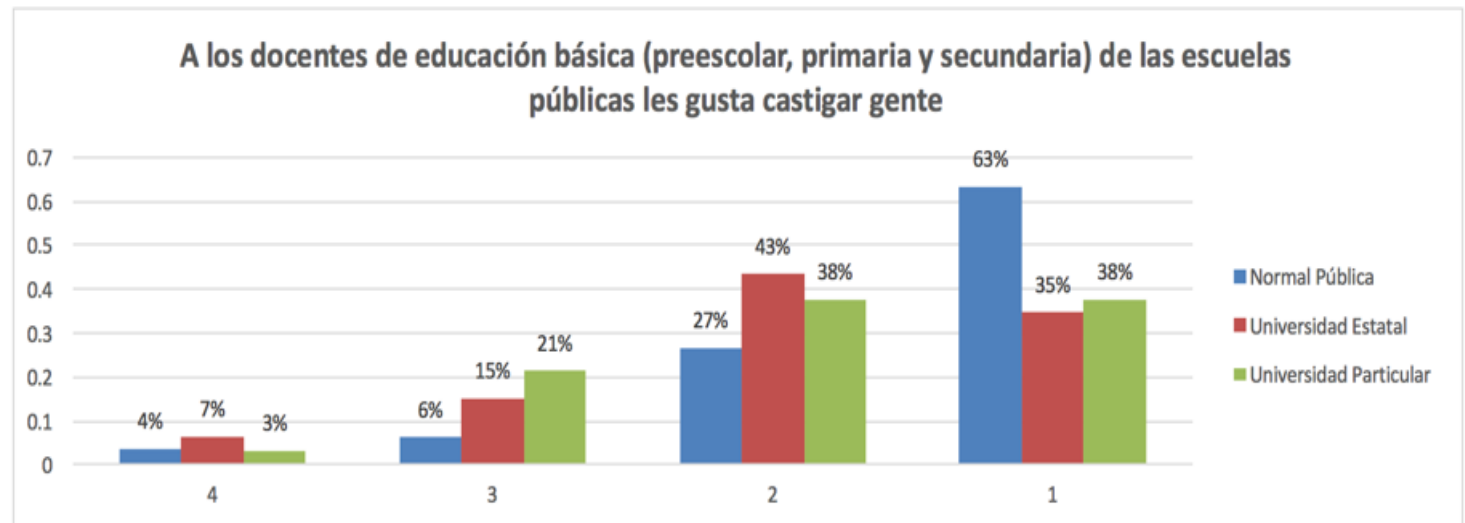

Ante la declaración de una concepción conflictiva y problemática del docente (Gráfico 10), el 91\% de los alumnos de escuela normal mostraron su desacuerdo; aunque así lo consideran los universitarios, no lo hacen en la misma proporción, ya que para los estudiantes del estado sólo el 68\% estaba en desacuerdo, el porcentaje se redujo al 59\% en la percepción de los particulares. 
Gráfico 10. Los docentes son problemáticos y conflictivos

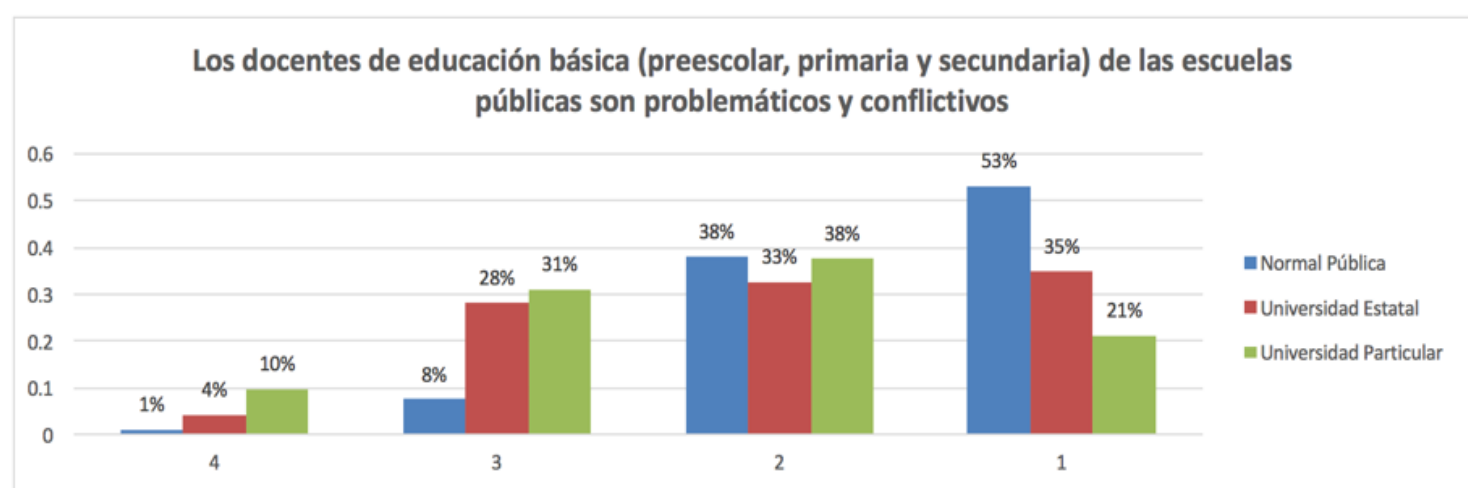

En el apartado que implica "las cualidades del docente que manifiestan su compromiso social", se encontró que sólo el 75\% de los normalistas estuvieron de acuerdo con que los maestros hacen mucho trabajo extraescolar; el 66\% de los universitarios de instituciones privadas y el $54 \%$ del estado manifestaron su desacuerdo (Gráfico 11).

\section{Gráfico 11. Los docentes hacen mucho trabajo extraescolar}

Para el $72 \%$ de los estudiantes de licenciatura de la Normal y el 60\%

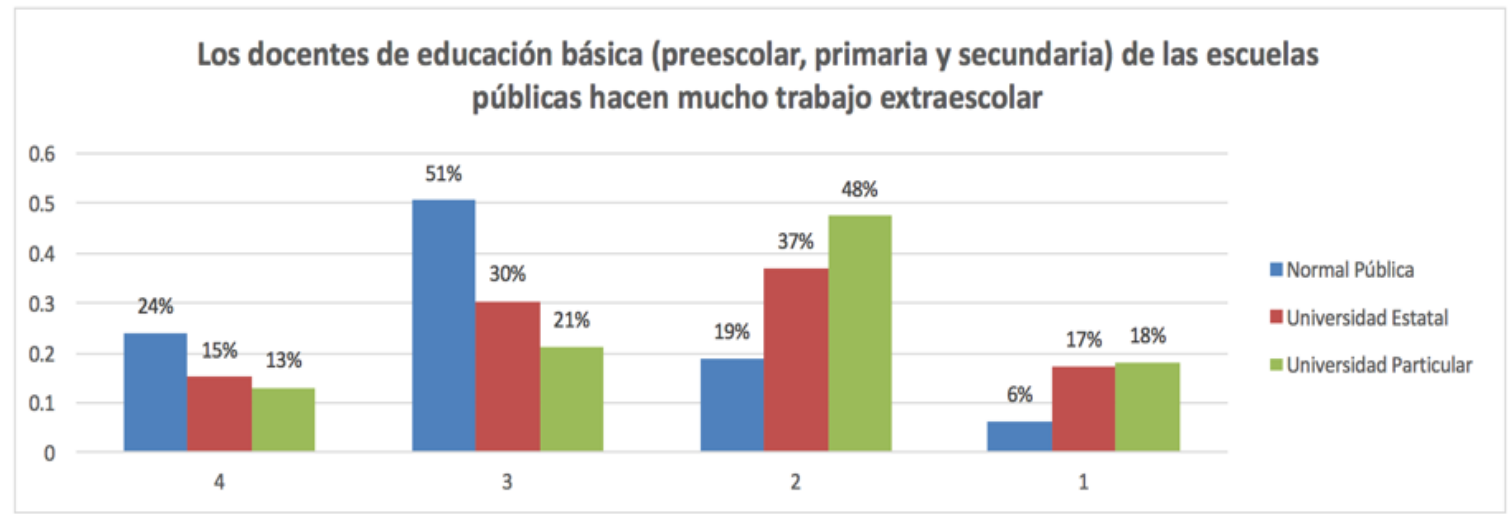

de los universitarios del estado, están de acuerdo con afirmar que los docentes en la actualidad tienen vocación; en tanto que el 65\% de los particulares señalaron su desacuerdo (Gráfico 12). 
Gráfico 12. Los docentes en la actualidad tienen vocación

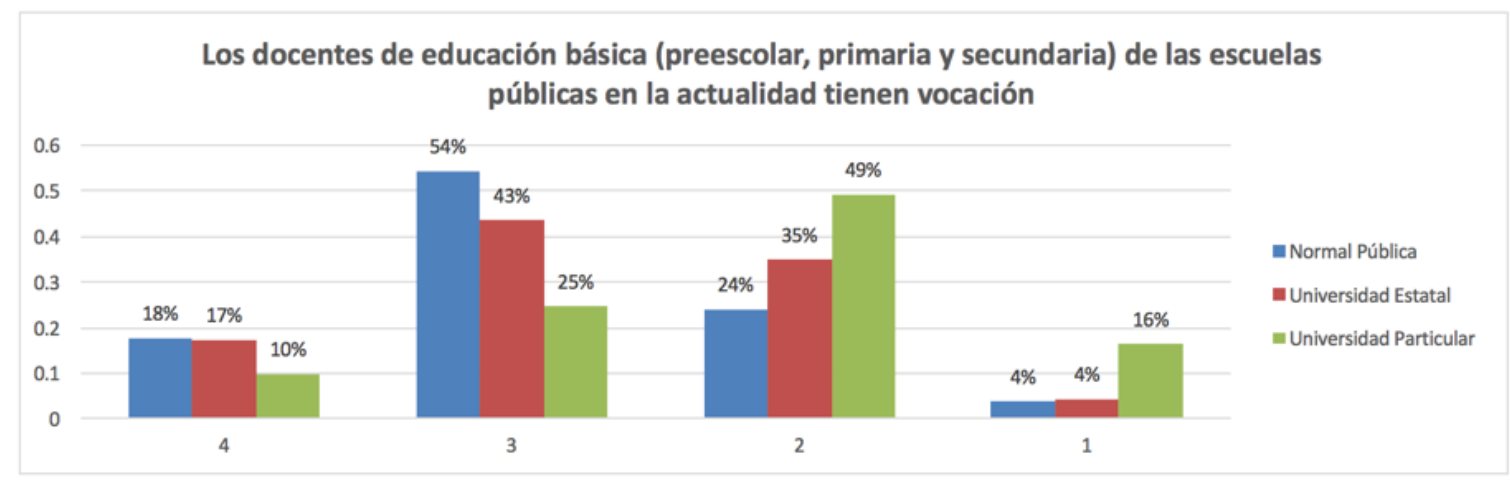

Aunque para la mayoría de los universitarios están en acuerdo con afirmar que los docentes son personas comprometidas con la comunidad (ver gráfico 13), es mayoritario este reconocimiento en el $79 \%$ de los normalistas; sólo por el $60 \%$ de los universitarios del estado y el $56 \%$ de los de particulares.

Gráfico 13. Los docentes son personas comprometidas con la comunidad

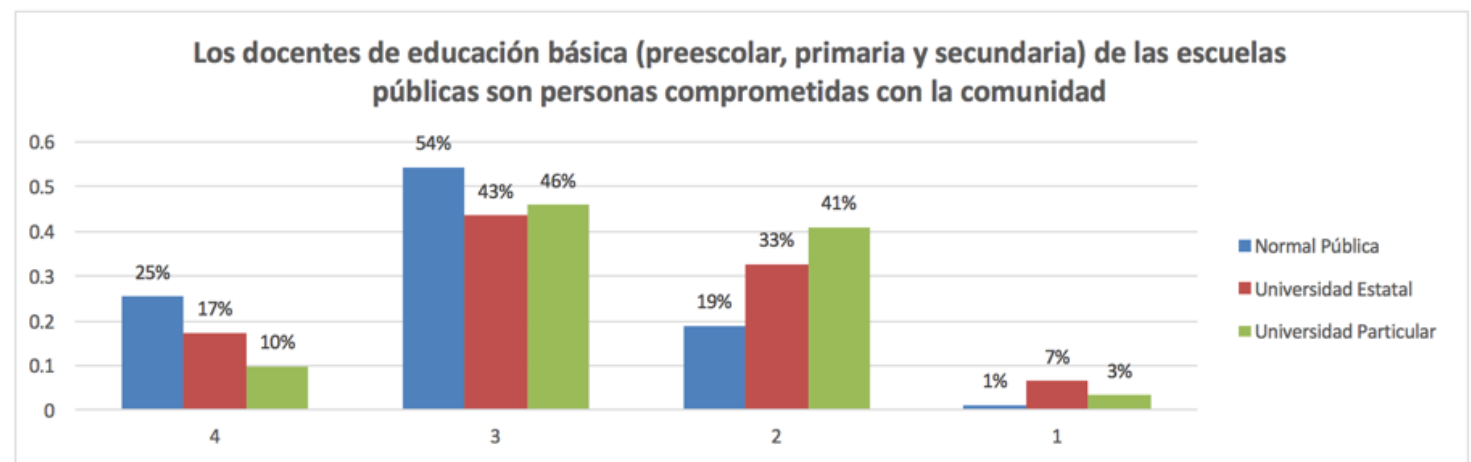

En cuanto a si a los docentes de educación básica de escuelas públicas les gusta su trabajo (Gráfico 14), el 90\% de los normalistas están en acuerdo con señalarlo, sin embargo, aunque es valorado así por universitarios del estado y particulares no lo es tan claro, los universitarios estatales señalaron su acuerdo en un $65 \%$ y con una opinión muy dividida, solo un $51 \%$ de los particulares. 
Gráfico 14. A los docentes les gusta su trabajo

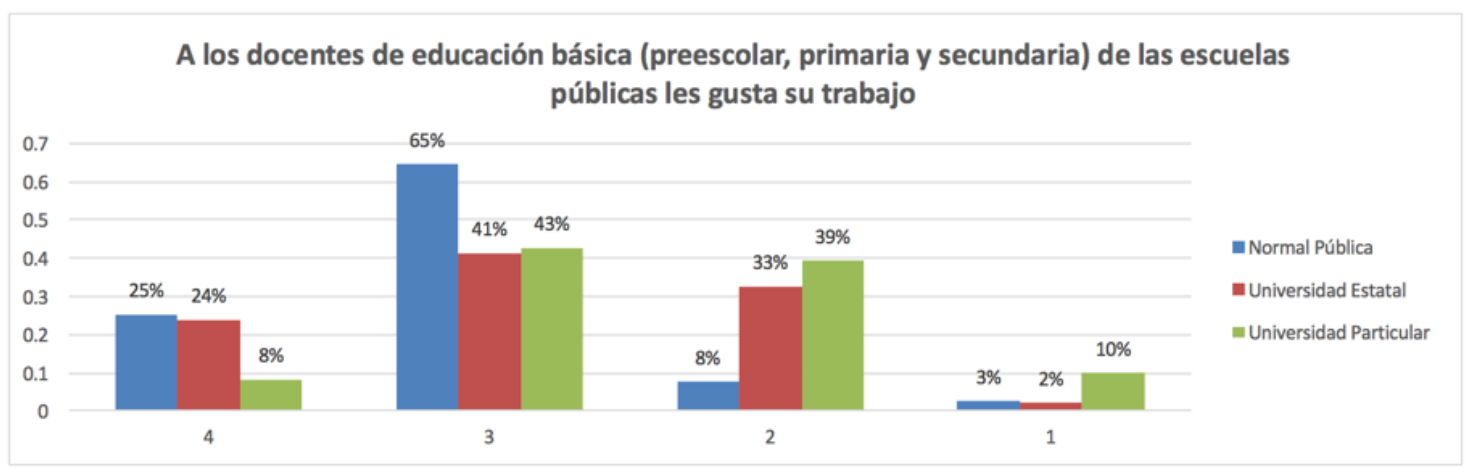

En torno a las cualidades asociadas a la innovación el 67\% de los normalistas y el 59\% de los universitarios del estado señalaron estar de acuerdo con la afirmación de que los docentes de educación básica de escuelas públicas son hábiles en el manejo de la tecnología; en tanto que el $62 \%$ de los de universidad particular señalaron su desacuerdo (Gráfico 15).

\section{Gráfico 15. Los docentes son hábiles en el manejo de la tecnología}

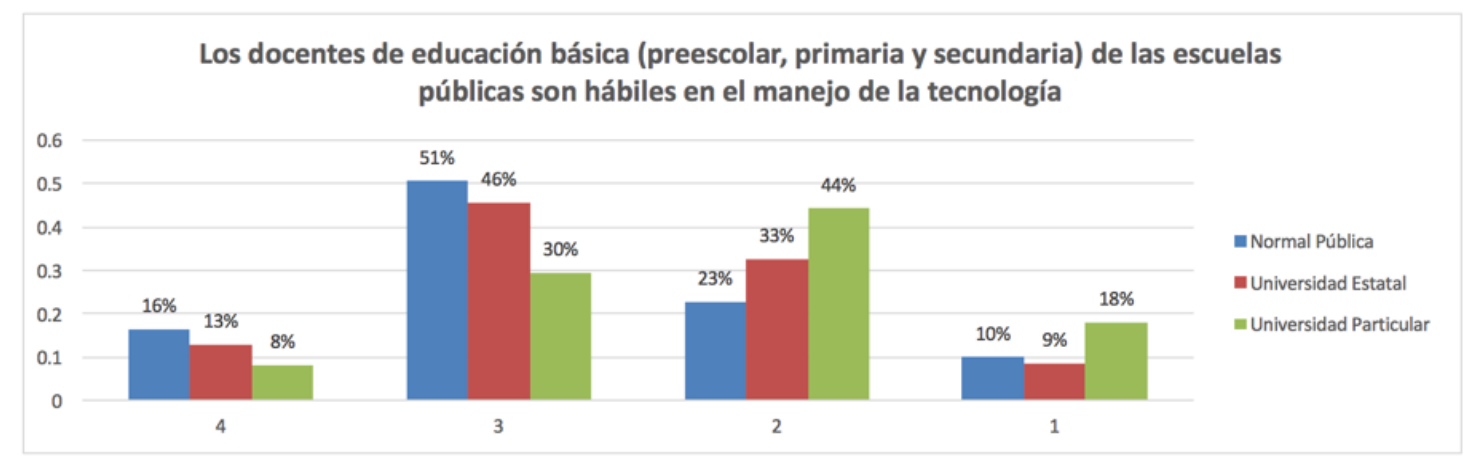

En lo referente al uso de la tecnología en sus clases (Gráfico 16), los normalistas en un 59\% piensan que esto es cierto; más que la opinión entre las universidades estatales y sumamente dividida en un $50 \%$, mientras que los estudiantes de escuelas privadas están completamente en desacuerdo con esta aseveración. 
Gráfico 16. Los docentes usan la tecnología en sus clases

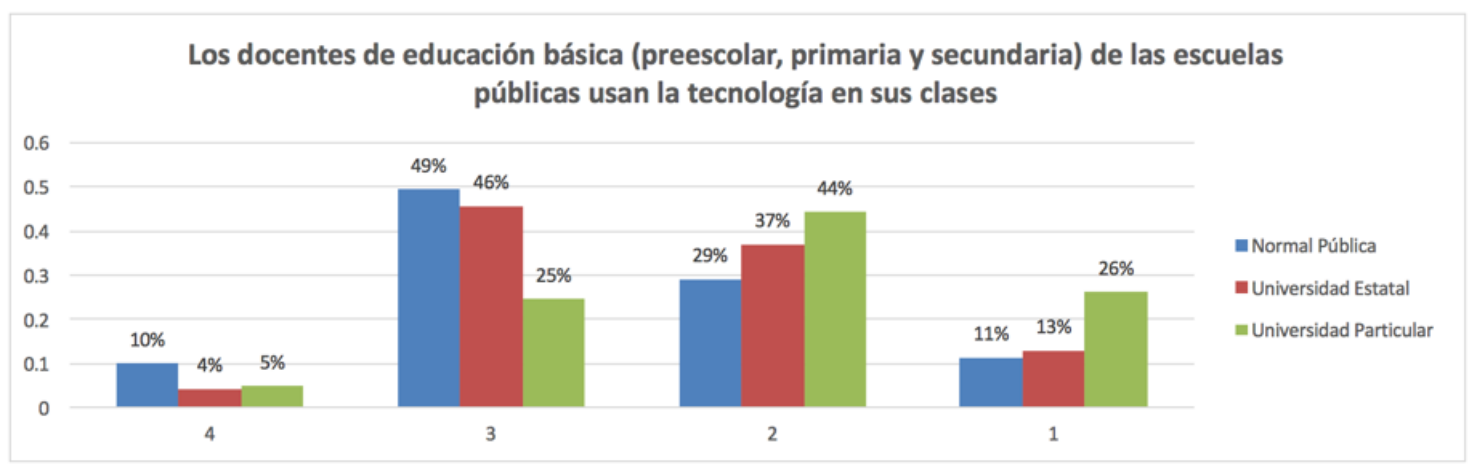

Los docentes son considerados como innovadores (Gráfico 17) sólo para el 58\% de los normalistas, la opinión de los estudiantes universitarios del estado está dividida, 50\% está de acuerdo con la afirmación y el otro 50\% en desacuerdo; en tanto que el 68\% de los alumnos de la institución particular está en desacuerdo con la aseveración.

\section{Gráfico 17. Los docentes son innovadores}

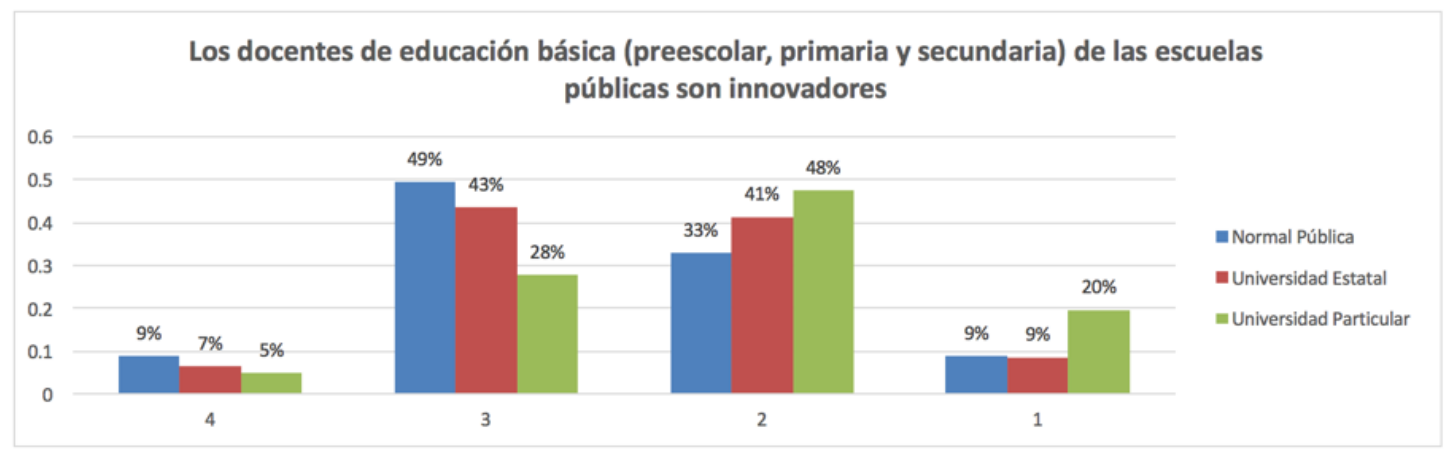

Como se pudo observar la imagen que tienen de los docentes los normalistas es positiva; en torno a los 17 ítems sobre los que se les cuestionó, señalaron siempre los atributos positivos del maestro, expresándose a favor de éstos. Su elección siempre fue muy alta. Los dos indicadores más bajos en cuanto a consenso fueron el reconocimiento del profesor como innovador (58\%) y la aceptación de que utilizaban tecnología en el aula (59\%) ambos corresponden a atributos asociados a la innovación. Las afirmaciones que rechazaron categóricamente fueron que les gustaba castigar (90\%) así como que fuesen conflictivos y problemáticos (91\%) ambos atributos de la personalidad; reconocen que a éstos les gusta su trabajo (90\%) 
atributos de compromiso social y que saben mucho (88\%) asociado al ámbito profesional.

La opinión que los estudiantes universitarios tienen del docente es más moderada que la de los grupos de estudiantes de la escuela normal, pero mayoritariamente en favor del docente, reconocen positivamente 13 de los 17 ítems. En 2 de los atributos asociados a la innovación las opiniones están divididas: 50\% reconoce del profesor como innovador y la otra parte no, lo mismo sobre el uso de la tecnología en el aula, la mitad dice sí y la otra que no. El punto más alto de consenso se obtuvo en torno al atributo de la personalidad donde se expresaron en desacuerdo con la idea de que a los maestros les gusta castigar (78\%).

En cuanto a la elección de los estudiantes de licenciatura de la universidad particular se observó que estos reconocían sólo 8 cualidades docentes como positivas. El mayor consenso se obtuvo en el desacuerdo con la afirmación de un atributo laboral de que los maestros estuvieran bien pagados $(79 \%$ ) y su rechazo a que les gustara castigar $(76 \%)$. Los puntos donde casi no logran ponerse de acuerdo $(51 \%)$ fueron afirmar que estaban mal preparados y que les gustaba su trabajo.

\section{La remembranza docente}

El segundo punto de análisis buscó recuperar el tipo de experiencias asociados a la docencia que tenían los estudiantes, se encontró una respuesta muy similar, ya que tenían muy buenos recuerdos sobre sus maestros tanto en normalistas (94\%), como en estudiantes de la universidad estatal (93\%) y la privada (94\%). De hecho, para los de particulares el 69\% estaba totalmente de acuerdo con ellos, fue el porcentaje más elevado de remembranza positiva (ver gráfico 18).

Gráfico 18. Tengo muy buenos recuerdos sobre algunos de mis maestros

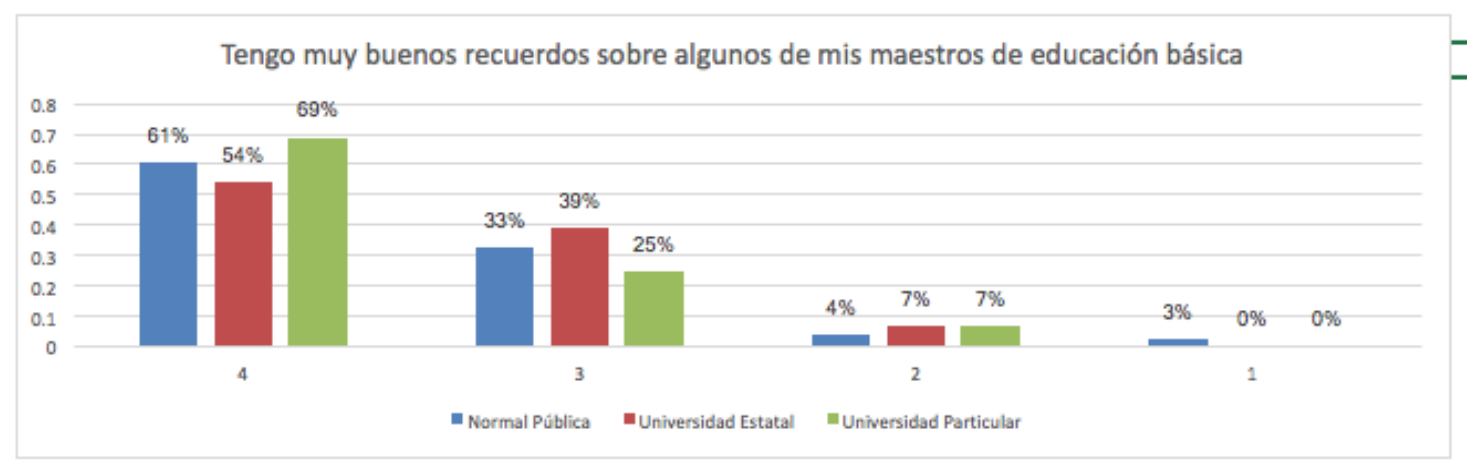


En cuanto a los recuerdos que los encuestados tienen de sus maestros, un porcentaje reducido señaló tener muy malos recuerdos, entre ellos el $26 \%$ de los normalistas, el $29 \%$ de los estudiantes de licenciatura de la universidad estatal y el 34\% de los particulares (Gráfico 19).

Gráfico 19. Tengo muy malos recuerdos sobre algunos de mis maestros

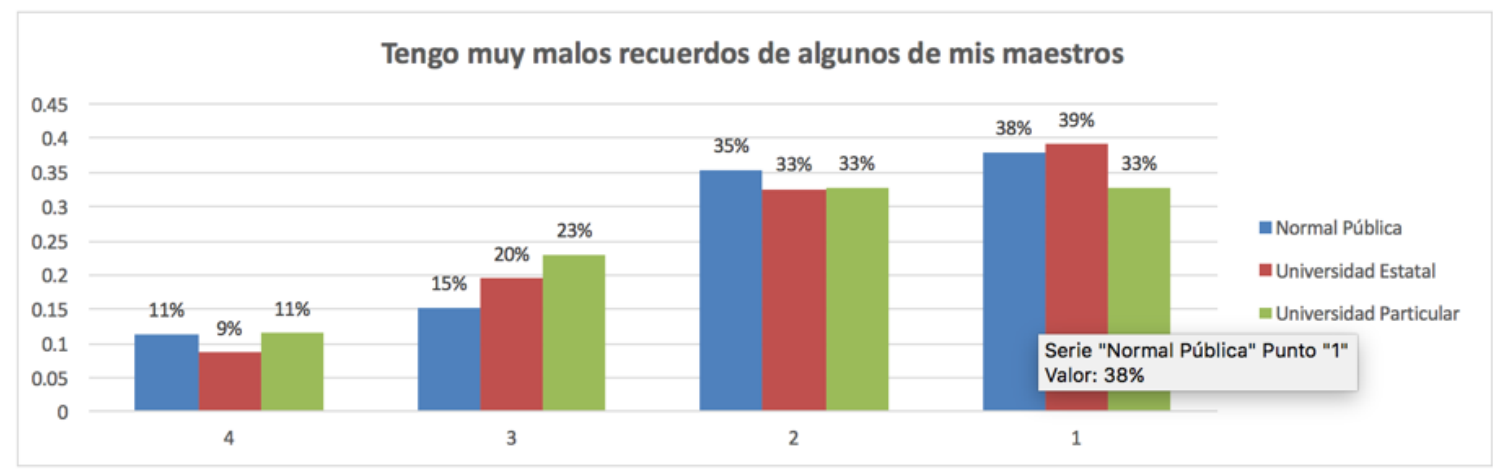

Con base en lo anterior, se puede resaltar que hay un predominio sobre los recuerdos positivos que tienen de los docentes en los tres grupos de participantes con el mismo porcentaje; lo mismo ocurre con los recuerdos negativos, los cuales tienen un porcentaje bajo. En ambos resultados los universitarios de universidades particulares destacaron.

\section{La valoración de la profesión}

Para este tercer corte de análisis de datos, se encontró que los tres grupos coincidieron en afirmar que la sociedad no valora a los docentes (Gráfico 20): el 79\% de los universitarios particulares, el 69\% de los normalistas y el 58\% de los universitarios estatales.

Gráfico 20. La sociedad valora positivamente el trabajo de los profesores

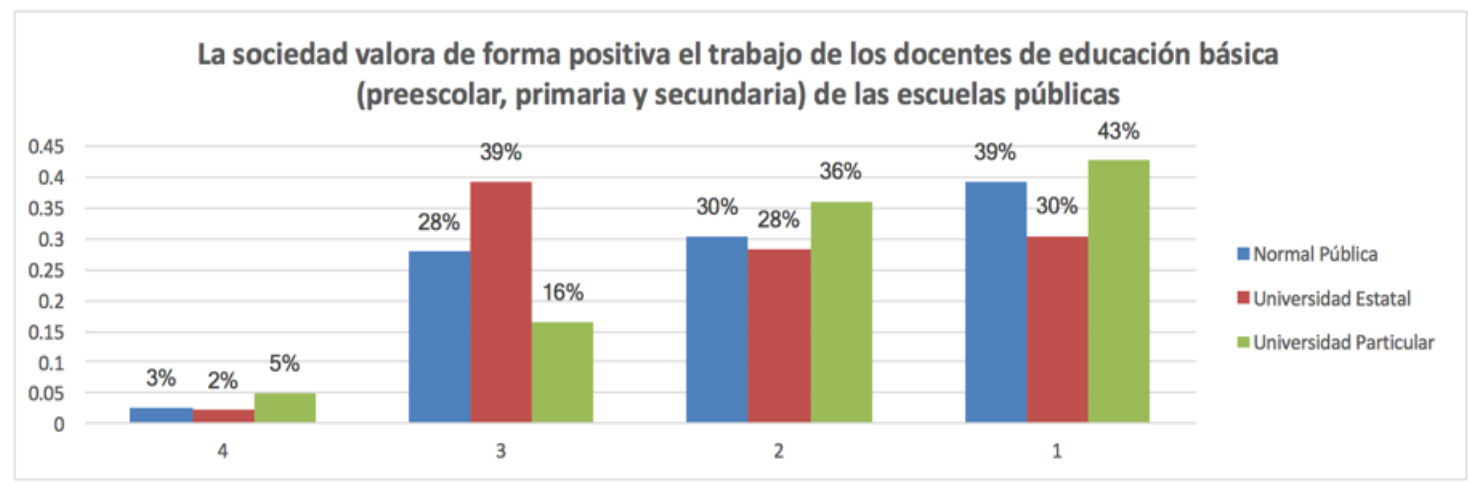


No obstante de este resultado, los normalistas (89\%) consideran que el docente es una figura de inspiración, así como el 65\% de los universitarios estatales y el $52 \%$ de los universitarios particulares, manifestándose la poca claridad que estos dos últimos grupos perciben del docente como inspiración (Gráfico 21).

\section{Gráfico 21. Los docentes inspiran respeto}

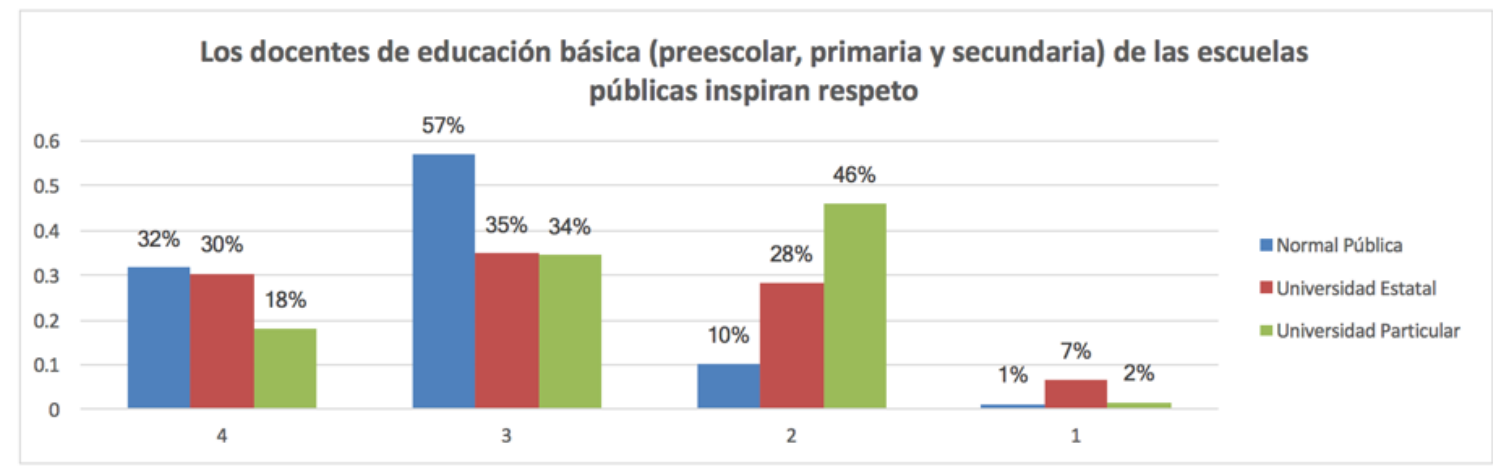

Además, se muestra una clara idea en los tres grupos de participantes que el trabajo que realiza el profesor es difícil, señalado por el $79 \%$ de los universitarios particulares, el 78\% de los normalistas y el 59\% de los universitarios estatales (Gráfico 22). Lo que marca que una diferencia en la tendencia de los resultados anteriores.

\section{Gráfico 22. El trabajo del profesor es difícil}

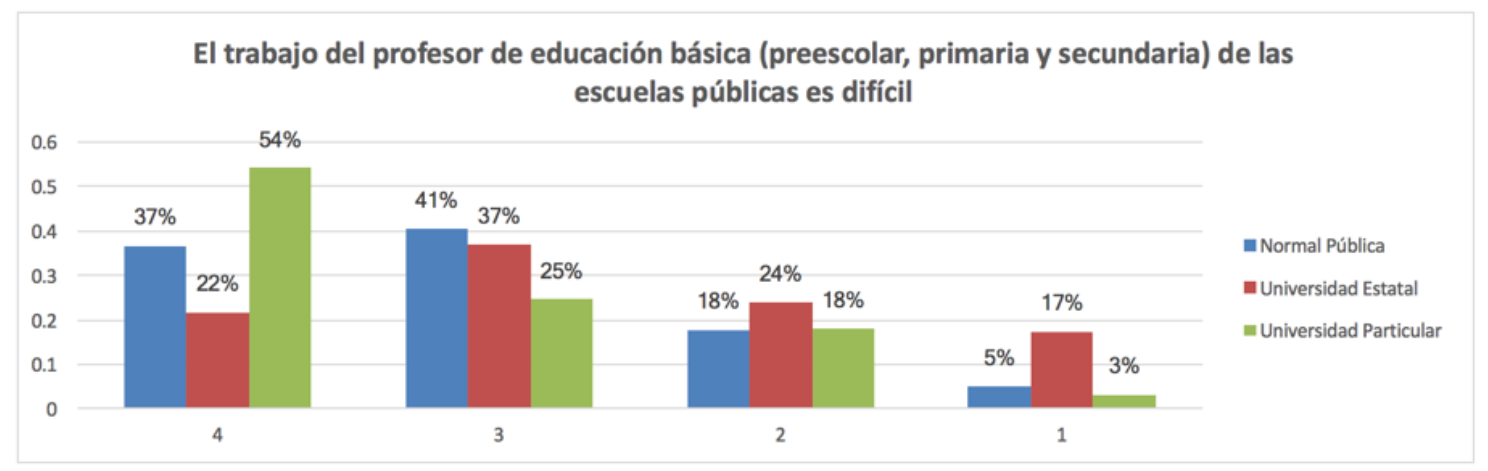

En el aspecto de valoración del trabajo docente hubo respuestas variadas; el 85\% de los estudiantes de la universidad particular confirmo una valoración positiva del trabajo de los profesores de educación básica, contra un $95 \%$ de los normalistas y el $78 \%$ de la institución estatal (ver gráfico 23). 
Gráfico 23. Valoró positivamente el trabajo de los profesores

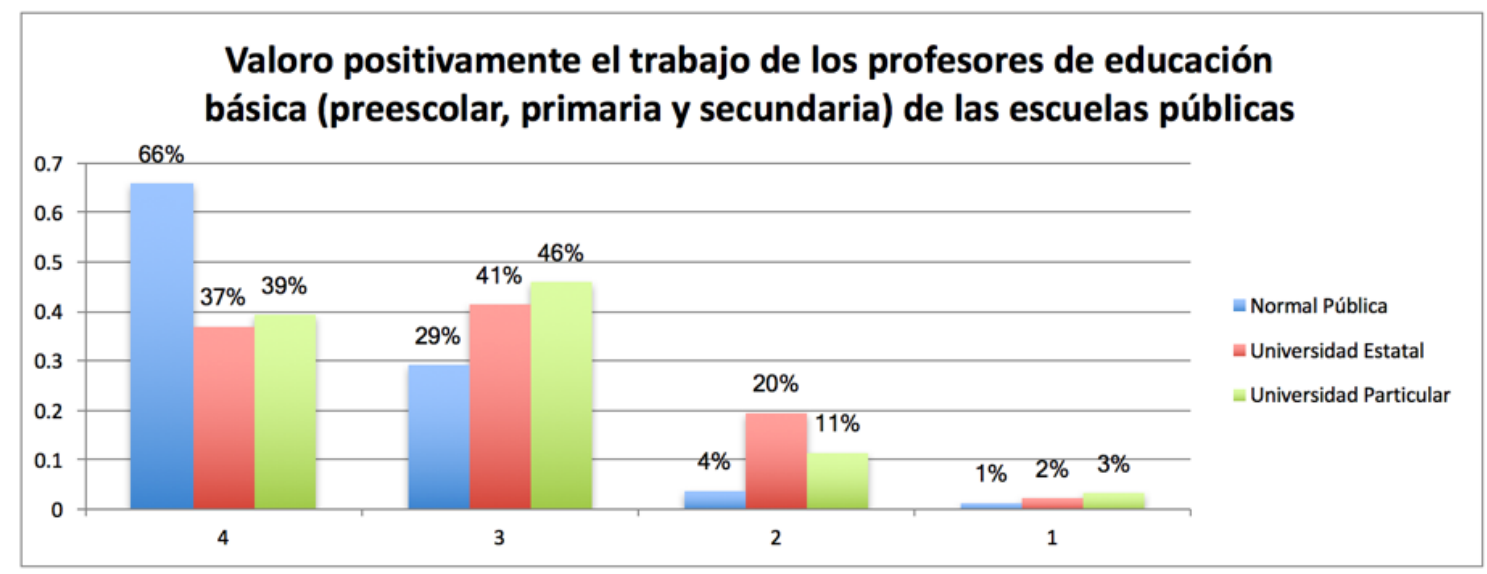

Sin embargo, al cuestionárseles sobre la percepción sobre el docente en sí, se encontraron respuestas incoherentes con el rubro anterior (valorar positivamente el trabajo del maestro). Ante la pregunta directa de su percepción sobre el docente de educación básica de las escuelas públicas (ver gráfico 24), se registró que para los normalistas dicha imagen si fue positiva, así lo señaló el 94\% de los encuestados; no así para el total de los alumnos de la universidad estatal; sólo el 61\% de ellos contestó afirmativamente. En cambio, el 59\% de los estudiantes de la universidad particular señalaron tener una imagen negativa de ellos. Esto es congruente con lo que se pudo apreciar en sus respuestas, pues son ellos quienes piensan que esta profesión desde la otredad es valorada socialmente, más no lo es para ellos.

Gráfico 24. Mi percepción sobre el docente de educación básica

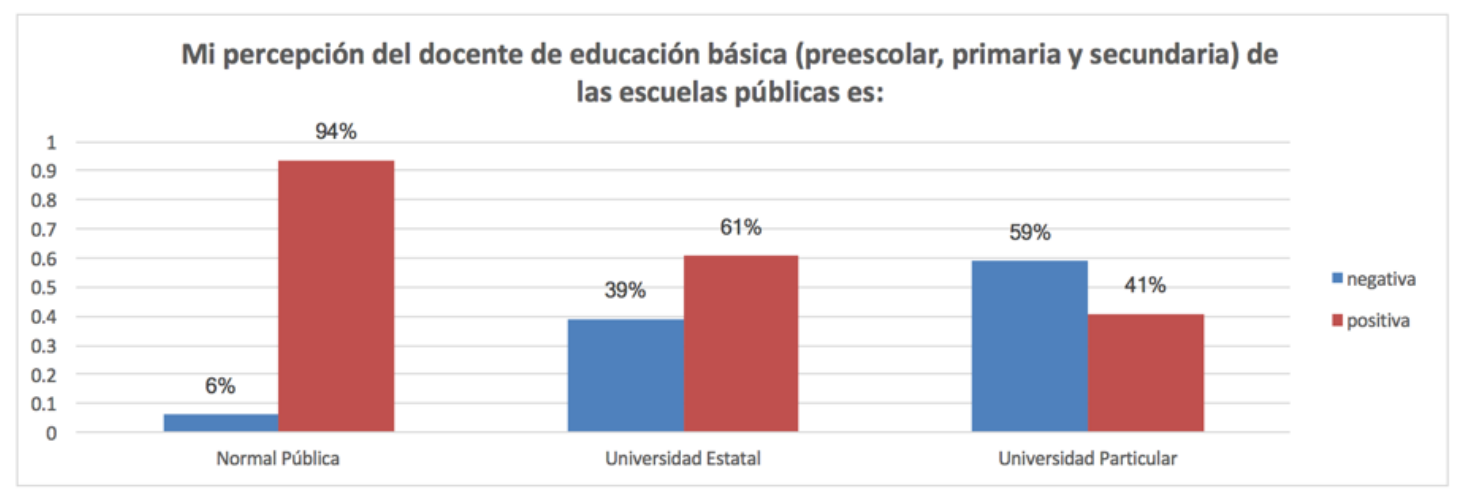

Se percibe, una vez hecho el análisis de las gráficas, que la imagen altamente positiva del docente que los alumnos de las escuelas 
normales tienen del docente, se debe a que ellos mismos se identifican con la profesión; el 72\% señala las experiencias personales como la principal influencia, luego con un 46\% de alusiones, se reconocen las experiencias de amigos y/o familiares; para un $25 \%$ el tercer factor son las redes sociales y los medios de comunicación como la radio y la televisión, en tanto que el 19\%, y para un 1\% refiere el impacto de las Jornadas de Observación y Práctica, y la valoración personal de la profesión respectivamente (ver gráfico 25).

Los estudiantes de la universidad estatal coinciden con los normalistas en el orden jerárquico de los primeros cuatro elementos, aunque en diferente proporción como influyentes en su concepción, sea esta positiva o negativa. Los primeros, con un tienen mayoritariamente una imagen positiva del docente (61\%) los segundos valoran la experiencia personal (61\%), las experiencias de amigos y familiares (54\% de ellos), las redes sociales $(37 \%)$ y los medios de comunicación (30\%) (ver gráfico 25).

Los alumnos de la universidad particular, en contraste afirman tener una imagen negativa del docente de educación básica de la escuela pública (59\%); identifican que en su percepción (tanto positiva como negativa) el primer elemento de influencia es la experiencia de los amigos (56\%); el 54\% señaló a los medios de comunicación (radio y televisión); en tercer lugar las experiencias personales (46\%), en cuarto lugar se hizo referencia a las redes sociales (41\%), en quinto lugar se señaló a la investigación y al criterio propio (2\%), (ver gráfico 25).

\section{Gráfico 25. Elementos que contribuyen a la construcción de la imagen docente}

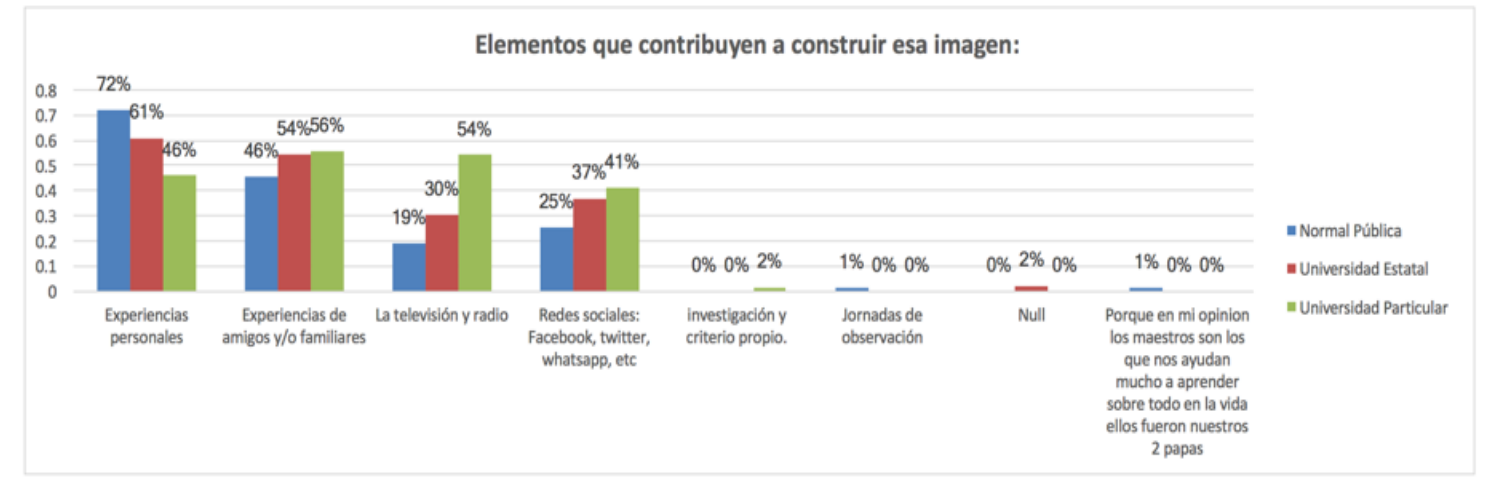


Los docentes son claramente identificados con una imagen positiva; lo anterior se percibe a través de las respuestas del estudiante de la escuela normal. Tal vez porque ellos como futuros profesionales de la educación pública se reconocen quizá en ellos. Los de la institución estatal mantienen una postura conservadora; por otra parte, los universitarios como institución pública también, mostraron contradicciones, ellos son quienes señalan que la docencia no es una profesión valorada por la sociedad. En sí, la reconocen mayoritariamente como una tarea difícil; sin embargo, la percepción de ellos hacía la docencia es negativa en su mayoría, aun y cuando hay estudiantes del área de educación entre ellos.

\section{Identidad profesional docente}

Esta parte del estudio se centrará en los estudiantes de la docencia, ya sean de la escuela normal (100\%) o bien de la universidad, tanto pública $(13 \%)$ como privada (52\%). Cabe aclarar que un $19 \%$ de la normal no participó en las respuestas debido a que no se auto reconocen como estudiantes de esta carrera, lo cual no es posible ya que sí lo eran. Los participantes fueron 65 de la normal, 5 de la institución estatal y 33 de la privada, fueron un total de 103 casos los que a continuación se analizan.

Para conocer más sobre la identidad profesional docente, se les cuestionó sobre la razón por la cual decidieron elegir la carrera, los motivos se presentan a continuación:

- 45 expresaron que les gustaba, sólo uno usó el término vocación.

- 25 señalaron que fueron sus experiencias personales.

- 12 indicaron la influencia de un docente en su decisión.

- 18 mencionaron que su importancia, uno de ellos proyecta su impacto en el país.

- 2 lo consideran una oportunidad de retribuir a la sociedad.

- 1 dijo que era el deseo de sus padres.

- 1 deseaba inspirar y potenciar la capacidad de los niños. 
Las referencias de los estudiantes de la universidad pública o estatal hicieron referencia -en su mayoría- a las experiencias personales y el gusto por la docencia. La concepción de retribución social fue referida sólo por los de la universidad particular al igual que quien atiende la normal por el deseo de sus padres. De los alumnos de la escuela normal hay 10 de las 12 referencias del impacto, con respecto a la imagen de un profesor en su decisión, además por querer potenciar el aprendizaje. Los sujetos encuestados eligieron de entre un listado de 15 cualidades las que consideraban que un buen maestro debía tener; a continuación, se presentan las que son reconocidas por la mayoría según la institución de procedencia (ver tabla 1).

Tabla 1. Características de un buen maestro

\begin{tabular}{lll}
\hline Escuela Normal & Universidad Pública & Universidad Particular \\
\hline Comprometido & Preparado & Comprometido \\
Paciente & Comprometido & Paciente \\
Preparado & Paciente & Preparado \\
Dinámico & Organizado & Domina la materia \\
Organizado & Dinámico & Atiende a sus alumnos \\
\hline
\end{tabular}

En general lo más valorado en un buen docente es que sea comprometido, paciente, preparado, dinámico y organizado.

Posteriormente, eligieron de un listado de características de un "mal maestro" las que ellos consideraban les representaba, se presenta dicho orden a continuación (ver tabla 2).

Tabla 2. Características de un mal maestro

$\begin{array}{lll}\text { Escuela Normal } & \text { Universidad Pública } & \text { Universidad Particular } \\ \text { Flojo } & \text { Flojo } & \text { Indiferente } \\ \text { Impuntual } & \text { Indiferente } & \text { Mal preparado } \\ \text { Rutinario } & \text { Impuntual } & \text { Flojo } \\ \text { Desorganizado } & \text { Autoritario } & \text { Rutinario } \\ \text { Faltista } & \text { Explica mal } & \text { Autoritario } \\ \text { Indiferente a los } & \text { No domina la materia } & \\ \text { alumnos } & & \end{array}$


Los atributos señalados en general que identifican a este tipo de docente los reconocen como flojos, indiferentes a las necesidades de los alumnos, impuntuales, rutinarios y desorganizados.

\section{Conclusiones}

A partir del análisis cuantitativo que se realizó a los estudiantes de licenciatura, se concluye que la imagen social de los docentes de educación básica de escuelas públicas indica predominantemente un acuerdo en torno a cualidades positivas del docente, sin embargo, varían de acuerdo con la institución de procedencia.

Un aspecto importante a considerar, a pesar de que la mayoría de los estudiantes reconocen cualidades positivas, es que hay un importante porcentaje de ellos que tiene una imagen más conflictiva, menos idílica de la docencia; en algunos casos hay una decisión dividida.

Con respecto a los atributos profesionales se considera que los maestros están bien preparados y que saben mucho, sólo los estudiantes que proceden de una institución particular señalan que no es así. Asimismo, se encontró que para quienes estudian en una institución privada estos -los docentes- son considerados como huelguistas. Curiosamente hubo consenso en cuanto aspectos laborales como el salario de los profesores y las vacaciones; del primero se opina que estos no son bien pagados, del segundo ellos consideran que las vacaciones que tienen no son muchas.

Asimismo, se encontró que, los tres grupos de estudiantes opinaron que no existe cualidad negativa de la personalidad; es decir, no están de acuerdo en que a los docentes se les considere gritones ni punitivos; con menor consenso, pero aún mayoritario, se indica que no tienen mal carácter, ni son flojos, conflictivos o problemáticos.

Las opiniones sobre los atributos de compromiso social fueron de nuevo motivo de discrepancia, ya que los normalistas son los únicos que consideran que los profesores tienen muchas actividades extraescolares; la vocación y el gusto del trabajo es sólo reconocido por los estudiantes de la escuela normal y la universidad estatal; todos coincidieron en que existe, por parte de los docentes, un gran compromiso con la comunidad. 
En lo que se refiere a atributos relacionados con innovar, sólo los estudiantes de la escuela normal reconocen que los docentes son hábiles en el manejo de la tecnología, que este uso tiene un carácter innovador en el aula; a pesar de ello lo hicieron con los porcentajes más bajos de reconocimiento. Los universitarios de públicas y estatales están en desacuerdo con dichas afirmaciones. El alto índice con el que aparece esta concordancia hace que esta falta de habilidad aparezca como una real área de oportunidad.

De acuerdo con los estudiantes de licenciatura de diferentes contextos socioeconómicos: universidad pública y privada, y al comparar la imagen social de los docentes de educación básica de escuelas públicas, se encontró que los de instituciones particulares emitían juicios más asociados a la imagen conflictiva que se tiene de la docencia, en tanto que los de escuela normal tendían más a la versión idílica; los estudiantes del estado tenían posturas intermedias.

La imagen social de los docentes, de acuerdo con los estudiantes de licenciatura, con y sin acentuación en formación docente, se concibe como discordantes; como se dijo en el párrafo anterior, quizá como parte de la identidad docente a estos se les considera con más bondades, por ello les atribuyen cualidades positivas, ya que los estudiantes así votaron mayoritariamente sobre los 17 ítems establecidos.

Los tres grupos tienen en su mayoría recuerdos positivos de docentes; no obstante, atribuyen características negativas a los que consideran malos docentes. A estos se les reconoce como flojos e indiferentes a las necesidades de los alumnos; además de impuntuales, rutinarios y desorganizados. En tanto que lo más valorado en un buen docente es que este sea comprometido, paciente, preparado, dinámico y organizado.

Finalmente, con base en las respuestas de los encuestados, se ratificó que la identidad de los estudiantes normalistas es fuerte, pues muestran desacuerdo en cuanto a cualidades negativas más no así sobre las positivas. Estos estudiantes decidieron su profesión con base en la vocación y en el gusto por la carrera; por experiencias personales que los orientaron hacia ella, como el haber tenido una figura docente de influencia positiva; por considerarla como importante para el país; en 
resumen y en forma idílica, como una oportunidad de retribución social.

\section{Referencias bibliográficas}

Buzzi, R., \& Dubiella, E. (2013). Factors promo ng malaise or wellbeing along teaching profession according to the opinion presented by teachers at the nal stage of their careers. Diálogo Educativo, 13(40), p. 1041-1061.

Esteve, J. (1994). El malestar docente. Barcelona: Paidós.

Esteve, J. (2001). La imagen Social de los Profesores. Consultado en: http://www.juntadeandalucia.es/educacion/vscripts/w cea/pd fs/Jornadas/10\%20a 05\%20E.pdfhttp://www.juntadeandaluci a.es/educacion/vscripts/w_cea/pdfs/Jornadas/10 a_05 E.pdf

Gil-Monte, P., \& Peiró, J. (1997). Desgaste psíquico en el trabajo: el síndrome de quemarse. Madrid: Síntesis.

Imbernón, F.; Jarauta, B.; y Bozu, Z (s/f). La Función y la Imagen Social del Profesorado en Revista Infancia y Educación. Departamento de Educación y Humanidades de la Universidad Arturo Prat. Vol.2, No 1.

Núñez, I. (2004). La Identidad de los Docentes. Una mirada histórica en Chile. Chile: Ministerio de Educación y Programa Interdisciplinario de Investigaciones en Educación.

Pérez, P. (2012). El Malestar docente. Temas para la Educación(21).

Prieto, E. (2008). el papel del profesorado en la actualidad. su función docente y social. Foro de Educación(10), pp. 325-345.

Real Academia de la Lengua española (2016). Diccionario de la Lengua Española consultado en http://dle.rae.es/?id=KzwDY4y.

Sayago, Z.; Chacón, M. y Rojas, M. ( 2008). Construcción de la Identidad Profesional Docente en Estudiantes Universitarios en Educere, Investigación Arbitrada. Año 12, No 42, Julio-Agosto-Septiembre. pp. 551-561. UNESCO, 2016. Día Mundial de los Docentes en Agenda UNESCO. Consultado en http://www.unesco.org/new/es/unesco/events/prizes-andcelebrations/celebrations/international-days/worldteachersday/http://www.unesco.org/new/es/unesco/events/p rizes-and-celebrations/celebrations/international-days/worldteachersday/ 
Urusa, S. y Malik, S. (2013). Image of an effective teacher in 21th Century Classroom en Journal ofe education and Instructional Studies in the World, November 2013, Volume 3, Issue 4. pp. 61 - 68.

Veirave, D.; Ojeda, M.; Núñez, C.; y Delgado, P. (2006). La construcción de la identidad de los profesores de enseñanza media. Biografías de profesores en Revista Iberoamericana de Educación. No 40/3, 25 de octubre de 2006. Argentina: OEI.

Latorre, A. (2005). LA investigación-acción. Conocer y cambiar la práctica educativa. Barcelona, España: Garó. 


\title{
Importancia de la validación de instrumentos de investigación: Un caso de medición para la obtención del perfil del branding axiológico
}

\author{
Selene Céspedes del Fierro \\ Universidad Autónoma de Nuevo León, México \\ Temistocles Muñoz López \\ Universidad Autónoma de Coahuila, México
}

\section{Prefacio}

T A sociedad es cada vez más participativa y más informada, gracias L a los insospechados avances de las tecnologías de información y comunicación que han convertido al mundo en la llamada aldea global. Sin embargo, la calidad de la información y sus fuentes puede ponerse en entredicho debido a los diferentes conceptos y significados de lo que se difunde, resultando una responsabilidad ética de los comunicadores quienes permanentemente proyectan una imagen valoral (Branding Axiológico ${ }^{\circledR}{ }^{1}$ ) ante sus audiencias.

\footnotetext{
1 Marca registrada por Selene Céspedes del Fierro con número de expediente:1665767. Dimensión teleológica que gestiona una imagen integral y genuina en estudiantes y profesionales, que implique sus valores intrínsecos como ente influyente en la sociedad, considerando las actitudes frente a la dignidad de su profesión.
} 
Los profesores, son una especie de comunicadores del conocimiento y hablaremos de ellos por ser la población objeto de estudio, cuyas audiencias son sus alumnos. Dado a las exigencias del contexto educativo y generacional, el docente ha modificado su rol y participación dentro de las aulas. En el pasado éste exponía a manera de soliloquio, los temas concernientes a su materia, sin propiciar la participación de los estudiantes, después se le instruyó al docente que actuara como facilitador del conocimiento y que provocara en los alumnos la autogestión del conocimiento. En la actualidad, el profesor tiene la encomienda de conducirse como un motivador para transformar positivamente el desempeño de los estudiantes tanto en su constitución de saberes pragmáticos y teóricos, como en la formación de seres íntegros apegados a valores axiológicos.

El docente juega un papel fundamental como fuente de información dentro de las aulas, pues la asesoría y guía que proporciona, influye en gran medida en las capacidades para la praxis en apego a las actitudes ético morales de los aprendices, lo que provoca que el profesor sustente sus hallazgos y ofrezca información fidedigna y validada mediante diversos métodos científicos, que a su vez le permite ser percibido por sus alumnos como un actor confiable dentro de su contexto formativo generándole un branding axiológico positivo.

\section{El profesor como motivador axiológico en la formación de profesionistas}

Tradicionalmente los expertos en la rama de la educación han considerado que el profesor puede ser una fuente de inspiración y motivación para el estudiante. Su labor permite formar a los alumnos para aportar beneficios materiales y morales a la sociedad, los motiva para que se visualicen como personas éticas, de éxito y preparados para afrontar el campo laboral de su especialidad. Lograr lo anterior, puede resultar complejo si los discípulos no reciben de sus maestros una postura ética.

Más específicamente, ha sido consignado que la formación universitaria está encaminada a edificar el actuar del profesionista con fuerte soporte moral y preparados para actuar con base en los valores humanos globales, y que persigan proyectos que contemplen la 
responsabilidad que guardan para el bien de la sociedad (González, 2013).

Para construir profesionistas con verdadero apego moral en su actuar profesional, el papel de los docentes será valioso en dicha edificación formativa. Sobre esto (Delgado (2001), propone que los maestros motiven el crecimiento moral de sus alumnos a través de la aplicación de dilemas morales, en donde se consideren los diferentes estilos y entornos de aprendizaje.

El espíritu del docente y su nivel de motivación para promover y reforzar los valores que atañen a la práctica profesional, puede influir en el desarrollo moral de los estudiantes. Un profesor pulcro, ético, confiable y congruente con su discurso moral, reúne el perfil axiológico idóneo para lograr un ambiente favorable en las aulas que permita el proceso de enseñanza - aprendizaje, a favor no sólo de los aspectos teórico-prácticos, sino de los morales. Medir el perfil axiológico de los docentes a través de un instrumento validado, nos permite reunir datos esenciales para la toma de decisiones respecto a los valores que se consideran relevantes para ser aplicados en la práctica del comunicador.

\section{Una investigación pertinente y empírica}

Diseñar y validar un instrumento objetivo y confiable nos brinda una certera visión científica, logrando constatar si lo que se publica y comenta es válido y está sustentado en evidencias empíricas, y no tanto en creencias que responden más que todo a ideologías deformantes de los hechos.

En este capítulo presentamos un caso de medición, mediante un instrumento que tuvo como objetivo evaluar el perfil axiológico del profesor, implementado en la tesis doctoral de la autora principal, en la que se examinó la información obtenida que brindó datos para el desarrollo de estrategias y metodologías de formación para los estudiantes de comunicación, que permitan gestarle su perfil profesional valoral a manera de Branding Axiológico.

Para la medición del perfil axiológico del profesor, se tomaron en cuenta el diseño y validación de un instrumento, elementos tan 
importantes que permiten la confiabilidad en los resultados de una investigación.

Como en cualquier investigación, un paso por demás relevante consiste en elaborar un instrumento que permita asir, capturar, aprender el fenómeno de estudio que se realizó con sumo cuidado con el fin de medir el perfil axiológico de los profesores en comunicación, de acuerdo a sus propias prioridades valorales.

El primer paso en el diseño y construcción del instrumento para los profesores, fue definir y operacionalizar las variables a partir de lo que propone Solís (2013), citado por (Hernández, Fernández \& Baptista, 2014), así se seleccionaron las variables que representaran la mayor relevancia para recabar la información de interés, tales como, refuerzo de valores en el aula, abordaje de los valores que deben considerarse para la práctica de la comunicación, dilemas axiológicos, dilemas a los que se enfrenta el comunicador en formación, y estratégicas metodológicas para trabajar los valores en clase, dichas variables fueron convertidas en los ítems que formaron parte del instrumento para medir y analizar el perfil axiológico de los profesores.

Previo a la aplicación del instrumento se consideró la opinión de expertos para su validación, quienes también fueron sujetos a una evaluación con instrumento desarrollado por otros autores y que permitieron medir su nivel de habilidad y experiencia para calificar instrumentos de investigación.

\section{Medición de la experticia de los jueces}

Antes de explicar el procedimiento para medir la pericia de los jueces validadores del instrumento, vale la pena exponer que un experto de acuerdo con Almenara \& Osuna (2013), "es aquel con capacidad de proporcionar evaluaciones fiables sobre el problema en cuestión, y que tiene la capacidad de recomendar alternativas de mejora o cambio a partir de su nivel de competencia”.

Para la medición de la experticia de los jueces, se utilizó el patrón de (Oñate, 1990 en García, et al., 2012), en el que consideramos dos elementos: 
1) El conocimiento o información que el experto domina del tema, y se derivó de su autoevaluación de dicho conocimiento.

2) Su capacidad de argumentación derivada de su experiencia docente y su experiencia profesional; con ambos datos, se calculó el coeficiente de competencia del participante, Oñate, (1990) en García, Aquino, Guzmán, \& Medina (2012), lo que permitió evaluar la diferencia de la pericia entre los expertos agrupados en docentes-investigadores y profesionales de la comunicación en empresas públicas y privadas.

El coeficiente de competencia es: $K c o m p=0.5(K c+K a)$.

Donde:

$K c=$ La autoevaluación de un sujeto en una escala del 0 al 10 para valorar el nivel de conocimientos que domina sobre el tema del estudio.

$K a=$ Es el coeficiente de argumentación o el valor que resulta de sumar los grados de influencia que el sujeto considera que han tenido distintas fuentes de argumentación, en el conocimiento acumulado por él respecto a un tema en particular.

Para determinar el coeficiente de conocimiento $(K c)$ se les solicitó a 32 jueces que se auto evaluaran del 0 al 10, donde el 10 era el valor máximo, respecto a:

- Su dominio de la axiología en el campo de la comunicación.

- Su dominio en metodología de la investigación.

- Su experiencia en el campo de la comunicación.

El promedio de las tres respuestas se multiplicó por 0.1, que es el valor total de la escala (0-10). De esta forma, una calificación de 0 , indicó que el experto no contaba con el conocimiento de la problemática, y una calificación de 1.0 significa que el experto tenía pleno conocimiento de la problemática.

Se puede ver a continuación que para la medición de la experticia de los jueces se consideró como criterio el coeficiente de conocimiento, a partir de la calificación que los participantes se auto asignaron en los rubros de comunicación, axiología y metodología (Tabla 1). 
Tabla 1. Coeficiente de conocimiento (experticia) de los jueces

\begin{tabular}{|c|c|c|c|c|c|}
\hline $\mathbf{N}^{\mathbf{o}}$ & $\begin{array}{l}\text { Experiencia en } \\
\text { comunicación }\end{array}$ & $\begin{array}{l}\text { Dominio de } \\
\text { la axiología }\end{array}$ & $\begin{array}{r}\text { Dominio de la } \\
\text { metodología }\end{array}$ & Promedio & $\begin{array}{l}\text { Coeficiente de } \\
\text { conocimiento }\end{array}$ \\
\hline 1 & 9 & 9 & 9 & 9.00 & 0.90 \\
\hline 2 & 10 & 9 & 8 & 9.00 & 0.90 \\
\hline 3 & 10 & 10 & 9 & 9.67 & 0.97 \\
\hline 4 & 9 & 9 & 9 & 9.00 & 0.90 \\
\hline 5 & 8 & 9 & 9 & 8.67 & 0.87 \\
\hline 6 & 9 & 7 & 10 & 8.67 & 0.87 \\
\hline 7 & 10 & 10 & 7 & 9.00 & 0.90 \\
\hline 8 & 7 & 4 & 9 & 6.67 & 0.67 \\
\hline 9 & 10 & 9 & 10 & 9.67 & 0.97 \\
\hline 10 & 9 & 9 & 9 & 9.00 & 0.90 \\
\hline 11 & 10 & 10 & 10 & 10.00 & 1.00 \\
\hline 12 & 9 & 6 & 9 & 8.00 & 0.80 \\
\hline 13 & 9 & 8 & 10 & 9.00 & 0.90 \\
\hline 14 & 10 & 9 & 10 & 9.67 & 0.97 \\
\hline 15 & 8 & 8 & 5 & 7.00 & 0.70 \\
\hline 16 & 8 & 9 & 10 & 9.00 & 0.90 \\
\hline 17 & 9 & 8 & 9 & 8.67 & 0.87 \\
\hline 18 & 9 & 9 & 9 & 9.00 & 0.90 \\
\hline 19 & 8 & 6 & 7 & 7.00 & 0.70 \\
\hline 20 & 10 & 9 & 10 & 9.67 & 0.97 \\
\hline 21 & 10 & 10 & 10 & 10.00 & 1.00 \\
\hline 22 & 9 & 7 & 5 & 7.00 & 0.70 \\
\hline 23 & 10 & 9 & 8 & 9.00 & 0.90 \\
\hline 24 & 8 & 7 & 9 & 8.00 & 0.80 \\
\hline 25 & 8 & 8 & 10 & 8.67 & 0.87 \\
\hline 26 & 7 & 8 & 5 & 6.67 & 0.67 \\
\hline 27 & 9 & 10 & 10 & 9.67 & 0.97 \\
\hline 28 & 10 & 10 & 10 & 10.00 & 1.00 \\
\hline 29 & 6 & 6 & 9 & 7.00 & 0.70 \\
\hline 30 & 10 & 9 & 10 & 9.67 & 0.97 \\
\hline 31 & 10 & 9 & 9 & 9.33 & 0.93 \\
\hline 32 & 8 & 10 & 9 & 9.00 & 0.90 \\
\hline
\end{tabular}

Respecto al coeficiente de argumentación se formó con dos datos: los años de experiencia docente y los años de experiencia profesional en el campo de la comunicación. Primero se calcularon las medidas de tendencia central y de dispersión de ambos datos de los participantes, donde éstos tenían un promedio de 18 años de experiencia profesional en el campo de la comunicación y un promedio de 14 años de experiencia docente como se puede observar en la Tabla 2. 
Tabla 2. Registro de experiencia docente y profesional de los jueces participantes

\begin{tabular}{|c|c|c|}
\hline $\mathbf{N}^{\mathbf{o}}$ & Años de experiencia docente & Años de experiencia profesional \\
\hline 1 & 15 & 15 \\
\hline 2 & 20 & 14 \\
\hline 3 & 1 & 7 \\
\hline 4 & 8 & 3 \\
\hline 5 & 40 & 41 \\
\hline 6 & 15 & 20 \\
\hline 7 & 1 & 15 \\
\hline 8 & 0 & 1 \\
\hline 9 & 24 & 24 \\
\hline 10 & 6 & 27 \\
\hline 11 & 24 & 21 \\
\hline 12 & 20 & 38 \\
\hline 13 & 15 & 20 \\
\hline 14 & 23 & 15 \\
\hline 15 & 1 & 12 \\
\hline 16 & 40 & 40 \\
\hline 17 & 33 & 20 \\
\hline 18 & 15 & 10 \\
\hline 19 & 0 & 5 \\
\hline 20 & 40 & 40 \\
\hline 21 & 8 & 25 \\
\hline 22 & 1 & 6 \\
\hline 23 & 0 & 11 \\
\hline 24 & 10 & 4 \\
\hline 25 & 11 & 11 \\
\hline 26 & 0 & 15 \\
\hline 27 & 0 & 20 \\
\hline 28 & 0 & 15 \\
\hline 29 & 29 & 29 \\
\hline 30 & 25 & 26 \\
\hline 31 & 40 & 34 \\
\hline 32 & 0 & 5 \\
\hline Máximo & 40.00 & 41.00 \\
\hline Mínimo & 0.00 & 1.00 \\
\hline Promedio & 14.53 & 18.41 \\
\hline Desviación estándar & 13.87 & 11.49 \\
\hline $\mathrm{N}+1$ & 28.41 & 29.90 \\
\hline $\mathrm{N}-1$ & 0.66 & 6.91 \\
\hline
\end{tabular}

Empleando estos datos, se adaptó el patrón de valoración de las fuentes de argumentación por García, (et al. 2012) a través de una clasificación determinada estadísticamente en las mismas cuatro 
categorías propuestas por Oñate \& Martínez (1990), tales como baja, buena, alta, experto; obteniendo las siguientes distribuciones para valorar las fuentes de argumentación experiencia docente y experiencia profesional como se puede ver en las (Tabla 3) y (

Tabla 4).

Tabla 3. Categorías para la valoración de experiencia docente

\begin{tabular}{lll}
\hline Nivel & Límite inferior & Límite superior \\
\hline Bajo (1) & 0 & 0.66 \\
Bueno (2) & 0.66 & 14.53 \\
Alto (3) & 14.53 & 28.41 \\
Experto (4) & 28.40 & 40 \\
\hline
\end{tabular}

Tabla 4. Categorías para la valoración de experiencia profesional

\begin{tabular}{lll}
\hline Nivel & Límite inferior & Límite superior \\
\hline Bajo (1) & 1 & 6.91 \\
Bueno (2) & 6.91 & 18.41 \\
Alto (3) & 18.41 & 29.90 \\
Experto (4) & 29.90 & 41 \\
\hline
\end{tabular}

Al sumarle a la media una desviación estándar, obtenemos un límite llamado $\mathrm{N}+1$, y al restarle a la misma media una desviación estándar tenemos otro límite inferior llamado N-1. Esto es muy importante para analizar una población como en este caso de jueces, ya que dentro de $\mathrm{N}+1$ y $\mathrm{N}-1$ queda comprendida una población normal, que es aproximadamente el 68.23 de la población total de expertos (Mendenhall, 1979).

Los casos que obtuvieron una calificación mayor que $\mathrm{N}+1$ son sobresalientes de los normales considerados aquí, y son validados como expertos, en tanto que los que se encontraron con menos calificación al valor de $\mathrm{N}+1$ y mayor que la media son considerados como Alto; los de valor menor a la Media, pero mayores a N-1 son clasificados como Bueno y los menores a N-1 son considerados como Bajo.

Por otra parte, en la Tabla 5 se puede ver que, para la valoración de la experiencia docente y la experiencia profesional de los jueces participantes, se empleó el patrón de valoración de las fuentes de argumentación para 
la obtención del coeficiente de argumentación (ka), basado en García et al., 2012).

Tabla 5. Coeficiente de argumentación de los jueces

\begin{tabular}{l|l|l|l|l|l|l|l}
\hline $\mathbf{N}$ & $\begin{array}{l}\text { Experiencia } \\
\text { Docente }\end{array}$ & $\begin{array}{l}\text { Experiencia } \\
\text { Profesional }\end{array}$ & $\begin{array}{l}\text { *Clase Exp. } \\
\text { Prof. }\end{array}$ & $\begin{array}{l}\text { *Clase Exp. } \\
\text { Doc. }\end{array}$ & $\begin{array}{l}\text { GI Exp. } \\
\text { Prof. }\end{array}$ & $\begin{array}{l}\text { GI Exp. } \\
\text { Doc. }\end{array}$ & Ka \\
\hline 1 & 15 & 15 & 2 & 3 & 0.4 & 0.45 & 0.85 \\
2 & 20 & 14 & 2 & 3 & 0.4 & 0.45 & 0.85 \\
3 & 1 & 7 & 2 & 2 & 0.4 & 0.4 & 0.8 \\
4 & 8 & 3 & 1 & 2 & 0.3 & 0.4 & 0.7 \\
5 & 40 & 41 & 4 & 4 & 0.5 & 0.5 & 1 \\
6 & 15 & 20 & 3 & 3 & 0.45 & 0.45 & 0.9 \\
7 & 1 & 15 & 2 & 2 & 0.4 & 0.4 & 0.8 \\
8 & 0 & 1 & 1 & 1 & 0.3 & 0.3 & 0.6 \\
9 & 24 & 24 & 3 & 3 & 0.45 & 0.45 & 0.9 \\
10 & 6 & 27 & 3 & 2 & 0.45 & 0.4 & 0.85 \\
11 & 24 & 21 & 3 & 3 & 0.45 & 0.45 & 0.9 \\
12 & 20 & 38 & 4 & 3 & 0.5 & 0.45 & 0.95 \\
13 & 15 & 20 & 3 & 3 & 0.45 & 0.45 & 0.9 \\
14 & 23 & 15 & 2 & 3 & 0.4 & 0.45 & 0.85 \\
15 & 1 & 12 & 2 & 2 & 0.4 & 0.4 & 0.8 \\
16 & 40 & 40 & 4 & 4 & 0.5 & 0.5 & 1 \\
17 & 33 & 20 & 3 & 4 & 0.45 & 0.5 & 0.95 \\
18 & 15 & 10 & 2 & 3 & 0.4 & 0.45 & 0.85 \\
19 & 0 & 5 & 1 & 1 & 0.3 & 0.3 & 0.6 \\
20 & 40 & 40 & 4 & 4 & 0.5 & 0.5 & 1 \\
21 & 8 & 25 & 3 & 2 & 0.45 & 0.4 & 0.85 \\
22 & 1 & 6 & 1 & 2 & 0.3 & 0.4 & 0.7 \\
23 & 0 & 11 & 2 & 1 & 0.4 & 0.3 & 0.7 \\
24 & 10 & 4 & 1 & 2 & 0.3 & 0.4 & 0.7 \\
25 & 11 & 11 & 2 & 2 & 0.4 & 0.4 & 0.8 \\
26 & 0 & 15 & 2 & 1 & 0.4 & 0.3 & 0.7 \\
27 & 0 & 20 & 3 & 1 & 0.45 & 0.3 & 0.75 \\
28 & 0 & 15 & 2 & 1 & 0.4 & 0.3 & 0.7 \\
29 & 29 & 29 & 3 & 4 & 0.45 & 0.5 & 0.95 \\
30 & 25 & 26 & 3 & 3 & 0.45 & 0.45 & 0.9 \\
31 & 40 & 34 & 4 & 4 & 0.5 & 0.5 & 1 \\
32 & 0 & 5 & 1 & 1 & 0.3 & 0.3 & 0.6 \\
\hline & & & 2 & 3 & & & \\
\hline
\end{tabular}

Posteriormente, sobre la valoración de las fuentes de argumentación para la obtención del coeficiente de argumentación basado en García et al. (2012) se midieron los grados de influencia de cada una de las fuentes, considerando los años de experiencia docente y los años de experiencia profesional como se puede ver en la Tabla 6. 
Tabla 6. Valoración de las fuentes de argumentación para la obtención del coeficiente de argumentación ( $k a)$

\begin{tabular}{lllll}
\hline Fuente de argumentación & $\begin{array}{l}\text { Grados de } \\
\text { influencia de cada } \\
\text { uno de las fuentes }\end{array}$ & & & \\
\hline & Experto & Alto & Bueno & Bajo \\
Años de experiencia docente & 0.5 & 0.45 & 0.4 & 0.3 \\
$\begin{array}{l}\text { Años de experiencia } \\
\text { profesional }\end{array}$ & 0.5 & 0.45 & 0.4 & 0.3 \\
\hline
\end{tabular}

El coeficiente promedio de los entrevistados fue 0.85 (pericia alta), con una desviación estándar de 0.09 ; en un rango de $0.3(0.64-.99)$, lo que significa que la pericia de los entrevistados para evaluar el cuestionario es la adecuada, desde el punto de vista de su auto evaluación del conocimiento del tema y su conocimiento adquirido a través de su experiencia profesional y/o docente.

Una vez obtenidos el coeficiente de conocimiento y el coeficiente de argumentación de los expertos, se estimó su pericia para validar el cuestionario, empleando el Coeficiente de Competencia (Kcomp) aplicando la función:

$K c o m p=0.5(K c+K a)$.

Donde el criterio de interpretación, utilizando la estadística para evitar la arbitrariedad en la clasificación es:

- Los jueces con un coeficiente de competencia superior a 0.95 fueron clasificados con pericia de expertos.

- Los jueces con un coeficiente igual o superior a 0.86 e inferior a 0.95 fueron clasificados con pericia alta.

- Los jueces con un coeficiente igual o superior a 0.8 e inferior a 0.86 fueron clasificados con pericia buena.

- Los jueces con un coeficiente inferior a 0.8 fueron clasificados con pericia baja.

La clasificación referida con anterioridad utilizada en esta investigación se adaptó de García (et al. 2012). La adaptación consistió en separar cuatro rangos con criterios estadísticos para percibir más claramente los niveles de pericia de cada uno de los jueces utilizando la media \pm 1 $\sigma$ de acuerdo con Mendenhall (1979), obteniendo así el coeficiente de 
conocimiento de los 32 jueces participantes, descartando a aquellos que resultaron con una calificación de coeficiente bajo para mayor certeza en la investigación, quedando un total de 25 jueces validadores con amplio conocimiento del tema, evaluados con coeficiente de bueno a experto. Lo anterior se puede demostrar en la siguiente tabla.

Tabla 7. Evaluación de la pericia de los expertos clasificados por ocupación

\begin{tabular}{|c|c|c|c|c|c|}
\hline $\mathbf{N}^{\circ}$ & Perfil & \begin{tabular}{|l}
$\begin{array}{l}\text { Coeficiente de } \\
\text { conocimiento }\end{array}$ \\
\end{tabular} & \begin{tabular}{|l|}
$\begin{array}{l}\text { Coeficiente de } \\
\text { argumentación }\end{array}$ \\
\end{tabular} & $\begin{array}{l}\text { Coeficiente de } \\
\text { competencia }\end{array}$ & \begin{tabular}{|l} 
Interpre \\
tación
\end{tabular} \\
\hline 1 & $\begin{array}{l}\text { Profesional de la } \\
\text { comunicación }\end{array}$ & 0.97 & 1 & 0.99 & Experto \\
\hline 2 & $\begin{array}{l}\text { Profesor- } \\
\text { Investigador }\end{array}$ & 0.93 & 1 & 0.97 & Experto \\
\hline 3 & $\begin{array}{l}\text { Profesor- } \\
\text { Investigador }\end{array}$ & 1 & \begin{tabular}{|l|}
0.9 \\
\end{tabular} & 0.95 & Experto \\
\hline 4 & $\begin{array}{l}\text { Profesor- } \\
\text { Investigador }\end{array}$ & 0.9 & 1 & 0.95 & Experto \\
\hline 5 & $\begin{array}{l}\text { Profesor- } \\
\text { Investigador }\end{array}$ & \begin{tabular}{|l|}
0.87 \\
\end{tabular} & 1 & 0.94 & Alto \\
\hline 6 & $\begin{array}{l}\text { Profesor- } \\
\text { Investigador }\end{array}$ & 0.97 & 0.9 & 0.94 & Alto \\
\hline 7 & $\begin{array}{l}\text { Profesor- } \\
\text { Investigador }\end{array}$ & 0.97 & 0.9 & 0.94 & Alto \\
\hline 8 & $\begin{array}{l}\text { Profesor- } \\
\text { Investigador }\end{array}$ & 1 & 0.85 & 0.93 & Alto \\
\hline 9 & $\begin{array}{l}\text { Profesor- } \\
\text { Investigador }\end{array}$ & \begin{tabular}{|l|}
0.97 \\
\end{tabular} & 0.85 & 0.91 & Alto \\
\hline 10 & $\begin{array}{l}\text { Profesor- } \\
\text { Investigador }\end{array}$ & \begin{tabular}{|l|}
0.87 \\
\end{tabular} & 0.95 & 0.91 & Alto \\
\hline 11 & $\begin{array}{l}\text { Profesor- } \\
\text { Investigador }\end{array}$ & 0.9 & 0.9 & 0.9 & Alto \\
\hline 12 & $\begin{array}{l}\text { Profesional de la } \\
\text { comunicación }\end{array}$ & 0.97 & 0.8 & 0.89 & Alto \\
\hline 13 & \begin{tabular}{|l|} 
Profesor- \\
Investigador
\end{tabular} & 0.87 & 0.9 & 0.89 & Alto \\
\hline 14 & $\begin{array}{l}\text { Profesor- } \\
\text { Investigador }\end{array}$ & 0.9 & 0.85 & 0.88 & Alto \\
\hline 15 & $\begin{array}{l}\text { Profesional de la } \\
\text { comunicación }\end{array}$ & 0.9 & 0.85 & 0.88 & Alto \\
\hline 16 & \begin{tabular}{|l|} 
Profesor- \\
Investigador
\end{tabular} & 0.9 & 0.85 & 0.88 & Alto \\
\hline 17 & $\begin{array}{l}\text { Profesor- } \\
\text { Investigador }\end{array}$ & 0.8 & 0.95 & 0.88 & Alto \\
\hline 18 & $\begin{array}{l}\text { Profesor- } \\
\text { Investigador }\end{array}$ & 0.9 & 0.85 & 0.88 & Alto \\
\hline 19 & $\begin{array}{l}\text { Profesional de la } \\
\text { comunicación }\end{array}$ & 0.97 & 0.75 & 0.86 & Alto \\
\hline 20 & $\begin{array}{l}\text { Profesional de la } \\
\text { comunicación }\end{array}$ & 0.9 & 0.8 & 0.85 & Bueno \\
\hline 21 & $\begin{array}{l}\text { Profesional de la } \\
\text { comunicación }\end{array}$ & 1 & 0.7 & 0.85 & Bueno \\
\hline
\end{tabular}




\begin{tabular}{|c|c|c|c|c|c|}
\hline $\mathbf{N}^{\mathbf{o}}$ & Perfil & $\begin{array}{l}\text { Coeficiente de } \\
\text { conocimiento }\end{array}$ & $\begin{array}{l}\text { Coeficiente de } \\
\text { argumentación }\end{array}$ & $\begin{array}{l}\text { Coeficiente de } \\
\text { competencia }\end{array}$ & \begin{tabular}{|l}
$\begin{array}{l}\text { Interpre } \\
\text { tación }\end{array}$ \\
\end{tabular} \\
\hline 22 & $\begin{array}{l}\text { Profesor- } \\
\text { Investigador }\end{array}$ & 0.87 & 0.8 & 0.84 & Bueno \\
\hline 23 & $\begin{array}{l}\text { Profesor- } \\
\text { Investigador }\end{array}$ & 0.7 & 0.95 & 0.83 & Bueno \\
\hline 24 & $\begin{array}{l}\text { Profesor- } \\
\text { Investigador }\end{array}$ & 0.9 & 0.7 & 0.8 & Bueno \\
\hline 25 & $\begin{array}{l}\text { Profesional de la } \\
\text { comunicación }\end{array}$ & 0.9 & 0.7 & 0.8 & Bueno \\
\hline 26 & $\begin{array}{l}\text { Profesional de la } \\
\text { comunicación }\end{array}$ & 0.7 & 0.8 & 0.75 & Bajo \\
\hline 27 & $\begin{array}{l}\text { Profesor- } \\
\text { Investigador }\end{array}$ & 0.8 & 0.7 & 0.75 & Bajo \\
\hline 28 & $\begin{array}{l}\text { Profesional de la } \\
\text { comunicación }\end{array}$ & 0.9 & 0.6 & 0.75 & Bajo \\
\hline 29 & $\begin{array}{l}\text { Profesional de la } \\
\text { comunicación }\end{array}$ & 0.7 & 0.7 & 0.7 & Bajo \\
\hline 30 & $\begin{array}{l}\text { Profesional de la } \\
\text { comunicación }\end{array}$ & 0.67 & 0.7 & 0.69 & Bajo \\
\hline 31 & $\begin{array}{l}\text { Profesional de la } \\
\text { comunicación }\end{array}$ & 0.7 & 0.6 & 0.65 & Bajo \\
\hline 32 & $\begin{array}{l}\text { Profesional de la } \\
\text { comunicación }\end{array}$ & 0.67 & 0.6 & 0.64 & Bajo \\
\hline
\end{tabular}

\begin{tabular}{|l|l|l|l|l|}
\hline Donde & Máximo & 1.00 & 1.00 & 0.99 \\
\hline & Promedio & 0.87 & 0.83 & 0.85 \\
\hline & Desviación estándar & 0.103 & 0.121 & 0.093 \\
\hline & $\mathrm{N}+1$ & 0.98 & 0.95 & 0.95 \\
\hline & $\mathrm{N}-1$ & 0.77 & 0.70 & 0.76 \\
\hline
\end{tabular}

Las características de género, nacionalidad, país de residencia, nivel académico y ocupación de los 25 jueces que resultaron seleccionados para la validación de los instrumentos dado a su nivel de pericia, se pueden observar en la Tabla 8, predominando en los participantes, el género femenino y la nacionalidad mexicana, así como el nivel académico de doctorado y la ocupación de docentes- investigadores.

Tabla 8. Características del perfil de los 25 expertos validadores

\begin{tabular}{l|l|l}
\hline Género & Femenino & 16 \\
& Masculino & 9 \\
\hline Nacionalidad & Mexicana & 22 \\
& Española & 2 \\
& Argentina & 1 \\
\hline País en el que radica & México & 23 \\
& España & 2 \\
\hline
\end{tabular}




\begin{tabular}{l|l|l}
\hline Nivel académico & $\begin{array}{l}\text { Licenciatura } \\
\text { Maestría }\end{array}$ & 5 \\
& Doctorado & 18 \\
\hline Ocupación & $\begin{array}{l}\text { Docente-investigador. } \\
\text { Profesional de la comunicación en } \\
\text { empresas privadas y públicas. }\end{array}$ & 18 \\
\hline
\end{tabular}

Una vez que los jueces expertos fueron seleccionados, se les distribuyó el instrumento de medición del perfil axiológico del docente de comunicación, para que evaluaran la univocidad, pertinencia e importancia de los ítems con un sí (es unívoco) o un no (es unívoco), y con un sí (es pertinente) o un no (es pertinente); siguiendo el formato propuesto por París, 2014, en el que se considera la concordancia de dos terceras partes de los expertos como excelente y la concordancia menor de dos terceras partes de los validadores como marginal.

Acerca de la importancia de los ítems, siguiendo la misma referencia, los expertos calificaron cada ítem empleando una escala del uno al cuatro, en donde cuatro significa la máxima importancia y uno la mínima importancia. En la siguiente

Tabla 9 se puede ver el formato utilizado para someter a validación el cuestionario.

Tabla 9. Formato para validación de instrumento de medición, propuesto por París (2014)

\begin{tabular}{|c|c|c|c|c|c|c|c|c|c|c|c|}
\hline Ítem & Univocidad & Pertinencia & Importancia & Decisión & & & & & & & \\
\hline & Sí & No & Sí & No & 1 & 2 & $\begin{array}{ll}3 & 4 \\
\end{array}$ & Media & DS & $\mathrm{N}+1$ & $\begin{array}{c}\text { Mantener } \\
\text { Mejorar } \\
\text { Eliminar }\end{array}$ \\
\hline Pregunta... & & & & & & & & & & & \\
\hline
\end{tabular}

Los instrumentos fueron validados con la metodología descrita, donde la importancia de cada ítem se promedió entre todos los jueces participantes, y se sumó la media a una desviación estándar para reconocer aquellos ítems que están en el nivel superior de la normalidad estadística a una sigma para cada ítem. En conjunto con los resultados de univocidad y pertinencia, el nivel de importancia permitió calificarlo como Mantener, Mejorar o Eliminar, empleando el siguiente patrón de criterios, propuesto por París (2014) como se observa en la Tabla 10. 
Tabla 10. Criterios de validación por expertos para los ítems del cuestionario. París (2014)

\begin{tabular}{l|l|l|l}
\hline Univocidad & Pertinencia & Importancia & Decisión \\
\hline$\geq 2 / 3$ & $\geq 2 / 3$ & $\bar{x}+s \geq 3.7$ & Mantener \\
\hline$<2 / 3$ & $\geq 2 / 3$ & $\bar{x}+s \geq 3.7$ & Mejorar \\
\hline$\geq 2 / 3$ & $\geq 2 / 3$ & $\bar{x}+s<3.7$ & Mejorar \\
\hline$\geq 2 / 3$ & $<2 / 3$ & $\bar{x}+s \geq 3.7$ & Eliminar \\
\hline$<2 / 3$ & $<2 / 3$ & $\bar{x}+s<3.7$ & Eliminar \\
\hline
\end{tabular}

\section{Lo que los expertos dicen sobre el instrumento}

En muchas ocasiones, los expertos evalúan favorablemente los ítems del cuestionario, sin embargo, el abrir la oportunidad de que éstos brinden observaciones o sugerencias de mejora, permitirá replantear la formulación de las preguntas de forma más precisa y clara, pero sobre todo objetiva. En el caso de los resultados de la validación del cuestionario para profesores, los ítems tres y nueve, recibieron por parte de los expertos menos de dos terceras partes de los si acerca de su univocidad, por lo tanto, se sugirió revisar tales ítems. Así mismo, los ítems dos y cuatro recibieron, las calificaciones más bajas en la medición de la importancia de su inclusión en el cuestionario (promedios de 3.2 y 2.8, respectivamente).

En conclusión, la totalidad de los ítems del cuestionario fueron evaluados bajo el criterio de mantener a excepción del número tres y el nueve, en donde sólo se indicó su mejora. A pesar de la evaluación positiva de los ítems, los jueces hicieron ciertas observaciones que fueron consideradas para lograr mayor claridad y lógica de la información que se solicitó; por ejemplo, se eliminaron los rangos al preguntar las edades de los respondientes para evitar arbitrariedad, se eliminó el número del semestre que los estudiantes cursan manteniendo la pregunta abierta para evitar confusiones, se omitieron las opciones de áreas de la comunicación que los estudiantes prefieren ejercer al egresar, dejando la pregunta abierta y solicitando cinco opciones en orden de importancia, para no sesgar la respuesta o evitar omisión de alguna área que ellos consideren parte de la comunicación. 
Por otra parte, se agregaron rangos del 1 al 10 y del 0 al 100 en algunos ítems del cuestionario para medir con mayor precisión índices de importancia de la formación en valores y frecuencias en tiempo invertido en formar axiológicamente.

También se optó por tomar en cuenta la recomendación de listar por orden de importancia cinco valores que se promueven en clase por parte de los maestros y los valores que se consideran relevantes para ser aplicados como comunicadores, ya que esto aportó información que pudo ser tratada cualitativa y cuantitativamente con paquetes de análisis estadísticos que permitieron medir la validez, confiabilidad y consistencia de los datos, obteniendo las preguntas del instrumento final, las cuales se observan a continuación:

1. Indique su género. (m) (f)

2. Indique su edad.

3. Mencione la(s) materia(s) que imparte.

4. Mencione la dependencia en la que trabaja.

5. Indique del 0 al 10 (siendo el cero ausencia de valor y 10 el de mayor valor) la importancia que le da usted al refuerzo de valores en su clase, a los que ha de apegarse el comunicador.

6. Del 0 al 100 del tiempo invertido en cada una de sus clases durante el semestre, ¿qué porcentaje destina a promover con sus estudiantes los valores que deben predominar en el ejercicio profesional del comunicador?

7. En escala de importancia, enliste cinco valores para la práctica de la comunicación, que promueva en clase.

8. ¿Emplea usted en clase el análisis y discusión de diferentes dilemas axiológicos a los que se enfrenta el comunicador en su ámbito laboral?

9. ¿Qué tipo de dilemas axiológicos emplea en clase y con qué estrategias?

10. Enliste cinco dilemas axiológicos más comunes a los que se enfrenta un comunicador en formación. 
11. Aparte de la implementación del análisis y discusión de dilemas axiológicos, ¿qué otras estrategias metodológicas consideran que son relevantes para formar en valores a los estudiantes de comunicación?

\section{Conclusiones de la confiabilidad de los instrumentos de medición a través de jueces expertos}

En relación con la validación del nivel de pericia de los jueces, consideramos fundamental que antes de pasar a la fase de la validación del instrumento, medir el grado de experticia de a quienes se someterán los instrumentos para ser validados y posteriormente ser aplicados a la población seleccionada, contribuirá en gran medida a la confiabilidad y resultados de la investigación.

Respecto a la validación del instrumento por jueces expertos, sabemos que existen métodos para validar cuestionarios de manera más práctica, como aplicar por ejemplo el alfa de Crombach para escalas continuas de mayores dimensione que las escalas Likert, no obstante recurrir a jueces expertos favorece a la experiencia de conocer posturas y observaciones que tienen una gran riqueza contextual, aunado a el hecho de poder conocer una red de personas que tienen interés y experticia en el tema propio de investigación.

Siendo el instrumento sometido a la validación por jueces expertos y adecuado conforme a sus recomendaciones, nos dio la certeza de que la aplicación del cuestionario a profesores de comunicación, contribuyó en recopilar datos de manera objetiva, que apoyaron en dimensionar la importancia que los profesores le dan al refuerzo de los valores en las clases que imparten, medir el tiempo que invierten en promover los valores propios de la profesión, detectar los valores más importantes para ellos, así como los tipos de estrategias que implementan para formar en valores a los estudiantes de comunicación y los dilemas más comunes a los que los comunicadores se enfrentan. Los resultados fueron tratados estadísticamente para evitar el sesgo y arbitrariedad de la investigación de tal manera que la información pudo ser utilizada para proponer métodos o estrategias que se pueden implementar en clase para el desarrollo del perfil axiológico del comunicador que conlleve a tornarse en la creación de un Branding Axiológico. 


\section{Referencias bibliográficas}

Almenara, j. C., \& Osuna, j. B. La utilización del juicio de experto para la evaluación de tic: el coeficiente de competencia experta. Bordón, 25-38.

Delgado, F. A. (2001). Formación Valoral a Nivel Universitario (1a. ed.). México: Universidad Iberoamericana, A.C.

García, V., Aquino, S., Guzmán, A., \& Medina, A. (2012). El uso del Método Delphi como estrategia para la valoración de indicadores de calidad en programas educativos a distancia. 200-222.

ADDIN Mendeley Bibliography csl_bibliography González, E. (2013). Formación ética de los profesionales. Forjando el interés desde la razón y la emoción. Revista Internacional de Organizaciones, 10, 40. Recuperado en:

http:/ / ed.dgespe.sep.gob.mx/materiales/primaria/normativida d.gestion.y.etica.docente/que.son.los.valores.pdf.

Hernández S. R., Fernández, C. C, \& Baptista, L. P. (2014). Metodología de la Investigación. México: Mc Graw Hill Education.

Mendenhall, W. (1979). Introduction to Probability and Statistics. North Scituate: Duxbury Press.

Oñate, N. \& Martínez, L. (1990). Utilización del método Delphy en la pronosticación: Una experiencia inicial. Instituto de Investigaciones Económicas. Cuba: JUCEPLAN.

- París Mañas, G. (2014). Los profesionales de la Formación Profesional para el Empleo: competencias y desarrollo profesional. Recuperdo en: HYPERLINK "http://www.tesisenred.net/bitstream/handle/10803/285529/t gpm1de4.pdf?sequence $=2 "$ http://www.tesisenred.net/bitstream/handle/10803/285529/t gpm1de4.pdf?sequence $=2$ 



\title{
Emprender en la innovación social con estrategias de personal branding
}

\author{
Arturo González López \\ Universidad Autónoma de Nuevo León, México \\ Pablo Adán Micó \\ Universidad Católica de Valencia, Valencia, España
}

\section{Resumen}

Hablar de personal branding es referirse a la congruencia entre lo interno y lo externo; su aportación es rescatar la esencia del individuo que trasmite los valores con los cuales se desarrolló; frente a ellos se explota la imagen personal que está implícita en su estilo, vestimenta, comportamiento, actitud. Sirve básicamente para posicionarse como profesional en un entorno competitivo, donde no sólo consiguen el éxito los que se lo proponen, sino los que saben llevar a cabo un plan de marketing personal, que pone en visibilidad, conocimiento y acción la propia marca. El trabajo que se presenta se centra en un proyecto macro sobre la importancia de la imagen en la innovación social, cuyo objetivo es reconocer el valor de la primera impresión en el entorno profesional con el fin de integrar el concepto de personal branding en la formación emprendedora como parte de la autoimagen y el autoconcepto.

Palabras claves: Personal branding, imagen, comunicación, innovación social. 


\section{Introducción}

T A comunicación es un aspecto inherente en la vida del ser humano e indiscutiblemente es clave dentro de la innovación social que no es más que el enfoque a un cambio del paradigma personal, creando estrategias para el logro de objetivos profesionales. Desde que Tom Peters en 1997 utilizó por primera vez el término para referirse a lo que hacen las personas para destacar en un mundo competitivo y posicionarse en el mercado laboral. El nuevo concepto llevado a la teoría es actualmente uno de los grandes fenómenos culturales en Europa y América del Norte.

Para las nuevas generaciones es importante aprender estos nuevos conceptos y trasladar el mensaje adecuado, en el momento adecuado, por lo que esta característica hace que visualicen proyectos fuera del contexto empleado y busquen la manera de emprender, fomentando una personalidad convincente y persuasiva. Los millennials ${ }^{2}$ emprendedores escuchan y observan, como parte de la actividad de la comunicación, con ello mantiene una actitud abierta a nuevas necesidades, propuestas e ideas.

Hay otras muchas cualidades que seguro definen un perfil adecuado para una persona emprendedora, como la seriedad, la responsabilidad, la constancia, la memoria, la capacidad de análisis y algunas otras más; sin embargo, autores como Mariano, Trejo y Palaci (Mariano et al., 2001, p. 230), definen al emprendedor como "la persona que pone en marcha una iniciativa empresarial, crea su propia empresa, solo o asociado con otros promotores, asumiendo los riesgos financieros que esto supone, aportando su trabajo y ocupándose de la dirección de la empresa". El trabajo en equipo y la capacidad de organización y dirección también son cualidades sociales para el emprendimiento.

Los autores de este capítulo consideran que las cualidades personales y sociales no pueden estar separadas de los conocimientos profesionales (Adán y González, 2015); por lo que el perfil profesional del emprendedor debe considerar muy bien la experiencia al desarrollar un

\footnotetext{
${ }^{2}$ La generación Millennials define a los nacidos entre 1981 y 1995, jóvenes entre 20 y 35 años que se hicieron adultos con el cambio de milenio (en plena prosperidad económica antes de la crisis).
} 
proyecto, así que, se debe de tener en primer lugar, visión de negocios. En otras palabras, el emprendedor tiene la habilidad para detectar oportunidades de negocios que otros no pueden ver, y la capacidad para diferenciar las verdaderas oportunidades de las simples posibilidades de negocios.

Muchos jóvenes tienen desarrollada la inquietud de abrir un negocio, sin embargo, cuando se quiere emprender es importante tener el conocimiento profesional de la actividad a desarrollar y de la función específica que el proyecto va a necesitar. Un emprendedor va desarrollando habilidades adicionales como la administración de empresas, marketing y ventas, idiomas, aspectos jurídicos y financieros, aspectos tecnológicos y redes sociales.

Se debe de tener conocimiento del sector en el que se piensa competir, así como fuentes de información necesarias para el control de los cambios del mercado, la dinámica de liderazgo en el sector, las decisiones políticas o económicas que puedan afectar sus determinaciones (Adán y González, 2015).

Se han presentado alrededor de 18 cualidades para el emprendimiento, no obstante, hay un sector poco analizado por los autores en el área: el personal branding y la importancia que tiene esta técnica en el nuevo milenio.

\section{Metodología}

El proyecto que se presenta es una investigación de tipo experimental cuantitativo, utilizando un razonamiento deductivo para llegar a la verificación de la hipótesis presentada en la línea de investigación y generación del conocimiento: "Tendencias del marketing holístico para el desempeño individual y profesional”, en donde generalmente se utilizan mediciones ordinales, la operacionalización es esencial.

Es decir, que, a pesar de ser un experimento enfocado a personas, específicamente jóvenes, cuya respuesta puede variar según el momento de la entrevista, se ha creado un instrumento de medición que arroja información pertinente sobre el objeto en cuestión, en este caso, el personal branding. 
Como hipótesis, o supuesto cuantitativo del estudio, se plantea que (Hi) la falta de valor que se le da al concepto de personal branding en la formación emprendedora es debido al poco interés académico en el manejo de la autoimagen y el autoconcepto profesional.

El proceso metodológico define conceptos difusos, sin embargo, se permiten ser medidos empírica y cuantitativamente a través de una definición operacional. Se estableció un sistema de medición numérica para permitir el análisis estadístico y replicación sobre las variables de edad, género y nivel socioeconómico, utilizando 60 ítems en una escala de Linket, con afirmaciones referidas a este apartado del personal branding; aspectos sobre las variables conceptuales tales como la primera impresión, vestimenta, actitud, personalidad y la influencia de lo atractivo, entre otros. La intención de las afirmaciones ha sido valorar las opiniones, los gustos, la satisfacción y el conocimiento frente a las áreas mencionadas explorando las tendencias y las discrepancias de las respuestas respecto a variables analizadas.

Para su análisis se ha empleado la Chi cuadrada de Pearson, ya que el objetivo es conocer qué tanto se parece la distribución observada con los resultados teóricos. El tipo de muestra es probabilístico estratificado, es decir, cada elemento de la población bajo estudio tiene una probabilidad de ser seleccionado dentro de las unidades de observación agrupadas con base a características similares en función al número de población clave dentro del área metropolitana de Monterrey. Se consideró a hombres y mujeres mayores de 15 años como parte de la muestra representativa.

El proyecto se basa en las teorías de los efectos y en la de simbolismo interaccionista. La primera determina la eficacia de la comunicación centrada en el emisor, por lo que el sujeto receptor está condicionado para imitar automáticamente lo que ve en los medios. En el simbolismo interaccionista se enfatiza el proceso interactivo en la experiencia de los medios. Es decir que el individuo actúa libremente gracias a esta interacción simbólica, que le permite crear significados de acuerdo con otros. El sujeto relaciona el mensaje recibido con su propia identidad y contexto social. 


\section{El posicionamiento personal y el éxito}

En los últimos meses conceptos como imagen personal, Marca Personal ${ }^{\circledR}$, Imagen Pública ${ }^{\circledR}$ y por supuesto, Personal Branding $₫$, están tomando mayor relevancia, pues se trata de una estrategia de acción, un instrumento para el posicionamiento personal y el éxito.

Personal Branding® es lo que hace diferente a un individuo de los demás, lo que ayuda a trazar un camino, lo que posiciona como persona y como profesional. Es la suma de las habilidades, conocimientos, valores y expectativas (Marcos y Pérez, 2007). Muchos autores confunden personal branding con marca personal; sin embargo, son conceptos diferentes, el segundo es consecuencia del primero; en otras palabras, marca personal es el resultado de las estrategias conscientes elaboradas para un fin o propósito.

En el emprendimiento una de las claves de éxito es ser reflexivo de las habilidades que se poseen, pues son un referente para dar valor ante los demás, mientras que los conocimientos hacen referencia al valor profesional.

Los valores son las convicciones de los seres humanos que determinan su manera de ser y orientan su conducta (Delgado, 2013). Los valores involucran nuestros sentimientos y emociones, por lo que valores, actitudes y conducta están relacionados. Este tipo de aspectos del individuo se van adquiriendo con base al entorno en donde nos desenvolvemos y las consecuencias de acciones hechas.

Para muchos autores, el Personal Branding® está asociado a la imagen física y por ende al aspecto superficial, banal y superfluo, pero va más allá de esto. La imagen es percepción, es comunicación verbal y no verbal y es, en gran medida, parte del desarrollo personal y profesional en el entorno social.

El desarrollo de las personas y las empresas, tanto en el aspecto integral como en el profesional, se va formando a través de intervenciones inconscientes que obtienen de los patrones adquiridos en el entorno familiar y la comunidad. Es decir, el éxito o fracaso de una persona o una empresa se basa en la asimilación de tradiciones informales y la subjetividad de los lazos sociales (González López, 2012). 
Innovación social es un concepto que se ha venido utilizando hace poco más de una década en países europeos. Está basado en el precepto taoísta de movimiento. Es decir, para esta corriente filosófica no hay nada estático; todo cambia y todo fluye. No se puede llegar a un punto estático llamado meta porque no existe nada estático. Lo importante es disfrutar del camino, aprender de él, y observar cómo todo cambia día a día. No importa si se recorre activamente con un trabajo personal o pasivamente dejando que la vida presente experiencias; siempre se está en el camino.

Para Echeverría, "la innovación social, ha de referirse a valores sociales, por ejemplo, el bienestar, la calidad de vida, la inclusión social, la solidaridad, la participación ciudadana, la calidad medioambiental, la atención sanitaria, la eficiencia de los servicios públicos o el nivel educativo de una sociedad" (Echevarría, 2008, p. 610).

Este tipo de ideología debe estar acuñada en el emprendimiento, ya que siempre se está en movimiento, viviendo diferentes experiencias, pero siempre desarrollando la conciencia.

Como hablan los expertos en ventas y superación personal: "El éxito no es un lugar al que se llega después de recorrer un camino. El éxito es el camino mismo. Se recorre cada día. Se construye cotidianamente en todas las áreas de vida: personal, familiar, laboral, económica, emocional y espiritual" (Díaz, 2013, p. 471).

La percepción de la imagen provoca que se dote de identidad a la persona, sin embargo, la homogenización de las personas, provocada por los años laborales han creado un entorno social y profesional donde parece que la igualdad de cualidades, principios y valores favorece la identificación personal. No obstante, el tránsito hacia la competitividad ha obligado a la búsqueda de recursos y herramientas que favorezcan la identidad propia por encima de la igualdad. En otras palabras, es importante destacar en un mundo competitivo, pero no con mentiras o creando apariencias falsas, sino destacando el potencial propio de cada individuo.

"Ciertamente mucho hemos de aprender las personas de aquellas parcelas del marketing, cuya finalidad es la de posicionar y diferenciar marcas, a menudo sobre productos iguales o muy 
similares, y generar valor frente a su público potencial" (Adán y González, 2015).

Las estrategias de marketing utilizadas para el posicionamiento de una empresa o marca, desarrolla su parte más humana y se relaciona con las personas para llevar a cabo tácticas de empoderamiento personal y de identificación de perfiles de valor frente al entorno social.

El Personal Branding $®$ es entonces, de forma necesaria, un activo preciso e intangible que responde a la suma de identidad, propuesta de valor y diferencia, que recurre al marketing personal como estrategia de posicionamiento y comunicación al entorno, y cuyo objetivo es la selección última de una persona frente a otras opciones (Ortega, 2014).

\section{El impacto de las primeras impresiones}

Se puede crear una imagen de alguien o algo, pensar si es bueno o malo, agradable o no, si tiene algo "diferente" o es igual a las otras u otros con sólo verles o escucharles. Hay quienes perciben los olores de manera increíble que pueden identificar de qué se trata.

La comunicación mueve al mundo. El cómo, cuándo y por qué una persona o empresa dice una determinada cosa son aspectos centrales de las relaciones interpersonales eficaces. El oyente o receptor del mensaje se forma una opinión acerca de quién le habla, o a quién ve y esa opinión contribuye a su vez, a formar una imagen, la cual juega un importante papel en el éxito o el fracaso de cada uno de nosotros (González López, 2012).

En segundos se puede determinar si es o está alto, bajito, gordo, flaco, feo, bonito con sólo ver, oír, tocar, oler o degustar. Es decir, se van creando imágenes a través de los sentidos. "La Comunicación es el eje central de la vida humana, no es sólo un aspecto que nos informa, sino que es un proceso de intercambio de ideas, sentimientos y experiencias entre personas o empresas" (González López, 2012, p. 19).

La comunicación es un aspecto inevitable en la vida humana, no existe la no comunicación, cada aspecto de la vida de percibe a través de estímulos emitidos y recibidos por los sentidos. La forma más representativa de la comunicación es el lenguaje. Existen una gran cantidad de estudios en revistas y científicos dedicados a defender la 
forma correcta de utilizar el lenguaje verbal, a criticar la evolución del idioma, su significado ante un determinado grupo social o bien el contexto en el que se encuentra.

Sin embargo, el lenguaje también es no verbal y va más allá de las formas físicas y los colores, también entra con ello, el tono de voz, el timbre, los sonidos que emitimos o escuchamos. El llanto, la risa, el ritmo, la fluidez de las palabras. Es decir, un emprendedor debe de ser consciente de esa parte de la comunicación que refuerza a las palabras o que hablan por sí solas.

En 1967 Albert Mehrabian, conocido por su trabajo pionero en el campo de la comunicación no verbal. Llevó a cabo experimentos sobre actitudes y sentimientos y encontró que en ciertas situaciones en que la comunicación verbal es altamente ambigua, solo el $7 \%$ de la información se atribuye a las palabras, mientras que el 38\% se atribuye a la voz (entonación, proyección, resonancia, tono, etc.) y el 55\% al lenguaje corporal (gestos, posturas, movimiento de los ojos, respiración, etc.). Dando lugar a la conocida "regla 7\%-38\%-55\%", sin embargo, otros investigadores como el antropólogo Raymond Birdwhistell, encontró que cerca de un 35\% de la comunicación proviene del contenido verbal, mientras que el 65\% restante es el resultado del lenguaje corporal (Sánchez, 2015, p. 93)

Se puede concluir que las palabras, la voz y el cuerpo tienen que ser coherentes entre sí. Esta incoherencia puede ser percibida, de ser así es menos probable que la gente se crea lo que se está diciendo. En cuanto a la regla mencionada de Mehrabian, es aplicable exclusivamente cuando la conversación es de índole emocional (sentimientos) y cuando surge en este proceso una incongruencia entre lo verbal y lo no verbal, primando en este caso la comunicación no verbal.

En la cultura empresarial afecta la actitud de los individuos, "la imagen que se tiene de los empresarios y con las percepciones de los individuos acerca de su propia capacidad como posibles empresarios" (OECD, 2013) determinan el emprendimiento en la actualidad.

De manera natural e inconsciente el ser humano da y recibe constantemente primeras impresiones. Se etiqueta a un emprendedor o empresa con esa primera información que nos proporcionan, determinando cómo las personas se ven entre sí. Aunque es posible 
que las personas cambien su opinión con el tiempo, las primeras impresiones suelen durar mucho y esto puede ser un factor de riesgo al momento de emprender (Huber, 2001).

Las primeras impresiones forman parte de todos los niveles de vida, y en ocasiones afectan el resultado de decisiones importantes que tienen un impacto directo sobre el proyecto a emprender. En general, Huber (2001) afirma que las primeras impresiones son importantes en las primeras citas y en entrevistas laborales, y dependen de una variedad de aspectos, tanto de personalidad como de actitud. Un emprendedor debe ser consciente que la primera impresión que causará en una persona o empresa puede no ser la misma que la que quiere causar en otra.

Las buenas primeras impresiones continuas pueden hacer que se promueva con más rapidez el concepto que se está emprendiendo, o llegar a otros de forma personal o profesional. Es probable que entablar una entrevista con un inversionista no será igual que exponer sus ideas a nuevos clientes. Se requiere presentar una impresión distinta.

El marco de tiempo en el que se puede causar una primera impresión es muy limitado. Los otros notan elementos claves de la primera impresión, como la forma de vestir, y completan su impresión luego de que se empieza a hablar y exponer sus ideas de lo que se está emprendiendo.

La vestimenta y la presentación general son extremadamente importantes en una situación que provoque una primera impresión (Elsea, 2000). La vestimenta revela mucho de las personas ante los ojos de los demás, sin embargo, como parte del Personal Branding®, la manera de hablar y comportarse también son cruciales al causar una primera impresión. Utilizar un discurso inteligente con un vocabulario que fluya, ayuda a causar la primera impresión indicada que un emprendedor debe considerar.

El cause de la relación es, generalmente, provocada por la primera impresión. Es fundamental que se cuiden todos los detalles y se muestre una imagen armónica, que contemple tanto la parte física como la calidad humana y el conocimiento adquirido, ya sea a base de estudio o experiencia en el área (Elsea, 2000). 


\section{Resultados}

Para que un proyecto emprendedor se desarrolle, el aporte de valor y la generación de confianza que una persona pueda brindar son claves primordiales, no obstante, aspectos como la forma de vestir (estilo), tipo de vestuario, la actitud y personalidad, así como la seguridad en sí mismo son parte de lo atractivo y por ende influye en la toma de decisiones en el emprendimiento.

Ante la afirmación "lo que veo de inmediato en una persona es su forma de vestir", los resultados arrojados por la Chi Cuadrada (p) con respecto al grupo de edades de la muestra analizada, indican que existe diferencia significativa. Se puede comprobar en la Tabla 1. Donde $X 2$ $(18, N=356)=30.559, p=.032]$. Se puede observar cómo son los más jóvenes los que están en desacuerdo con la afirmación $(71.9 \%)$ dejando entender que es este grupo de edad el que menos interés ponen en la imagen física, existe independencia de estereotipos. No obstante, el grupo en donde generalmente se encuentran los emprendedores (1924 años) refleja el mayor interés por la apariencia de la contraparte con un $55.1 \%$.

Tabla 1 Afirmación: Lo que veo de inmediato en una persona es su forma de vestir

\begin{tabular}{|c|c|c|c|c|c|c|c|}
\hline & & & $\begin{array}{l}\text { Nada } \\
\text { probable o } \\
\text { Completame } \\
\text { nte en } \\
\text { desacuerdo }\end{array}$ & $\begin{array}{l}\text { Poco } \\
\text { probable o } \\
\text { En } \\
\text { desacuerdo }\end{array}$ & $\begin{array}{l}\text { Probable o } \\
\text { De acuerdo }\end{array}$ & $\begin{array}{l}\text { Totalmente } \\
\text { probable o } \\
\text { Completamente } \\
\text { de acuerdo }\end{array}$ & Total \\
\hline \multirow{13}{*}{ EDAD } & \multirow[t]{2}{*}{$15-18$} & Conteo & 14 & 9 & 5 & 4 & 32 \\
\hline & & $\%$ EDAD & $43.8 \%$ & $28.1 \%$ & $15.6 \%$ & $12.5 \%$ & $100.0 \%$ \\
\hline & \multirow[t]{2}{*}{$19-24$} & Conteo & 12 & 10 & 15 & 12 & 49 \\
\hline & & $\%$ EDAD & $24.5 \%$ & $20.4 \%$ & $30.6 \%$ & $24.5 \%$ & $100.0 \%$ \\
\hline & \multirow[t]{2}{*}{$25-30$} & Conteo & 21 & 9 & 10 & 14 & 54 \\
\hline & & $\%$ EDAD & $38.9 \%$ & $16.7 \%$ & $18.5 \%$ & $25.9 \%$ & $100.0 \%$ \\
\hline & \multirow[t]{2}{*}{$31-40$} & Conteo & 22 & 11 & 18 & 14 & 65 \\
\hline & & $\%$ EDAD & $33.8 \%$ & $16.9 \%$ & $27.7 \%$ & $21.5 \%$ & $100.0 \%$ \\
\hline & \multirow[t]{2}{*}{$41-50$} & Conteo & 23 & 14 & 14 & 13 & 64 \\
\hline & & $\%$ EDAD & $35.9 \%$ & $21.9 \%$ & $21.9 \%$ & $20.3 \%$ & $100.0 \%$ \\
\hline & \multirow[t]{2}{*}{$51-60$} & Conteo & 20 & 7 & 13 & 8 & 48 \\
\hline & & $\%$ EDAD & $41.7 \%$ & $14.6 \%$ & $27.1 \%$ & $16.7 \%$ & $100.0 \%$ \\
\hline & $61+$ & Conteo & 22 & 5 & 0 & 17 & 44 \\
\hline
\end{tabular}




\begin{tabular}{|l|l|l|l|l|l|l|l|}
\hline & $\%$ EDAD & $50.0 \%$ & $11.4 \%$ & $0.0 \%$ & $38.6 \%$ & $100.0 \%$ \\
\hline \multirow{2}{*}{ Total } & Conteo & 134 & 65 & 75 & 82 & 356 \\
\cline { 2 - 7 } & $\%$ EDAD & $37.6 \%$ & $18.3 \%$ & $21.1 \%$ & $23.0 \%$ & $100.0 \%$ \\
\hline
\end{tabular}

Ante esta misma afirmación, se puede denotar que no existe diferencia significativa ni por sexo $[X 2(3, N=356)=.773, p=.856]$ ni por nivel socioeconómico $[X 2(12, N=356)=14.593, p=.264]$.

Como forma de corroborar la afirmación anterior se presentó a la muestra una nueva oración "Lo más importante en la primera impresión es el vestuario", confirmando a través de la Chi cuadrada la significación en el grupo de edad [X2 (18, N=356)=29.275, $p=.045]$ (Tabla 2).

Tabla 2 Lo más importante es el vestuario

\begin{tabular}{|c|c|c|c|c|c|c|c|}
\hline & & & $\begin{array}{l}\text { Nada probable o } \\
\text { Completamente } \\
\text { en desacuerdo }\end{array}$ & $\begin{array}{l}\text { Poco } \\
\text { probable o } \\
\text { En } \\
\text { desacuerdo }\end{array}$ & $\begin{array}{l}\text { Probable o } \\
\text { De acuerdo }\end{array}$ & $\begin{array}{l}\text { Totalmente } \\
\text { probable o } \\
\text { Completamen } \\
\text { te de acuerdo }\end{array}$ & Total \\
\hline & Máximo & 1.00 & 1.00 & 0.99 & & 5 & 32 \\
\hline & Promedio & 0.87 & 0.83 & 0.85 & & $15.6 \%$ & $100.0 \%$ \\
\hline & Desvia- & 0.103 & 0.121 & 0.093 & & 14 & 49 \\
\hline & $\begin{array}{l}\text { estándar } \\
\mathrm{N}+1\end{array}$ & 0.98 & 0.95 & 0.95 & & $28.6 \%$ & $100.0 \%$ \\
\hline & & 0.77 & 0.70 & 0.76 & & 12 & 54 \\
\hline & $\mathrm{N}-1$ & $\begin{array}{l}\% \\
\text { EDAD }\end{array}$ & $38.9 \%$ & $24.1 \%$ & $14.8 \%$ & $22.2 \%$ & $100.0 \%$ \\
\hline Donde & & Conteo & 23 & 14 & 14 & 14 & 65 \\
\hline & $31-40$ & $\begin{array}{l}\% \% \\
\text { EDAD }\end{array}$ & $35.4 \%$ & $21.5 \%$ & $21.5 \%$ & $21.5 \%$ & $100.0 \%$ \\
\hline & & Conteo & 16 & 8 & 20 & 20 & 64 \\
\hline & $41-50$ & $\begin{array}{l}\% \% \\
\text { EDAD }\end{array}$ & $25.0 \%$ & $12.5 \%$ & $31.3 \%$ & $31.3 \%$ & $100.0 \%$ \\
\hline & & Conteo & 13 & 8 & 10 & 17 & 48 \\
\hline & $51-60$ & $\begin{array}{l}\% \\
\text { EDAD }\end{array}$ & $27.1 \%$ & $16.7 \%$ & $20.8 \%$ & $35.4 \%$ & $100.0 \%$ \\
\hline & & Conteo & 18 & 5 & 7 & 14 & 44 \\
\hline & $61+$ & $\begin{array}{l}\% \\
\text { EDAD }\end{array}$ & $40.9 \%$ & $11.4 \%$ & $15.9 \%$ & $31.8 \%$ & $100.0 \%$ \\
\hline & & Conteo & 112 & 70 & 78 & 96 & 356 \\
\hline Total & & $\begin{array}{l}\% \% \\
\text { EDAD }\end{array}$ & $31.5 \%$ & $19.7 \%$ & $21.9 \%$ & $27.0 \%$ & $100.0 \%$ \\
\hline
\end{tabular}


Para la muestra representativa no existe significancia sobre si la vestimenta debe de ser costosa, ya que según la Chi Cuadrada de Pearson tanto en los grupos de edad $[X 2(18, N=356)=11.993$, $p=.848]$, género $[X 2 \quad(3, N=356)=2.533, \quad p=.469] \quad y$ nivel socioeconómico $[X 2(12, N=356)=20.705, p=.055]$ no hay relación entre la afirmación con su forma de pensar.

Tanto para hombres como para mujeres "saber vestir a la moda es sinónimo de imagen personal”, así lo indica la Chi cuadrada $X 2$ (3, $N=356)=7.948, p=.047]$. Como se puede notar en la Tabla 3 el porcentaje en contra de la afirmación en ambos géneros es significativa (53.5\% y $52.2 \%$ hombres y mujeres respectivamente). Como era de imaginar el porcentaje mayor con respecto a la aseveración se encuentra reflejado en el sexo femenino con un $47.8 \%$, mientras que el $46.4 \%$ en el grupo masculino sorprende la hipótesis planteada.

Tabla 3 Vestir a la moda reflejo de buena imagen personal

\begin{tabular}{|c|c|c|c|c|c|c|c|}
\hline & & & $\begin{array}{l}\text { Nada probable o } \\
\text { Completamente } \\
\text { en desacuerdo }\end{array}$ & $\begin{array}{l}\text { Poco probable } \\
\text { o En } \\
\text { desacuerdo }\end{array}$ & $\begin{array}{l}\text { Probable o } \\
\text { De acuerdo }\end{array}$ & $\begin{array}{l}\text { Totalmente } \\
\text { probable o } \\
\text { Completa- } \\
\text { mente de } \\
\text { acuerdo }\end{array}$ & Total \\
\hline & Masculino & Conteo & 40 & 28 & 29 & 30 & 127 \\
\hline & & $\% \mathrm{SEXO}$ & $31.5 \%$ & $22.0 \%$ & $22.8 \%$ & $23.6 \%$ & $100.0 \%$ \\
\hline SEXO & Femenino & Conteo & 90 & 29 & 41 & 68 & 228 \\
\hline & & $\% \mathrm{SEXO}$ & $39.5 \%$ & $12.7 \%$ & $18.0 \%$ & $29.8 \%$ & $100.0 \%$ \\
\hline Total & & \begin{tabular}{|l|} 
Conteo \\
\end{tabular} & 130 & 57 & 70 & 98 & 355 \\
\hline & & $\% \mathrm{SEXO}$ & $36.6 \%$ & $16.1 \%$ & $19.7 \%$ & $27.6 \%$ & $100.0 \%$ \\
\hline
\end{tabular}

La imagen que las personas reciben de tanto de un emprendedor como de cualquier persona, viene dada por muchos aspectos y lógicamente el primero, es su aspecto exterior. Por otra parte, las actitudes son aspectos que se van adquiriendo con el tiempo, es decir, son aprendidas y en consecuencia pueden ser diferenciadas de los motivos biosociales como el hambre, la sed y el sexo, que son parte de la naturaleza del ser humano. Las actitudes suelen permanecer muy estables con el tiempo. Estas son dirigidas siempre hacia un objeto o idea particular.

Cuando se habla de apariencia se hace referencia estrictamente a ese ser externo de una persona o cosa y que no por cómo sea éste o la sensación que ese afuera produce, será así internamente esa persona. 
Es decir, es la sensación que se percibe con respecto a alguien, que en muchas ocasiones no representa a quién es en realidad la persona.

Como parte de la investigación se presentó a la muestra la afirmación: "Me interesa más la actitud que la apariencia" viendo reflejada la relación significativa dentro del nivel socioeconómico según la Chi cuadrada de Pearson $[X 2(12, N=356)=22.467, p=.033]$. En la Tabla 4 se puede observar cómo es la clase media alta con un $82.9 \%$ donde se refleja con mayor claridad la afirmación, es decir, que a la mayoría le es más importante la actitud de una persona que su apariencia física.

Ante la afirmación sobre si la imagen de una persona influye en su personalidad, según los datos recabados, se puede decir que no hay una relación en ninguno de los grupos analizados, ni por edad $X 2$ (18, $N=356)=25.993, p=.100]$, ni por género $[X 2(3, N=356)=.192$, $p=.979]$, al igual que por el nivel socioeconómico $[X 2(12, N=356)$ $=13.702, p=.3207$. Queda por sentado que la muestra tiene claro la diferencia entre imagen y personalidad.

Tabla 4 Actitud contra apariencia

\begin{tabular}{|c|c|c|c|c|c|c|c|}
\hline & & & $\begin{array}{l}\text { Nada probable o } \\
\text { Completamente } \\
\text { en desacuerdo }\end{array}$ & $\begin{array}{l}\text { Poco probable } \\
\text { o } \\
\text { En desacuerdo }\end{array}$ & $\begin{array}{l}\text { Probable } \\
\text { o De } \\
\text { acuerdo }\end{array}$ & $\begin{array}{l}\text { Totalmente } \\
\text { probable o } \\
\text { Completam } \\
\text { ente de } \\
\text { acuerdo }\end{array}$ & Total \\
\hline \multirow{10}{*}{ NSE } & \multirow{2}{*}{$\begin{array}{l}\text { Nivel bajo } \\
\text { extremo (D) }\end{array}$} & Conteo & 1 & 0 & 0 & 1 & 2 \\
\hline & & $\%$ NSE & $50.0 \%$ & $0.0 \%$ & $0.0 \%$ & $50.0 \%$ & $100.0 \%$ \\
\hline & \multirow{2}{*}{$\begin{array}{l}\text { Nivel bajo } \\
\text { típico }(\mathrm{D}+)\end{array}$} & Conteo & 14 & 10 & 8 & 35 & 67 \\
\hline & & $\% \mathrm{NSE}$ & $20.9 \%$ & $14.9 \%$ & $11.9 \%$ & $52.2 \%$ & $100.0 \%$ \\
\hline & \multirow{2}{*}{$\begin{array}{l}\text { Nivel medio } \\
\text { típico }(\mathrm{C})\end{array}$} & Conteo & 7 & 13 & 20 & 50 & 90 \\
\hline & & $\% \mathrm{NSE}$ & $7.8 \%$ & $14.4 \%$ & $22.2 \%$ & $55.6 \%$ & $100.0 \%$ \\
\hline & \multirow{2}{*}{$\begin{array}{l}\text { Nivel medio } \\
\text { alto }(\mathrm{C}+)\end{array}$} & Conteo & 8 & 10 & 17 & 70 & 105 \\
\hline & & $\% \mathrm{NSE}$ & $7.6 \%$ & $9.5 \%$ & $16.2 \%$ & $66.7 \%$ & $100.0 \%$ \\
\hline & \multirow{2}{*}{$\begin{array}{ll}\text { Nivel alto } \\
(\mathrm{A} / \mathrm{B})\end{array}$} & Conteo & 15 & 10 & 25 & 42 & 92 \\
\hline & & $\% \mathrm{NSE}$ & $16.3 \%$ & $10.9 \%$ & $27.2 \%$ & $45.7 \%$ & $100.0 \%$ \\
\hline \multirow{2}{*}{\multicolumn{2}{|c|}{ Total }} & Conteo & 45 & 43 & 70 & 198 & 356 \\
\hline & & $\%$ NSE & $12.6 \%$ & $12.1 \%$ & $19.7 \%$ & $55.6 \%$ & $100.0 \%$ \\
\hline
\end{tabular}

En cuanto a la confianza y seguridad que presenta una persona, en este caso los emprendedores, representa la capacidad de defenderse de forma honesta y respetuosa. Es decir, tener un estilo de comunicación seguro puede ayudar a hacer los que se desea, pero es mucho más que eso. Cuando un emprendedor se siente seguro de sí mismo, se respeta y logra que los demás lo respeten. 
Las personas que hablan con seguridad y confianza demuestran que creen en sí mismas. No son demasiado tímidas ni demasiado avasalladoras. Saben que sus ideas y sus sentimientos son importantes. Tienen confianza.

Las personas seguras de sí suelen hacer amigos con más facilidad. Se comunican con respeto hacia las necesidades de las otras personas y a sus propias necesidades. Suelen ser buenas para resolver conflictos y desacuerdos.

Como resultado ante la afirmación: "Tener confianza en sí mismo ayuda para dar una buena impresión", según la Chi cuadrada no existe relación alguna con respecto a la muestra. Edad $[X 2(18, N=356)$ =14.907, $p=.668]$, Sexo $[X 2(3, N=356)=4.354, p=.226]$, nivel socioeconómico $X 2(12, N=356)=19.773, p=.071]$. No obstante, la seguridad sí se ve reflejada según el estrato socioeconómico [X2 (18, $N=356)=30.559, p=.032]$, como se puede distinguir en la Tabla 5.

La balanza se inclina hacia lo positivo de la afirmación: "No pido opinión de nadie, tomo mis propias decisiones". La afirmación es muy subjetiva, sin embargo, se buscó plantear de manera rápida para que el inconsciente tomara la decisión de respuesta.

Tabla 5 Seguridad en sí mismo

\begin{tabular}{|c|c|c|c|c|c|c|c|}
\hline & & & $\begin{array}{l}\text { Nada probable } \\
\text { o } \\
\text { Completamente } \\
\text { en desacuerdo }\end{array}$ & $\begin{array}{l}\text { Poco probable } \\
\text { o En } \\
\text { desacuerdo }\end{array}$ & $\begin{array}{l}\text { Probable o } \\
\text { De } \\
\text { acuerdo }\end{array}$ & $\begin{array}{l}\text { Totalmente } \\
\text { probable o } \\
\text { Completamente } \\
\text { de acuerdo }\end{array}$ & Total \\
\hline \multirow[t]{10}{*}{ NSE } & \multirow{2}{*}{$\begin{array}{l}\text { Nivel bajo } \\
\text { extremo (D) }\end{array}$} & Conteo & 0 & 0 & 0 & 2 & 2 \\
\hline & & $\% \mathrm{NSE}$ & $0.0 \%$ & $0.0 \%$ & $0.0 \%$ & $100.0 \%$ & $100.0 \%$ \\
\hline & \multirow{2}{*}{$\begin{array}{l}\text { Nivel bajo } \\
\text { típico (D+) }\end{array}$} & Conteo & 11 & 4 & 12 & 40 & 67 \\
\hline & & $\%$ NSE & $16.4 \%$ & $6.0 \%$ & $17.9 \%$ & $59.7 \%$ & $100.0 \%$ \\
\hline & \multirow{2}{*}{$\begin{array}{l}\text { Nivel medio } \\
\text { típico }(\mathrm{C})\end{array}$} & Conteo & 4 & 16 & 17 & 53 & 90 \\
\hline & & $\%$ NSE & $4.4 \%$ & $17.8 \%$ & $18.9 \%$ & $58.9 \%$ & $100.0 \%$ \\
\hline & \multirow{2}{*}{$\begin{array}{l}\text { Nivel medio } \\
\text { alto }(C+)\end{array}$} & Conteo & 12 & 9 & 16 & 68 & 105 \\
\hline & & $\%$ NSE & $11.4 \%$ & $8.6 \%$ & $15.2 \%$ & $64.8 \%$ & $100.0 \%$ \\
\hline & \multirow{2}{*}{$\begin{array}{l}\text { Nivel alto } \\
\text { (A/B) }\end{array}$} & Conteo & 10 & 17 & 22 & 43 & 92 \\
\hline & & $\%$ NSE & $10.9 \%$ & $18.5 \%$ & $23.9 \%$ & $46.7 \%$ & $100.0 \%$ \\
\hline \multirow{2}{*}{\multicolumn{2}{|c|}{ Total }} & Conteo & 37 & 46 & 67 & 206 & 356 \\
\hline & & $\%$ NSE & $10.4 \%$ & $12.9 \%$ & $18.8 \%$ & $57.9 \%$ & $100.0 \%$ \\
\hline
\end{tabular}

En este apartado sólo se ha querido distinguir algunos aspectos del Personal Branding $®$ con respecto a la primera impresión, los resultados en su mayoría han sido no significativos, es decir, se acepta la hipótesis 
nula de independencia y por lo tanto se concluye que ambas variables estudiadas son independientes, no existe una relación entre ellas. Esto significa que existe más de un $5 \%$ de probabilidad de que la hipótesis nula sea cierta en nuestra población y se considera suficiente para aceptar. El valor de 0.05 es un valor establecido de acuerdo al nivel de confianza del 95\%.

\section{Conclusiones}

Al pretender exponer el proceso de la comunicación verbal y no verbal a través de la imagen, se parte de las manifestaciones teóricas de los estudios que visualizan estas relaciones con otros procesos sociales y naturales. La sociedad se mueve constantemente y la propuesta como línea de investigación que emplea este proyecto se desarrolla desde diversos vértices de la psicología, la sociología, hasta puede formar parte de la administración del factor humano, pero en general evoca al proceso de comunicación mismo.

Investigar el Personal Branding ${ }^{\circledR}$ como parte de la gestión de la imagen es un excelente instrumento para examinar las emociones y conductas humanas y comprender por qué algunas personas destacan por su imagen más que por su capacidad cognitiva y captan nuestra atención, incluso tienen capacidad para influir en nuestra conducta. Pudiera parecer que tiene un enfoque más psicológico que mediático, no obstante, el interés del proyecto va más allá. Aunque netamente como individuos no somos un producto fabricado en un gran almacén, si, metafóricamente hablando, somos un producto diseñado por la sociedad y los medios masivos y digitales son el medio de comunicación en los que nos promocionamos.

De las Universidades salen cientos de jóvenes con un mismo interés, igual que con un mismo título de grado, sin embargo, no todos cubren las expectativas de las empresas, no tienen un perfil adecuado o adaptado a las necesidades actuales. La línea de investigación se enfoca más allá del verse bien, saber, hablar o comportarse; lo que se busca es concientizar a la juventud y a la sociedad en general que estamos en un cambio radial en los procesos de comunicación en la búsqueda de empleo, reclutamiento empresarial. 
Se puede afirmar que dentro del sector de emprendimiento es importante utilizar las técnicas de marketing para conseguir mayor relevancia como marca. Gracias al Personal Branding $®$ se puede alcanzar y gozar de un prestigio o reputación profesional, lo que puede favorecer a la hora de arrancar un sueño o idea.

Para poder empoderar una marca personal a través de las estrategias que el Personal Branding $®$ destaca, es importante considerar la emulación de la persona que se quiere ser; es decir, tener un referente claro del objetivo propio a alcanzar. Un segundo aspecto a discurrir, es que se requiere inversión de tiempo y perseverancia, es con base al esfuerzo, con trabajo y dedicación como se puede posicionar en el mercado emprendedor y laboral. Por último, hay que ser conscientes que el Personal Branding® es más que una técnica, es un estilo de vida planeado y llevado a cabo. Ninguna marca se posiciona de la noche a la mañana.

\section{Referencias bibliográficas}

Adán, P., \& González, A. (2015). Emprender con Éxito. México: Alfaguara.

Delegado Domenech, B. (2013). Psicología del desarrollo en la infancia y la adolescencia. Alicante: Publicaciones Universidad de Alicante.

de Lucas Osorio, J. (2013). La comunicación en el empoderamiento de la cultura emprendedora. Revista de Comunicación de la SEECI, (30), 1-33.

Díaz Suárez, D. J. (2013). ¡Tienes las herramientas! ¡Aprende a utilizarlas!

Estrategias y Consejos Esducativos para Mestros, Padres y

Estudiantes. Bloomington: Palibrio LCC.

Echevarría, J. (2008). El manual de Oslo y la innovación social. Arbor, 184(732), 609-618.

Elsea, J. G. (2000). La primera impresión: una técnica infalible para ofrecer la mejor imagen. Grijalbo.

Ferreyra, H. A. (2007). Educar en la acción para aprender a emprender: organización, gestión de proyectos socio-productivos y cooperativos. Buenos Aires: Ediciones Novedades Educativas.

Huber, C. (2001). La primera impresión: tu cuerpo habla: técnicas para interpretar los mensajes no verbales y crear una buena impresión.

Editorial Océano, SL. 
González López, A. (2012). La Comunicación, herramienta para el desarrollo personal y profesional en el entorno social. Monterrey: UANL.

Marcos, T., y Pérez, A. (2007). ¿Quién teme al Personal Branding? Capital Humano, (210), 94-106.

Mariano, J., Trejo, E., \& Palaci, F. (2001). El perfil psicosocial del emprendedor: un estudio desde la perspectiva de los valores. Revista de Psicología Social, 2, 229-242.

Martín Cruz, N., Hernangómez Barahona, J., Rodríguez Escudero, A., \& Saboia Leitao, F. (2010). La formación de los emprendedores y sus consecuencias sobre la innovación y el éxito empresarial. Dirección y Organización (41), 86-95.

OECD. (2013). Panorama del emprendimiento 2012. Monterrey: OECD, TESM, Instituto de Emprendimiento.

Ortega, A. P. (2014). Marca personal. Centro Libros PAPF. Pizarro Moreno, I., Real Fernández, J. C., \& Sousa Ginel, E. (2000). El emprendedor como motor de la creación de conocimiento. In XIV Congreso Nacional De AEDEM: Inteligencia Empresarial. La gestión del conocimiento en la empresa.

Rodríguez, L. G. (2015). Educación para emprender, una opción para el mundo en desarrollo. Revista EAN, (25-26), 55-62.

Sánchez Gómez, R. (2015) Acción y reflexión: Cómo desarrollar el pensamiento y las habilidades directivas. Madrid. ESIC Editorial.

Telléz Figueroa, J. F. (2013). Emprendedurismo en América Latina. CPMARK Cuaderno Profissional de Marketing, 1 (1), 51-63. 



\title{
Planificación por competencias, herramienta para mejorar la docencia e imagen profesional de los formadores de docentes
}

\author{
Dr. Inocente Melitón García \\ Escuela Normal de Atlacomulco "Profesora Evangelina Alcántara \\ Díaz”, México
}

\section{Resumen}

Para entender los retos que enfrenta el docente frente a la innovación del currículo y la enseñanza, es importante adentrarse en el terreno del estado de conocimiento de la educación normal, analizar y sistematizar la producción generada en torno a este campo denominado la planificación didáctica del profesorado. Puede decirse que, para hablar sobre el trabajo cotidiano de la práctica docente, es necesario considerar dos vertientes: una referida a la formación, que prepara al maestro para su ejercicio profesional, en las escuelas normales, y la otra a la actualización y superación, que lo acompañan durante su desempeño profesional.

La veta elegida para estudiar lo relacionado con la planificación del trabajo docente, desde la percepción del formador de docentes de la escuela normal, ha sido poco tratada por los investigadores o por los estudiosos de la educación. El impacto de la planificación docente por competencias va más allá de la simpleza de una estrategia metodológica, se convierte en la oportunidad transformadora de ser concebidos con una imagen profesional actualizada y competitiva; por 
ende, la procuración de una docencia distinta, prospectiva, postmoderna, necesaria y urgente.

Palabras clave: Planificación, práctica, formación, identidad.

\section{Introducción}

— $\mathrm{N}$ los procesos de reforma curricular emprendidos - en las instituciones educativas de educación normal durante la última década, los profesores aparecen como responsables últimos de concretar los modelos educativos innovadores en el aula. Para entender los retos que enfrenta el docente frente a la innovación del currículo y la enseñanza, hay que "avanzar en la comprensión de cómo es que aprenden los profesores, qué los impele a cambiar o no sus prácticas educativas, qué procesos ocurren cuando se enfrenta la tarea de innovar o qué condiciones se requieren para que un cambio real ocurra y se consolide" (Zabala Vidiella, 2006, p. 18). En este proceso investigativo se revisan algunos estudios que dan cuenta de dichos procesos, así como una serie de análisis y propuestas emanadas de especialistas en el tema.

Abordar la planificación didáctica de los profesores es una tarea que tiene que ver sobre los requerimientos de la práctica docente en su dimensión ontológica pedagógica, y una posibilidad de conocer el entramado (complexus) que impera en su diseño, creación y aplicación en el aula de clase, porque de ella depende el logro de una práctica eficiente encaminada al desarrollo de los aprendizajes esperados en el alumno normalista.

Las prácticas institucionales y las tradiciones pedagógicas contribuyen a configurar condiciones concretas en la que el discurso y las propuestas de transformación cobran sentido en la praxis (acción) de cada formador en la medida que son conscientes de poder dialogar entre la verdad y el error; particularmente en las aulas en donde se gestan las acciones, tradiciones y creencias sobre la actuación del profesorado, a través de una lectura objetiva de lo real y concreto, así como el deber ser y hacer con respecto a las estrategias o actividades planeadas previamente desde la semántica de la competencia de los 
propósitos educativos, y desde una relación espacio y tiempo de cada sesión de clase.

La racionalidad de la planificación didáctica en la escuela normal demanda nuevas cualidades pedagógicas del docente como: planear el proceso de enseñanza-aprendizaje, seleccionar y preparar los contenidos disciplinares, ofrecer información y explicaciones comprensibles y organizadas, hacer uso de la tecnología, diseñar la metodología y organizar actividades, comunicarse con los alumnos, tutorizar, evaluar, reflexionar sobre la enseñanza, identificarse con la institución y trabajar en equipo. Existen incertidumbres en algunas clases cuando se ignora esta experiencia didáctica con propiedad, tanto en su diseño, ejecución y evaluación, ya que cuando sólo se planea para cumplir una orden administrativa, más aún cuando no hay voluntad pedagógica para planear anticipadamente, deja a la vista de lo que se hace o se deja de hacer en salón de clases. Es aquí donde cabe la posibilidad de establecer una primera aproximación al objeto a partir de la siguiente pregunta central: ¿De qué manera incide la planificación didáctica del docente normalista en el logro de los rasgos del perfil de egreso del estudiante en formación? ¿Cómo esta herramienta metodológica transforma mi ser y deber ser profesional, propiciando una imagen innovadora como docente postmoderno, implicando en ello el tránsito de la docencia hacia la matética?

Actualmente la planificación didáctica es vista como un instrumento que nos permite introducir en las diferentes formas de intervención aquellas actividades que posibiliten una mejora de nuestra actuación en las aulas como resultado de un conocimiento y dominio amplio de los contenidos o temas de enseñanza de la malla curricular. Es una tarea importante, porque mediante ésta se describen de manera específica las actividades y estrategias metodológicas que se llevarán tanto fuera como dentro del espacio áulico en tiempos específicos, en busca de lograr de una forma consciente y organizada, los propósitos aprendizajes deseados en la formación inicial. En este sentido, la planificación didáctica se convierte en un mecanismo de orientación de los procesos de enseñanza y aprendizaje. 
Esta postura invita a plantear y estudiar como objeto de estudio a la planificación didáctica que se desarrolla en la escuela normal, como una inquietud pedagógica para el desarrollo del currículo y como factor que interviene en el proceso de apropiación de las competencias profesionales de los futuros docentes. Destacando la importancia de la planificación en la mejora del proceso educativo, se tiene como pretexto revisar el sentido de la planificación como recurso para la toma de decisiones del maestro, la necesidad de la coherencia interna entre los elementos de un plan, la importancia de considerar el contexto y las necesidades de los alumnos, y las consecuencias de asumir posiciones contrapuestas como la improvisación o una planificación rígida, técnica o instrumental.

Hablar de la planificación didáctica, es referirse al estudio de los criterios básicos de la planificación, en particular la necesidad de considerar la relación entre los propósitos educativos, las características de los alumnos y la articulación de los contenidos. Además, cómo los docentes formadores realizan actividades relacionadas con el proceso de planificación, tales como el diagnóstico de necesidades de aprendizaje de los alumnos, la selección y organización de contenidos y el diseño de estrategias generales de trabajo. Para realizar estas actividades se parte de la idea de que los conocimientos y experiencias que han adquirido los docentes durante su trayectoria profesional son los referentes para diseñar propuestas diversas de planificación, considerando las condiciones del grupo, aprovechar las situaciones imprevistas y las propuestas de los alumnos.

Se asienta como relevante recuperar, dentro del plan de estudios (1999) de educación normal, el trabajo que los profesores normalistas realizan con la planificación didáctica al organizar o definir las actividades de enseñanza y aprendizaje de su práctica docente, así como los propósito y enfoques de las asignaturas a desarrollar en el aula de clases, y por la forma en que son llevadas a cabo, son consideradas como limitantes para el desarrollo profesional de los alumnos y logro de los aprendizajes esperado. En otros estudios se hace énfasis en los procedimientos que favorecen o dificultan incorporar las experiencias de los docentes normalistas, en los programas de actualización ofrecidos por diversas instituciones de la SEP. 
La planificación es una exigencia que se impone día a día en todas las actividades humana. El trabajo docente no se escapa a esta exigencia, máxime si tenemos en cuenta las consecuencias morales y sociales que el implica. El planeamiento didáctico se hace necesario por razones de responsabilidad moral, económica, adecuación laboral y eficiencia. El profesor necesita saber, para llevar a cabo su planeamiento, que, por qué, a quién y cómo enseñar.

El proyecto original consideraba asumir una revisión exhaustiva, acerca de la planificación didáctica que realizan los docentes de la Escuela Normal Atlacomulco, no obstante, se han considerado dos perspectivas como elementos de singular importancia generadora de propuestas: la visión del profesor normalista y la visión del estudiante en formación, considerando a ambos como sujetos de la investigación. Siendo el topos logoi del proceso investigativo: Destacar la importancia de la planificación en la mejora del proceso educativo, se tiene como pretexto revisar el sentido de la planificación como recurso para la toma de decisiones del maestro, la necesidad de la coherencia interna entre los elementos de un plan, la importancia de considerar el contexto y las necesidades de los alumnos, y las consecuencias de asumir posiciones contrapuestas como la improvisación o una planificación rígida, técnica o instrumental.

Por ello y con la intención de analizar la función pedagógica y características de la planificación, enfatizando la congruencia que debe guardar con los propósitos y contenidos de aprendizaje, su permanencia a lo largo del proceso educativo y la necesaria participación tanto de alumnos como del maestro, se han revisado los diferentes instrumentos y formatos que el docente utiliza para realizar la planificación didáctica de su clase; se ha entrevistado al subdirector académico de la institución respecto de la intención una planificación didáctica anual y por clase, así como los resultados que esta implementación ha provocado. Iniciando con esta acción la etapa de implementación de trabajo de campo, soportado en un esquema metodológico de recogida de información empírica.

Se aplicó un instrumento de campo a 62 alumnos de la Licenciatura en Educación Secundaria con Especialidad en Lengua Extranjera Inglés y Español respecto a los aspectos generales sobre el desarrollo académico de la institución, instrumento que contempla el conocer - 
desde el punto de vista del alumno normalista-, cómo los docentes formadores realizan actividades relacionadas con el proceso de planificación, tales como el diagnóstico de necesidades de aprendizaje de los alumnos, la selección y organización de contenidos y el diseño de estrategias generales de trabajo. Se tiene ya resultados de concentración parciales, falta aún trabajar respecto a la estadística inferencial. Y se revisa la pertinencia de aplicar dos instrumentos más respecto a las categorías: Desarrollo del trabajo docente y actividades de análisis y reflexión sobre la práctica.

\section{Marco teórico}

La práctica docente en la escuela normal está en una constante reconstrucción por mejorar la calidad de los aprendizajes. Promueve y organiza propósitos centrados en una enseñanza situada para organizar con sentido formativo sus objetivos, planificación y el desarrollo de competencias profesionales.

La necesidad de revisar el desempeño académico de los formadores responde a la problemática que se ha encontrado en algunos docentes de la institución, ya que esto desvían el compromiso de enseñar con profesionalismo, confundiéndolo con la venta de una idea sobre la educación integral, que muchas veces no se lleva a cabo en realidad.

En la medida en que los docentes se comprometan y trabajen con planeaciones estructuradas y organizadas, con base en las competencias disciplinares, conozcan, reconozcan, pero sobre todo aplique como tal el plan y programas de estudio de la licenciatura como base para su trabajo, mejorara indudablemente el logro de los rasgos del perfil de egreso de los estudiantes y a su vez, corregirán y mejoraran el servicio educativo que ofrecen. Sólo habrá un cambio en el docente si hay una debida reflexión de lo que debe hacerse en clase para asegurar el buen control de la enseñanza.

Por el contrario, si los docentes se limitan a seguir trabajando para sólo cumplir la parte administrativa de la docencia, descuidando el desarrollo de hábitos, habilidades, actitudes, aptitudes, etc., los cuales impactarán en la formación de los estudiantes, haciendo de su desempeño algo difícil, ya que no contarán con las competencias didácticas para desempeñarse como docentes de educación básica, en 
términos del deber ser y hacer de la práctica en condiciones reales de trabajo, ya que es necesario que el docente signifique el nuevo saber en relación directa con la reflexión de su hacer.

Ante los nuevos enfoques curriculares por competencias se habla ampliamente y con autoridad del aprendizaje experiencial y del basado en problemas; de la enseñanza reflexiva y de la que se fundamenta en el análisis de casos, de las experiencias pedagógicas sirviendo en contextos comunitarios y de la evaluación autentica; la apropiación de los conocimientos escolares ha de promoverse asumiendo la situacional esencial del conocimiento humano y situacional deseable de los procesos educativos.

La investigación se desarrolla desde un enfoque constructivistainterpretativa; el interés que guía es comprender la relación o proceso dialéctica entre la planificación y las prácticas de enseñanza que generan al interior del aula, así como la construcción del conocimiento a partir de una situación y la propuesta de secuencias didácticas que se determinan de manera intencional, a fin de dar respuesta a los rasgos del perfil de egreso del plan de estudios de la licenciatura.

La investigación se aborda desde la perspectiva fundamental de la fenomenología que ha dado lugar al nacimiento de la teoría interpretativa. "La fenomenología es una corriente de pensamiento propia de la investigación interpretativa que aporta como base del conocimiento la experiencia subjetiva inmediata de los hechos tal como se perciben" (Forner y Latorre, 1996, p. 73).

El objeto de la investigación es la acción humana, a las causas de esas acciones residen en el significado entrepretado que tienen para las personas que las realizan antes que en la similitud de conductas observadas.

\section{Metodología}

La planificación como una actividad básica se analiza desde una dimensión pedagógica para cualquier docente, no sólo porque mediante ella se establecen con claridad los pasos que seguirá en su clase sino también porque es a través de esta actividad que se pone sobre la mesa cómo se piensa alcanzar las metas propuestas. 
También es necesario referimos a la metodología de secuencia didáctica por competencias desde el enfoque socio-formativo que aborda Tobón Tobón (2010), ya que retoma las enseñanzas del constructivismo y por ello se insistirá en la necesidad de tener problemas retadores, que sean identificados en el contexto (personal, familiar, comunitario, laboraprofesional, etc.), para que de esta forma los estudiantes tengan un escenario complejo que lleve al análisis, la comprensión y la interacción de variables, pero también a tener una mayor vinculación con la realidad y a generar el compromiso de buscar que el mundo sea mejor.

Para conocer la práctica docente ha sido necesario llevar a cabo una investigación metodológica y partiendo de que, dentro de la escuela y más particularmente dentro del salón de clase se deriva una interacción social, podemos decir que el tipo de investigación que se realizó está dentro del marco de referencia de las ciencias sociales. El propósito de la investigación es develar los múltiples usos (sentidos) y significados de la planificación didáctica en el ámbito de la práctica, por lo que lo que enfatizaremos desde el carácter cualitativo, ya que "en las disciplinas del ámbito social existen diferentes problemáticas, cuestiones y restricciones que no se pueden explicar ni comprender en toda su extensión desde la metodología cuantitativa" (Pérez Serrano, 1994, p. 26).

La investigación se sitúa en el paradigma cualitativo, pues éste responde a una metodología cualitativa (constructivista) basada en la rigurosa descripción contextual, de un hecho o una situación que garantice la máxima intersubjetividad en la captación de una realidad compleja mediante la recogida sistemática de datos, misma que haga posible un análisis interpretativo.

Con el propósito de hacer un desarrollo metodológico en profundidad, se han elegido dos de las alternativas metodológicas con más potencial en la investigación social, en razón al grado de desarrollo del conjunto de su propuesta; nos referimos a la de tipo etnográfico y fenomenológico (desde el plano sociológico, inaugurada por Schutz (1977), Berger y Luckmann (1985), ya que se traza como eje argumental la defensa del carácter específico de la realidad humana, que la hace irreductible a las categorías de análisis de la realidad física cuya esencia son los objetos o cosas materiales. 
En esta investigación ha requerido de algunas herramientas que son básicas para la recuperación y tratamiento de los datos que se obtengan para llevar a cabo su estudio. Según Woods (1995) la metodología etnográfica utiliza diversas técnicas y herramientas o instrumentos como: Observación interna o participante, entrevistas en profundidad, semiestructuradas o abiertas (guion de preguntas y registros), diario de campo, registros narrativos, notas de campo, grabación en video y grabación en audio.

La encuesta a los alumnos forma parte de una estrategia más general de indagación sobre el desarrollo académico de la escuela normal. Es un instrumento que está destinado a recopilar información acerca de los aspectos generales sobre el desarrollo académico de la institución; y fue aplicado a egresados y alumnos del 8 semestre de ambas licenciaturas (español e inglés) del ciclo escolar 2013-2014. Para su tratamiento de contraste en estadística inferencial, el universo de encuestados (62) fue dividido en tres grupos indistintos de género, situación académica y edad.

El diseño de la encuesta considera las ventajas y limitaciones que se presentan en un instrumento de este tipo: su reducción a la percepción de sólo uno de los actores de un proceso que involucra a más personas, su carácter de herramienta metodológica que pretende sistematizar datos seleccionados de un fenómeno más complejo como lo es el trabajo y práctica docente versus planificación didáctica; y la limitación en el tiempo disponible para atender los requerimientos de la encuesta, entre otras.

\section{Resultados}

La Escuela Normal de Atlacomulco (ENA) ha priorizado entre sus académicos la implementación de actividades de planificación que se van desarrollando en las jornadas de actualización al inicio de cada semestre, a través de una propuesta pedagógica para la elaboración de planes semestrales y planes de sesión semanales, mismo que son revisados (leídos) y autorizados por los asesores académicos que participan en el Departamento de Formación Inicial y la Subdirección Académica. Al ser desarrollada la planificación didáctica, la totalidad de 
los docentes cumplen con ello, pero no existen evidencias y/o que muestren en qué condiciones, cómo y para qué se realiza.

Documentar y cuestionar el trabajo docente que realiza el profesor en cada sesión de clase resultado de una planificación intencionada y estratégica, debe ser motivo de análisis y apoyo a los estudiantes, de manera que no sólo aprendan cómo utilizar determinados procedimientos, sino cuándo y por qué pueden utilizarlos y en qué medida favorecen la resolución de las tareas implicadas en la formación profesional, sin perder de vista los referentes curriculares relacionados con el perfil de egreso de la licenciatura, ya que es colocado como eje de la formación de los profesores noveles.

Sin embargo, se evidencia que en los docentes de la Escuela Normal de Atlacomulco existe falta de interés por cumplir el proceso didáctico de la planificación como una estrategia de prevención de lo que tiene que hacerse para evitar la improvisación, ignorando al mismo tiempo los acuerdos establecidos y consensuados a nivel institución escolar, y colectivo docente de la academia.

La acción docente se ve afectada por múltiples factores administrativos, académicos, sindicales, políticos, sociales, culturales-, muchos de ellos inesperados, los cuales obligan a tomar decisiones para improvisar y volver a determinado nivel de rutina de la práctica, desarrollando los contenidos sin tener cuidado una secuencia didáctica.

Es necesario, promover los procesos de análisis y reflexión sobre la transformación pedagógica de la propia planificación y las estrategias de enseñanza que configuran las diferentes unidades de aprendizajes de las asignaturas antes y durante la práctica docente en el aula, ya que se seleccionan y se trabajan varios contenidos educativos para formar nuevos esquemas de pensamientos, sabiendo distinguir desde su propia praxis lo conceptual, procedimental y actitudinal. Sobre todo, en esta sociedad compleja, global y cambiante cuando se pretende educar por competencias.

De esta manera, las competencias no podrían abordase como comportamientos observables solamente, sino una compleja estructura de atributos necesarios para el desempeño en situaciones diversas en las cuales se combinan conocimientos, habilidades, valores y actitudes 
con las tareas que se tienen que desempeñar en determinadas situaciones (Perrenaud, 1999).

Ciertamente, cuando nos fijamos a determinar una propuesta de planificación, poco hacemos por preguntar los fines educativos que pretendemos alcanzar o desarrollar en la formación inicial de los alumnos en cada unidad didáctica de las asignaturas que conforman el plan de estudios, con sentido crítico y paradigma teórico-metodológico que lo sustenta. La forma de presentación y la relación que existe entre ellos nunca son arbitrarias; al contrario, obedece a unos criterios que hacen que la selección de contenidos de cada unidad o bloque y el tipo de relaciones que entre ellos se establecen sea de una manera y no de otra. Esto supone que dichas unidades giren en torno a temas, preguntas, apartados y lecciones que articulan y relacionan los diferentes contenidos de una manera determinada.

Ante los nuevos enfoques curriculares por competencias se habla ampliamente y con autoridad del aprendizaje experiencial y del basado en problemas; de la enseñanza reflexiva y de la que se fundamenta en el análisis de casos, de las experiencias pedagógicas sirviendo en contextos comunitarios y de la evaluación autentica. Se trata, también, de la apropiación de los conocimientos escolares ha de promoverse asumiendo la situacional esencial del conocimiento humano y situacional deseable de los procesos educativos.

\section{Conclusiones}

En la Escuela Normal de Atlacomulco:

- El planeamiento didáctico se hace necesario por razones de responsabilidad moral, económica, adecuación laboral y eficiencia. El profesor necesita saber, para llevar a cabo su planeamiento, que, por qué, a quien y como enseñar.

- La racionalidad de la planificación didáctica demanda nuevas cualidades pedagógicas del docente como: planear el proceso de enseñanza-aprendizaje, seleccionar y preparar los contenidos disciplinares, ofrecer información y explicaciones comprensibles y organizadas, hacer uso de la tecnología, diseñar la metodología y organizar actividades, comunicarse con los alumnos, tutorar, 
evaluar, reflexionar sobre la enseñanza, identificarse con la institución y trabajar en equipo.

- La enseñanza reflexiva fundamenta el análisis de casos, de las experiencias pedagógicas y de la evaluación autentica; la apropiación de los conocimientos escolares ha de promoverse asumiendo la situacional esencial del conocimiento humano y situacional deseable de los procesos educativos.

- Es determinante implementar una planificación didáctica efectiva para el desarrollo de competencias profesionales propias para la formación de docentes a fin de responder a los nuevos desafíos del siglo XXI.

- Se requiere documentar y cuestionar el trabajo docente que realiza el profesor en cada sesión de clase resultado de una planificación intencionada y estratégica, como vehículo de análisis y apoyo a los estudiantes, de manera que no sólo aprendan cómo utilizar determinados procedimientos, sino cuándo y por qué pueden utilizarlos y en qué medida favorecen la resolución de las tareas implicadas en la formación profesional.

- La planificación por competencias debe ser considerada como una herramienta metodológica que transforme el paradigma formativo y de competitividad académica de las instituciones formadoras de docentes.

- Es urgente una transformación de la imagen profesional del docente normalista, migrar del esquema "prusiano" al escenario postmodernista de la docencia. Considerando en ello el tratamiento científico de la formación docente; es decir, transformar la docencia y la imagen del docente hacia una postura protagónica en la sociedad del conocimiento.

\section{Referencias bibliográficas}

Álvarez-Gayou Jurguenson, J. L. (2003). Cómo hacer investigación cualitativa. Paidós: México.

Bertely Busquets, María (2004). Conociendo nuestras escuelas. Un acercamiento a la cultura escolar. Paidós: México.

Cázares Aponte, Leslie y Cuevas de la Garza, José Fernando (2010). Planeación y evaluación basadas en competencias. Fundamentos y prácticas 
para el desarrollo de competencias docentes, desde preescolar hasta elposgrado. Trillas: México.

Díaz Barriga Arceo, Frida (2006). Enseñanza situada: vínculo entre la escuela y la vida. McGrawHill: México.

Hernández Sampieri, Roberto (2007). Metodología de la investigación. McGraw-Hill Interamericana: México.

Hidalgo Guzmán, Juan Luis (1997). Investigación educativa: Una estrategia constructivista. Castellanos: México.

Frade Rubio, Laura (2009). Desarrollo de competencias en educación: desde preescolar hasta bachillerato. Inteligencia educativa: México.

Lozano Andrade, Inés y Mercado Cruz, Eduardo (2009). Cómo investigar la práctica docente. Orientaciones para elaborar el documento recepcional. ISCEEM. México.

Perrenaud, P. (1999). Construir competencias desde la escuela. Dolmen: Santiago.

Perales Ponce, Ruth C. (2009). La significación de la práctica educativa. Paidós: México.

Pérez Serrano, Gloria (1994). Investigación cualitativa: Retos e interrogantes, técnicas y análisis de datos. La Muralla S. A: México.

Tobón Tobón, Sergio, Pimienta Prieto, Julio H. y García Fraile, Juan Antonio (2010) Secuencias didácticas: Aprendizaje y evaluación de competencias. Pearson: México.

Zabala Vidiella, Antoni (2006). La práctica educativa. Cómo enseñar. Grao: México. 



\title{
Alfabetización digital para el desarrollo de la Marca Personal de niñ @s indígenas migrantes de Monterrey, Nuevo León
}

\author{
Dra. Monserrat Arango Morales \\ M.E.S. Lucinda Sepúlveda García \\ Universidad Autónoma de Nuevo León, México
}

\section{Resumen}

No todas las personas tienen las mismas oportunidades para acceder al uso de computadoras e internet y esto los convierte en analfabetas digitales.

El objetivo de esta investigación fue describir la importancia de la adquisición de conocimientos digitales en las niñas y niños indígenas migrantes de Nuevo León, con el fin de generar mayores oportunidades de obtener en el futuro una fuente de trabajo, ya que, el desarrollo del Personal Branding en esta comunidad, permite destacar el valor de su persona en el desempeño del mercado laboral teniendo impacto tanto a nivel personal como profesional. Se utilizó la metodología cualitativa, a través de entrevistas a profundidad a personas relacionadas con comunidades indígenas. Algunos resultados fueron: Las niñas y los niños migrantes indígenas, se ven inmersos en una cultura en la que el uso de computadoras e internet son herramientas indispensables para competir por un empleo.

Hay un rezago en el acceso de niñas y niños indígenas a la tecnología debido a la carencia de equipo de cómputo en las escuelas públicas y en las instituciones al servicio de las comunidades indígenas. 
Palabras clave: alfabetización digital, analfabetas digitales, nativos digitales, migrantes digitales.

\section{Introducción}

— N México, la educación se enfrenta a uno de los grandes desafíos 1 del siglo XXI, la necesidad de emprender de modo urgente acciones de alfabetización digital con el fin de formar a las niñas y los niños en el uso y apropiación de la computadora de manera responsable, así como el uso del internet y redes sociales, con la finalidad de ofrecerles elementos básicos para la comprensión y dominio del lenguaje computacional. El paradigma sería formar una sociedad de usuarios que incorporen esta herramienta como una nueva forma de crear conocimiento.

Rodríguez, M., \& Dolores, M. (2008) argumentan que la alfabetización digital (AD) promueve el aprendizaje de lenguajes propios generados por las nuevas tecnologías ya que este proceso ha alcanzado todos los colectivos sociales cuyo uso se impone sobre las generaciones que carecen de destrezas para su utilización.

Sobre este mismo tema, Casado Ortíz (2006) señala que a través de la alfabetización digital se adquieren conocimientos necesarios para conocer y utilizar de forma adecuada las tecnologías para mantenerse informados, y de esta manera "responder críticamente a los estímulos y exigencias de un entorno informacional cada vez más complejo, con variedad y multiplicidad de fuentes" (p.52). Actualmente, los avances tecnológicos han provocado que tanto adultos como menores se encuentren en la necesidad de actualizarse de manera continua, como consecuencia de los cambios digitales. Por ello, la mayor parte de los gobiernos y sus instituciones consideran la $\mathrm{AD}$ como el instrumento capaz de difundir, comprender y utilizar información en múltiples formatos a partir de fuentes de diverso origen.

Estos cambios evidencian la necesidad de las sociedades de estar a la vanguardia, sin embargo, su introducción en los centros educativos, es todavía mínima. En este contexto, el problema básico reside en que no todas las personas tienen las mismas oportunidades para acceder al uso de computadoras e internet, y esto los convierte en analfabetas digitales, un ejemplo de ellos, son los sujetos de este estudio, niñas y 
niños indígenas que provienen de zonas rurales del país y tienen que enfrentar el problema de ser doblemente migrantes; por un lado se trasladan de sus lugares de origen a las grandes ciudades, y por el otro, migran de su sistema tradicional de educación hacia los adelantos que exige la actualización digital en la sociedad moderna o sociedad del conocimiento.

Para el proceso formativo de estos menores se expone como importante explotar el tema de la Marca Personal para determinar como la percepción que se tiene de estas comunidades indígenas puede ponerlos en desventaja laboral por los estereotipos que llevan a juzgarlos por sus conocimientos, es por ello que al alfabetizarlos digitalmente les brindan fortalezas en cuanto a conocimientos que a su vez les ayuda a romper con los prejuicios sobre la falta de capacidades tecnológicas de los niños y niñas indígenas.

El objetivo de esta investigación es describir la importancia de la adquisición de conocimientos digitales en las niñas y niños indígenas migrantes de Nuevo León, con el fin de generar mayores oportunidades de obtener en el futuro una fuente de trabajo.

Planteamiento del Problema: Las niñas y niños Indígenas que migran al área metropolitana de Monterrey, N.L. no cuentan con la herramienta tecnológica por lo que no pueden acceder al Internet.

\section{Metodología}

Robles (2011) señala muy acertadamente, que los métodos cualitativos se apoyan en la "interpretación" de la realidad social, los valores, las costumbres, las ideologías y a partir de esta información, se construyen las cosmovisiones, ya que el investigador debe asignar significado a la experiencia de cada uno de los entrevistados.

Este mismo método es definido por Orozco (1996, citado en Castro, 2010) como un "proceso de indagación de un objeto al cual el investigador accede a través de interpretaciones sucesivas, con la ayuda de instrumentos y técnicas, que le permiten involucrarse con el objeto para interpretarlo de la forma más integral posible" (p.33).

Por tanto, dentro de los estudios cualitativos existen diferentes técnicas que ayudan a aproximarse a los fenómenos sociales, una de estas 
técnicas es la entrevista a profundidad que se estructura a partir de objetivos concretos, por ello resulta complicado determinar un número mínimo o máximo de entrevistados, pues la finalidad consiste en obtener información que se obtenga de las conversaciones con los entrevistados (Robles, 2011).

Para efecto de este trabajo de investigación, se realizaron cinco entrevistas a los actores directamente relacionados con el objeto de estudio que son las niñas y los niños indígenas migrantes del sur del país (México), que llegan al Estado de Nuevo León con sus familias, en búsqueda de mejores oportunidades de educación y empleo. Se aplicó un cuestionario estructurado que consistió en preguntas abiertas a tres entrevistados, sin embargo, de acuerdo a las respuestas de los actores, se les cuestionó sobre subtemas relacionados con los menores indígenas, como la discriminación, que, aunque no se encontraba como tema principal, fue desarrollado como un subtema por los entrevistados expertos en el tema.

A través de las entrevistas a profundidad, se pretende tener una visión más clara de cuál es la situación actual en la que se encuentran los menores indígenas, en relación al acceso a las herramientas electrónicas y uso del Internet. Para lograr que la información fuera fidedigna y los datos exactos, se les solicitó a los entrevistados su autorización para llevar a cabo grabaciones en audio y video en formato digital para recolectar los datos, de esta manera se logró una transcripción detallada de todas las conversaciones. Las entrevistas a los actores se llevaron a cabo en sus centros de trabajo, que son espacios donde pueden interactuar de manera directa con los menores indígenas.

En base a los datos obtenidos, se analizó, sintetizó y evaluó la información obtenida de estas entrevistas, encontrándose puntos de coincidencia, que permitieron llegar a conclusiones descriptivas directamente relacionadas con el grupo objeto de este estudio.

\section{Desarrollo del tema Alfabetización Digital (AD)}

El uso de la tecnología constituye uno de los mayores desafíos académicos, ya que, para temas de educación y entretenimiento, no está al alcance de todas las personas. Para los menores indígenas, objeto de estudio de este trabajo de investigación, se presenta un problema más 
profundo ya que son migrantes de la tecnología, es decir, no conocen lo qué es y para qué sirve, León, P. \& Adolfo, S. (2015) mencionan que "muchos individuos de las zonas urbanas rurales, que viven en los alrededores de las grandes ciudades, son analfabetos digitales" (p. 3).

La UNESCO (2004) señala que para mejorar la calidad de la educación, los maestros pueden lograr a través de la utilización de las tecnologías de la información y comunicación proveer a sus alumnos de conocimientos necesarios que se requieren en este siglo.

Prinsky, citado en Paz Saavedra, 2012, refiere que existen dos grupos de personas relacionadas con los adelantos científicos: un primer grupo lo conforman los nativos digitales, que son los individuos que tienen un contacto permanente con los diferentes tipos de tecnología; aprendiendo habilidades muy desarrolladas en este mundo globalizado, no rebasan los 30 años; el segundo grupo está integrado por los migrantes digitales quienes han aprendido a utilizar la tecnología por motivos de estudio, trabajo o inclusive por autoaprendizaje; la mayoría de ellos son personas adultas, que han aprendido a convivir con la tecnología.

La UNESCO (2008) establece que la capacitación tecnológica didáctica de los docentes, tutores y alumnos debe ser continua, a fin de generar espacios virtuales de calidad. Estos espacios son áreas de oportunidad para los alumnos ya que necesitan contextos formativos que generen competencia por medio de la inteligencia colectiva, conocimiento compartido, la cooperación y la visión crítica entre otros. Por tanto, la competencia, solo será posible a través la alfabetización tecnológica.

A través de la $\mathrm{AD}$ se adquieren conocimientos necesarios para utilizar las tecnologías y poder atender las demandas de la sociedad actual, porque una verdadera $\mathrm{AD}$ no solo significa enseñar a utilizar la computadora y las distintas aplicaciones informáticas, sino lo más importante es desarrollar capacidades que permitan la comprensión y dominio del lenguaje codificado (Levis, 2006).

Actualmente México enfrenta el desafío de vencer la brecha tecnológica a través de la incorporación efectiva de las tecnologías de la información y comunicación (TIC) en las instituciones educativas, en este contexto, es imperante que las escuelas generen competencias que produzcan en los estudiantes una mejor formación y desarrollo 
personal y social, y que ellos puedan mejorar y transformar su entorno, así como su calidad de vida.

León, Gamboa, Espinosa y López (2013) proponen el desarrollo de habilidades digitales básicas, a través de talleres de alfabetización digital que consisten en proporcionar al alumno información elemental sobre el buen uso y cuidados que se deben tener al manejar la computadora y la Internet para convertirse en usuarios responsables en esta era denominada de la información y del conocimiento; también conocerán los peligros de la red al navegar por internet

Sánchez, I.O. (2009) señala que mediante la alfabetización tecnológica se consigue:

- Competencias para saber utilizar las tecnologías, competencias socio- comunicativas, se aprende a gestionar el conocimiento, se desarrolla el aprendizaje autónomo y el colaborativo, se aprende a tomar decisiones, aprendizaje de nuevas formas de interacción y participación social, se logra una inclusión social, se generan comunidades virtuales y redes sociales, se logra una inclusión laboral, empleabilidad, visión crítica de las tecnologías, se disminuyen las rupturas intergeneracionales, se fomenta el aprendizaje a lo largo de la vida

\section{Alfabetización Digital (AD) en Nuevo León}

Para lograr que la alfabetización tecnológica llegue a las niñas y los niños indígenas que han migrado a la ciudad de Nuevo León, es necesario el establecimiento de políticas educativas que no solo estén orientadas a dotar de computadoras y acceso al internet en las escuelas, sino que proporcionen los conocimientos necesarios para la utilización didáctica de las tecnologías, su apropiación y el acceso al conocimiento. Los docentes deben estar preparados para un adecuado uso de las TIC en el aula, de manera que les permita utilizarlas como algo más que un pizarrón o un cuaderno electrónico.

Tello (2007) apunta que las nuevas tecnologías van a ser un elemento dinamizador en las sociedades, para quienes de manera individual, o de forma colectiva logren apropiarse y desarrollar la infraestructura y las capacidades para utilizarlas, serán considerados como grupos 
privilegiados, ya que tendrán la capacidad de influir en la construcción de una sociedad del conocimiento.

\section{Zihuame Mochilla}

Zihuame Mochilla es una Institución que está dedicada al servicio de las comunidades y personas indígenas en Nuevo León, nace hace 13 años, en el 2003), trabaja con la población a través de programas y proyectos sostenibles brindando atención a mujeres, niñas, niños y adolescentes, con el objetivo de erradicar cualquier forma de exclusión social, originando la autonomía, a la igualdad de género, a la violencia hacia las mujeres y el respeto a la multiplicidad cultural. Esta institución atiende a más de 19 etnias distintas.

Este organismo tiene como visión ser líder en el impulso y amparo de los derechos humanos de las comunidades indígenas, que generen y fortalezcan destrezas que contribuyan a reducir los índices de marginación, exclusión y pobreza, sostenida en los elementos de igualdad y respeto, que origina la educación y el desarrollo de mujeres y hombres indígenas a través de programas sustentables e incurre en el medio social para erradicar la discriminación. Trabaja para combatir de forma estructural estas condiciones y por ende contribuir a mejorar su calidad de vida.

Participa con individuos responsables en la búsqueda de una transformación en las condiciones de inequidad que viven las personas indígenas, donde se trabaja en sinergia con:

- Mujeres indígenas que defienden su derecho a la igualdad; jóvenes indígenas que buscan superarse a través de la educación; personas indígenas que buscan el reconocimiento de su derecho a la nacionalidad e identidad; mujeres indígenas que forman cooperativas; personas indígenas adultas que trabajan para erradicar el analfabetismo y continuar su educación formal; personas indígenas que buscan conocer y ejercer sus derechos humanos

Algunas de las áreas de intervención son:

- Derechos humanos; Juventud indígena; Educación y desarrollo comunitario; Mujeres indígenas; Incidencia política. 


\section{Fundamentos Legales del Derecho a la Educación}

Con respecto a los derechos de las niñas, niños y adolescentes a la educación se ha emitido La Ley de Los derechos de niñas, niños y adolescentes (2014), que en el artículo 57 de la Ley General de los Derechos de Niñas, Niños y adolescentes se asume que los menores "tienen derecho a una educación de calidad que contribuya al conocimiento de sus propios derechos, basada en un enfoque de derechos humanos y de igualdad sustantiva, que garantice el respeto a su dignidad humana", así mismo en el inciso IV establece las condiciones necesarias para fortalecer la calidad educativa, así como la disposición de la infraestructura y equipamiento adecuados para el aprendizaje, y para las prácticas de enseñanza.

Del mismo modo, en el inciso VII, se marca que se debe garantizar el derecho a la educación de niñas, niños y adolescentes que enfrentan situaciones de vulnerabilidad por origen étnico o migratoria; mientras que en el inciso XX, se establecen mecanismos para fomentar el uso responsable y seguro de las tecnologías de información y comunicación.

A nivel local se establece la Ley de educación para el estado de Nuevo León (2000), que señala los objetivos sobre los cuales se impartirá la educación en el Estado. Esta ley refiere claramente en su artículo 15, que "el servicio educativo se ofrecerá en igualdad de condiciones y circunstancias a los hombres y a las mujeres sin discriminación alguna de raza, edad, religión, estado civil, ideología, grupo social, lengua y forma de vida".

\section{Resultados}

En las entrevistas a profundidad se encontraron resultados concluyentes dado que los participantes coinciden en sus opiniones.

Cornelio Martínez (2016), maestro bilingüe de educación indígena del estado de Nuevo León, señala que este Estado se ha convertido en un receptor de población indígena que ha emigrado de sus lugares de origen en busca de una mejor calidad de vida, que de acuerdo a la Comisión Nacional para el Desarrollo de los Pueblos Indígenas, en el estado de Nuevo León viven más de 80,000 indígenas, y que la 
Secretaría de Educación señala que en la entidad existen 85 escuelas a las que asisten más de 3000 menores indígenas quienes son apoyados por 23 maestros bilingües que forman parte del Departamento de Educación Indígena.

Martínez añade que la mayoría de las comunidades indígenas pierden parte de sus usos y costumbres al abandonar su lugar de origen e iniciar su lucha por encajar en una cultura completamente diferente a la suya, esto provoca que las niñas y los niños de esta población tengan que enfrentar diversos retos, como el aprendizaje de un nuevo lenguaje y el aprendizaje y uso de sistemas de cómputo y acceso a Internet. Él mismo señala que las niñas y los niños provenientes de una familia indígena se ven inmersos en una cultura en la que el uso del Internet y las redes sociales son herramientas indispensables para competir por un empleo, que no solo les permita cubrir sus necesidades básicas sino ampliar las áreas de su desarrollo personal y su integración a la sociedad.

En referencia a la importancia del uso del Internet en la socialización de los niños con los sistemas tecnológicos, Martínez menciona que con el uso de esta herramienta se busca que los alumnos en términos generales conozcan cómo viven otros pueblos, cómo son sus usos y costumbres, su manera de vestir y su forma de comer, a fin de lograr más que una integración, una inclusión, porque tiene la teoría de que la violencia sobre los grupos minoritarios puede ser generada por la falta de información, por la falta de conocimientos de cómo se desarrollan estos grupos distintos a las demás comunidades.

Los niños indígenas no tienen acceso a las computadoras ni al Internet en sus lugares de origen, sin embargo, dice Martínez, en las ciudades donde migran existe una estructura tecnológica mayor, y eso les permite tener una mayor apertura al conocimiento y de esta manera tener una mejor oportunidad en el futuro laboral. Para este grupo minoritario, en un futuro próximo, las nuevas tecnologías ayudarán en la realización de tareas e investigaciones ya que es una herramienta de trabajo muy necesaria para lograr una mejor educación. Es a través de esta herramienta que los menores indígenas tienen la oportunidad de conocer sus raíces, su cultura alimentaria, su ropa, edificios etc. Costumbres que se pierden cuando llegan a las grandes ciudades y pretenden olvidarse de sus antecedentes para ubicarse dentro de la 
nueva cultura, ya que en las grandes ciudades se ha perdido el interés por descubrir nuevas aventuras respecto a su lugar de origen, y es a través del internet que puede rescatarse la información.

Los grupos de migrantes indígenas se desplazan hacia sociedades más grandes aspirando a una mejor forma de vida para ellos y una oportunidad educativa para sus hijos, logrando con ello convertirlos en migrantes digitales, en búsqueda de adelantos de la sociedad actual. En este sentido, la maestra bilingüe responsable de educación indígena del Estado de Nuevo León, María Irene Cárdenas Castro (2016) indica que constitucionalmente existe la protección para pueblos indígenas en cuanto a sus usos y costumbres, y señala que los alumnos deben recibir una educación de acuerdo al grupo étnico al que pertenecen. Para cumplir con esto, Nuevo León ha contratado maestros de los estados de donde provienen esos alumnos, que hablan diferentes lenguas prioritarias entre las que se han identificado el náhuatl, zapoteco, mixteco, huasteco y ñañú.

Agrega Cárdenas que en la Asociación Zihuame Mochilla se han detectado 21 lenguas diferentes, siendo la mayoritaria el náhuatl, que comprende un 40\% de la población indígena; otras lenguas son: zapoteco, mixteco, ñañú, tene o huasteco, mazahua, rarámuri y tzotzil. Se cuenta con 23 maestros, cada uno domina su lengua, sin embargo, para traducir algunas palabras que desconocen, invitan a los padres de familia para que expliquen algo de su lenguaje. Agrega que las familias que más migran son las de Veracruz e Hidalgo, cuya lengua es el náhuatl.

En referencia a lo anterior, Carmen Farías (2016), directora de Zihuame Mochilla señala que hay una gran carencia de acceso a las computadoras y al internet, sin embargo, ella misma apunta que en los Centros de Desarrollo Comunitario que opera la Secretaría de Desarrollo Social, si hay acceso tanto al internet como al equipo de cómputo. Para ellos como institución, es muy importante que las niñas y los niños desarrollen habilidades para el uso de computadoras y acceso a internet y redes sociales, porque consideran que esa brecha puede crear un analfabetismo digital que podría ser comparable a lo que el fue el analfabetismo en los años cincuenta.

La responsable de Zihuame agrega importante información sobre la 
herramienta Internet, al plantear que los planteles educativos del sector público que cuentan con equipo computacional lo obtienen a través de donativos o del esfuerzo de las sociedades de padres de familia y que ante esta situación, la organización trabaja no solo para lograr la inclusión de estos menores sino también para facilitarles el acceso a estas herramientas.

En cuanto al trabajo con niños, la institución está trabajando más con niños náhuatl y otomíes cuya edad es de 5 años en adelante, brindándoles apoyo educativo. Las localidades donde más trabajo realizan es en Juárez N. L. donde existe un Centro Rotario de aprendizaje y la biblioteca María Pascual, ahí reciben apoyo de diferentes grupos rotarios de la entidad que pertenecen al distrito 4130 que abarca Nuevo León y Tamaulipas; ellos donaron en 2013 equipos de cómputo que está al servicio de la comunidad, y también ofrecen apoyo para realizar tareas de educación primaria, secundaria y preparatoria abierta o en línea.

También menciona que los niños que radican en las colonias de los alrededores de los centros comunitarios también hacen uso de las computadoras, no solo los indígenas, porque lo que se busca con estas acciones es fomentar la inclusión y la no discriminación, por eso se da servicio a toda la comunidad. Datos que demuestran la importancia de generar este tipo de instituciones que apoyan a la comunidad, es que se reciben por semana entre 30 y 40 niños para hacer uso de esta herramienta, así como el préstamo de libros, para fomentar la lectura. Estos centros culturales creados específicamente para menores indígenas, pero que recibe a todos los menores ha creado círculos de lectura, para de esta manera adquieran buenos hábitos desde temprana edad.

Señala que se trabaja en otros dos centros de la comunidad donde hay niños de familias otomíes en la colonia Lomas Modelo, donde hay un salón comunitario. Además, se busca establecer otro centro comunitario en ampliación Colinas de Topo Chico y Escobedo; sin embargo, no se cuenta con equipos de cómputo para dar inicio a las labores comunitarias.

Carmen Farías finaliza diciendo que en los centros de desarrollo comunitario que opera la Secretaría de Desarrollo Social si hay equipo 
de cómputo, sin embargo, hay un rezago en el acceso de niños a internet en los centros comunitarios de aprendizaje.

Uno de los datos más importantes que se extrajo de la entrevista a Carmen Farías fue que se generaron cursos de Internet, al que se inscribieron una gran cantidad de niños, detectándose que los menores no conocían el acceso a las computadoras.

\section{Conclusiones}

Las dos leyes señaladas previamente, no establecen en su redacción, imperativos necesarios en la actualización de uso de las nuevas tecnologías, ni se señala la apropiación de programas necesarios para que los estudiantes de manera general y los indígenas de manera particular, puedan hacer uso de las herramientas y navegar en las redes con seguridad. Solo se señala la disposición respecto a la infraestructura y equipamiento adecuados para el aprendizaje, sin especificar claramente a que se refiere.

De acuerdo a lo anterior, se puede presuponer que las leyes no se encuentran actualizadas en sus redacciones, o que las nuevas tecnologías aún no son un referente principal en la aplicación del conocimiento, sin tomar en cuenta que en las escuelas se preparan a los alumnos para trabajar en un mercado, que actualmente se desarrolla de manera directa con las nuevas tecnologías. Alfabetizarlos digitalmente les brinda herramientas para fomentar y fortalecer su cultura, su identidad, sus valores y su sello personal ante otras comunidades y público.

Aunque las instituciones dedicadas al servicio de las comunidades indígenas están realizando grandes esfuerzos por alfabetizar digitalmente a las niñas y niños indígenas, no logran totalmente su cometido, pues son muchos de estas comunidades con esta necesidad y pocos los maestros capacitados para este fin.

Las niñas y los niños indígenas que provienen de zonas rurales del país tienen que enfrentar el problema de ser doblemente migrantes; por un lado se trasladan de sus lugares de origen a las grandes ciudades, y por el otro, migran de su sistema tradicional de educación hacia los adelantos que exige la actualización digital en la sociedad moderna o 
sociedad del conocimiento.

\section{Referencias bibliográficas}

Casado Ortiz, R. (2006). Alfabetización tecnológica. ¿Qué es y cómo debemos entenderla?. En Casado Ortiz, R. (coord.) Claves de la Alfabetización digital. Barcelona: Editorial Ariel. Fundación telefónica.

Castro M.E. (2010). El estudio de casos como metodología de investigación y su importancia en la dirección y administración de empresas. Recuperado de https://dialnet.unirioja.es/descarga/articulo/3693387.pdf

León, P., \& Adolfo, S. (2015). Estudio comunicacional del alto indice de analfabetismo digital en la población adulta en la comuna Subida Alta, perteneciente a la parroquia Puná del cantón Guayaquil, elaboración y aplicación de talleres digitales y tecnológicos.

León, V. C., Gamboa, H. A., Espinosa, E. G., \& López, A. S. (2013). Derechos humanos, Alfabetización digital. Promoción de la lectura y Liderazgo en el aula para niños de Chiapas, México. Atenas, 3(19). Levis, Diego, (2006) Alfabetos y saberes: la alfabetización digital. Comunicar [en línea] 2006, (marzo): [Fecha de consulta: 27 de septiembre de 2016] Disponible en: <http://www.redalyc.org/articulo.oa?id=15802612> ISSN 1134-3478

Murillo, Javier (S.F). Métodos de la investigación educativa. Recuperado de https://www.uam.es/personal_pdi/stmaria/jmurillo/Investigac ionEE/Presentaciones/Curso_10/EstCasos_Trabajo.pdf

Paz Saavedra, L. E. (2012). Alfabetización digital en el adulto maduro, una estrategia para la inclusión social. Universidad de Nacional de Colombia, 2.

Robles, Bernardo(2011). La entrevista en profundidad: una técnica útil dentro del campo antropofísico. Cuicuilco, 18(52), 39-49. Recuperado en 28 de agosto de 2016, de http:/ / www.scielo.org.mx/scielo.php?script=sci_arttext\&pid= S0185-16592011000300004\&lng=es\&tlng=es.

Rodríguez, M., \& Dolores, M. (2008). Alfabetización digital: el pleno dominio del lápiz y el ratón. Comunicar. Revista Científica de Comunicación y Educación, No. 30, v. XV, 2008, pp. 137-146. 
Sánchez, I. O. (2009). La alfabetización tecnológica. Education in the knowledge society (EKS), 10(2), 11-24.

30, v. XV, 2008, Revista Científica de Comunicación y Educación; ISSN: 113páginas Tello, E. (2007). Las tecnologías de la información y comunicaciones (TIC) y la brecha digital: su impacto en la sociedad de México. RUSC. Universities and Knowledge Society Journal, 4(2), 5.

UNESCO (2004): Las tecnologías de la información y la comunicación en la formación docente. París, Informe UNESCO.

UNESCO (2008). Estándares de competencias en TIC para docentes. http://portal.unesco.org/es/ev.phpURL_ID $=41553 \& U R L \_D O=D$ O_TOPIC\&URL_SECTION=201.html http://cst.unescoci.org/sites/projects/cst/default.aspx. (Consultado 28/09/2016) 


\title{
Estudiantes de nivel superior y el impacto de las redes sociales en su personal branding
}

\author{
Dra. Janet García González \\ Dra. María Mirna Granat Ramos \\ M.E.S. Lucinda Sepúlveda García \\ Universidad Autónoma de Nuevo León, México
}

\section{Resumen}

Las nuevas tecnologías de la información intervienen directamente en las relaciones interpersonales, así como la producción del sentido, identificación cultural, la ética y toda la esfera de la vida humana. Esta investigación examina y describe la interacción de los estudiantes de nivel superior con las redes sociales, así como los efectos causados por dichas plataformas, generando un panorama general del contexto social actual y sus apropiaciones en su personal branding. Estudio descriptivo trasversal, con metodología cuantitativa. Resultados, un 13\% afirma tener una sola red social, el restante $87 \%$ cuenta con dos o más y de estos el $29 \%$ dedica 4 o más horas a dichas redes; para la mayoría de los jóvenes resultan conocidos los términos anglosajones y relacionan las nuevas tecnologías con la palabra "Facebook", limitándose el gran abanico de posibilidades que ofrecen las nuevas tecnologías. Además, mediante la satisfacción de necesidades que retribuyen a los usuarios, 
39 de los 96 encuestados indican un estímulo positivo en la autoestima y la satisfacción de parte de las necesidades afectivas.

Palabras clave: interaccionismo simbólico, usos y gratificaciones, redes sociales.

\section{Introducción}

T AS redes sociales han tenido un desarrollo constante desde su creación, rompiendo las barreras geográficas y los paradigmas de comunicación existentes, los cuales se han ido remplazando por nuevos sistemas virtuales que permiten la interacción casi de forma instantánea (Quintanilla, 2010; Quiroga, 2011).

Ante este nuevo contexto, la sociedad ha evolucionado de manera paralela, modificando sus hábitos de conducta, el uso de su tiempo y la satisfacción de sus necesidades por medio de las redes sociales.

A las nuevas generaciones nacidas en la era digital se les ha denominado nativos digitales frente a los que han nacido con anterioridad llamados inmigrantes digitales; los primeros han nacido y se han formado utilizando la particular lengua digital de juegos por ordenador, video e internet, mientras que los segundos, al igual que los migrantes, aprenden a adaptarse al entorno y al ambiente, pero conservando siempre una cierta conexión (la cual denomino acento) con el pasado. De esta diferencia generacional surge un problema, una brecha digital, donde convergen tanto nativos e inmigrantes digitales. Esta brecha produce una ruptura entre generaciones haciendo cada vez más difícil la interacción social (Tello, 2008).

Objetivo. Describir los efectos de las redes sociales en los estudiantes universitarios

Objetivos específicos:

- Analizar el acceso de los jóvenes universitarios a las nuevas tecnologías.

- Examinar los efectos de redes sociales en los estudiantes de nivel superior.

- Contrastar los cambios que se han producido en los estilos de vida debido a las redes sociales. 
- Reconocer el sentido simbólico que el usuario le otorga a las redes sociales.

- Determinar el uso y las gratificaciones de las redes sociales en los estudiantes de educación superior.

Hoy en día, las redes sociales han cobrado gran relevancia a nivel mundial revolucionando la forma de comunicarnos y expresarnos en la red digital. Estas nuevas plataformas favorecen la comunicación y las relaciones interpersonales.

\section{Metodología}

El presente estudio es de tipo descriptivo-transversal (agostodiciembre de 2014). Se busca examinar y describir la interacción de los estudiantes de nivel superior con las redes sociales, haciendo énfasis en el uso y la satisfacción de necesidades, así como en el sentido simbólico que se atañe a dichas redes.

El método cuantitativo responde a la necesidad de establecer patrones de comportamiento de la población desde un punto de vista objetivo para representar el ambiente social que se desea estudiar. Se utiliza la encuesta como instrumento y el cuestionario como técnica de recolección de datos porque facilita la recopilación y no requiere de la orientación de un encuestador. Análisis estadístico descriptivo a partir de SPPS.

Universo la población: Estudiantes de la Universidad Autónoma de Nuevo León, que consta de 174 mil estudiantes de nivel superior, inscritos en alguna de las 26 facultades de la Universidad Autónoma de Nuevo León, y tiene presencia en todo el estado. Destacan los campus Ciudad Universitaria, Ciencias de la Salud, Mederos, Marín, Ciencias Agropecuarias, Sabinas Hidalgo y Linares. En todos suman 26 facultades.

La muestra es de tipo aleatorio estratificado, para garantizar la representatividad de los estudiantes de nivel superior y las diferentes áreas de conocimiento. Con base en el tamaño del universo de 96 personas y con un margen de error de $10 \%$ y un nivel de confianza del $90 \%$. 
Se clasificó las facultades por área de conocimiento y se tomó una parte representativa de cada una:

Humanidades: Facultad de Ciencias de la Comunicación, Facultad de Artes Visuales, Facultad de Ciencias Políticas.

Económico-Administrativa: Facultad de Economía, Facultad de Contaduría Pública y Administración.

Ciencias de la Salud: Facultad de Nutrición, Facultad de Psicología

Exactas e Ingenierías: Facultad de Ingeniería Civil, Facultad de Ciencias Físico-Matemáticas.

Ciencias Biológicas y Agropecuarias: Facultad de Medicina Veterinaria y Zootecnia.

Una vez determinados los sectores, se dividirá la muestra entre el número de facultades, dando como resultado 9.6 encuestas por facultad.

Criterios de inclusión: Individuos de género masculino/femenino, en un rango de edad de 18 a 24 años, inscritos en alguna de las facultades de la Universidad Autónoma de Nuevo León y jóvenes con una cuenta en las redes sociales.

Criterios de exclusión: No pertenecer a la Universidad Autónoma de Nuevo León.

\section{Desarrollo del tema}

\section{Las redes sociales en la educación}

A pesar de las oportunidades que ofrecen estas redes para la evolución de la comunicación en diferentes ámbitos, poco se han aprovechado. Además, el uso que le dan los jóvenes está encaminado hacia el entretenimiento. Sin embargo, estudios revelan que existe una actitud favorable por parte de los jóvenes para la utilización de las redes sociales en la educación. Los estudiantes han tomado la iniciativa utilizándolas para la resolución de dudas, trabajos en equipo y movimientos estudiantiles, pero no se ha explotado todo su potencial (Aguilar, 2012; De Haro, 2010; Roldán-Cataluña, 2014). 
Según Torre (2009) menciona que "no es una pérdida de tiempo para los jóvenes navegar por internet o el uso de redes sociales, ya que están asimilando competencias tecnológicas y comunicativas muy necesarias para el mundo contemporáneo". Según las investigaciones, las redes sociales favorecen la consulta de innumerables fuentes de información, la retroalimentación, la capacidad de compartir información a una escala global, el autoaprendizaje, el trabajo en equipo y el contacto con expertos de cualquier parte del mundo (Sabater, 2011, Juárez, 2013, Vázquez, 2013 (Páez, 2014).

De acuerdo al interaccionismo simbólico, las personas son capaces de modificar o alterar los significados y los símbolos que usan en la acción y la interacción sobre la base de su interpretación de la situación (Roca, 2010). Así, la manera en que las personas se comunican evoluciona, cambiando la forma de interactuar y con ello el pensamiento, formando nuevas representaciones sociales de la realidad, contribuyendo a la integración de su personal branding. Estas construcciones se dan tanto de manera individual como social, en tanto que el individuo no construye su representación, o su marca personal de manera aislada, sino a partir de la relación con los demás miembros de su cultura.

Mead plantea al self como la capacidad de los seres humanos de percibirse a sí mismos y lo considera desde dos perspectivas, como sujeto: la reacción de un organismo en relación a los actos de otros. Y como objeto: Los actos de los otros adoptados por uno mismo. Con ello se aprecia una relación simbiótica del individuo con la sociedad, los cuales no pueden manejarse de forma aislada; principalmente determinando sus características, o la formación de su personal branding.

Por otra parte, el uso de las redes sociales será estudiado a partir de la teoría de usos y gratificaciones, la cual tiene sus bases en la comunicación de masas que nos ayuda a entender las funciones del medio para el individuo y para la sociedad.

Las redes sociales están respondiendo a la necesidad del ser humano para comunicarse y socializarse (Sabater, 2011). El éxito desmesurado de las redes sociales ha convertido a Facebook en una red compuesta por más de 500 millones de usuarios. Se dice que si Facebook fuera un país sería el tercer país más poblado del mundo. Está traducido a 70 
idiomas, tiene más de 500.000 aplicaciones diferentes y se estiman que ha subido más de 5 mil millones de fotos de usuarios.

\section{Resultados}

\section{Perfil de los estudiantes de nivel superior}

El perfil de los jóvenes fue medido con base a factores sociales, económicos y demográficos que en conjunto construyen una imagen detallada de este sector de la sociedad. De los 96 estudiantes encuestados el 54\% fueron mujeres y el $46 \%$ varones. El promedio de la población es de 20 años de edad; asimismo, el 80.2\% de la población encuestada se concentra en las edades de 18 a 21 años, mientras que el $17.7 \%$ corresponde a edades de 24,23 y 22 años y solo el $2 \%$ sale de estos rangos.

De acuerdo a los valores establecidos por AMAI (Asociación Mexicana de Agencias de Investigación de Mercados y Opinión Pública), las clases sociales localizadas son las siguientes: De la población encuestada, el $46.4 \%$ de la población pertenece a la clase $C+$ que representa al segundo estrato con el más alto nivel de vida e ingresos del país; el $22.2 \%$ a clase C, llamada media aunque en realidad se encuentra arriba del promedio poblacional de bienestar; el $21.2 \%$ a la clase $A B$, estrato con más alto nivel de vida en ingresos del país y el $7.7 \%$ lo ocupa la clase $\mathrm{D}+$ que representa a la clase que tiene cubierta la mínima infraestructura sanitaria de su hogar.

\section{Acceso a las nuevas tecnologías}

De la población que conforman la muestra, diez no cuentan con un teléfono inteligente (en su mayoría de la clase $\mathrm{C}$ y D+), 55 cuentan con uno, 11 con dos, 14 con tres y solo seis de ellos tiene cuatro o más dispositivos de este tipo (pertenecientes a las clases $\mathrm{AB}$ y $\mathrm{C}+$ ). En cuanto a la posesión de otros aparatos diferentes al smartphone o teléfono inteligente (Ipod, Ipad, Tablet, Tv, Sistema de sonido) con sistema de conexión a internet, los resultados arrojaron que 22 de los encuestados no tienen otro dispositivo desde donde conectarse a internet, 57 cuentan con al menos uno, 11 con dos, 4 con tres y 2 con cuatro o más dispositivos. Y el $91 \%$ de los estudiantes de nivel superior 
tiene servicio de internet en su casa, 62\% de los encuestados cuentan con un plan telefónico, mientras que $34 \%$ de ellos no. De acuerdo a las respuestas de los jóvenes, el dispositivo desde el cual se conectan más frecuentemente es el celular (69), seguido por la PC de escritorio (14), la laptop (11), tablet y por otros mecanismos de conexión (1). Los lugares desde donde se conectan comúnmente los estudiantes son en primer lugar, la casa, en segundo la escuela y en tercero las bibliotecas o los sitios de renta de computadoras.

\section{Nuevas tecnologías de la información: redes sociales}

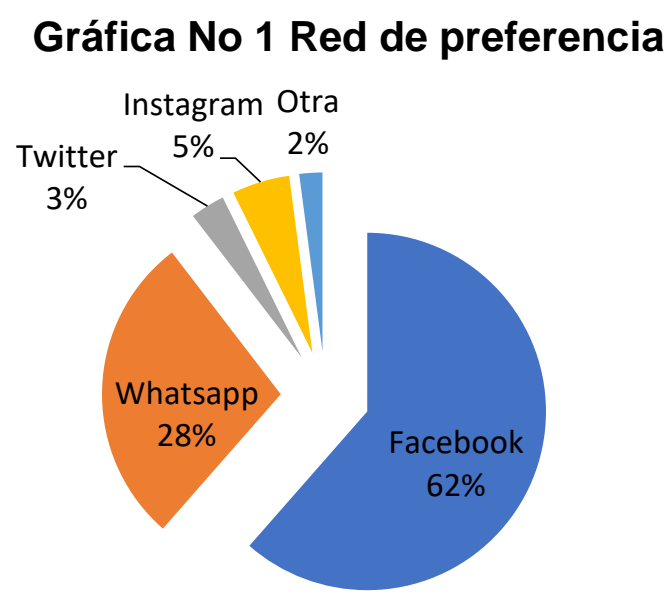

En este apartado se analizó mediante el número de redes a las que un individuo pertenece, la red de preferencia y los motivos para preferirla sobre las demás. En pertenencia, el 34\% de los jóvenes universitarios pertenece a dos redes sociales, el $32 \%$ a tres, el $21 \%$ a cuatro y solo el $13 \%$ está afiliado a una sola red. El 62\% de los estudiantes prefieren Facebook sobre las demás redes, el 28\% se inclina por Whatsapp, al $5 \%$ le gusta Instagram, al 3\% Twitter y un 2\% dijo preferir una red social diferente a las anteriores.

Las cualidades por las cuales los usuarios prefieren a Facebook son: $58 \%$ porque ahí están la mayoría de sus amigos; $25 \%$ porque ofrece un abanico de posibilidades y herramientas para la comunicación; $12 \%$ porque allí se encuentra la información social de sus conocidos; $3 \%$ por ser la primera red social de la que formaron parte; $2 \%$ por la facilidad de manejo. 
Algunos usuarios prefieren Whatsapp: 52\% por considerarla más personal a la hora de interactuar con otros usuarios; $40 \%$ por su rapidez para mandar mensajes; $4 \%$ por su facilidad de uso; $4 \%$ por su practicidad.

Quienes prefirieron Instagram atribuyeron a lo siguiente: $60 \%$ por las fotos; $20 \%$ debido a intereses laborales (Fotógrafos); $20 \%$ por la caracteristica de seguir la actividad de las personas agregadas.

Twitter es la red de menor preferencia por los universitarios. Un 67\% basó su decisión de elegirla por la rápida transmisión de la información noticiosa y un $33 \%$ por las funciones que esta plataforma ofrece al usuario.

\section{El uso de las redes sociales}

\section{Gráfica No 2. Usos frecuentes de las redes sociales}

\begin{tabular}{|c|c|c|c|c|c|c|c|c|c|c|}
\hline \multirow{4}{*}{ 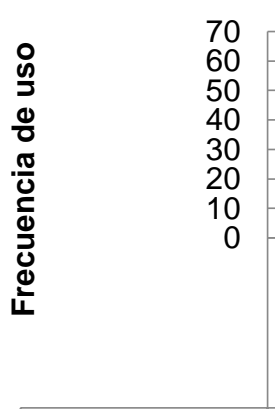 } & \multicolumn{10}{|c|}{ 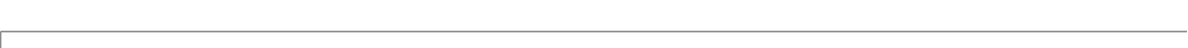 } \\
\hline & & & & & & & & & & \\
\hline & & & & & & & & & & \\
\hline & $\begin{array}{c}\text { Chatear } \\
\text { con } \\
\text { amigos }\end{array}$ & $\begin{array}{c}\text { Conocer } \\
\text { nuevas } \\
\text { persona } \\
\text { s }\end{array}$ & $\begin{array}{c}\text { Encontr } \\
\text { ar } \\
\text { pareja }\end{array}$ & $\begin{array}{l}\text { Medio } \\
\text { de } \\
\text { entreten } \\
\text { imiento }\end{array}$ & $\begin{array}{c}\text { Seguimi } \\
\text { ento de } \\
\text { persona } \\
\text { jes } \\
\text { públicos }\end{array}$ & $\begin{array}{c}\text { Compra } \\
\text { o venta } \\
\text { de } \\
\text { product } \\
\text { os }\end{array}$ & $\begin{array}{c}\text { Tareas } \\
0 \\
\text { trabajos }\end{array}$ & $\begin{array}{l}\text { Informar } \\
\text { se }\end{array}$ & $\begin{array}{l}\text { Particip } \\
\text { ación en } \\
\text { eventos } \\
\text { sociales }\end{array}$ & $\begin{array}{c}\text { Ver } \\
\text { publicac } \\
\text { iones de } \\
\text { amigos }\end{array}$ \\
\hline - Siempre & 40 & 7 & 3 & 36 & 10 & 7 & 34 & 19 & 11 & 23 \\
\hline Frecuentemente & 43 & 12 & 2 & 30 & 16 & 12 & 38 & 35 & 13 & 23 \\
\hline Ocasionalmente & 10 & 24 & 10 & 17 & 26 & 15 & 19 & 21 & 27 & 27 \\
\hline Rara vez & 2 & 45 & 20 & 12 & 20 & 23 & 3 & 18 & 30 & 19 \\
\hline Nunca & 1 & 8 & 61 & 1 & 24 & 39 & 2 & 3 & 15 & 4 \\
\hline
\end{tabular}

Ésta se llevó a cabo mediante el análisis de la variable tiempo y finalidad, entendiendo la primera como la cantidad de horas, minutos, segundos, etc. que le son dedicados a dichas redes y la segunda como los fines para los que son consumidas.

El número de horas que los estudiantes de nivel superior le dedican diariamente: el 29\% dispone 4 o más horas, el 28\% 3, el 23\% una hora y el $20 \%$ dos horas al día, concluyendo que el $77 \%$ de los jóvenes gasta 2 o más horas en las redes sociales.

Los jóvenes universitarios utilizan frecuentemente las redes sociales para platicar con sus amigos, pero rara vez las ocupan para crear nuevos 
vínculos de amistad y nunca con la intención de formar una relación amorosa.

Las redes sociales representan principalmente un medio de entretenimiento, utilizado en ocasiones para seguir a personajes públicos con los que se puede interactuar de forma bidireccional, ejemplo de ello es Twitter. Sin embargo, esta red social no es la preferida por los jóvenes universitarios.

El comercio cibernético tampoco es prioridad para los estudiantes, siendo muy pocas las personas que afirman utilizar las redes sociales con este fin. Las tareas escolares, en cambio, son un fin frecuente para el uso de las redes, permitiendo la colaboración conjunta, los equipos de trabajo y la ruptura las barreras geográficas y de falta de tiempo.

La adquisición de información noticiosa a través del canal de las redes sociales es frecuente, pero a pesar de ello la participación en eventos sociales se da en raras ocasiones.

Efectos de las redes sociales en la conducta de los jóvenes universitarios

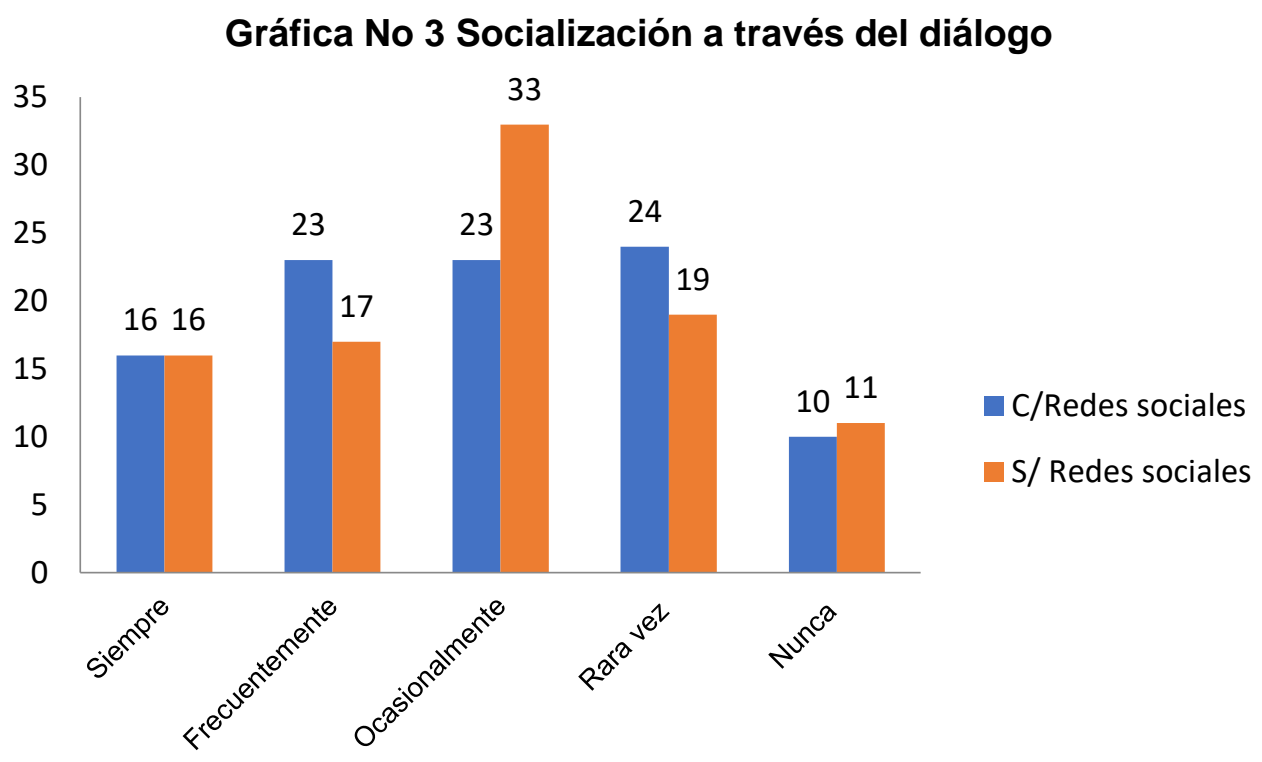

Se evaluó desde los aspectos adaptativos y desadaptativos de la conducta. Entre ellos se encuentra la capacidad de socialización, el desempeño escolar, la relación con los padres, la autoestima, la atención y las situaciones depresivas. 
Para un mejor análisis de los cambios de conducta a causa de las redes sociales se hace un contraste con una misma pregunta respondida desde diferentes contextos (dentro de las redes sociales y fuera de ellas). Se encontró que, a los estudiantes de nivel superior les cuesta mantener un diálogo cara a cara con personas que no están dentro de su círculo social. Las redes sociales facilitan el entablar una conversación con otra persona, a pesar de que le sea desconocida; debido probablemente a que la marca personal la manejan públicamente a partir de un perfil favorable.

A los universitarios se les dificulta realizar actividades académicas sin el apoyo de un ordenador. Las nuevas tecnologías de la información facilitan la realización de las actividades escolares, considerando que la interacción entre los estudiantes se ve favorecida una vez que cuentan con herramientas digitales similares, que a la vez forman parte de su marca personal.

Gráfica No 4 Afección de las TIC en los hábitos de estudio

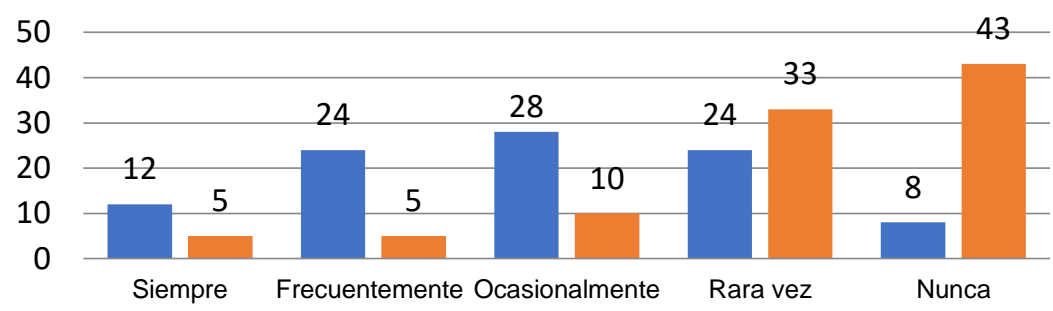

$\square$ S/Resdes sociales $\quad \square$ C/ Redes sociales

De las cifras obtenidas se puede inferir que los jóvenes universitarios mantienen una comunicación de manera personal con sus padres por al menos 30 minutos al día. Sin embargo, la comunicación de manera virtual con los padres se da en menor medida (solo 24 de ellos dieron una respuesta positiva, 17 afirmaron conversar con sus padres ocasionalmente y 55 afirmaron platicar con ellos rara vez o nunca). Observamos que la marca personal entre los padres y los hijos, varía a partir de las actividades que desempeñan diariamente.

Los estudiantes de nivel superior prestan atención fuera de las redes sociales, aún cuando realizan alguna otra actividad. Sin embargo, 
cuando se encuentran conectados, la mayoría (44 afirman que siempre o frecuentemente frente a 28 que dicen que rara vez o nunca lo hacen) asegura que espera a terminar de hacer lo que está haciendo para responder al llamado, con lo cual se puede concluir que las redes sociales disminuyen la atención de los jóvenes.

Facebook es la red que los jóvenes universitarios tienen más presente, y se comprueba nuevamente su preferencia. Ellos están conscientes de que las redes sociales son un medio de comunicación y no solo una plataforma unidireccional, incluso, una manera de fortalecer su marca personal. Relacionan las redes sociales con la palabra amigos, esto se debe posiblemente a que Facebook es la única red que maneja el término amigo para denominar a los usuarios añadidos a un perfil. El ocio es uno de los principales usos que le dan a las redes sociales. Aunque un $70 \%$ podría pasar una semana sin las redes sociales mientras que un $30 \%$ asegura no poder hacerlo.

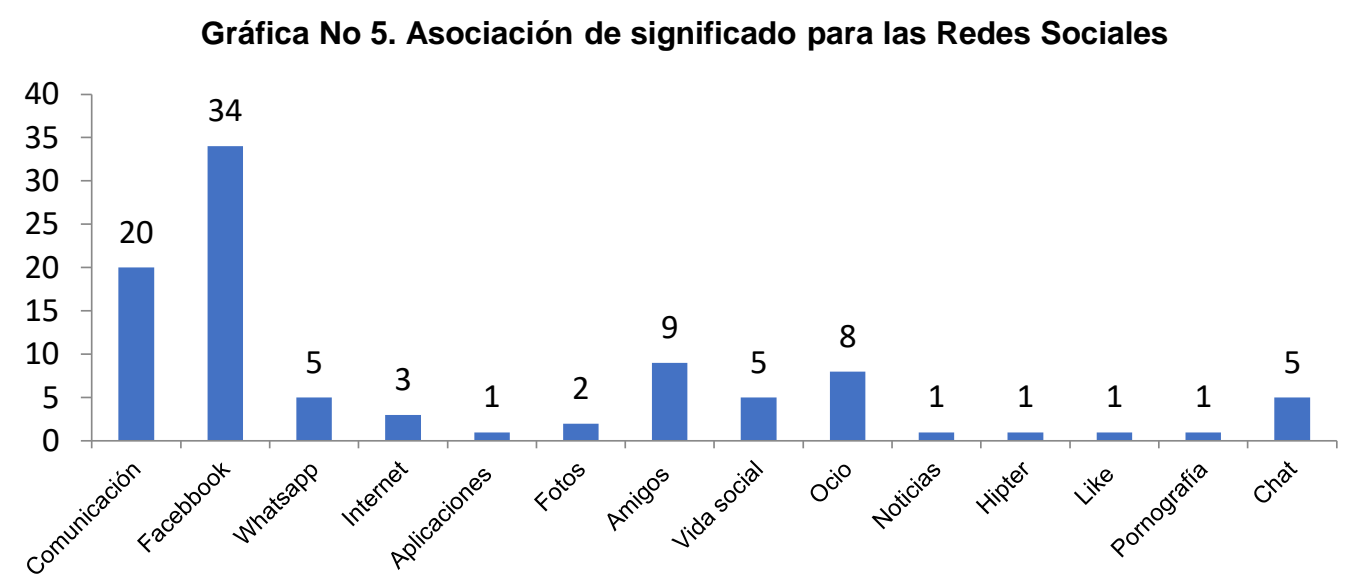

El entretenimiento sigue siendo el fin principal de estas redes, sin embargo, cuando se trata de buscar un motivo para alejarse de ellas, los jóvenes que exponen no poder hacerlo argumentan que es debido a sus actividades escolares antes que su entretenimiento, esto se debe, quizá, a que dejar de lado los trabajos académicos implica consecuencias en su vida estudiantil.

Las redes sociales son utilizadas por los usuarios como un medio de comunicación, como una herramienta para socializar y como forma de entretenimiento, lo que contribuye al crecimiento de su marca personal. Estas redes cambiaron las relaciones humanas y los 
paradigmas de comunicación existentes, trasladando la conversación a una plataforma virtual. (Véase Tabla 2 en anexos).

Los jóvenes son vulnerables a situaciones en las redes sociales que pudieran disminuir su autoestima, pero son influidos satisfaciendo la necesidad afectiva de éstos. Las redes sociales influyen positivamente en la autoestima, asimismo esta confianza les permite una mayor socialización con otras personas, consiguiendo mayor éxito en las relaciones sociales y profesionales.

\section{Gráfica No 6 Necesidades Integrativas}

(Autoestima y confianza)

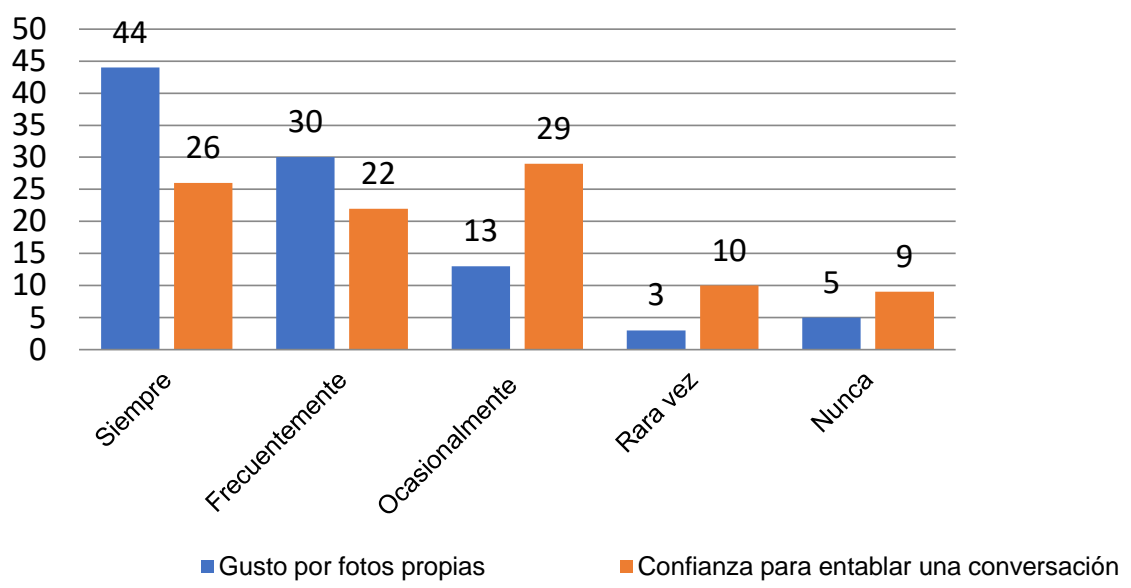

Las cifras indican que un 7\% de los jóvenes se mantiene activo en los grupos de Facebook, un 17\% lo hace frecuentemente, el 30\% lo hace de manera ocasional, otro $30 \%$ lo hace rara vez y un 16\% nunca participa en las redes sociales de manera grupal, con lo que se puede concluir que los estudiantes de nivel superior prefieren una comunicación uno a uno que una construcción colectiva.

Por otro lado, las cifras indican que los juegos de Facebook no satisfacen a los usuarios, ya que solo 15 de los 96 encuestados afirman que éstos son divertidos. De lo anterior se puede concluir que las redes sociales no satisfacen las necesidades escapistas de los jóvenes, ya que solo un pequeño porcentaje ve en ellas una distracción a sus contrariedades y un alivio de la tensión por medio de los juegos. 


\section{Conclusiones}

Uno de los principales problemas globales es la llamada brecha tecnológica, la cual aleja a gran parte de la población mundial de los beneficios que los avances tecnológicos traen consigo.

El acceso desigual a estas nuevas tecnologías conlleva múltiples problemas desde la educación hasta la salud, además este es la clave para la protección de múltiples derechos individuales y colectivos que caracterizan a un sistema democrático.

Mediante esta investigación se determinó que el acceso de estudiantes de nivel superior a las nuevas tecnologías está determinado por el nivel socioeconómico al que pertenecen.

En la medida que ese nivel socioeconómico se los permite, el personal branding de cada uno de los consumidores de las redes sociales se ve afectado favorable o desfavorablemente.

Algunos de los problemas que conllevan las redes sociales son la dispersión de la atención y la ralentización de las conversaciones por su característica multitarea, condiciones que cambian el estilo de vida de los estudiantes de nivel superior.

$\mathrm{El}$ individualismo es otro factor que afecta a los cibernautas ya que tiende a producir un aislamiento de la vida real, compensado por las realidades virtuales. Por ello, es importante determinar el sentido que los jóvenes le dan a las redes sociales, siendo diferentes, originales, resaltando por su marca personal.

La investigación reconoció que la mayoría de los jóvenes usan símbolos cada vez más globales, que no se limitan a un idioma o sitio geográfico, hoy en día vivimos la generalización de los sistemas de comunicación.

Asimismo, se determinó que las redes sociales forman parte de la vida cotidiana de los estudiantes de nivel superior, los cuales dedican, en su mayoría, más de dos horas a dichas plataformas con el fin de entretenerse y mantenerse en contacto con su grupo de amigos. 


\section{Referencias bibliográficas}

Aguilar, M. G., Campos, S. R., \& Batlle, P. F. (2012). El uso académico de las redes sociales en universitarios. Comunicar, 19(38), 131-138.

Castells, M. Hacia el estado red. Globalización económica e instituciones políticas en la era de la información. Sociedad e Reforma do Estado. Seminario Internacional. Sao Paulo. 1998. Escuela Nacional de Administración Pública.

Castillo, O. E. (1998): Las nuevas tecnologías de la información en la comunicación: ¿Para bien o para mal? Revista latina de comunicación social, 12.

De Haro, J. J. (2010). Redes sociales para la educación. Ponencia Uso educativo de las redes sociales.

Del Carmen G. M., \& Del Hoyo, M. (2013). Redes sociales, un medio para la movilización juvenil. Zer-Revista de Estudios de Comunicación, 18 (34).

Tello L. E. (2008). Las tecnologías de la información y comunicaciones (TIC) y la brecha digital: su impacto en la sociedad de México. En Las tecnologías de la información y comunicaciones (TIC) y la brecha digital: su impacto en la sociedad de México (8). México: Revista de Universidad y Sociedad del Conocimiento.

Instituto Nacional de Estadística. (2014). Definición de los indicadores demográficos. 20/10/2014, de Instituto Nacional de Estadística de la República Oriental de Uruguay Sitio web:

http://www.ine.gub.uy/banco $\% 20 \mathrm{de} \% 20$ datos/soc_proyecciones/D ef_ind_dem.pdf

Quintanilla M. G. (2010). El uso de las nuevas tecnologías en México. Una sociedad mejor informada. (15). México:

Ordenjuridico.gob

Roca J. L. (2010). Lo simbólico como orden necesario del lenguaje y de la ley y. 18/10/2014, de A Parte Rei, revista de filosofía Sitio web: http://serbal.pntic.mec.es/AParteRei/jusmet70.pdf

Páez, J. J. P., Peloso, M. L. B., \& Fajula, a. (2014). Comunicación y sociedad 27(1), 205-224.

Menéndez P. (2014). Día de internet. En Día mundial del internet, México 2014(20). México: AMIPCI.

Quiroga M. P. (2011). El impacto de las nuevas tecnologías y las nuevas formas de relación en el desarrollo. En El impacto de las nuevas tecnologías 
y las nuevas formas de relación en el desarrollo (147-161). España:

Colegio oficial de psicología de Madrid.

Rondán-Cataluña, J., Arenas-Gaitán, J., \& Ramírez-Correa, P. (2014).

Un análisis empírico de las recomendaciones comerciales en los sitios de redes sociales. Ingeniare. Revista chilena de ingeniería, 22(3), 431-434.

Rosario, J. (2005). La Tecnología de la Información y la

Comunicación (TIC). Su uso como Herramienta para el

Fortalecimiento y el Desarrollo de la Educación

Virtual. Disponible en el ARCHIVO del Observatorio para la CiberSociedad, Recuperado el, 17.

Sabater, C. P. (2011). Cartas por Internet: Las implicaciones lingüísticas y estilísticas de los mensajes de correo electrónico y los comentarios del sitio de redes sociales Facebook. Revista española de lingüistica aplicada, (24), 111-130.

Uribe Saavedra, F., Rialp Criado, J., \& Llonch Andreu, J. (2013). El uso de las redes sociales digitales como herramienta de marketing en el desempeño

empresarial. Cuadernos de Administración, 26(47), 205-232.

Juárez R. (2013). MKT digital y redes sociales en México.

18/10/2014, de AMIPCI Sitio web:

https://www.amipci.org.mx/estudios/otros_estudios/MKT_D igital_y_Redes_Sociales_en_M\%C3\%A9xico_2013.pdf

Vázquez. R. (2014). Las redes sociales para el 2014. 18/10/2014, de Forbes Aulaticujap. (2014). Web 2,0+ TIC hacia donde. 18/10/2014, de aulaticujap Sitio web: http://aulaticujap.wordpress.com/perfil-del-estudiante/ 
Anexo: Tabla No. 1. Cuadro de categorías de análisis y variables

\begin{tabular}{|c|c|c|c|}
\hline $\begin{array}{l}\text { Pregunta de } \\
\text { investigación }\end{array}$ & Objetivos & Categorías de análisis & Variables \\
\hline \multirow{18}{*}{$\begin{array}{l}\text { ¿Qué determina } \\
\text { el acceso a las } \\
\text { nuevas } \\
\text { tecnologías en } \\
\text { México? }\end{array}$} & \multirow{18}{*}{$\begin{array}{l}\text { Analizar el acceso de } \\
\text { los jóvenes } \\
\text { universitarios a las } \\
\text { nuevas tecnologías }\end{array}$} & \multirow[t]{4}{*}{ Acceso } & $\begin{array}{l}\text { acceso físico a las nuevas } \\
\text { TICS }\end{array}$ \\
\hline & & & acceso al servicio de internet \\
\hline & & & fuentes de acceso \\
\hline & & & acceso público \\
\hline & & \multirow{3}{*}{$\begin{array}{l}\text { Jóvenes: Perfil } \\
\text { demográfico }\end{array}$} & Edad \\
\hline & & & Sexo \\
\hline & & & Lugar de residencia \\
\hline & & \multirow{3}{*}{$\begin{array}{l}\text { Jóvenes: perfil } \\
\text { sociocultural }\end{array}$} & Ocupación \\
\hline & & & Estado civil \\
\hline & & & Religión \\
\hline & & \multirow{5}{*}{$\begin{array}{l}\text { Jóvenes: perfil } \\
\text { económico }\end{array}$} & Número de televisión a color \\
\hline & & & Número de focos \\
\hline & & & Número de autos \\
\hline & & & Número de habitaciones \\
\hline & & & Educación del jefe de familia \\
\hline & & $\begin{array}{l}\text { Nuevas tecnologías: } \\
\text { Redes sociales }\end{array}$ & Preferencia \\
\hline & & \multirow[t]{2}{*}{ Uso } & Tiempo \\
\hline & & & Finalidad \\
\hline \multirow{5}{*}{$\begin{array}{l}\text { ¿Cuáles son los } \\
\text { efectos } \\
\text { producidos por } \\
\text { las nuevas } \\
\text { tecnologías? }\end{array}$} & \multirow{5}{*}{$\begin{array}{l}\text { Examinar los efectos } \\
\text { de las redes sociales } \\
\text { en los estudiantes de } \\
\text { nivel superior }\end{array}$} & \multirow[t]{5}{*}{ Conducta } & habilidades para el estudio \\
\hline & & & relaciones con los padres \\
\hline & & & $\begin{array}{l}\text { autoestima y confianza en sí } \\
\text { mismo } \\
\text { ansiedad }\end{array}$ \\
\hline & & & problemas de atención \\
\hline & & & depresión \\
\hline \multirow{2}{*}{$\begin{array}{l}\text { ¿Cuál es el } \\
\text { sentido que le da } \\
\text { el usuario a las } \\
\text { redes sociales? }\end{array}$} & \multirow{2}{*}{$\begin{array}{l}\text { Reconocer el sentido } \\
\text { simbólico que } \\
\text { el usuario le otorga a } \\
\text { las redes sociales }\end{array}$} & \multirow{2}{*}{$\begin{array}{l}\text { Interaccionismo } \\
\text { simbólico: sentido }\end{array}$} & Lenguaje \\
\hline & & & Prácticas sociales \\
\hline \multirow{4}{*}{$\begin{array}{l}\text { ¿Cuáles son los } \\
\text { usos y } \\
\text { gratificaciones } \\
\text { que le da el } \\
\text { usuario a las } \\
\text { redes sociales? }\end{array}$} & \multirow[t]{4}{*}{$\begin{array}{l}\text { Determinar el uso y } \\
\text { las gratificaciones de } \\
\text { las redes sociales }\end{array}$} & \multirow[t]{4}{*}{$\begin{array}{l}\text { Usos } \\
\text { Gratificaciones }\end{array}$} & $\begin{array}{l}\text { Necesidades afectivas: } \\
\text { Experiencias emocionales y } \\
\text { placenteras }\end{array}$ \\
\hline & & & $\begin{array}{l}\text { Necesidades integrativas: } \\
\text { Autoestima, confianza y } \\
\text { estabilidad del individuo }\end{array}$ \\
\hline & & & $\begin{array}{l}\text { Necesidades integrativas en lo } \\
\text { social: } \\
\text { Afiliación, pertenencia a } \\
\text { unidades mayores que el } \\
\text { individuo, familia, amigos, etc. }\end{array}$ \\
\hline & & & $\begin{array}{l}\text { Necesidades escapistas: } \\
\text { Alivio de tensiones, diversión. }\end{array}$ \\
\hline
\end{tabular}


Tabla 2. Interacción simbólica de las redes sociales: sentidos y significados

\begin{tabular}{|c|c|c|}
\hline Símbolo & Proporción & Representación \\
\hline \multirow{8}{*}{ Tres puntos $(\ldots)$} & 38 & Continua/ tiene algo más que decir \\
\hline & 20 & Pausa \\
\hline & 18 & Estar pensando lo que se va a decir \\
\hline & 9 & Para dar una espacio de suspenso \\
\hline & 6 & Estar enojado (a) \\
\hline & 4 & Asombro \\
\hline & 4 & No se \\
\hline & 1 & Silencio \\
\hline \multirow{5}{*}{$\mathrm{xD}$} & 43 & Carita sonriente \\
\hline & 33 & Risa \\
\hline & 13 & Alegría \\
\hline & 5 & Por dios \\
\hline & 2 & No sabe \\
\hline \multirow{7}{*}{ LOL } & 78 & Mucha risa \\
\hline & 11 & Ni idea \\
\hline & 3 & Diversión \\
\hline & 1 & Amor \\
\hline & 1 & Burla \\
\hline & 1 & Asombro \\
\hline & 1 & Juegos en línea \\
\hline \multirow{5}{*}{ WTF } & 58 & ¡Qué diablos! / ¡Qué rayos! \\
\hline & 11 & Sorpresa / sorprendido (a) \\
\hline & 7 & ¿¿Qué onda!? \\
\hline & 7 & ¡Maldición! \\
\hline & 6 & Duda ¿iQué!? \\
\hline \multirow[t]{9}{*}{ TOQUE } & 31 & Ni idea \\
\hline & 17 & Quiere comenzar una conversación \\
\hline & 17 & Llamar la atención \\
\hline & 10 & Acoso \\
\hline & 7 & Gustarle a esa persona \\
\hline & 5 & Marihuana \\
\hline & 3 & Recordatorio \\
\hline & 2 & Molestia \\
\hline & 1 & Nada \\
\hline \multirow{5}{*}{ OMG } & 59 & ¡Oh mi Dios! \\
\hline & 29 & Sorpresa \\
\hline & 5 & Asombro \\
\hline & 2 & ¡No manches! \\
\hline & 1 & Shock eléctrico \\
\hline
\end{tabular}





\title{
Construcción de marcas personales a través de las Selfies
}

\author{
Dra. Alicia de la Peña de León, \\ Dr. Juan Bernardo Amezcua Núñez, \\ Dra. Juana María Saucedo Soto, \\ Dra. Alicia Hernández Bonilla, \\ Dulce Karen Herrera Mata, estudiante \\ Universidad Autónoma de Coahuila, México
}

\section{Resumen}

Los llamados teléfonos inteligentes ofrecen a los usuarios diferentes herramientas que les ayudan a crear y compartir su imagen personal. Esta construcción de imagen se logra principalmente con la publicación de selfies o autofotos en las redes sociales, logrando así transmitir un mensaje único de cada usuario. El objetivo de este estudio es analizar con técnicas cualitativas, el comportamiento de aquellos atletas que suelen publicar auto fotografías de sus logros deportivos en las redes sociales. Los hallazgos sugieren que existen al menos cuatro segmentos de corredores; quienes además de promover su propia imagen, se vinculan con marcas de prestigio, convirtiéndose así en evangelizadores de las marcas, las cuales obtienen de forma gratuita menciones en las distintas redes sociales incrementando su atractivo para los consumidores. 
Palabras Clave: Autofoto, marca personal, mercadotecnia, redes sociales.

\section{Introducción}

A L hablar de una marca comercial, se hace alusión a un bien o 1 servicio que posee un nombre comercial específico, y que al ser mencionado ya sea en conversaciones informales o en los medios, trae a la mente de los individuos un sinnúmero de atributos y cualidades representados por esa marca (Aaker, 1996; Keller, 1993). El término marca, aplica también para los individuos, quienes buscan construir su marca personal en base a características distintivas que les permitan potencializar sus calidades y presentarse ante los demás, como un individuo con cierto valor y relevancia para competir por un puesto laboral o incluso para entablar nuevas relaciones interpersonales (Fournier, 2010; Peters, 1997).

En esta creación de marca personal, los individuos adquieren, utilizan y muestran productos que, de manera simbólica, les ayuden a presentarse ante los demás con ciertas características y atributos. Así al contar con una identidad adecuada, podrán alcanzar ciertas metas (Dahl, 2013; Sirgy, 1982). Sin embargo, la construcción de identidad personal no se limita únicamente al uso de productos para compartir un mensaje. El creciente uso de redes sociales permite a los individuos contar con nuevas formas de presentación y construcción de su imagen, utilizando símbolos digitales para transmitir su mensaje e identidad a los integrantes de su red virtual (Belk, 2013; Doster, 2013).

Para explorar el fenómeno de construcción de marca personal en las redes sociales a través del uso de selfies o auto fotografías, se realizó un estudio cualitativo que permita dar respuesta a las siguientes preguntas de investigación:

(1) ¿Qué recursos utilizan las personas para construir su marca personal en las redes sociales?

(2) ¿Existen distintos perfiles de consumidores?

(3) ¿Qué vínculo existe entre la marca personal y las marcas comerciales? 
Este artículo se divide en cuatro secciones. En la primera presentamos el marco teórico, donde revisamos literatura sobre el uso de tecnología digital; la publicación de selfies en la construcción de la marca personal digital; y los eventos deportivos como espacio para la construcción de marca personal. En seguida, explicamos la metodología cualitativa utilizada para la realización del estudio. En la tercera sección hacemos un análisis de los hallazgos y segmentamos a los individuos en cuatro grandes segmentos; y finalmente en la cuarta sección, presentamos nuestras conclusiones e ideas para estudios futuros.

\section{Marco teórico}

El creciente acceso a internet y tecnologías digitales ha generado un impacto en la manera en que las personas se comunican e interactúan entre sí. Se estima que en México hay 65 millones de internautas; y de ellos, un $77 \%$ utiliza su smartphone o teléfono inteligente para navegar en internet y acceder a sus redes sociales (AMIPCI, 2016). Estos nuevos hábitos de los mexicanos nos llevan a pensar que la construcción de una marca personal en el entorno digital presenta características específicas, que tienen además un efecto en las marcas comerciales.

\section{El uso de tecnología digital}

Los avances tecnológicos han abierto una puerta para facilitar la comunicación interpersonal. Hoy en día más de 51 millones de mexicanos cuentan con un teléfono inteligente, que les permite conectarse a internet y utilizar diferentes aplicaciones (apps) para comunicarse no sólo a través de una llamada, sino también enviar mensajes, compartir fotografías o acceder a sus redes sociales para mantenerse en contacto constante con sus grupos de amigos y familiares (INEGI, 2016). De igual forma, la tecnología ha modificado la forma de consumir y comportarse en el mercado, permitiendo que las marcas aprovechen las redes sociales para comunicarse con los consumidores y descubrir nuevas oportunidades de mercado (Drenten, 2012). 
Con un smartphone en la mano, una buena conexión a internet y una cuenta propia en las redes sociales, cualquier persona puede convertirse en vocero de su propia marca y en un líder de opinión para sus seguidores y amigos; quienes, equipados con un dispositivo similar podrán comentar, aprobar o desaprobar la publicación hecha por un miembro de su red social. Además, las tecnologías digitales permiten que los individuos administren su marca personal a través de la creación de páginas personales en redes sociales en donde publican sus fotos y expresan sus opiniones; de igual forma crean blogs, participan en foros y se unen a comunidades, donde además de fotografías y videos comparten puntos de vista, ideas y opiniones, creando así una reputación digital (Labrecque, Markos y Milne, 2011; Pera, Viglia y Furlan, 2016).

\section{La marca personal}

Investigaciones previas señalan, que la marca personal se ha analizado desde distintas perspectivas: el impacto de la presentación personal en la búsqueda de pareja (Ellison, Steinfield, y Lampe, 2007; Ellison, Heino y Gibbs, 2006); la construcción de imagen en la búsqueda de empleo (Chiang y Suen, 2015; Labrecque et al., 2011); y de forma más reciente, la imagen y reputación personal como bases de la economía compartida (Pera et al., 2016).

De manera muy particular, la economía compartida funciona en base a un valor intangible: la reputación de la persona con quien se va a compartir casa o automóvil (Pera et al., 2016). En este nuevo esquema económico, las personas utilizan Airbnb para encontrar un sitio económico y conveniente para hospedarse al viajar; o a través de BlaBlaCar comparten automóvil con otros para economizar combustible y contaminar menos. Cuando el individuo que busca rentar su casa o compartir su coche con otros logra presentar una imagen digital favorable, es entonces cuando se convierte en empresario con una oferta que es evaluada por otros en base a dicha reputación digital.

La reputación de una persona no sólo se evalúa al momento de elegir un sitio para hospedarse o un auto para compartir, sino también al entablar relaciones sociales y afectivas; de tal forma que un individuo 
que busca nuevos amigos o una pareja, emplea las redes sociales y se inscribe en distintos foros donde crea un perfil y busca presentarse ante los demás como una persona atractiva e interesante; para ello utiliza distintas claves o símbolos que le permiten construir su identidad o marca digital (Ellison et al., 2006); o bien utiliza redes especializadas como Linkedin para publicar su currículum y presentarse como un buen candidato para determinado puesto laboral (Chiang y Suen, 2015).

La construcción de una buena reputación inicia por lo general con la proyección de una imagen o marca personal. Esta marca personal se construye en base a las competencias, carisma, carácter y personalidad de un individuo. Son los rasgos que le hacen ser único y especial, y le permiten presentarse ante los miembros de una red social y/o profesional generando un valor (Dahl, 2013). Al momento de iniciar la construcción de un perfil digital, suele iniciarse con una fotografía. De igual forma, la marca personal se va elaborando con la publicación de fotografías subsecuentes, muchas de las cuales son auto fotografías o selfies.

\section{Las selfies y la construcción de la marca personal digital}

Las fotografías, además de servir como recuerdo de eventos previos, se han convertido en una forma de expresión de identidad. De manera particular, a las personas les gusta compartir de forma inmediata las fotografías tomadas con su celular, y muchas de éstas son selfies (Drenten, 2012). Una auto fotografía o selfie es una fotografía que un individuo ha tomado de sí mismo, generalmente con un smartphone o con la cámara de su propia computadora y que posteriormente es publicada en una red social (Oxford, 2013; Qiu et al., 2015).

La publicación de selfies se da por razones diversas: algunas personas las publican por vanidad, para satisfacer su ego y hacen un despliegue narcisista de su rostro y su cuerpo (Kim et al., 2016); en tanto que otras buscan desplegar su personalidad, estilo de vida y preferencias (Sung et al., 2016). De acuerdo a Schau y Gilly (2003, p. 386) "somos lo que publicamos" y pareciera entonces que las personas buscan ser percibidas por los demás como atractivas y exitosas; por tanto, eligen publicar fotografías que destaquen sus mejores atributos físicos y las muestren al mundo como exitosas. 
En las redes sociales como Facebook o Instagram, los usuarios construyen de manera intencional su marca para mostrarse al mundo a veces de manera real, a veces de forma idealizada, pero buscando siempre crear una imagen que genere un impacto y un recuerdo positivo y memorable (Belk, 2013). Para Schultz (2015), la publicación de una selfie equivale al proceso de apareamiento del pavorreal. El pavorreal macho despliega sus plumas y se pasea frente a la hembra buscando llamar su atención. De manera similar, el usuario de una red social, publica sus selfies para auto-promoverse, vender sus ideas e impresionar a los demás con imágenes de sus viajes, fiestas y logros personales; convirtiendo a las fotografías en la campaña publicitaria de una marca personal (Schultz, 2015).

Estudios previos señalan que las personas publican sus fotos en base a cuatro motivaciones: (1) Llamar la atención, (2) comunicar, (3) archivar recuerdos, y (4) entretener (Sung et al., 2016). Estas cuatro motivaciones equivalen a las actividades mercadológicas de las marcas comerciales, que buscan a través de distintos medios comunicar y llamar la atención del consumidor (Keller, 1993); o bien generar entretenimiento a través de lo que se conoce como branded entertainment (Hudson y Hudson, 2016).

\section{Los eventos deportivos como espacio para la construcción de la marca personal}

Así como las marcas requieren de un lugar en el anaquel de una tienda, o de un espacio en los medios de comunicación, los individuos también necesitan de un espacio para promoverse y darse a conocer. Uno de los lugares donde es común encontrar personas tomando selfies y compartiendo sus éxitos es en las carreras atléticas. Tan sólo en México existen 2.5 millones de corredores que participan de forma frecuente en las cientos de carreras que se organizan en distintas ciudades del país (Rodríguez, 2015). Salir a correr se ha convertido en una actividad cotidiana para miles de personas, que por un lado buscan hacer ejercicio para cuidar su salud y por otro, convivir con personas con intereses afines, hacer nuevos amigos y pasar un rato divertido (González Garzón, 2016). 
Los avances tecnológicos han permitido que los corredores cuenten con equipamiento especial que facilita su actividad. Si bien es cierto que lo principal es el zapato especial para correr, los smartphones, las cámaras GoPro y los drones forman parte también del equipo de miles de personas. Gracias al smartphone y sus aplicaciones, el corredor puede registrar cada entrenamiento y cada carrera, utilizar el GPS para medir la distancia y por supuesto, tomar fotografías antes, durante y después de la carrera para compartirlas con amigos y conocidos a través de las redes sociales.

Compartir en las redes se ha vuelto importante para las personas (Kotler, Kartajaya y Setiawan, 2016). Los corredores comparten fotos de sus zapatos especializados, sus playeras y sus medallas; aprovechan los reconocimientos virtuales que brindan las aplicaciones para compartir sus logros y presumen sus medallas al llegar a la meta. Estas publicaciones dan lugar entonces a la promoción de la marca personal de cada corredor. Aunque el objetivo en la mayoría de los casos es hacer una publicación personal, es inevitable que muchas de estas fotografías vayan ligadas a marcas de artículos deportivos que están presentes en la forma de logotipos impresos o bordados en playeras, cachuchas y zapatos deportivos; así como a la presencia en el fondo de las fotografías, de las marcas de los patrocinadores y organizadores de los eventos atléticos. De esta forma el consumidor se convierte en un abogado promotor de la marca y en un modelo a seguir (Cregan-Reid, 2017; Kotler et al., 2016).

Para poder presentarse en el mundo virtual, los individuos utilizan referentes digitales, y aprovechando la estructura del ambiente virtual son libres de controlar la información que publican, haciéndola visible o invisible a distintos grupos de amigos (Boyd y Ellison, 2007; Schau y Gilly, 2003). Facebook por ejemplo, permite a los usuarios administrar su presentación en línea y decidir qué aspectos de su persona revelar y cuáles mantener ocultos, lo cual pudiera resultar conveniente sobre todo cuando se trata de compartir información relacionada con la apariencia física o el peso corporal; así como también con los fracasos en la consecución de metas personales (Walther, 2007; Zywica y Danowski, 2008).

La mayoría de las ocasiones, los individuos buscan presentar una imagen positiva ante los demás (Barasch y Berger, 2014) (Argo et, al. 
2005) descubrieron, que cuando el auditorio es grande, como pudiera ser el caso de los grupos de Facebook, las personas tienden a evitar publicar contenido que les haga proyectar una imagen negativa ante su grupo de referencia. En Facebook, una persona maneja su imagen en base a los mensajes, fotografías, videos o trofeos que comparte con los demás para demostrar sus logros, habilidades o esfuerzos (Schau y Gilly, 2003), lo cual sugiere que el individuo buscará que su muro de Facebook tenga publicaciones favorecedoras o positivas.

\section{Metodología}

Con el objetivo de analizar el comportamiento de los corredores del norte de México en Facebook, se realizó un estudio cualitativo que permitió identificar las actividades de auto-promoción que las personas realizan al actualizar su estado en la red social, cuando participan en carreras y competencias atléticas (Hackley, 2003).

Para llevar a cabo la investigación se realizó una etnografía y una netnografía (Kozinets, 2010; Kozinets, 2006; Kozinets, 2002) de una comunidad de corredores del norte de México llamada "Rapport", que se reúne al menos tres veces por semana para entrenar y participar en carreras en distintas ciudades. Las observaciones presenciales tuvieron lugar por un periodo de doce meses tanto en entrenamientos, como en carreras importantes (p.ej. 21K Coahuila, Carrera Imagen Kellogg's Monterrey, Carrera Duendes Monterrey). De manera simultánea se realizó un análisis de la comunidad de Rapport en Facebook (https://www.facebook.com/groups/rapportmex/?fref=ts) y se hicieron algunas entrevistas de profundidad con corredores para identificar los motivos por los cuáles publican sus fotografías.

La información recabada se clasificó en archivos digitales para su posterior análisis (Spiggle, 1994). En seguida, realizamos un análisis de contenido, que nos permitió clasificar los datos de los corredores en base a sus publicaciones; e identificar nuevos temas y patrones relacionados a la construcción de una marca personal (Creswell, 2013; Rose, 2016). 


\section{Resultados}

En el proceso de analizar los datos emergieron temas que sugieren que las redes sociales sirven como plataforma para que las personas construyan su marca personal. De forma particular, llegamos a la conclusión de que existe entre los aficionados a correr un interés por publicar y compartir selfies y otras imágenes relacionadas para registrar su trayectoria, compartir sus logros y construir una buena imagen para compartir con sus conocidos y amigos.

Un gran número de corredores suele documentar con fotografías y actualizaciones de estado en sus redes sociales, las distintas etapas de una carrera. Desde la llegada para el calentamiento, hasta el encuentro con otros corredores para la foto de la buena suerte, todo queda registrado en las memorias del smartphone. Observar a los corredores, tanto de forma virtual como presencial, nos permitió clasificar a los corredores y su comportamiento:

\section{Antes muerta que sencilla}

Generalmente, participar en una carrera implica terminar cansado y cubierto de sudor. Aun así, observamos que la apariencia personal es importante, por lo que los corredores procuran llegar con zapatos y ropa especializados; y en el caso de las mujeres, maquilladas y bien peinadas. La selfie y el video previos a la carrera parecen ser una regla no escrita entre un gran número de participantes; quienes buscan a través de estos medios anunciar entre sus amigos que están participando en un evento deportivo:

"Quiero que la gente sepa que voy a correr y que empecé fresca y lista para hacer mi mejor papel” (Claudia, 40).

"Me gusta que mi hijo me tomé video antes de iniciar, es como un ritual para enviar saludos a mis contactos. El video inicia desde casa, cuando estoy terminando de maquillarme y ponerme los zapatos. Todo me combina, los tenis, los shorts, los lentes... así soy yo" (Lucía, 48).

"Siempre uso mis propias playeras, a mí no me gustan las playeras que dan en las carreras, son muy grandes y me estorban al correr, además... me veo gorda con ellas" (Anna, 21). 


\section{Inspirando a los demás}

Correr es una actividad individual, sin embargo, al publicar en las redes sociales los logros y premios recibidos permite que las personas se conviertan en promotores de un estilo de vida saludable (Ba y Wang, 2013; Cregan-Reid, 2017; Royne y Levy, 2011). De tal manera que en las comunidades virtuales suelen surgir líderes de opinión que incentivan y motivan a otros a modificar sus patrones de conducta:

"Me gusta usar aplicaciones como Nike y compartir mis logros en las redes. Quiero que las personas que me conozcan sepan que estoy cambiando mi estilo de vida y que si yo pude hacerlo ellos también podrán lograrlo. Es como mi campaña publicitaria personal de sí se puede" (Guillermo, 47).

"Publico antes para decirle al mundo que estoy haciendo algo por mí y mi salud. Jamás tomó fotos durante la carrera, pero al llegar a la meta vuelvo a las selfies. Quiero contagiar con mi sonrisa y mis momentos a los demás, para que quienes las vean decidan hacer algo por su cuerpo y por su vida" (Sergio, 34).

"Comparto lo que disfruto y quiero incentivar a que otros incluyan el ejercicio en su vida" (Carlos, 42).

\section{Corredores anónimos}

No todos los corredores están en buena forma ni llegan rápido a la meta; algunos tienen sobre peso o carecen de una buena condición física y su desempeño es malo en comparación a los demás. Congruente con los hallazgos de Barasch y Berger (2014), descubrimos que las personas evitan hacer publicaciones que dañen su imagen o los hagan verse mal ante los demás. De esta manera, las publicaciones de atletas con sobrepeso por lo general no incluyen fotografías individuales, e incluso en sus perfiles prefieren mostrar fotos de paisajes o mascotas y no de ellos mismos:

"Algún día publicaré mis fotos individuales, pero con este cuerpo prefiero salir al fondo en las fotos grupales, o subir únicamente las fotos de mis tenis y mis medallas..." (Francis, 35). 
"Yo apenas y corro. La verdad vengo porque todas mis amigas de la dieta están aquí, pero de seguro me voy a tardar como dos horas en llegar a la meta. Así es que nada más vengo con ellas, pero jamás me tomo fotos ni publico nada. En mi muro sólo hay fotos de mis hijos" (Paty, 35).

\section{Corredores con causa}

Participar en una carrera ofrece beneficios a los corredores que van más allá del simple ejercicio o de la medalla recibida al finalizar. Existen personas que participan en carreras con causa para demostrar su afiliación con ciertas organizaciones filantrópicas y de caridad (Bennett et al., 2007). Al pagar una cuota que se traduce en donativos para una causa social, los participantes reciben no sólo las bondades del correr, sino que además alimentan su autoestima al sentirse bien por apoyar a otros; y al compartir sus fotografías en las redes construyen una imagen favorable:

"Mi hijo tiene una enfermedad degenerativa y no ha sido fácil encontrar médicos y pagar los tratamientos. Pero mis amigas del grupo Locas que corren no me han dejado sola. Por eso corremos todas las carreras a beneficio de... que nos encontramos, para ayudar a los demás. Sobre todo, corremos carreras que apoyan a niños" (Teresita, 38).

"De correr por cualquier cosa a correr por los Rotarios y apoyarlos en sus programas, prefiero siempre estar aquî" (Víctor, 42).

“¿Qué te puedo decir? Yo soy de Cuatro Ciénegas. Y cuando vi que la carrera era para apoyar a mi pueblo, me encantó la idea. No corro mucho, pero es para mi gente" (Elvia, 46).

\section{El vínculo entre la marca personal y la marca comercial}

El consumo de simbólico es una parte esencial de la construcción de marca, de tal forma que las publicaciones en las redes sociales proveen una plataforma en la cual los individuos presentan distintos elementos que les ayudan a construir su marca personal. En muchas ocasiones esta imagen personal va vinculada a la imagen de marcas comerciales populares, lo que convierte a la selfie en una herramienta con un valor 
doble, pues por un lado promueve al corredor, y por otro genera comunicaciones virales positivas para las empresas y sus marcas.

La mayoría de las carreras cuentan con patrocinadores importantes, que además, de contribuir con recursos para organizar la carrera y premiar a los participantes, aprovechan la oportunidad para promover sus marcas, entregar muestras gratis y construir valor en torno a un elemento intangible de gran valor en la actualidad: la salud (González Garzón, 2016).

Los corredores valoran la presencia de las marcas, ya que una carrera organizada o patrocinada por una marca líder suele ser un evento de calidad, que ofrece además entretenimiento y diversión:

"Me enloquecen las metas. Cada vez colocan más pantallas, más lonas, más botargas. A lo largo de la carrera hay fotógrafos que toman tu foto y luego la suben a las redes para que la puedas compartir. Es todo un espectáculo..." (Sergio, 34).

"Mis carreras favoritas son las que te dan de todo. La de Lego es genial, ¿ya viste las medallas? ¡Súper cool! En la de Kellogg's te diviertes mucho, están las botargas de los personajes, hay marcos para fotos, portadas de revista y te llenan de cajas de cereal..." (Claudia, 40).

\section{Conclusiones}

Partiendo de estudios previos sobre la construcción de imagen personal, los hallazgos de esta investigación nos permitieron identificar y comprender mejor las características y motivaciones de quienes comparten sus fotografías en Facebook.

En cada publicación observamos que el usuario es el productor, el director y la estrella de su propia campaña de imagen. Aquellos que utilizan aplicaciones para monitorear su actividad física, publican sus mejores resultados y cubren así un doble objetivo: se dan a conocer como personas exitosas que alcanzan sus metas; y a la vez motivan a otros a buscar estilos de vida saludables.

Lo que pareciera una publicación espontánea, lleva de fondo un análisis cuidadoso de la imagen a proyectar; siguiendo un esquema muy similar al que utilizan los publicistas y creativos al momento de tomar las 
fotografías de un producto. El corredor elige su mejor ángulo, se coloca la medalla al frente y busca colocarse en la meta teniendo como fondo las marcas que patrocinan la carrera. Así entonces genera fotos y vídeos que le permiten mostrar a sus contactos sociales una imagen positiva, lo que los publicita como personas que gozan de buena salud y están llenos de energía; pero que además se fijan metas y las cumplen. En ocasiones incluso le añaden un halo de bondad a sus acciones al vincular su actividad atlética a una causa social.

Podemos concluir entonces, que la selfie cubre tres funciones importantes para los individuos que buscan construir su marca personal: (1) es una manera de expresar la pertenencia a una tribu urbana con características únicas; (2) permite celebrar los éxitos y logros personales; y (3) se convierte en un símbolo de status y autopromoción personal.

\section{Limitaciones y estudios a futuro}

En esta investigación se realizó únicamente un análisis cualitativo de los corredores y su imagen, más no incluye la percepción de su red de amigos y conocidos, que en un contexto comercial serían el equivalente a los consumidores de una marca. En una siguiente etapa de esta investigación, buscaremos analizar el impacto que tiene la publicación de selfies en los grupos de referencia e identificar sí existe una coincidencia entre la imagen que los corredores quieren transmitir y la imagen que percibe su público.

Hoy en día, existen métricas que permiten medir el impacto de las distintas publicaciones, por lo que en esta segunda etapa de la investigación se puede medir el impacto de la selfie en la construcción de una marca personal de forma cuantitativa. Al contabilizar los me gusta, retweets y me encanta, se podrá entonces valorar si la imagen publicada resulta o no atractiva para el público (Rappaport, 2014).

Esta investigación se limita al estudio de un solo caso: los corredores y sus publicaciones en Facebook. Sin embargo, los hallazgos generan información que nos permite identificar la manera en que las personas construyen su marca personal a través de la publicación de selfies, que les ayudan a incrementar su visibilidad y los convierte en marcas y referentes para otras personas. La publicación de selfies es sólo una de 
las muchas acciones que los usuarios de redes pueden llevar a cabo para comunicar sus intereses, actividades y logros con sus grupos de referencia. Examinar los comentarios y los videos que las personas comparten, así como analizar otras plataformas como Instagram o Snapchat permitirá tener un panorama más completo de las formas empleadas por los individuos para convertirse en promotores de su propia marca.

\section{Implicaciones empresariales}

La derrama económica que generan las carreras atléticas es de suma importancia tanto para la ciudad donde se llevan a cabo como para los organizadores del evento (González Garzón, 2016). Por otra parte, los corredores invierten fuertes sumas calzado y ropa especializados, así como en gadgets que les facilitan y apoyan en sus carreras; en cada uno de estos productos hay una marca comercial que se beneficia por las ventas directas; pero que además adquiere valor y reputación en cada publicación de los corredores, quienes se convierten en evangelizadores de las mismas al compartir con sus redes fotografías donde en ocasiones las marcas aparecen en un primer plano sin haber desembolsado un peso.

Los resultados de esta investigación permitirán a las marcas comerciales y a los organismos de la sociedad civil diseñar estrategias promocionales invitando a los usuarios a compartir sus selfies y agregar un hashtag determinado como pie de foto, y comenzar así una campaña viral, donde compradores auténticos de la marca actúan como embajadores y promotores de la misma, generando una mayor credibilidad hacia la marca y sus atributos.

\section{Referencias bibliográficas}

Aaker, D. A. (1996). Measuring brand equity across products and markets.California management review, 38(3), 102-120.

AMIPCI (2016). $12^{\circ}$ Estudio sobre los hábitos de los Usuarios de Internet en México 2016. Recuperado el 15 de Agosto de 2016, de Asociación de Internet: 
https://www.amipci.org.mx/images/Estudio_Habitosdel_U suario_2016.pdf

Argo, J. J., Dahl, D. W., y Manchanda, R. V. (2005). The influence of a mere social presence in a retail context. Journal of Consumer Research, 32(2), 207-212.

Ba, S. y Wang, L. (2013). Digital health communities: The effect of their motivation mechanisms. Decision Support Systems, 55(4), 941-47.

Barasch, A. y Berger, J. (2014). Broadcasting and Narrowcasting: How Audience Size Impacts What People Share. Journal of Marketing Research, 51(3), 286-299.

Belk, R. W. (2013). Extended self in a digital world. Journal of Consumer Research, 40(3), 477-500.

Bennett, R., Mousley, W., Kitchin, P., y Ali-Choudhury, R. (2007). Motivations for participating in charity-affiliated sporting events. Journal of Customer Behaviour, 6(2), 155-178.

Boyd, D. M. y Ellison, N. B. (2007). Social network sites: Definition, history, and scholarship. Journal of Computer-Mediated Communication, 13(1), 210-230.

Chiang, J. K. H., y Suen, H. Y. (2015). Self-presentation and hiring recommendations in online communities: Lessons from LinkedIn. Computers in Human Behavior, 48, 516-524.

Cregan-Reid, V. (2017). Footnotes: How running makes us human. Thomas Dunne Books.

Creswell, J. W. (2013), Qualitative inquiry and research design.

Choosing among five approaches. Third edition. Sage Publications, Inc.: Los Angeles, CA.

Dahl, S. (2013). Positioning your personal brand. American Marketing Association Career Resource Center. Recuperado el 15 de Agosto de 2016, de American Marketing Association: https://www.ama.org/career/Pages/Positioning-YourPersonal-Brand.aspx 
Doster, L. (2013). Millennial teens design and redesign themselves in online social networks. Journal of Consumer Behaviour, 12(4), 267-279.

Drenten, J. (2012). Snapshots of the self. En Close, A. G. (Ed.), Online consumer behavior: Theory and research in social media, advertising, and e-tail, Capítulo 1, pp. 3-34. New York: Routledge.

Ellison, N. B., Steinfield, C. y Lampe, C. (2007). The Benefits of Facebook "Friends:" Social Capital and College Students' Use of Online Social Network Sites. Journal of ComputerMediated Communication, 12(4), 1143-68.

Ellison, N., Heino, R., y Gibbs, J. (2006). Managing impressions online: Self-presentation processes in the online dating environment. Journal of Computer-Mediated Communication, 11(2), 415-441.

Fournier, S. (2010). Taking stock in Martha Stewart: A cultural critique of the marketing practice of building personbrands. NA-Advances in Consumer Research Volume 37.

González Garzón, C. (2016). Patrocinadores a toda velocidad. Mundo Ejecutivo, 444(1), 74-81.

Hackley, C. (2003), Doing research projects in marketing, management and consumer research. Routledge, London.

Hudson, S., y Hudson, D. (2006). Branded entertainment: a new advertising technique or product placement in disguise?. Journal of Marketing Management, 22(5-6), 489-504.

INEGI (2016). Estadísticas a propósito del Día Mundial del Internet 2016. Recuperado el 15 de Agosto de 2016, de INEGI: http://www.inegi.org.mx/saladeprensa/aproposito/2016/int ernet2016_0.pdf

Keller, K. L. (1993). Conceptualizing, measuring, and managing customer-based brand equity. The Journal of Marketing, 57(1), $1-22$.

Kim, E., Lee, J. A., Sung, Y., y Choi, S. M. (2016). Predicting selfieposting behavior on social networking sites: An extension of 
theory of planned behavior. Computers in Human Behavior, 62, 116-123.

Kotler, P., Kartajaya, H., \& Setiawan, I. (2016). Marketing 4.0: Moving from Traditional to Digital. John Wiley \& Sons.

Kozinets, R.V. (2010), Netnography. Doing ethnographic research online. SAGE, California.

Kozinets, R.V. (2006), Netnography, 2.0. Published in Belk, R.W. (Ed.) Handbook of Qualitative Research Methods in Marketing. MPG Books Ltd. G.B.

Kozinets, R.V. (2002), "The Field Behind the Screen: Using Netnography for Marketing Research in Online Communities," Journal of Marketing Research, vol. 39(1), Febrero, p. 61-72.

Labrecque, L. I., Markos, E., y Milne, G. R. (2011). Online personal branding: processes, challenges, and implications. Journal of Interactive Marketing, 25(1), 37-50.

Oxford Dictionary (2013). The Oxford Dictionaries Word of the Year 2013. Recuperado el 15 de Agosto de 2016, de Diccionario Oxford: http://blog.oxforddictionaries.com/press-releases/oxforddictionaries-word-of-the-year-2013/

Pera, R., Viglia, G., y Furlan, R. (2016). Who Am I? How Compelling Self-storytelling Builds Digital Personal Reputation. Journal of Interactive Marketing,35, 44-55.

Peters, T. (1997). The brand called you. Fast Company, 10(10), 83-87.

Qiu, L., Lu, J., Yang, S., Qu, W., y Zhu, T. (2015). What does your selfie say about you?. Computers in Human Behavior, 52, 443449.

Rodríguez, R. (2015). El crecimiento del running en México.

Recuperado el 16 de Agosto de 2016, de Grupo Milenio: http://m.milenio.com/masaficion/Running_MexicoCrecimiento_Running_Mexico-

Carrera_Running_Mexico_2015_0_455354577.html 
Rose, G. (2016). Visual methodologies: An introduction to researching with visual materials. Sage.

Royne, M.B. and Levy, M. (2011). Marketing for Public Health: We Need an App for That. The Journal of Consumer Affairs, Spring. 1-6

Schau, H. J., y Gilly, M. C. (2003). We are what we post? Selfpresentation in personal web space. Journal of Consumer Research, 30(3), 385-404.

Schultz, D. (2015). On Selfies and Preening Like a Peacock. Marketing News. Recuperado el 16 de Agosto de 2016, de American Marketing Association: https://www.ama.org/publications/MarketingNews/Pages/ on-selfies-and-preening-like-a-peacock.aspx

Sirgy, M. J. (1982). Self-concept in consumer behavior: A critical review. Journal of consumer research, 9(3), 287-300.

Sung, Y., Lee, J. A., Kim, E., y Choi, S. M. (2016). Why we post selfies: Understanding motivations for posting pictures of oneself. Personality and Individual Differences, 97, 260-265.

Walther, J. B. (2007). Selective self-presentation in computermediated communication: Hyperpersonal dimensions of technology, language, and cognition. Computers in Human Behavior, 23(5), 2538-2557.

Zywica, J., y Danowski, J. (2008). The faces of Facebookers: Investigating social enhancement and social compensation hypotheses; predicting Facebook ${ }^{\mathbf{T M}}$ and offline popularity from sociability and self-esteem, and mapping the 


\title{
Una experiencia exitosa: Los entornos telemáticos en la práctica profesional de los futuros maestros
}

\author{
Arturo Pérez Patiño \\ Guadalupe Minerva Castillo Hernández \\ Héctor Alonso Rosas Álvarez \\ Sandra Nelly Martínez Cantú
}

Escuela Normal "Miguel F. Martínez" Centenaria y Benemérita,
México

\section{Resumen:}

Las prácticas profesionales que realizan los futuros maestros durante su último año de su formación inicial les permite enfrentar los retos como docente en condiciones reales de trabajo. Es el contexto escolar donde desarrolla todas sus habilidades personales y competencias profesionales enfocadas hacia una práctica educativa con calidad que contribuya a formar en sus alumnos individuos íntegros. Una de las competencias profesionales de egreso es el uso de las TIC en la educación. En la actualidad el empleo de la tecnología es primordial para ejercer la docencia. El conocimiento y la aplicación de entornos telemáticos como estrategia de enseñanza en el aula permite al futuro educador innovar y perfeccionar su práctica educativa. La presente investigación contribuyó a conocer la influencia de los entornos telemáticos cuando los normalistas lo implementaron en su trabajo docente. El estudio se llevó a cabo en una escuela normal de educación 
superior del Estado de Nuevo León, México, dedicada a formar licenciados en educación física, educación primaria y educación preescolar. El universo de estudio fueron 140 estudiantes normalistas de las tres licenciaturas que cursaban el séptimo y octavo semestres. La duración fue de dos ciclos escolares, el primero se consideró como diagnóstico y el segundo se evaluaron los resultados utilizando la metodología cualitativa.

Palabras clave: Entornos telemáticos, habilidades digitales, estrategias de enseñanza con TIC.

\section{Introducción}

T A sociedad actual exige individuos que estén capacitados en 1 conocimientos, habilidades, valores, destrezas y competencias para aplicarlos en la vida cotidiana. La educación actual exige al maestro que desarrolle su labor docente con calidad. Una competencia imprescindible es aplicar las Tecnologías en Información y Comunicación (TIC) en su desempeño académico porque en los últimos años la evolución de ellas ha provocado cambios radicales en las formas como se accede a la información y a la comunicación, sobre todo entre la población joven (Sánchez \& Castro, 2013).

En la actualidad donde los avances científicos y tecnológicos propician cambios significativos en la vida diaria. Las instituciones educativas son las responsables de formar individuos capaces de adaptarse a esos cambios vertiginosos, desarrollando en ellos las competencias cognitivas, valores y habilidades para aplicarlos al enfrentarse a los retos que se les presenta en los diversos contextos en que se desenvuelve: familiar, escolar, social, entre otros. El plan de estudios de educación básica manifiesta la necesidad de "egresar estudiantes que posean competencias para resolver problemas; tomar decisiones..." (SEP, 2011, pág. 9), y poseer dominio de "las tecnologías de la información y la comunicación, y en general de las plataformas digitales, como herramientas del pensamiento, la creatividad y la comunicación” (SEP, 2011, pág. 10). 


\section{Metodología}

La metodología empleada en esta investigación "Los entornos telemáticos en la práctica profesional de los futuros maestros" es de enfoque cualitativo, de alcance explicativo. Se considera cualitativa porque estudia las situaciones que se observan en sujetos o poblaciones específicas tratando de descubrir el fenómeno por medio de la reflexión y el análisis permanente del mismo (Hernández Sampieri, Fernández y Baptista, 2010). En ella se describen, analizan y explican la relación entre las variables. Es un estudio de caso porque se pretende describir y analizar unidades sociales, observando los métodos y procesos de interacción entre ellos (Albert,2007).

El objetivo de esta investigación fue reflexionar sobre el impacto de la aplicación de los entornos telemáticos como estrategia de enseñanza para desarrollar en los alumnos del nivel de preescolar y primaria aprendizajes significativos y permanentes. Otro propósito fue consolidar las competencias personales y profesionales de los futuros licenciados de educación física, primaria y preescolar.

Se consideró que los estudiantes normalistas en su último año de formación inicial poseían competencias digitales y que eso les permitiría aplicarlas hacia dos rumbos: Uno el conocimiento de algunas tecnologías y el otro aplicarlas como un recurso didáctico innovador durante su práctica pedagógica promoviendo así un aprendizaje significativo en los educandos. Estas habilidades contribuyen a que los futuros maestros consoliden sus competencias genéricas $y$ profesionales indispensables para su labor docente al implementar las TIC como herramienta de aprendizaje, al conocer, usar, desarrollar y valorar los recursos tecnológicos y aplicarlos en situaciones didácticas durante su trabajo docente (Montes, 2014)

El presente estudio está focalizado en las prácticas profesionales que realizan 140 normalistas aplicando los entornos telemáticos como estrategia de enseñanza en el séptimo y octavo semestre de su formación inicial durante los ciclos escolares de 2014-2015 y 20152016. Ellos pertenecen a una escuela normal pública formadora de docentes del Estado de Nuevo León, México. Las licenciaturas que imparte esta institución educativa son: Licenciatura en Educación 
Física (LEF), Licenciatura en Educación Primaria (LEP) y Licenciatura en Educación Preescolar (LPP).

En el mes de septiembre de 2014 y 2015 se implementó un curso-taller a los alumnos normalistas de séptimo semestre de la LEF, LEP y LPP, aplicándoles una encuesta de entrada (diagnóstica) para conocer los conocimientos previos que tenían los estudiantes sobre el uso de las tecnologías de la información y comunicación (TIC), su conceptualización, aplicación en lo personal y profesional. Después de analizar los resultados se les impartió el curso- taller enseñándoles estrategias didácticas cómo: la clase inversa, el diseño y uso del portafolio electrónico y las páginas web, entre otros recursos telemáticos para mejorar e innovar en su práctica docente.

A partir del curso taller se monitoreó las producciones elaboradas por los futuros licenciados desde la plataforma. Otra estrategia para dar seguimiento a las producciones hechas por los normalistas fueron las observaciones y recomendaciones que se hicieron, de manera presencial y por video, cuando aplicaban estos recursos telemáticos en las aulas con sus alumnos, permitiendo así fortalecer las competencias de egreso de ellos además de atender las dudas o reconocer en su momento el buen trabajo realizado

La evaluación de los trabajos realizados por los normalistas y de la propia investigación se llevó a cabo en el mes de junio del 2015 y 2016 se aplicó una encuesta de salida que permitió establecer algunas conclusiones sobre la implementación de los entornos telemáticos como estrategia didáctica, para favorecer el aprendizaje significativo en los alumnos de educación básica.

Las técnicas e instrumentos aplicados en esta investigación fueron:

$\checkmark$ Encuesta de entrada: En septiembre del 2014 y 2015 antes de iniciar el curso- taller. Fase diagnóstica, contribuyó a valorar los conocimientos que poseían los estudiantes de $7^{\circ}$. Semestre de las licenciaturas de LEF, LEP y LPP sobre habilidades digitales, las TIC y los entornos telemáticos.

$\checkmark$ Visitas presenciales a las escuelas donde los alumnos desarrollan su trabajo docente y aplican los entornos telemáticos como estrategia de enseñanza: Mediante la observación directa se obtuvo información objetiva sobre 
las experiencias de los normalistas, aclarando las dudas, haciendo una retroalimentación in situ sobre el trabajo realizado.

$\checkmark$ Observaciones en video: Permitió el análisis de la práctica docente del normalista además de optimizar el tiempo, ante la imposibilidad de hacerlo presencial por lo numeroso de los grupos. El asesor observaba el video en casa o en la normal haciendo las recomendaciones pertinentes de forma escrita o vía correo electrónico

$\checkmark$ Rúbrica para la evaluación de los entornos telemáticos: del portafolio electrónico, la página web, el video de la clase, la clase inversa. Mediante la rúbrica el normalista reconocía fortalezas y sus áreas de oportunidad en cada uno de los entornos telemáticos evaluados.

$\checkmark$ Encuesta de salida: Junio del 2015 y junio 2016. Al finalizar cada ciclo escolar a los normalistas se les aplicó la encuesta de salida para analizar los resultados alcanzados sobre la relevancia del uso de los entornos telemáticos en su práctica docente y si eso contribuyó para el desarrollo de aprendizajes significativos en sus alumnos. Promover en ellos continuar con esas estrategias ahora en el plano profesional, además de fortalecer sus competencias genéricas y profesionales que exige el servicio profesional docente actual.

\section{Desarrollo del tema}

El aprendizaje es capacidad humana, a partir del funcionamiento del cerebro, éste hace posible las potencialidades que ordenan procesos y generan conductas adaptativas para solucionar problemas, según el contexto donde se desenvuelve la persona. El ser humano aprende por condición natural en la medida que cada persona es consciente de su proceso de aprender, reconoce su estilo y mantiene vivo el deseo de aprender, además, está en posibilidades de maximizar su propio aprendizaje.

En la actualidad, el uso de la tecnología en la escuela permite dar un salto cualitativo en la metodología de aula que conlleva ofrecer un aprendizaje que permita investigación y creación de conocimiento, de 
esta forma lo que los futuros maestros, podrán desarrollar competencias que les permitan dar el adecuado uso de la información, a través de un uso constante y responsable de las herramientas tecnológicas, tanto en la vida diaria como en la enseñanza. Un maestro debe dominar y conocer cómo captar la atención de sus alumnos y enseñarles a construir y apropiarse del conocimiento.

\section{Gestión de los procesos de enseñanza}

Una de las prioridades que se llevan a cabo en cualquier institución de educación superior, es la referente a la organización de las acciones para la adecuada fluidez entre los elementos que interactúan en el contexto académico y administrativo del centro de trabajo, de esta forma se debe tener un fácil manejo de los recursos, el personal, la infraestructura, los planes, los proyectos, los sistemas, etc. De acuerdo a los esfuerzos que la institución realice se tendrán resultados favorables si dichos elementos que la componen interactúan de manera coordinada y ordenada. De tal forma que ésta será el motor principal para consolidar las acciones a través de un mismo propósito, de lograr una identidad, un buen orden y, sobre todo, de un gran proceso de acción, todo ello contribuye al apoyo incondicional y definitivo de la gestión conceptualizada por la SEP. (2010) como:

El conjunto de acciones integradas para el logro de un objetivo a cierto plazo es la acción principal de la administración y eslabón intermedio entre la planificación y los objetivos concretos que se pretenden alcanzar... se caracteriza por una visión amplia de las posibilidades reales de una organización para resolver alguna situación o para alcanzar un fin determinado (p. 55).

Una de las principales tareas básicas en las instituciones de educación superior (IES) es la referente a la que se le denomina Gestión Educativa, encargándose de "estudiar las diversas acciones, actividades, procesos y funcionamiento de los respectivos proyectos educativos institucionales particulares o específicos, y generales o globales, en ámbitos diversos del mundo educativo" (Mora, 2009, p. 8). En esta actividad participan todos aquellos elementos sociales que se relacionan con la institución, ya sea dentro o fuera de ella. 
Apoyando lo anterior, se puede comentar que la Gestión Educativa analiza desde tres planos según su cometido: político, teórico y práctico, también llamados Gestión Institucional, Gestión Escolar y Gestión Pedagógica (SEP, 2010), las cuales interactúan y se complementan. Con relación a la primera de ellas la Gestión Institucional, es la que trata de establecer los lineamientos que proporcionan el rumbo a la administración educativa; por su parte la Gestión Escolar es referida al conjunto de operaciones necesarias que llevan a cabo todas las personas que se relacionan con el centro escolar para que los estudiantes aprendan, dicho de otra manera, es la que da sustento al quehacer pedagógico; y por último, y no menos importante, se encuentra la Gestión Pedagógica la cual se encarga de la interacción coordinada de las acciones concretas de enseñanza y la aplicación de recursos por parte del maestro.

La Gestión Pedagógica se realza en las acciones de las demás gestiones, todo esto se da en un marco específico como lo es el aula escolar, de tal manera que los buenos resultados escolares dependen de los quehaceres que se llevan a cabo dentro de ella. De esta forma, este tipo de gestión potencia su valor al interactuar entre sus elementos, ya sea el contexto escolar, las formas y estilos de enseñanza y de aprendizaje, es decir, la gestión de medios, recursos, tiempo y espacio, es lo que potencializa el logro de resultados favorables.

Hoy en día los medios de comunicación están en constante transformación gracias al avance acelerado de la tecnología, lo que compromete a los futuros maestros a estar permanentemente capacitados para aplicar los medios en sus aulas y aprovechar sus potencialidades. Las nuevas generaciones de docentes están conviviendo de manera natural con los últimos avances tecnológicos, motivo por el cual la educación está incluyendo a la tecnología en sus procesos y métodos de enseñanza.

\section{Habilidades digitales aplicadas a educación}

En la época actual y en el marco de la reforma educativa, es común ver el uso y aplicación de plataformas virtuales de aprendizajes en línea dentro de las instituciones, sobre todo en las de educación media superior y superior. Éstas son consideradas como herramientas 
fundamentales que complementan los saberes teóricos y prácticos de cada individuo, y en la gran mayoría de los casos, contar con habilidades digitales tecnológicas favorece la formación sistemática en las instituciones educativas modernas.

No cabe duda que el uso de la tecnología ha influido grandemente en las formas de aprender y de enseñar a una nueva generación de alumnos, los cuales desarrollan habilidades digitales de manera natural y continua; esto como consecuencia de estar continuamente en contacto con los ambientes tecnológicos de aprendizaje desde su nacimiento, a este tipo de individuos se les denomina "nativos digitales" (Reigeluth, 2012). Ellos adquieren su conocimiento influenciado por la teoría de la conectividad, además de basar su aprendizaje en una dependencia a la conexión del internet, de tal forma que su vida cotidiana se suscribe al uso de la tecnología. Con lo anteriormente dicho se puede afirmar que: la escuela que queremos para este nuevo siglo debe responder a las demandas educativas de los estudiantes, las cuales están basadas en el uso de los recursos tecnológicos. De esto se despliega la necesidad de contar con maestros que cuenten con las habilidades y competencias digitales necesarias para adecuar la enseñanza de tal forma que sus alumnos desarrollen competencias para la búsqueda, la resolución de problemas y uso de la información.

En la última década la práctica profesional del maestro ha experimentado una considerable evolución en el uso de los recursos de apoyo dentro del salón de clases, de tal forma que se ha apreciado una inclusión importante de herramientas digitales apoyadas en la tecnología. Dichos cambios y transformaciones están dirigidos a facilitar el acceso al conocimiento y esto ha inducido a que las instituciones se den a la tarea de integrarlos en los nuevos planes y programas de estudios, así como en las metodologías utilizadas por el docente en turno.

Para estar acorde con los nuevos enfoques metodológicos, las instituciones, así como los profesores de las mismas, deben adaptarse a este cambio significativo de la enseñanza- aprendizaje, ya que de no hacerlo ponen en riesgo la libre exploración de los saberes y la adquisición de nuevos conocimientos del individuo, debido a que a través de un navegador el alumno partirá de su propia significación y 
podrá llegar a su metacognición esperada. Castañeda y Quintero (2013) aseguran que el Sector Educativo: "no puede permanecer paralizado en sus prácticas ni en sus recursos, es preciso que se incorpore a los cambios que la ciencia está logrando" (p. 8).

No cabe duda que la integración de las redes sociales por parte del maestro en su quehacer docente tendrá un gran potencial dentro de la educación, ya que estas herramientas impulsan a los estudiantes a tener un rol más activo en su aprendizaje, por lo cual, es recomendable considerarlas como espacios factibles para hacer llegar información educativa; y una vez conectados los alumnos, pueden aprovechar su tiempo para consultar contenidos educativos e interactuar con profesores y compañeros. Para ello, se encuentran disponibles diversos sitios y servicios web que facilitan la generación de redes sociales privadas y públicas con fines específicos.

Algunos de los muchos beneficios que traen consigo las redes sociales son: favorecer la publicación de información, el aprendizaje autónomo, el trabajo en equipo, la comunicación, la retroalimentación, el acceso a otras redes afines y el contacto con otros expertos, en cualquier momento.

\section{Estrategias de enseñanza con el uso de las TIC}

Hoy en día la necesidad de que el docente esté en permanente actualización, sobre todo en lo relacionado al dominio de las TIC, es imperante, ya que el acceso a la información mantiene al día al alumnado, es indispensable que las actuaciones que se realicen dentro del aula sean innovadoras y partan de estrategias planeadas, que permitan que el aprendizaje sea significativo para el alumno.

Desde la perspectiva de la UNESCO (2008) los estándares establecidos hacen referencia al docente que el alumnado y él debe tener consolidado el dominio de las TIC, ya que esta competencia les permitirá desenvolverse de manera íntegra en la sociedad, siendo ciudadanos responsables, informados y capaces de desarrollarse y solucionar los problemas o situaciones que se les presenten. 
Cabe agregar que esta institución considera que el dominio de los medios electrónicos (móviles, ordenadores, tabletas, lectores de datos, etc.) son fundamentales para construir la sociedad del conocimiento.

Johnson, Becker, Estrada y Freeman (2014), quienes son expertos en el área de las tecnologías para la educación, plasmaron sus hallazgos en el informe "Horizon Report". En este documento identifican y describen que los aparatos tecnológicos son herramientas que impactan el aprendizaje, la enseñanza y la investigación creativa. Hacen una mención especial a los libros digitales y los teléfonos celulares, por la demanda especialmente de este último por los jóvenes.

Y a pesar de la creciente demanda de los dispositivos móviles, en la actualidad están prohibidos en muchas escuelas y, por ende, no son aprovechados como instrumentos propicios para el aprendizaje (Cárdenas, 2015; Gutiérrez, 2011; Loureiro, 2012; Robledo, 2013).

Considerando lo anterior, el Plan de Estudios 2012 (SEP, 2013) para la Licenciatura en Educación Primaria y Preescolar, puntualiza en el trayecto formativo de lengua adicional y TIC específicamente en la asignatura de "La tecnología informática aplicada a los centros escolares", lo que anteriormente refieren los autores y se plasma en el propósito que se persigue: que el docente desarrolle esas competencia digitales y las adapte acorde al contexto o ambiente educativo donde se desempeñe ya sea que utilice los ODA (objetos de aprendizaje) videojuegos, simuladores, herramientas para el trabajo colaborativo, tales como comunidades virtuales y plataformas.

Al hacer mención de una educación de calidad, el uso y dominio de las TIC tienen una diversidad de usos, ya que estos instrumentos van innovándose día con día y son más accesibles a los usuarios. Considerando esta accesibilidad, los libros de texto siguieren al docente, links que le permiten al docente reafirmar los contenidos que el plan de estudios establece. Tomado en cuenta esto, es indispensable que el docente plasme en sus estrategias las competencias con las que cuenta y éstas lo lleven a ser reconocido por la sociedad, iniciando desde su comunidad escolar.

Según lo determina el Plan de estudios (2012), el enfoque de la enseñanza debe estar centrado en el estudiante y que éste construya su conocimiento partiendo de aprendizajes que le sean significativos, por 
lo tanto el docente debe conocer los intereses de estos, facilitando esta significatividad del dominio y uso de las tecnologías que lo lleven a que los contenidos sean desarrollados y aprendidos de manera eficiente, ya que al ser utilizados por los alumnos, les permitan accesar de la mejor manera a la información y seleccionar la que le sea de utilidad en la resolución de problemas o en la adquisición de nuevos aprendizajes.

Considerando lo que el docente enfrentará en el aula, y los requerimientos que esto conlleva, es decir, que las escuelas formadoras de docentes contemplan desde su curricula, este rasgo es necesario al egreso (SEP, 2012):

- Competencias genéricas

- Emplea las tecnologías de la información y la comunicación

- Aplica sus habilidades digitales en diversos contextos

- Usa de manera crítica y segura las tecnologías de información y comunicación.

- Participa en comunidades de trabajo y redes de colaboración a través del uso de la tecnología.

- Competencias profesionales

$>$ Usa las TIC como herramienta de enseñanza y aprendizaje. * Aplica estrategias de aprendizaje basadas en el uso de las tecnologías de la información y la comunicación de acuerdo con el nivel escolar de los alumnos.

* Promueve el uso de la tecnología entre sus alumnos para que aprendan por sí mismos.

* Emplea la tecnología para generar comunidades de aprendizaje.

* Usa los recursos de la tecnología para crear ambientes de aprendizaje.

Dentro de los preceptos del plan de estudios de la LEP, dedica un trayecto formativo de los cinco que lo forman, al uso de las TIC, con el propósito de desarrollar habilidades digitales y tecnológicas, las cuales "le permitirá enriquecer el trabajo en el aula y favorecer el aprendizaje permanente y autónomo, rompiendo las barreras del espacio y el tiempo" (SEP, 2012). 
Y a la vez destina dos cursos al aprendizaje de las TIC en la educación, llamados: "Las TIC en la educación" y "La tecnología informática aplicada a los centros escolares", que se imparten en el primer y segundo semestres de la carrera respectivamente.

Como Barber y Mourshed (2008) lo afirman: "La calidad de un sistema educativo se basa en la calidad de sus docentes" (p. 15). Con este pensamiento, es necesario considerar la importancia del dominio de lo que para la sociedad del conocimiento se requiere, esto hace implícito el dominio óptimo de las TIC, la inmersión en el mundo de la informática no exime a las aulas, sino por el contrario, son la base fundamental del éxito, de esta nueva modalidad de enseñanza.

Aprendizaje que involucra a todos los actores educativos, dentro y fuera del ámbito escolar. Preparar al futuro docente, es darle las herramientas necesarias, para que como hacen mención los autores antes mencionados, poder ofrecer una educación de calidad necesaria para los docentes y alumnos del siglo XXI.

\section{Resultados}

La investigación se llevó a cabo con alumnos de séptimo y octavo semestre de las generaciones 2011-2015 y 2012-2016, en ésta última, en las licenciaturas de primaria y preescolar se implementaba un nuevo plan de estudios. El plan de estudios de la Licenciatura en Educación Preescolar de 1999, el de la Licenciatura en Educación Primaria de 1997 y el de la Licenciatura en Educación Física 2002, no contemplan asignaturas específicas que promuevan el desarrollo de habilidades tecnológicas en el futuro docente, mientras que el Plan de Estudios 2012 para preescolar y primaria incluye dentro de su malla curricular dos asignaturas que tienen como propósito favorecer en los estudiantes normalistas las habilidades tecnológicas y promover su uso en el aula como recurso educativo; y en el resto de las asignaturas que lo conforman se promueve el uso de las mismas como recurso de aprendizaje y enseñanza.

Los datos que se obtuvieron en la primera fase a partir de las observaciones realizadas en las prácticas docentes de los normalistas de $7^{\circ}$ semestre, donde se buscó qué impacto tenía la aplicación de la tecnología en las aulas, dentro de la información que se recabó fue que 
las dos generaciones tenían creatividad y facilidad para usarlas, aunque limitaban mucho su uso. Cuando la aplicación de la tecnología se mostraba obligatoria, las estrategias de enseñanza se veían favorecidas por éstas, pero cuando esto se dejaba a la elección de los futuros docentes su uso mermó notablemente.

A pesar de restringir su aplicación, se observó que los futuros docentes de las dos generaciones eran conscientes de que a través del uso de la tecnología se favorece la motivación, el interés y la curiosidad por aprender, que como recurso facilita el aprendizaje significativo y que es una herramienta hasta cierto punto familiar para los niños que asistían a sus clases.

En la segunda fase se aplicó una encuesta, la cual se dividió en 7 apartados, donde se obtuvo lo siguiente, considerando que el primer dato corresponde a la generación 2011-2015, en el ciclo escolar 20142015 y el segundo a la generación 2012-2016 en el ciclo escolar 20152016:

Competencias de entrada:

$\checkmark$ En las dos generaciones la experticia con el uso de recursos tecnológicos en su aprendizaje era del 94\%.

$\checkmark$ Las facilidades de acceso a internet en la escuela donde realizaban sus prácticas profesionales era del 36\% y 44\%.

$\checkmark$ Los normalistas consideraban que poseían suficientes o excelentes conocimientos acerca de la aplicación de los recursos tecnológicos en sus clases, eran del 85\% y 89\%.

\section{Factores de motivación}

$\checkmark$ El 94\% de ambas generaciones se sentían cómodos con el uso de tecnología digital como auxiliar en el proceso de enseñanza-aprendizaje.

\section{Habilidad en el uso de las Tics}

$\checkmark$ En la tabla 1 se puede apreciar que la generación 2012-2016 hacía uso de los recursos con mayor frecuencia que la otra. 
Tabla 1: Habilidades en el uso de las TIC (\%)

\begin{tabular}{|l|l|l|}
\hline $\begin{array}{l}\text { Generación } \\
\text { Recurso }\end{array}$ & 2014-2015 & $\begin{array}{l}\mathbf{2 0 1 5 -} \\
\mathbf{2 0 1 6}\end{array}$ \\
\hline Manejo de recursos & 68 & 93 \\
\hline $\begin{array}{l}\text { Confianza en el uso de las TIC frente a } \\
\text { grupo }\end{array}$ & 78 & 95 \\
\hline
\end{tabular}

Tabla de creación propia

\section{Aprendizaje}

El 43\% contra el 76\% de los normalistas manifestaron que los usos de los recursos tecnológicos contribuyeron significativamente para mejorar la impartición de sus clases.

\section{Opinión general}

$\checkmark$ En la tabla 2 se puede observar que las dos generaciones de normalistas consideraban que es importante el uso de los recursos tecnológicos en el aula.

Tabla 2: Opinión general sobre la importancia del uso de los recursos tecnológicos en clase (\%)

\begin{tabular}{|l|l|l|}
\hline $\begin{array}{l}\text { Generación } \\
\text { Recurso }\end{array}$ & 2014-2015 & 2015-2016 \\
\hline $\begin{array}{l}\text { Factor determinante en el } \\
\text { aprendizaje de los estudiantes }\end{array}$ & 73 & 89 \\
\hline $\begin{array}{l}\text { Herramienta de apoyo alternativa } \\
\text { para la enseñanza }\end{array}$ & 95 & 95 \\
\hline $\begin{array}{l}\text { Recurso importante para mejorar la } \\
\text { enseñanza }\end{array}$ & 85 & 93 \\
\hline $\begin{array}{l}\text { Promueve el interés y la motivación } \\
\text { de los alumnos }\end{array}$ & 95 & 98 \\
\hline $\begin{array}{l}\text { Facilita el trabajo en grupo y la } \\
\text { colaboración con los alumnos }\end{array}$ & 88 & 99 \\
\hline
\end{tabular}

Tabla de creación propia 
Necesidades de capacitación

$\checkmark$ En la tabla 3 se manifiesta que los estudiantes normalistas consideraban que habían recibido una buena capacitación sobre el uso de las TIC, más eran conscientes de que se necesita actualizarse constantemente para hacer frente a las demandas educativas.

Tabla 3: Importancia de la capacitación en el uso de TIC (\%)

\begin{tabular}{|l|l|l|}
\hline $\begin{array}{l}\text { Generación } \\
\text { Recurso }\end{array}$ & $\mathbf{2 0 1 4 - 2 0 1 5}$ & $\mathbf{2 0 1 5 - 2 0 1 6}$ \\
\hline $\begin{array}{l}\text { Cursos especiales de formación en el uso de } \\
\text { TIC para los futuros profesores }\end{array}$ & 84 & 87 \\
\hline $\begin{array}{l}\text { Formación en el uso de recursos tecnológicos } \\
\text { en el transcurso de la carrera }\end{array}$ & 79 & 87 \\
\hline
\end{tabular}

Tabla de creación propia

\section{Frecuencia y uso de tics}

$\checkmark$ En la tabla 4 se manifestaron nunca o rara vez hacer uso de los diferentes recursos tecnológicos en sus clases. En ésta se puede observar que la tendencia es a aumentar el uso de los recursos; sin embargo, aunque hacen uso constante de casi todos estos recursos de manera personal y cuentan con las habilidades suficientes para ello, no los involucran de forma clara en sus prácticas profesionales.

Tabla 4: \% de nunca o rara vez usar los recursos

\begin{tabular}{|l|l|l|}
\hline $\begin{array}{l}\text { Generación } \\
\text { Recurso }\end{array}$ & $\mathbf{2 0 1 4 - 2 0 1 5}$ & $\mathbf{2 0 1 5 - 2 0 1 6}$ \\
\hline Pizarrón electrónico & 86 & 65 \\
\hline Videoproyector & 44 & 22 \\
\hline Internet & 58 & 38 \\
\hline Juegos interactivos & 74 & 50 \\
\hline Chat & 97 & 87 \\
\hline Facebook & 97 & 82 \\
\hline Correo electrónico & 89 & 74 \\
\hline Videocámara & 93 & 87 \\
\hline Celular & 82 & 74 \\
\hline & &
\end{tabular}




\begin{tabular}{|l|l|l|}
\hline Sitios web & 81 & 57 \\
\hline Recursos REA & 97 & 83 \\
\hline Portafolio electrónico & 96 & 91 \\
\hline
\end{tabular}

Tabla de creación propia

\section{Conclusiones}

Aunque el uso personal y social de las TIC han alcanzado una expansión en varios ámbitos de la vida, al grado de considerarse imprescindible; en las prácticas docentes siguen ponderándose modelos tradicionales, donde el uso de las TIC en la escuela es bastante escaso y limitado (Andrade, 2013). Aún los estudiantes normalistas de la escuela en cuestión, quienes realizan sus prácticas profesionales en las escuelas de educación básica, ponderan por mucho el uso de materiales concretos sobre las tecnologías; lo que se puede constatar a través de los trabajos recibidos que se realizaron durante el octavo semestre y en los resultados de esta investigación.

El uso de materiales concretos ha estado presente desde el siglo pasado, sin embargo, en la actualidad existen en la red una sin número de recursos tecnológicos y cada segundo se generan más, los cuales están a disposición del público en general y de los estudiantes normalistas o de cualquier maestro, quienes pueden hacer uso libre, ya sea con fines didácticos o de gestión. Es importante mencionar que no se menosprecia la efectividad de los materiales concretos, por el contrario, se sugiere que se sigan utilizando como parte de los recursos de todo docente, pero en combinación con los recursos tecnológicos y digitales que las nuevas generaciones de niños y niñas, los tienen a su alcance de manera natural y forman parte de su vida cotidiana.

El maestro es el principal responsable de la aplicación de los recursos didácticos en el aula, sobre él recae la responsabilidad de diversificarlos; en la escuela normal, los estudiantes hacen un uso limitado de recursos, por lo que se hace necesario innovar, es menester del docente promover en sus estudiantes el uso de recursos tecnológicos tanto en sus clases en la escuela normal como en las jornadas de prácticas profesionales. Una de las dificultades de los profesores es el dominio de las TIC; por lo tanto, sus requisitos en clase se disminuyen en este rubro. Es necesario que los docentes hagan uso constante de las tecnologías en el salón de clase y de aquellas que se encuentran alojadas 
en la web, tal como lo afirma (Montes, 2015): “en el momento que el docente sea ciudadano digital, se encontrará en mejores condiciones de usar la tecnología de forma educativa con sus alumnos".

Los futuros docentes deben tener presente que ellos forman parte de las generaciones que nacieron con la tecnología en su vida cotidiana, esa es su realidad educativa, en las que el internet, la comunicación y el aprendizaje ha sido modificado y cobra mayor importancia en la sociedad actual, en la cual se insertaran como profesionales de la educación y a la cual deberán dar resultados de su trabajo. Por lo anterior se hace necesario que los estudiantes normalistas egresen con competencias en el uso pedagógico y gestión de la tecnología.

La escuela normal Miguel F. Martínez, como formadora de docentes se ha preocupado por favorecer en sus estudiantes las competencias genéricas y profesionales para que desarrollen una práctica profesional con más eficacia, de manera que se disminuya la brecha existente entre la escuela y la vida cotidiana de los niños, lo que resultaría en beneficio de los procesos de enseñanza-aprendizaje a través de los recursos tecnológicos, con profesores que innoven en sus clases. La formación de profesores debe brindarles las herramientas necesarias para llevar a cabo su labor, sobre todo, desarrollar en ellos el deseo de hacer uso de los recursos que son cercanos a sus alumnos.

Por lo tanto, la incorporación de entornos telemáticos en la formación de los estudiantes normalistas de séptimo semestre brinda una oportunidad para transformar el rol profesional que se ha venido desarrollando en las escuelas, así como los métodos y estrategias de enseñanza y de gestión; de tal manera que puedan incidir en el aprendizaje de los alumnos que tengan a su cargo, tal como la afirman Lafrenz y Friedman (1989): "los ordenadores no cambian la educación, los profesores, sí”.

\section{Referencias bibliográficas}

Cárdenas, A. (2015). jProbibido usar el celular en el salón de clases! Recuperado el 26 de 03 de 2016, de Forbes, México: http://www.forbes.com.mx/prohibido-usar-el-celular-en-el-salonde-clases/ 
Lafrenz, D., \& Friedman, J. (1989). Computers don't change education, teachers do! (Vol. 59). Harvard Educational Review.

Castañeda, A. Q. (2013). El uso de las TIC en Educación Primaria: la Experiencia ENCICLOMEDLA. México: Red de Investigadores Educativos, A. C.

Latorre, A., Rincón, D., \& Arnal, J. (2005). Bases metodológicas de la investigación educativa. Barcelona: Ediciones Experiencia.

Loureiro, M. (2012). Sobre la probibición del uso de teléfonos móviles en escuelas e institutos. (C. y. Ministerio de Educación, Productor) Recuperado el 15 de 03 de 2016,de educ@con TIC: http:/ /www.educacontic.es/blog/sobre-la-prohibicion-del-uso-detelefonos-moviles-en-escuelas-e-institutos

López, O. (2006). Medios y Materiales Educativos. Lambayeque, Perú: Universidad Nacional "Pedro Ruiz Gallo".

Andrade, J. (2013). Creencias sobre el uso de las TIC de los docentes de educación primaria en México. Sinéctica(41).

Araiza, M. (01 de 01 de 2012). Evaluación de Medios Instruccionales y Tecnología Educativa. Programa de Estudio. (E. d. Postgrado, Ed.) Monterrey, Nuevo León, México.

Barber, M., \& Mourshed, M. (2008). Cómo bicieron los sistemas educativos con mejor desempeño del mundo para alcanzar sus objetivos. Santiago, Chile: Editorial San Marino.

Dorrego, E. (14 de 04 de 2009). Diseño instruccional de los medios y estrategias cognitivas. Comunicar(08), 8.

Gutiérrez, F. (2011). El dispositivo móvil como espacio de aprendizaje e información en las redes sociales. Infoconexión(3), 1-11. Hernández, R., Fernández, C., \& Baptista, P. (2010). Metodología de la invstigación ( $5^{\mathrm{a}}$ ed.). México, México: McGraw-Hill.

Johnson, L., Adams, S., Estrada, V., \& Freeman, A. (2014). The NMC Horizon Report: 2014 Higher Education Edition. Austin, Texas: The New Media Consortium.

Johnson, L., Becker, S., Estrada, V., \& Freeman, A. (2014). NMC Horizon Report > 2014 Higher Education Edition. Austin, Texas, USA: The New Media Consortium.

Kerlinger, F., \& Howard, L. (2001). Investigación del comportamiento: Métodos de investigación en ciencias sociales ( $4^{\mathrm{a}} \mathrm{ed}$.). México: McGrawHill. 
Martínez, G. (2009). La Guía Metodológica. Linea de Trabajo. Uso didáctico de las Tecnologías de la Información y Comunicación. México: SEP.

Mora, D. (2009). Objeto e importancia de la gestión educativa . Integra Educativa. Revista de Investigación Educativa (6), 7-12.

Morduchowicz, R., Marcón, A., \& Camarda, P. (2006). Los Medios de Comunicación en la Escuela: un abordaje reflexivo, una actitud crítica. Argentina: Ministerio de Educación, Ciencia y Tecnología.

Robledo, J. (2013). Dispositivos móviles para el aprendizaje Lo que usted necesita saber. EDUTOPIA.

Roig-Vila, R. (2003). Análisis y valoración de sitios web de centros escolares. Nueva York: The Edwin Mellen Press.

Roquet, G., \& Gil, M. (2010). Los medios y los materiales didácticos en la educación a distancia: conceptualizaciones. (U. N. UNAM, Productor) Recuperado el 29 de 08 de 2013, de Boletín SUAyED: http:/ / www.cuaed.unam.mx/boletin/boletinesanteriores/boletinsu ayed $21 /$ medios.php

Schunk, D. H. (1997). Teorías del aprendizaje. México:: Prentice Hall Hispanoamericana.

Sánchez, A., \& Castro, D. (2013). Cerrando la brecha entre nativos e inmigrantes digitales a través de las competencias informáticas e informacionales. Apertura. Revista de innovación educativa5, (2).

SEP. (2009). ACUERDO número 494. Diario Oficial de la Federación, DCLXXII(5).

SEP. (2010). El Modelo de Gestión Educativa Estratégica. (SEP,

Productor) Recuperado el 22 de 10 de 2014, de Programa de Escuelas de Calidad:

http://basica.sep.gob.mx/pec/start.php?act=modelo

SEP. (2011). Plan de estudios 2011. Educación Básica. México: SEP.

SEP. (2012). Licenciatura en Educación Primaria (plan 2012). México: SEP.

Shulman, L. (2005). Conocimiento y Enseñanza: Fundamentos de la Nueva Reforma. Profesorado, 9(2).

Tynjälä, P. (1997). Developing education students' conceptions of the learning process in different learning environments. Learning and Instruction.

UNESCO. (2008). Estándares de Competencias en TIC para Docentes. Londres: OEI. 



\title{
10 \\ Matrimonios igualitarios, adopción homoparental y marcha por la familia: Una propuesta para estudiar la participación ciudadana en la construcción de controversias en la esfera pública digital mexicana
}

\author{
Brenda Azucena Muñoz Yáñez \\ Profesor Investigador, Universidad Autónoma de Coabuila \\ brenda.munoz@uadec.edu.mx \\ Miguel Sánchez Maldonado \\ Profesor Investigador, Universidad Autónoma de Coabuila \\ miguelsanchez@,uadec.edu.mx \\ Gabriela de la Peña Astorga \\ Profesor Investigador, Universidad Autónoma de Coahuila \\ gabriela.pena@uadec.edu.mx
}

\section{Resumen}

En esta comunicación presentamos el protocolo de investigación de nuestra propuesta para estudiar la participación ciudadana en la construcción de controversias en la nueva esfera pública mediatizada. Nuestro punto de partida es el cambio sustancial que sufre la esfera pública al integrar al debate público información y contenidos que circulan por plataformas y medios de comunicación emergentes que dan cabida a una pluralidad de perspectivas entre las cuales se escuchan las voces de ciudadanos. Tomamos como caso de estudio la controversia creada en torno a la legislación de matrimonios igualitarios y la adopción homoparental en México durante el segundo semestre de 2016. Nuestra propuesta se centra en recuperar los contenidos que circularon por distintas plataformas de la esfera pública digital mexicana con la finalidad de mapear la controversia, identificar los 
picos informativos, así como los principales actores y perspectivas planteadas. Todo esto, con la finalidad de observar la integración de contenidos generados por usuarios/ciudadanos a la narración de la controversia. Aunque cada plataforma de comunicación, como objeto de estudio, requiere un tratamiento especial de acuerdo a sus características distintivas, concluimos que no es posible hablar de temas como esfera pública y agenda mediática sin integrar al estudio un componente de cómo participan los ciudadanos en el debate público a través de estas plataformas.

Palabras clave: medios emergentes, participación, diversidad, agenda pública, controversias, contenidos alternativos.

\section{Abstract}

In this document we present the research protocol regarding our proposal to study citizen participation in construction of controversies in the new mediatized public sphere. Our starting point is the substantial change that the public sphere suffers when it incorporates to the public debate information and contents that flow through digital platforms and emergent media that accommodate a plurality of perspectives among which the voices of citizens are heard. We take as a case of study the controversy created around gay marriage and homoparental adoption legislation in Mexico during the second half of 2016. Our proposal focuses on retrieving the contents that circulated through the Mexican digital public sphere's different platforms. We aim to map the controversy, identify information peaks as well as the principal actors and perspectives exposed. All this, in order to look at the way user/citizen generated contents are integrated to the controversy's narrative. Even though each digital platform, as an object of study, requires a special treatment according to their distinctive features, we conclude that it is no longer possible to talk about public sphere and media agenda without the study of the way citizens participate in the public debate through these platforms.

Keywords: emergent media, participation, diversity, public agenda, controversies, alternative contents. 


\section{Introducción}

$\mathrm{E}$ L propósito de esta comunicación es presentar el protocolo de nuestra propuesta para el estudio de la participación ciudadana en la nueva esfera pública mediatizada. Cuando hablamos de la nueva esfera pública mediatizada, hacemos referencia a la transformación que sufre la esfera pública habermasiana al integrar al debate público información y contenidos que circulan en plataformas y medios de comunicación emergentes como YouTube, Twitter, Facebook, podcasts y agencias de noticias en línea. Aunque es probable que los medios tradicionales siguen constituyendo el primer plano de visibilidad de la escena pública, en el Cuerpo Académico (CA) "Comunicación, Diversidad y Desarrollo Social" (UACOAH-CA-87), creemos que la participación que tienen otros actores (organizaciones civiles, audiencias) en estos medios emergentes de comunicación contribuyen a enriquecer y expandir el alcance del debate sobre los distintos temas que se discuten en la esfera pública. Más aún, creemos que la información y contenidos que circulan por estas plataformas a las que hacemos alusión son más propensos a presentar una pluralidad de perspectivas que como menciona Peñamarín (2016) es esencial para asegurar la vida democrática de un país.

Este supuesto del que partimos no es una mera elucubración, sino que es congruente con el modelo desde el que surgen estas plataformas y medios de comunicación emergentes de los que hablamos. YouTube, por citar un ejemplo, propone una simplificación del proceso para la sumisión de video y una reducción de los requerimientos para reproducir video en línea de manera fiel, de tal forma que desde el 2005 funciona como un foro donde los creadores no profesionales publican y experimentan con la creación de mensajes audiovisuales que rompen la norma hollywoodense. La incursión de productores profesionales de contenidos en el sitio ha provocado que en dicha plataforma se entrelacen los distintos discursos que circulan en la población (oficial, no oficial, hegemónico, alternativo, resistente) de tal suerte que presenciamos ahí un debate digno de ser estudiado desde la agenda pública. De igual forma, podemos observar cómo cada una de las plataformas de comunicación de reciente creación advierten la remediación de una necesidad esencial: la inclusión de la voz ciudadana en las controversias que surgen en la esfera pública. 


\section{Antecedentes}

El año 2016 en México estuvo caracterizado por una serie de controversias que tuvieron lugar en la esfera pública mediatizada. Escándalos por la corrupción de exgobernadores, la captura de Joaquín "El Chapo" Guzmán, el narcotraficante más buscado en México y Estados Unidos, y la iniciativa presidencial por legalizar los matrimonios entre personas del mismo sexo ocuparon la mayor parte de la agenda mediática del país (Muñoz-Yáñez, 1 de enero de 2017). Nosotros hemos decidido centrarnos en el último de estos temas porque consideramos que tiene una mayor relevancia al tocar un tema sensible en toda la sociedad mexicana y sobre todo porque representa un cambio en la vida cotidiana de todos los ciudadanos. Sociedad civil, comunidad LGBT, Organizaciones No Gubernamentales e instituciones públicas se integraron al debate a través de la distribución de información y contenidos producidos por una pluralidad de voces, pero también a través de la acción social colectiva cristalizada en diversas marchas a lo largo y ancho del país a favor o en contra de la iniciativa planteada por el Presidente de la República (Rebolledo, 1 de enero de 2017).

La iniciativa presidencial de reconocimiento al matrimonio igualitario y la adopción homoparental fue recibida por el Congreso de la Unión el 18 de mayo de 2016. El propósito de dicha iniciativa fue modificar el artículo 4 constitucional y diversos artículos del Código Civil para garantizar la no discriminación a la comunidad LGBT. Su difusión mediática suscitó la polarización de posturas en la sociedad mexicana y dio nacimiento al Frente Nacional por la Familia (FNF, 2017). Respaldado por instituciones religiosas, el FNF convocó a una serie de marchas para exigir a los legisladores revocar la iniciativa presidencial agudizando aún más el conflicto en este tema. Dicha división de posturas se observó también entre los legisladores, quienes finalmente rechazaron la iniciativa en noviembre de ese mismo año (Aristegui Noticias, 9 de noviembre de 2016)

Por su parte, el reconocimiento a los derechos de la comunidad LGBT en Coahuila ha tenido otro camino. En enero de 2007, el Congreso del Estado aprobó la creación del Pacto Civil de Solidaridad que conllevó un conjunto de reformas al artículo 385-1 del Código Civil del Estado de Coahuila. Este Pacto Civil avala la unión civil de dos personas con 
mayoría de edad, sin importar su sexo o género, con la finalidad de organizar su vida en común. No obstante, este tipo de contrato tenía algunas carencias relacionadas a los derechos de seguridad social y vivienda de la pareja. Estas y otras carencias se subsanaron el 1 de septiembre de 2014 cuando el Congreso Estatal aprobó la legalización del matrimonio igualitario garantizando a las parejas homosexuales los mismos derechos que tuvieren las parejas heterosexuales. En relación a la adopción homoparental, el Código Civil del Estado de Coahuila fue modificado en febrero de 2014 al derogar el artículo 385-7 donde se prohibía a las parejas del mismo sexo realizar adopciones.

El caso del estado de Coahuila de Zaragoza es excepcional en relación a lo que ocurre al interior de la República Mexicana, donde la lucha por la legalización del matrimonio igualitario sigue durante el 2017. Y, en ese sentido, propone un escenario en donde las posturas en relación al tema de matrimonios igualitarios y adopción homoparental han ido madurando. Tal es así que en durante el periodo más agitado de la controversia se pudo observar a líderes religioso manifestarse a favor de los derechos de la comunidad LGBT (cf. Vanguardia, 12 de septiembre de 2016).

Tomando en consideración lo arriba planteado, el problema de investigación que detectamos consiste en que no conocemos cómo se construyó la controversia sobre la legislación de matrimonios igualitarios y la adopción homoparental en distintas plataformas y medios de comunicación de la esfera pública digital mexicana, a nivel nacional y estatal, durante el segundo semestre de 2016. Y, específicamente, cómo participaron los contenidos creados por usuarios/ciudadanos en dicho debate.

\section{Justificación}

El estudio de la comunicación de la diversidad es un trabajo esencial que realiza el CA "Comunicación, Diversidad y Desarrollo Social" (UACOAH-CA-87) desde su fundación en 2009. El tema de los derechos conyugales de parejas del mismo sexo ha sido una preocupación constante de nuestro grupo de investigación, especialmente desde que en 2014 se reconocieron estos derechos en el estado (Congreso del Estado Independiente, Libre y Soberano de Coahuila de Zaragoza, 1 de septiembre de 2014). En ese sentido, nos 
interesa seguir cultivando esta línea de investigación y conocer cómo se fue integrando a nivel nacional la polifonía del discurso sobre matrimonios igualitarios y adopción homoparental en medios y plataformas de comunicación emergentes.

Como grupo de investigación orientado al trabajo de investigación para el desarrollo social, creemos que el reconocimiento de los derechos que tiene la comunidad LGBTI en materia de matrimonio y adopción de menores contribuye a formar comunidades atentas a la diversidad que caracteriza a nuestra sociedad, a los cambios que ha sufrido el concepto de familia en nuestros tiempos y a la valoración de los derechos humanos que todos debemos tener. Además, creemos que la ciudadanía se construye en el debate racional de las cuestiones de la esfera pública donde haya una pluralidad de actores. Es por esto que nos interesa conocer con qué perspectivas sobre este tema se encuentra el consumidor de medios en Internet y si aprovecha las facilidades de estas plataformas para integrarse también en el debate público.

Académicamente, este estudio tributa a la investigación realizada sobre agenda mediática en la medida que ofrece una propuesta para estudiar la circulación de información y contenidos en este tipo de medios y plataformas que, por su naturaleza entrópica, en ocasiones parece impenetrable. En este punto, quisiéramos mencionar que este proyecto forma parte de la Red Temática de Colaboración Académica "Estudios mediáticos de la agenda pública", en la que los cuerpos académicos "Comunicación para el desarrollo social" (UCOAH-CA-87) de la Universidad Autónoma de Coahuila, "Estudios de Comunicación Mediática, Educativa y Organizacional" (UANL-CA-204) de la Universidad Autónoma de Nuevo León, y el Departamento de Periodismo III: Semiótica, Comunicación y Cultura de la Universidad Complutense de Madrid, proponemos múltiples perspectivas para estudiar la construcción de controversias en la esfera pública mediatizada. Creemos que al trabajar proyectos de este tipo en red con otros grupos de investigación tenemos la oportunidad de acceder a otros enfoques que enriquecen la propuesta metodológica para abordar este, relativamente nuevo, objeto de estudio. Este proyecto no sería posible sin el apoyo que hemos recibido por parte del Programa para el Desarrollo Profesional Docente de la Secretaría de Educación Pública Federal. 


\section{Objetivos de investigación}

Con el propósito de reconocer la participación de los distintos actores que participaron en la controversia sobre la legalización de matrimonios igualitarios y adopción homoparental, y sus perspectivas, se estableció como objetivo general de la investigación el siguiente:

Realizar un mapeo de la controversia generada en torno a la cuestión "legislación de matrimonios igualitarios y adopción homoparental" en la esfera pública digital mexicana durante el segundo semestre de 2016, con la finalidad de advertir la participación ciudadana en el cuasirrelato de la controversia.

A su vez, nos hemos planteado los siguientes objetivos específicos a fin de establecer una ruta por medio de la cual podamos alcanzar nuestro propósito.

1. Identificar los picos informativos en torno a la cuestión "legislación de matrimonios igualitarios y adopción homoparental" en los flujos de información de la esfera pública digital mexicana durante el segundo semestre de 2016. 2. Reconocer a los principales actores que participaron en la controversia generada en torno a la cuestión "legislación de matrimonios igualitarios y adopción homoparental" en el flujo de información de la esfera pública digital mexicana durante el segundo semestre de 2016.

3. Distinguir las diferentes perspectivas que fueron representadas en la controversia generada en torno a la cuestión "legislación de matrimonios igualitarios y adopción homoparental" en el flujo de información de la esfera pública digital mexicana durante el segundo semestre de 2016.

4. Reconocer la integración de contenidos generados por usuarios/ciudadanos en los flujos de información de la controversia.

\section{Delimitación y limitaciones del estudio}

A juzgar por los antecedentes del problema que hemos planteado, en Coahuila la controversia en torno a la cuestión "legislación de matrimonios igualitarios y adopción homoparental" es de tipo circular. 
Esto quiere decir que es una cuestión que se discute de manera recurrente en la esfera pública en correspondencia con el desarrollo de dicha legislación. Cada progreso registrado en dicha legislación enciende los ánimos de debate entre los distintos sectores de la población. En ese sentido, el posicionamiento federal realizado en mayo de 2016 ante dicha cuestión incitó un nuevo debate. En esta ocasión el punto más candente del debate se situó alrededor de un movimiento ciudadano nacional que promovía la defensa del paradigma tradicional de familia: Frente Nacional por la Familia. Por tal motivo, sin perder de vista la cuestión que nos interesa, el estudio que aquí proponemos está delimitado por el contexto específico que estimularon las marchas a las que convocó esta asociación el 10 y 24 de septiembre de 2016 (FNF, 2017).

Por otro lado, es importante mencionar que por ser un estudio a posteriori, nuestro proyecto tiene una limitación importante sobre todo en relación a la recuperación de la información en Twitter. Debido a nuestro interés en rastrear la participación ciudadana en la controversia que hemos venido discutiendo, esta situación es importante porque Twitter es quizá la red social en la que se discuten las cuestiones públicas por antonomasia. No obstante, para menguar esta limitación, como veremos en el siguiente apartado, nuestra estrategia metodológica tiene contemplado que todos los sectores de la población y sus posturas se vean representados en el mapeo de la controversia.

Para cerrar este apartado, quisiéramos precisar también que el mapeo de controversias no es un método de intervención social. Como puede verse en nuestros objetivos, nuestra intención es explorar y visualizar cómo se dio el debate sobre la cuestión que planteamos en los diferentes públicos y sectores de la población. En ese sentido, proponer soluciones al debate sobre "legislación de matrimonios igualitarios y adopción homoparental" cae fuera de los objetivos de este estudio. Buscaremos, no obstante, que la representación de la controversia que presentemos sea lo más neutral posible.

\section{Estrategia metodológica}

De acuerdo con Venturini, Ricci, Mauri, Kimbell y Meunier (2015), la fase más importante del análisis de una controversia es el diseño metodológico. De ahí que sea esencial reconocer que el estudio de 
controversias en la esfera pública es una tarea interdisciplinaria que involucra tanto a la sociología y la comunicación como a las ciencias computacionales y el análisis político (Marres, 2015). En la estrategia metodológica que presentamos para el estudio de la cuestión que hemos planteado, "legislación de matrimonios igualitarios y adopción homparental", se puede observar que tomamos mano de técnicas de investigación propias de la comunicación como el análisis de contenido, pero también de tácticas computacionales para recuperar altos volúmenes de información que nos ayuden a tener un amplio panorama de cómo se construyó dicha controversia.

En primer lugar, quisiéramos explicar el enfoque desde el cual hemos diseñado esta estrategia. Nuestro estudio se corresponde con el paradigma de métodos mixtos en la medida en que está contemplada la implementación de análisis de contenido, minería de datos, etnografía virtual y análisis semiótico-textual de forma complementaria. Marres (2015) propone tres enfoques desde los cuales se puede realizar la implementación digital del análisis de controversias: demarcación, discurso y empirismo. La demarcación se refiere a la utilización de métodos computacionales para reconocer cuestiones controversiales; el enfoque discursivo se refiere a la identificación de posturas en un debate; y el enfoque empirista a la utilización de métodos computacionales para identificar ocasiones para la investigación empírica (Marres, 2015, pp.658-659). Si bien la estrategia que aquí proponemos tiene un componente cercano al análisis del discurso al explorar la construcción narrativa de la controversia, el diseño tiene un enfoque empirista ya que pretendemos implementar técnicas de minería de datos con la finalidad de localizar los puntos de encuentro entre las distintas posturas que luego serán examinadas mediante análisis semiótico-textual. No obstante, estos enfoques, discursivo y empirista, no se contraponen ya que ambos comparten una preocupación por analizar la composición de la controversia.

En segundo lugar, quisiéramos exponer la estrategia metodológica general a implementar para cumplir nuestro objetivo: Realizar un mapeo de la controversia generada en torno a la cuestión "legislación de matrimonios igualitarios y adopción homoparental" en la esfera pública digital mexicana durante el segundo semestre de 2016, con la finalidad de advertir la participación ciudadana en el cuasirrelato de la controversia. Esta estrategia está diseñada de tal forma que podamos explorar la composición de la controversia en distintas 
plataformas de la esfera digital pública mexicana. El punto de arranque consiste en la aplicación de un instrumento de análisis de contenido a una muestra no probabilística recuperada por cuotas de los productores noticiosos online más relevantes en México. En dicha muestra se integran las dos agencias de noticias online más leídas, y otro tanto de diarios nacionales y locales en su versión electrónica, portales especializados y podcasts. Tomando como unidad de análisis la nota informativa, el análisis de contenido nos permitirá identificar los picos informativos de la controversia, los principales actores involucrados y las posturas manifestadas.

Una vez que hayamos identificado a los principales actores de la controversia, podremos continuar con el seguimiento de la controversia que los distintos públicos realizan en Twitter y YouTube. A través de la minería de datos, nuestro propósito es establecer la complejidad de la controversia y el grado de involucramiento de los públicos que, por un lado, constituyen dos aspectos esenciales en el mapeo de las controversias (Venturini et al., 2015), y, por otro lado, nos es útil para ubicar la participación ciudadana en la controversia. La minería de datos es el proceso de descubrir patrones en grandes corpus de datos para transformar dichos datos en estructuras propicias para la investigación. Para este proyecto en específico, en la Facultad de Ciencias de la Comunicación de la UAdeC contamos con una serie de códigos programáticos que facilitan la recopilación de datos de estos dos sitios. Estos códigos son administrados por el Dr. Antonio Corona, a quien también le agradecemos su apoyo.

La etapa final de nuestra estrategia consiste en la práctica de etnografía virtual para recuperar un corpus más pequeño de mensajes que representen las posturas más relevantes en la controversia. Sobre este corpus aplicaremos un instrumento de análisis semiótico textual a fin de reconocer la convergencia de distintas perspectivas y explorar la dimensión narrativa de la controversia. Si bien Venturini et al. (2015) consideran que este aspecto debería realizarse previo a la examinación del involucramiento de los públicos, nosotros lo colocamos al final porque creemos que los públicos también participan en la dimensión narrativa de la controversia. 


\section{Para concluir y discutir: participación ciudadana en la esfera pública mediatizada}

Al recuperar la teorización sobre esfera pública, Castañares (2016) sugiere que ésta puede ser considerada como un "escenario institucionalizado de interacción discursiva en el que los ciudadanos piensan y examinan asuntos comunes" (p. 1). En este sentido, una cuestión que trastoca la vida cotidiana de los ciudadanos, como la legislación de matrimonios igualitarios y la adopción homoparental, es más proclive a crear controversias en la esfera pública ya que implica un cambio en el paradigma de familia que ha caracterizado a nuestras sociedades. En este punto, en el CA "Comunicación, Diversidad y Desarrollo Social", nos enfrentamos ante una disyuntiva al realizar la delimitación del estudio. Si bien hemos delimitado nuestra controversia de forma temporal en torno a dos eventos masivos convocados por el Frente Nacional por la Familia, tememos que al estudiar la participación de este sector de la población estemos alentando las posturas oposicionales a la legislación de matrimonios igualitarios y adopción homoparental, cuando nuestro objetivo como CA es promover el aprecio a la diversidad.

Por otro lado, aunque la intención de proponer un diálogo sobre cierta cuestión en la esfera pública es que la comunidad llegue a un consenso, lo cierto que es que la exposición de posturas contrastadas sobre dicha cuestión propicia la aparición de conflictos entre los distintos actores (Castañares, 2016). En ese sentido, nos interesa que todas las voces se vean representadas y encontrar esos espacios que funcionan para el diálogo, esos espacios en los que el ciudadano común se integra al debate público sobre una cuestión controvertida.

Ahora bien, Saiz Echezarreta (2016) señala: “Al enfrentarse a una situación que interpretan como problemática, los sujetos movilizan su capacidad de agencia, poder y recursos simbólicos para imaginar, diseñar y desarrollar estrategias, programas de acción, compromisos, alianzas, etc." (Saiz Echezarreta, 2016, pp. 3-4). En el mismo tenor, Peñamarín (2016) propone integrar un componente pragmático al estudio de las controversias en la esfera pública. Este componente pragmático da cuenta de la evolución del debate público sobre una cuestión en relación a sí misma y sin tener actores constituidos de manera previa a su emergencia. Dar seguimiento a una controversia 
desde este componente pone en relieve la participación de distintos públicos que pueden verse afectados por dicha cuestión y podría nivelar la participación de voces de los distintos sectores de la sociedad.

No obstante, debemos agregar que, específicamente en el caso de plataformas y medios de comunicación emergentes como los que nos proponemos estudiar, la participación de los actores no es igual, sobre todo en lo que se refiere a la visibilidad de perspectivas alternativas. En YouTube, por ejemplo, se observa que son escasos los puntos de encuentro de contenidos profesionales y las propuestas alternativas que emergen de contenidos generados por usuarios (Muñoz, 2016) lo que nos lleva a pensar en que son escasos los espacios en que se lleva a cabo el diálogo entre actores con diferentes posturas.

Esto es importante porque quiere decir que, a diferencia de lo que ocurría antes, cuando la visibilidad de cuestiones de la esfera pública se concentraba en espacios fijos y estables, en la actualidad parece que las distintas perspectivas de una controversia tienen una alta visibilidad en una plataforma mientras que en otra tienen poca o nula presencia. Por ejemplo, en el caso que nos proponemos estudiar, podemos aventurar que en las agencias de noticias en línea orientadas a difundir el quehacer cristiano tendrán mayor visibilidad las perspectivas orientadas a preservar el paradigma de familia constituido por una pareja heterosexual e hijos; mientras que en los portales orientados al público gay observaremos predominancia de perspectivas a favor de la legislación de matrimonios igualitarios y adopción homoparental. El reto, para esta nueva composición de la esfera pública mediatizada, entonces, es reconocer cuáles son estos puntos de encuentro en el que se entrelazan y contrastan las perspectivas porque es ahí en donde se está realmente discutiendo la cuestión, ese es su espacio de diálogo.

\section{Referencias}

Aristegui Noticias. (2016, 9 de noviembre). Rechazan diputados reforma constitucional de EPN sobre matrimonios igualitarios. Disponible en:

http://aristeguinoticias.com/0911/mexico/rechazan-diputadosreforma-constitucional-de-epn-sobre-matrimonios-igualitarios/ [Consulta: 2017, 9 de agosto]. 
Castañares, W. (2016). Relato y controversia de un asunto de gran impacto público: la educación. Ponencia presentada en $L a$ Construcción de los Asuntos Públicos en la Esfera Mediatizada. Encuentro 2016, Universidad Complutense de Madrid, 18 y 19 de noviembre de 2016. Madrid, España.

CNN. (2014, 2 de septiembre). Coahuila aprueba el matrimonio entre parejas del mismo sexo. Expansión. Disponible en:

http://expansion.mx/nacional/2014/09/02/coahuila-aprueba-elmatrimonio-entre-parejas-del-mismosexo?internal source=PLAYLIST [Consulta: 2017, 9 de agosto].

Congreso del Estado Independiente, Libre y Soberano de Coahuila de Zaragoza. (2014, 1 de septiembre). Decreto de reforma y derogación a las disposiciones del Código Civil y Procesal Civil referente a "Requisitos para Contraer Matrimonio". Disponible en: http://www.congresocoahuila.gob.mx/portal/wpcontent/uploads/2014/11/20140901.pdf [Consulta: 2017, 9 de agosto].

Congreso del Estado Independiente, Libre y Soberano de Coahuila de Zaragoza. (2016, 13 de diciembre). Ley para las familias de Coahuila de Zaragoza. Capítulo décimo segundo del Pacto Civil de Solidaridad. Disponible en:

http://congresocoahuila.gob.mx/portal/wpcontent/uploads/2014/11/coa233.pdf [Consulta: 2017, 9 de agosto].

Frente Nacional por la Familia. (2017). ¿Quiénes somos? Disponible en: http://frentenacional.mx/ [Consulta: 2017, 9 de agosto].

Marres, N. (2015) Why map issues? On controversy analysis as a digital method. Science, Technology \& Human Values, 40 (5), 655-686. doi: 10.1177/0162243915574602

Muñoz, B. (2016). Distribución de videos profesionales y no profesionales en el entramado semántico de YouTube México. Ponencia presentada en el $7^{\circ}$. Congreso Internacional de Sociología. Voces de resistencia: miradas criticas desde la Sociología, Universidad Autónoma de Baja California, 26-29 de septiembre de 2016. Ensenada, México. 
Muñoz-Yáñez, S. (Ed.) (2017, 1 de enero). Resumen económico y de noticias 2016. El siglo de Torreón.

Peñamarín, C. (2016). Pragmática de la esfera pública. Issues, mediatización y controversias. Ponencia presentada en $L a$ Construcción de los Asuntos Públicos en la Esfera Mediatizada. Encuentro 2016, Universidad Complutense de Madrid, 18 y 19 de noviembre de 2016. Madrid, España.

Rebollledo, R. (2017, 1 de enero). Anuario 2016: Las 6 noticias de política nacional del año. El economista. Disponible en: http://eleconomista.com.mx/sociedad/2017/01/01/anuario2016-las-6-noticias-politica-nacional-ano [Consulta: 2017, 9 de agosto].

Saiz Echezarreta, V. (2016). Deliberación y trabajo sexual en la esfera pública mediatizada. Ponencia presentada en La Construcción de los Asuntos Públicos en la Esfera Mediatizada. Encuentro 2016, Universidad Complutense de Madrid, 18 y 19 de noviembre de 2016. Madrid, España.

Vanguardia. (2016, 12 de septiembre). Los homofóbicos están malitos de la cabeza: Obispo Raúl Vera. Disponible en: http://www.vanguardia.com.mx/articulo/los-que-dicen-que-elhomosexual-es-un-enfermo-son-los-que-estan-enfermos-obispo [Consulta: 2017, 9 de agosto].

Venturini, T., D. Ricci, M. Mauri, L. Kimbell, and A. Meunier. (2015). Designing Controversies and their Publics. Design Issues, 31 (3), 7487. doi: 10.1162/DESI_a_00340 


\section{Los Autores}

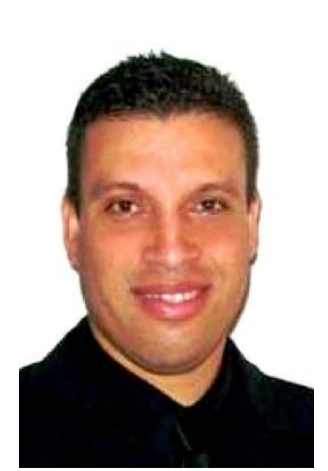

\section{Carlos Gustavo González Campos Universidad Rafael Urdaneta, Venezuela cggcna@,hotmail.com}

Magister en Gerencia de Empresas. Mención: Gerencia de Mercadeo, mención publicación en tesis de grado; Estudiante Doctorado en educación UNERMB; Profesor de cátedras de Mercadeo. Investigador con publicación de artículo científico en revista digital y de memorias en libro del congreso Iberoamericano de Personal Branding celebrado en UANL, México.

http://orcid.org/0000-0002-3945-8030

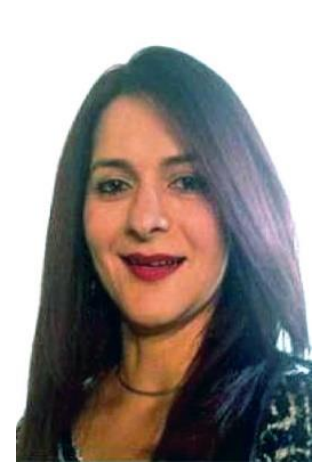

María Cristina Useche Aguirre, Universidad del Zulia, Venezuela

mariauseche@yahoo.es

Doctora en Ciencias Económicas. Magister en Gerencia de Empresas. Mención: Mercadeo. Economista. Investigadora del Consejo de Desarrollo Científico y Humanístico de la Universidad del Zulia. Docente titular en el departamento de ciencias administrativas, adscrita al Centro de Estudios de la Empresa de la Faculta de Ciencias Económicas y Sociales de la Universidad del Zulia. Premio Promoción a la Investigación e Innovación en Venezuela. Nivel C. http:orcid.org/0000-0001-5057-0034 


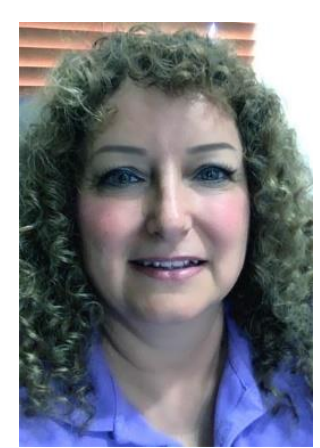

Flor del Carmen Montes Rodríguez

Escuela Normal Miguel F. Martínez

Centenaria y Benemérita, México

flor.montes@enmfm.edu.mx

Doctora en Educación con acentuación en Comunicación y Tecnología Educativa. Responsable del departamento de Tutorías y docente de tiempo completo de la Escuela Normal "Miguel F. Martínez". Líder del cuerpo Académico Lux, Pax, Vis: Modelos y procesos en la formación docente. http://orcid.org/0000-0002-8823-1780

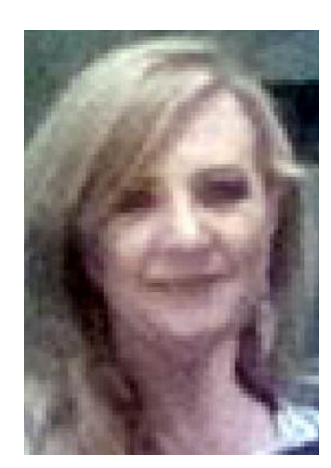

\section{Cyomara Inurrigarro Guillén}

Escuela Normal Miguel F. Martínez Centenaria y Benemérita, México

cyomara.inurrigarro@enmfm.edu.mx

Maestría en Metodología de la Ciencia. Catedrática de la ENMFM. Directora de Curriculum del Colegio San Patricio. Miembro del Cuerpo Académico Alma Mater. http:// orcid.org/0000-0002-9771-1794

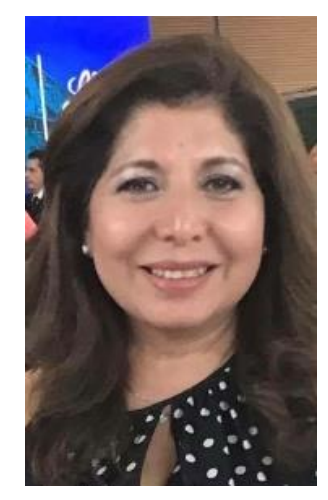

\section{Ma. Guadalupe Martínez Ortiz}

Escuela Normal Miguel F. Martínez

Centenaria y Benemérita, México

guadalupe.martinez@enmfm.edu.mx

Doctora en Investigación e innovación Educativas. Actualmente, docente de tiempo completo en la Escuela Normal Miguel F. Martínez e integrante del cuerpo académico "Alma Mater". Responsable de Planeación Estratégica en la Institución. Miembro del equipo de Evaluación CIEES a nivel nacional. http://orcid.org/0000-0002-1905-3597 


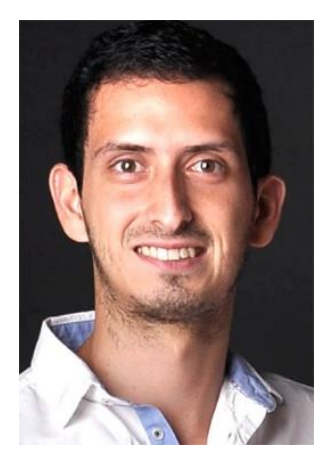

\section{Oscar Yael Navarro Montes}

Escuela Normal Miguel F. Martínez

Centenaria y Benemérita, México

oscar.navarro@enmfm.edu.mx

Licenciado en Educación Primaria por la Escuela Normal Miguel F. Martínez. Cursó Reflexión y Mejora de la Práctica Docente, y Gestión de los Procesos de Enseñanza y Aprendizaje dentro del Aula por el Instituto de Investigación, Innovación y Estudios de Posgrado para la Educación. http://orcid.org/0000-0001-9167-4454

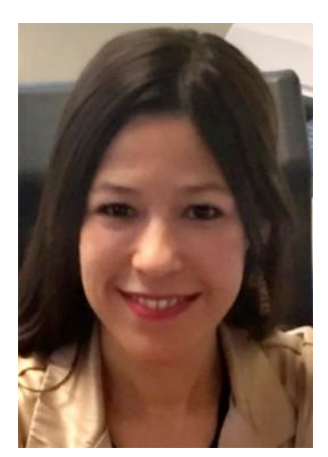

\section{Selene Céspedes del Fierro}

Universidad Autónoma de Nuevo León, México

selene.cespedesf@,uanl.mx

Doctora en Educación, Sociedad y Calidad de Vida con mención internacional por la Universidad de Lleida, España. Profesora de Relaciones Públicas en la Facultad de Ciencias de la Comunicación de la UANL. Ha participado en diversos congresos con temas sobre el perfil axiológico del comunicador y ha publicado artículos y capítulos de libros acerca del desarrollo moral del comunicador y el marketing holístico para el desempeño individual y profesional (branding axiológico). Es miembro del Cuerpo Académico de Investigación, Marketig desde la Perspectiva de la Comunicación, bajo la línea de investigación las relaciones públicas axiológicas. http://orcid.org/ 00000003-3988-3640

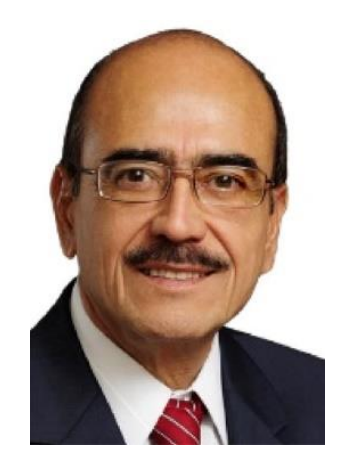

Temístocles Muños López

Universidad Autónoma de Coahuila

Maestro-Investigador del Posgrado de la Facultad de Ciencia, Educación y Humanidades de la Universidad Autónoma de Coahuila, Doctor con Post-Doctorado en Teoría de la Ciencia. Dirige la Línea de Investigación de Contextos Culturales y Educación del 
C. A. de Desarrollo Humano y es Perfil Deseable de la SEP desde 2005. Es Asesor y Consultor profesional de Logística Educativa.

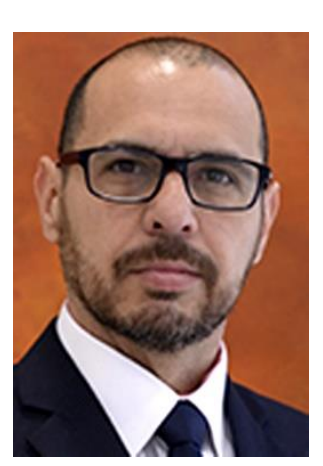

\section{Arturo González López}

Doctor en Ciencias de la Información (Universidad Complutense de Madrid).

Autor de libros y artículos científicos sobre marketing holístico para el desempeño individual y profesional (personal branding); la inserción al mercado laboral y emprendimiento; gestión de la imagen pública y sociología emocional. En el 2007 se incorpora a la Universidad Autónoma de Nuevo León como profesor titular. Actualmente es Subdirector de Estudios de Posgrado e Investigación en la Facultad de Ciencias de la Comunicación de la UANL.

https://orcid.org/0000-0003-4031-4592

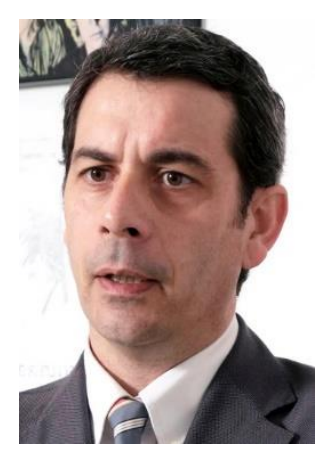

\section{Pablo Adán Micó Consultor de marketing, recursos humanos y estrategia personal}

También es conferenciante y ponente de congresos en España, México y Chile en liderazgo, comunicación y marca personal, así como formador en diversas escuelas directivas, escuelas de negocio y universidades, en máster y posgrados. Ha publicado varios libros sobre las materias. Su obra más reciente "El Reto, estrategia personal para tiempos de incertidumbre" ha sido referenciada por los mejores profesionales de marca personal en España e Iberoamérica siendo referente internacional en la materia. https:/ / orcid.org/0000-0002-8796-1642 


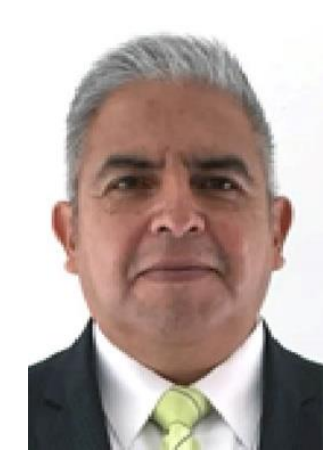

Inocente Melitón García

Facultad de Ciencia, Educación y Humanidades UAdeC

inocente.meliton@escuelanormaldeatlacomulco.edu.mx

Investigador educativo de tiempo completo, con reconocimiento al perfil deseable PRODEP. Catedrático de Posgrado en FCEyH. Jefe del Departamento de Investigación e Innovación Educativa y Posgrado en Normal de Atlacomulco. Miembro de: Red de Docentes de Iberoamericana, Red de Docentes de América Latina y el Caribe, Red de Cuerpos Académicos de Escuelas Normales, Red CODAES, Red Interamericana de Educación Docente.

http://orcid.org/0000-0001-8253-4476

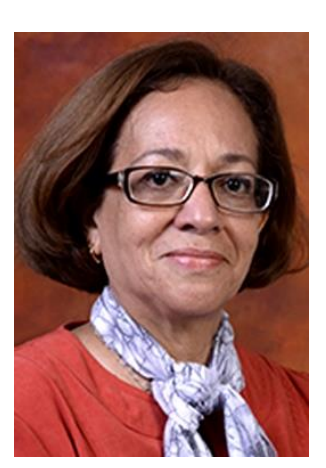

Monserrat Arango Morales

Universidad Autónoma de Nuevo León

ayeryhoy5@yahoo.com

Doctora en Filosofía en Ciencias Políticas, maestra de tiempo completo de la Facultad de Ciencias de la Comunicación de la UANL; 31 años de experiencia como productor de televisión cultural. Miembro del cuerpo académico de Estudio de Comunicación, Administración y Cultura; participante en Congresos como FELAFACS, AMIC, CONEIC, WAPOR entre otros. Actualmente asesora cuatro programas de la televisora estatal resultados de su tesis doctoral; Al presente ocupa la Subdirección de Comunicación Digital y Vinculación de la Facultad de Ciencias de la Comunicación. 


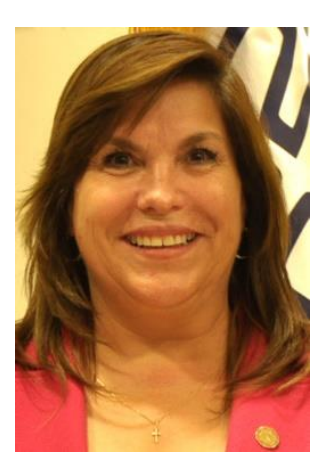

\section{Lucinda Sepúlveda García}

Universidad Autónoma de Nuevo León, México

ly.sepulveda@hotmail.com

Catedrática de la Facultad de Ciencias de la Comunicación, UANL, master en Enseñanza Superior por la Facultad de Filosofía y Letras, UANL. Representante del Consejo Nacional para la Enseñanza y la Investigación de las Ciencias de la Comunicación (CONEICC). Miembro de la Asociación

Mexicana de Investigadores de la Comunicación, A.C. (AMIC). Responsable del CA Medios de Comunicación para la Educación, el uso de las Tecnologías y el Desarrollo Social. Reconocida con perfil PRODEP que otorga la SEP.

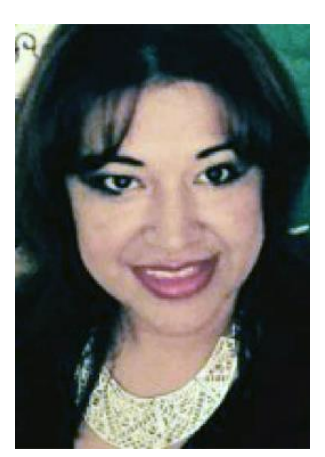

\section{Janet García González}

Universidad Autónoma de Nuevo León, México janetgarcia71@yahoo.com.mx

Doctora en Comunicación, Coordinadora de Maestría en la Facultad de Ciencias de la Comunicación de la UANL, vicecoordinadora del grupo de investigación de Comunicación y Salud de la Asociación Latinoamericana de Investigadores de Comunicación (ALAIC). http:/ / orcid.org/0000-0002-7188-5331

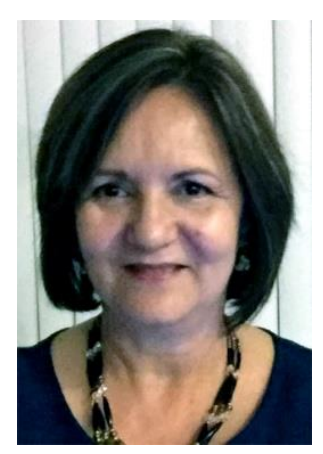

\section{María Mirna Granat Ramos} Universidad Autónoma de Nuevo León, México maria.granatrm@uanl.edu.mx

Doctora en Comunicación Social. Las materias que imparte son acerca del Periodismo y la Metodología de investigación en la comunicación. Cuenta con el reconocimiento perfil deseable PRODEP. Ha participado como ponente en encuentros organizados por AMIC, CONEICC, RAIC y WAPOR desde el 2005, a la fecha. Es integrante del UANL-CA-267-Medios de Comunicación para la Educación, el uso de las Tecnologías y el Desarrollo Social. Nivel: En Consolidación. 


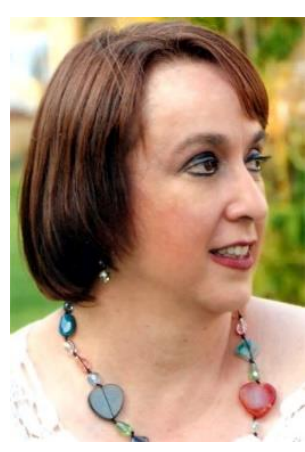

Dra. Alicia de la Peña de León Universidad Autónoma de Coahuila aliciadelapenadeleon@,uadec.edu.mx

Doctora en Ciencias Administrativas. Maestra investigadora en la Facultad de Mercadotecnia de la UA de C. Miembro del Cuerpo de Investigación Administración de la Mercadotecnia, con la línea de investigación en el área de Consumo Responsable. Candidata a SNI. http://orcid.org/0000-0001-6338-2067

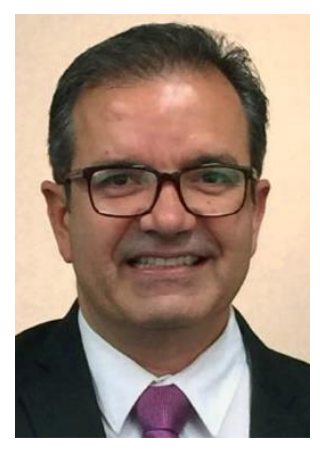

\section{Dr. Juan Bernardo Amezcua Núñez,} Universidad Autónoma de Coahuila ban@prodigy.net.mx

Doctor en Ciencias Administrativas. Maestro investigador en la Facultad de Mercadotecnia de la UA de C. Miembro del Cuerpo de Investigación Administración de la Mercadotecnia, con la línea de investigación en el área de Consumo Responsable.

http:/ orcid.org/0000-0001-6227-2202

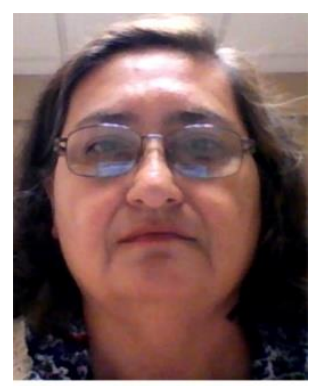

Dra. Juana María Saucedo Soto Universidad Autónoma de Coahuila juanasaucedosoto@,uadec.edu.mx

Doctora en Administración y Dirección de Empresas. Profesor-investigador en las Líneas de Generación y Aplicación del conocimiento: Marketing estratégico y operativo y Consumo responsable en la Facultad de Mercadotecnia de la UA de C. Líder del Cuerpo de Investigación Administración de la Mercadotecnia. http://orcid.org/0000-0002-8075-8764 


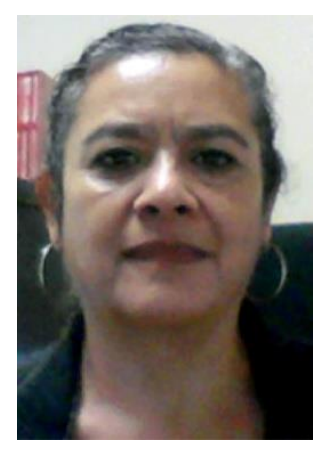

Dra. Alicia Hernández Bonilla, Universidad Autónoma de Coahuila alicitaher@hotmail.com

Candidata a Doctora en Administración. Maestra investigadora en la Facultad de Mercadotecnia de la UA de C. Miembro del Cuerpo de Investigación Administración de la Mercadotecnia, con la línea de investigación en el área de Marketing Estratégico.

http://orcid.org/0000-0003-0460-5755

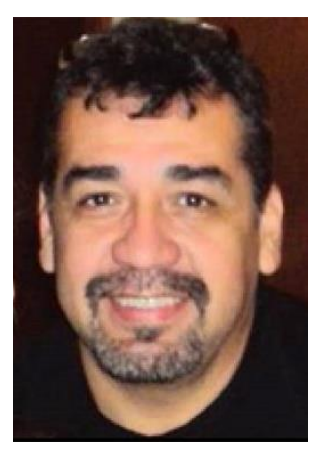

\section{Dr. Arturo Pérez Patiño}

Escuela Normal Miguel F. Martínez Centenaria y Benemérita

arturo.perez@,enmfm.edu.mx

Docente desde hace treinta y tres años de Educación Básica egresado del Centro de Estudios Universitarios como Profesor de Educación Física. Catedrático de la Normal Miguel F. Martínez Centenaria y Benemérita desde hace 29 años y Coordinación de Gestión de Educación Física de la Institución. A su vez Miembro del Cuerpo Académico Luz Pax Vis Modelos y Procesos en la Formación Docente.

http://orcid.org/0000-0003-1233-1301

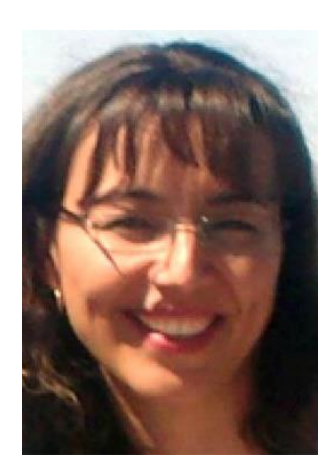

Mtra. Guadalupe Minerva Castillo Hernández

Escuela Normal Miguel F. Martínez Centenaria y Benemérita

guadalupe.castillo@enmfm.edu.mx

Docente desde hace 26 años de Educación Básica egresado de la Normal Miguel F. Martínez Centenaria y Benemérita. Catedrático de la Normal Miguel F. Martínez Centenaria y Benemérita desde hace 17 años y Jefa de Biblioteca de la institución. A su vez Miembro del Cuerpo Académico 
Luz Pax Vis Modelos y Procesos en la Formación Docente. http://orcid.org/0000-0001-6586-2355

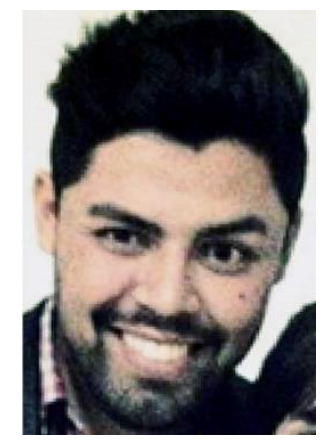

Mtro. Héctor Alonso Rosas Álvarez

Escuela Normal Miguel F. Martínez Centenaria y Benemérita

hector.rosas@.enmfm.edu.mx

Docente desde hace 10 años de Educación Básica egresado de la Normal Miguel F. Martínez Centenaria y Benemérita. Catedrático de la Normal Miguel F. Martínez Centenaria y Benemérita desde hace 5 años y Jefe del Departamento de Desarrollo Académico de la institución. A su vez, miembro del Cuerpo Académico Luz Pax Vis Modelos y Procesos en la Formación Docente. http://orcid.org/0000-0001-9718-9548

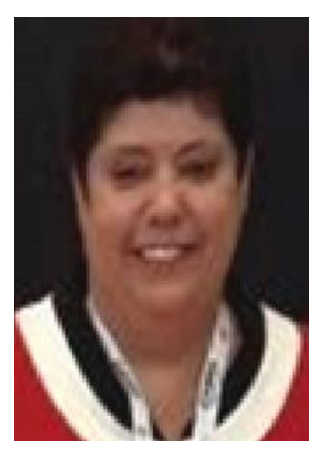

Mtra. Sandra Nelly Martínez Cantú

Escuela Normal Miguel F. Martínez Centenaria y Benemérita

sandra.martinez@enmfm.edu.mx

Docente desde hace treinta y tres años de Educación Básica egresado de la Normal Miguel F. Martínez Centenaria y Benemérita. Catedrático de la Normal "Miguel F. Martínez" Centenaria y Benemérita desde hace 25 años y Coordinadora Académica de la Licenciatura en Educación Física. A su vez Miembro del Cuerpo Académico Luz Pax Vis Modelos y Procesos en la Formación Docente. http://orcid.org/0000-0002-2659-1174 


\section{Prologuista}

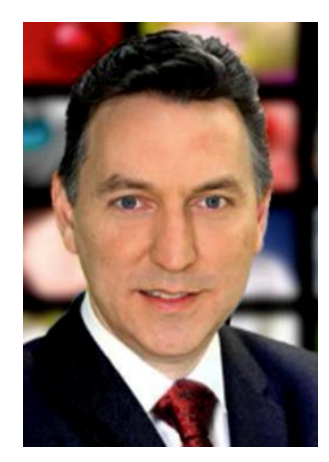

Gregorio Martínez Garza

Consultor en Comunicación

Socio Director de Gregorio Martínez Comunicación Estratégica, empresa de consultoría. Especialista en Prevención y Manejo de Crisis. Conductor de Noticieros en Televisa Monterrey. Licenciado en Economía. Maestría en Administración. 